\title{
Predicting the Seismic Behavior of the Dywidag Ductile Connector (DDC) Precast Concrete System
}

\author{
A Master's Project \\ Presented to \\ the Faculty of California Polytechnic State University \\ San Luis Obispo, California
}

In partial fulfillment

of the Requirements for the Degree

Master of Science in Architecture with a Specialization in Architectural Engineering

by

Elizabeth M. Kenyon

July 2008 
(C) 2008

Elizabeth Mary Kenyon ALL RIGHTS RESERVED 
COMMITTEE MEMBERSHIP

TITLE:

Predicting the Seismic Behavior of the Dywidag Ductile

Connector (DDC) Precast Concrete System

AUTHOR: $\quad$ Elizabeth Mary Kenyon

DATE SUBMITTED: July 2008

COMMITTEE CHAIR: $\quad$ Cole McDaniel, Ph.D., P.E.

COMMITTEE MEMBER: Pamalee Brady, Ph.D., P.E.

COMMITTEE MEMBER: Ansgar Neuenhofer, Ph.D., P.E.

COMMITTEE MEMBER: Kevin Dong, M.E., S.E. 


\begin{abstract}
Predicting the Seismic Behavior of the Dywidag Ductile Connector (DDC) Precast Concrete System

Elizabeth Mary Kenyon
\end{abstract}

Structural engineering is heavily dependent on the use of computers. When creating a building model using structural analysis software, it is required that the designer have an understanding of the system behavior and the modeling program capabilities.

Some engineers in the Southern California region are taking steps towards incorporating the Dywidag ductile connector (DDC) and super hybrid systems into building practice due to the advantages found in these systems' construction methods and seismic performance.

As the DDC and super hybrid systems reach industry, the design engineer will need to model these systems using structural analysis programs. This report describes two DDC specimens that were each modeled two ways: (1) using elastic members in conjunction with nonlinear rotational hinges (lumped plasticity model), and (2) using finite elements (fiber model). The experimental pushover curve for each test specimen was compared to the corresponding analytical backbone curves.

The fiber modeling focuses on providing a means to study the joint behavior as the parameters of the system change. The lumped plasticity model provides the design engineer with a means for modeling a three-dimensional DDC building in order to get acceptable global demand values. This project offers modeling suggestions for both the fiber models and the lumped plasticity models used to predict the seismic behavior of the DDC precast concrete system. 


\section{Table of Contents}

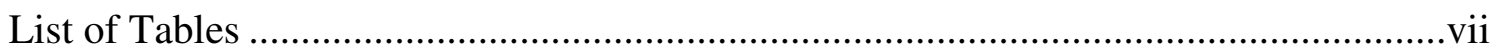

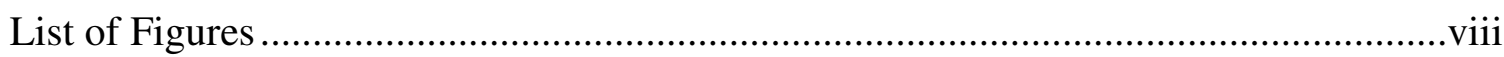

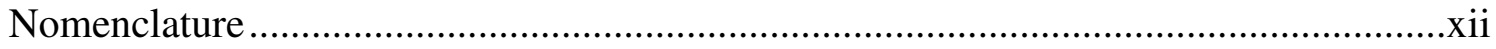

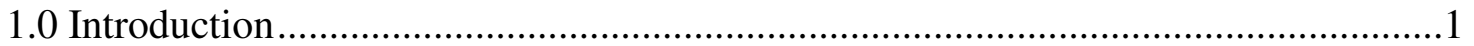

1.1 Advantages of Precast Frame Systems …………...........................................

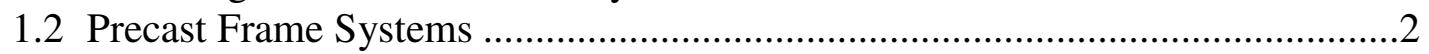

1.3 Gap-opening Frame Systems ......................................................................

1.3.1 Pure Hybrid Systems................................................................................

1.3.2 Dywidag Ductile Connector Systems ……………....................................6

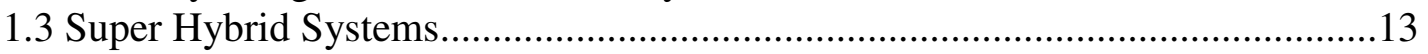

1.3.4 Advantages and Disadvantages in the Gap-Opening Systems ...................14

1.4 Current Industry Practices............................................................................2

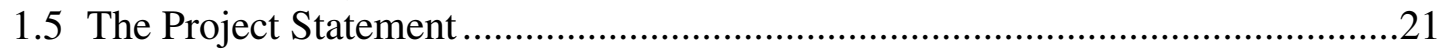

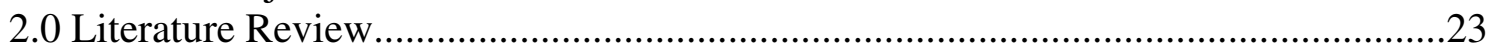

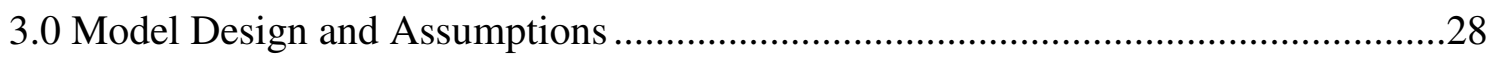

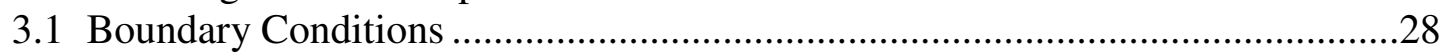

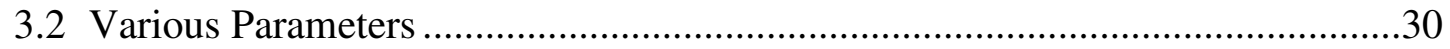

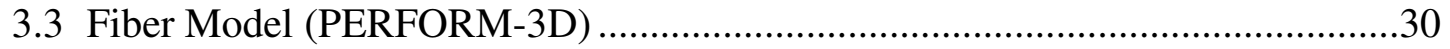

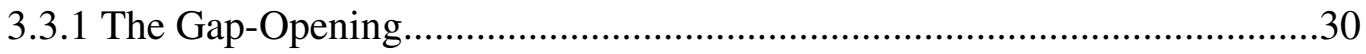

3.3.2 Fiber Elements …………………........................................................

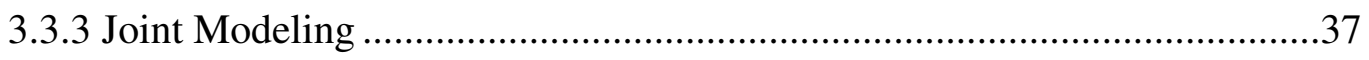

3.3.4 Ductile Rod Modeling.............................................................................41

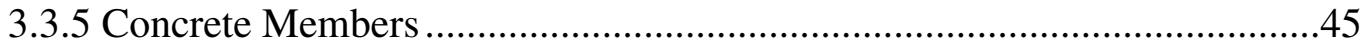

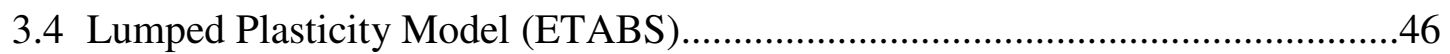

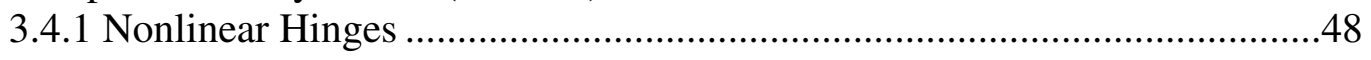

4.0 Theoretical Predictions ................................................................................52

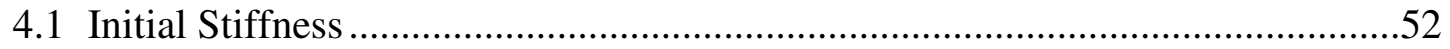

4.2 Moment at Tensile Rupture of the Concrete Beam ..........................................56

4.3 Nominal Moment and Drift at Yielding of the Ductile Rods ...............................57

4.4 Nominal Moment at Yielding of the Dywidag Bars ..........................................58

5.0 Modeling Results .............................................................................................6

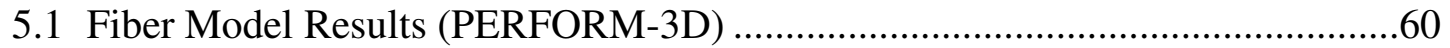

5.2 Lumped Plasticity Model Results (ETABS) .....................................................62

6.0 Summary, Conclusion, and Future Work ..............................................................66

6.1 Structural Behavior of Dywidag Ductile Connector Joints ....................................66

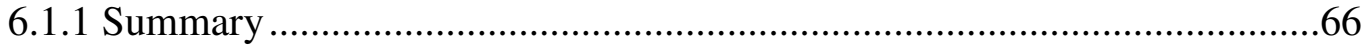

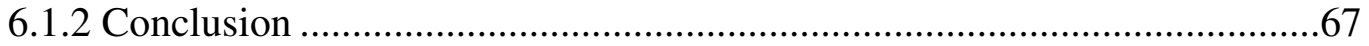

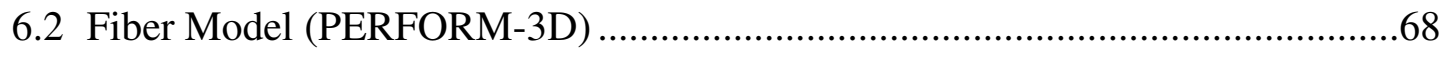

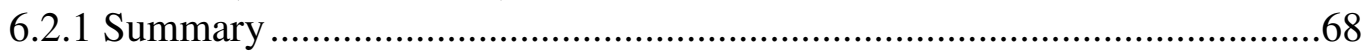

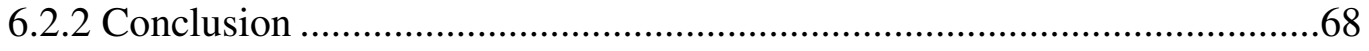

6.3 Lumped Plasticity Model (ETABS) ………………………………..................

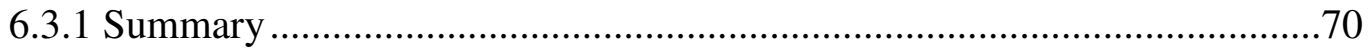

6.3.2 Conclusion …………………………………………........................... 


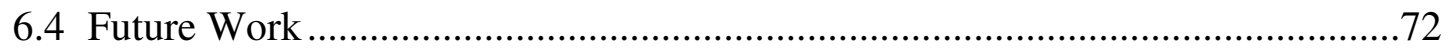

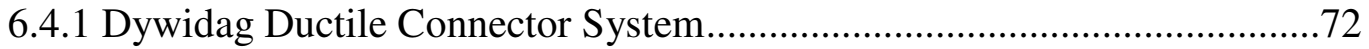

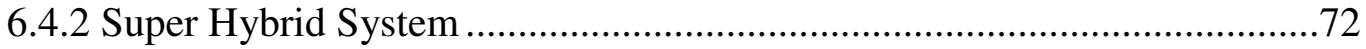

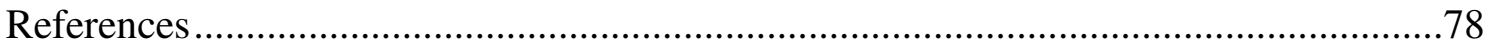

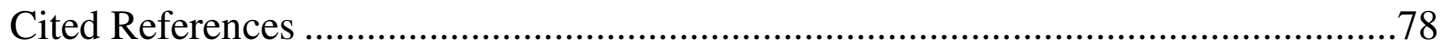

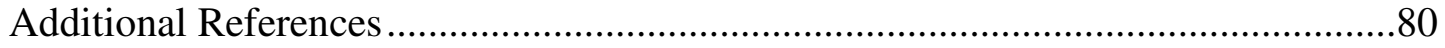

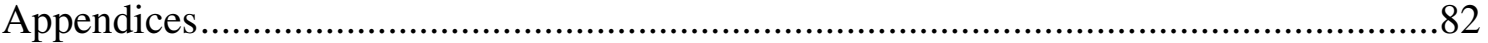

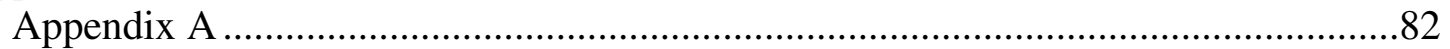

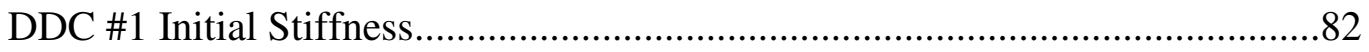

DDC \#1 Column Shear at the Tension Rupture of the Concrete.......................83

DDC \#1 Column Shear at Yielding of the Ductile Rods ..................................84

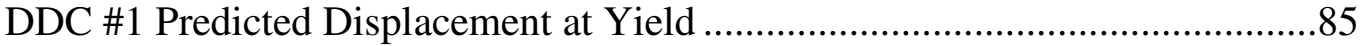

DDC \#1 Column Shear at Yielding of the Dywidag Bars ................................85

DDC \#1 Determining Rigid Link Length .......................................................86

DDC \#1 ETABS Nonlinear Hinge Properties ..................................................87

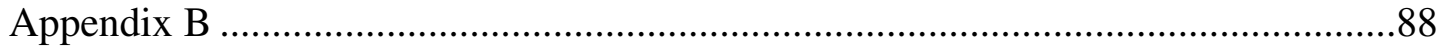

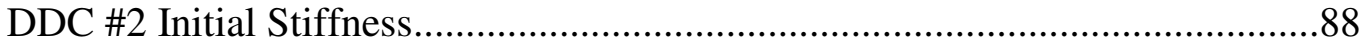

DDC \#2 Column Shear at the Tension Rupture of the Concrete ........................89

DDC \#2 Column Shear at Yielding of the Ductile Rods ...................................90

DDC \#2 Predicted Displacement at Yield ....................................................91

DDC \#2 Column Shear at Yielding of the Dywidag Bars ................................91

DDC \#2 Determining Rigid Link Length ....................................................92

DDC \#2 ETABS Nonlinear Hinge Properties ................................................93

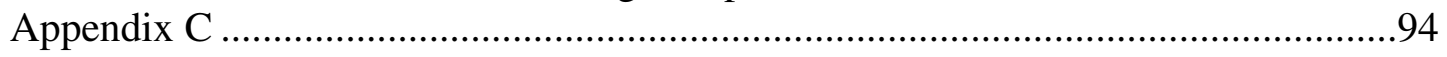

Super Hybrid Initial Stiffness ....................................................................94

Super Hybrid Column Shear at the Tension Rupture of the Concrete.................95

Super Hybrid Column Shear at Yielding of the Ductile Rods...........................96

Super Hybrid Predicted Displacement at Yield ................................................97

Super Hybrid Column Shear at Yielding of the Dywidag Bars.........................97

Super Hybrid Determining Rigid Link Length ...............................................98

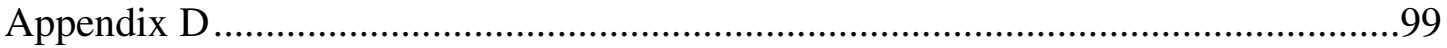

DDC \#1 XTRACT Input Properties ..........................................................99

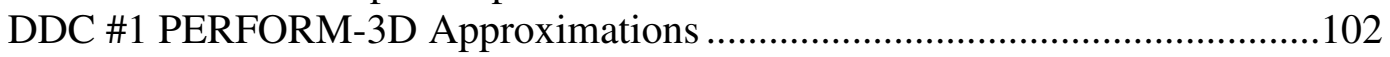

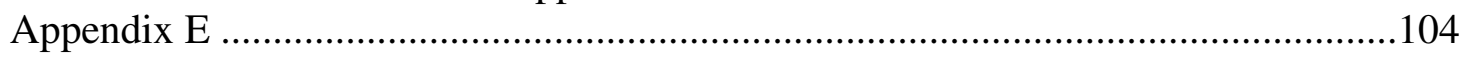

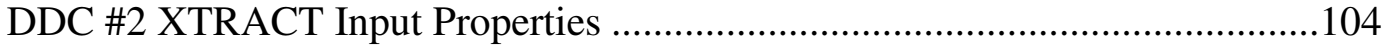

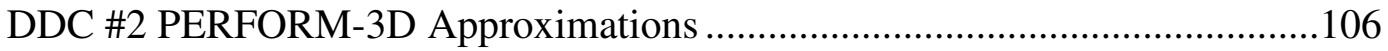

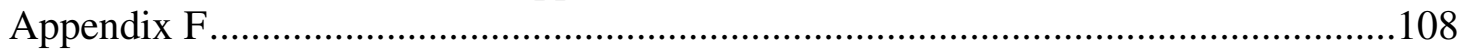

Super Hybrid XTRACT Input Properties ................................................. 108

Super Hybrid PERFORM-3D Approximations ..............................................110

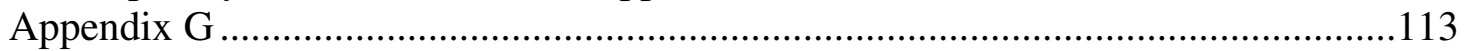

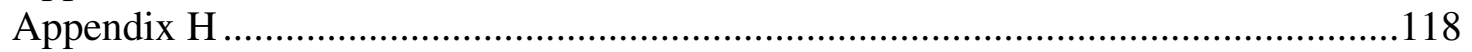

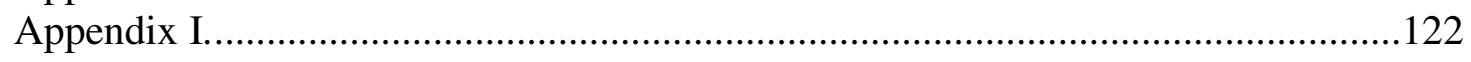




\section{List of Tables}

Table 1: The observed behavior in the Pankow \#4 DDC system subassemblage (Chang, Hutchinson, and Englekirk 2007) …………………….............................. 9

Table 2: Cantilevered fiber beam study results at a load factor of one............................. 36

Table 3: Effective stiffness valued recommended, (Table 6-5) in (ASCE 2000) .............. 48

Table 4: Theoretical predictions for the DDC subassemblage test specimens ..................59

Table 5: PT Steel Properties ………………………………………………………. 75

Table 6: DDC \#1 XTRACT input beam properties ………………………………….... 99

Table 7: DDC \#1 XTRACT input column properties..................................................... 101

Table 8: DDC \#2 XTRACT input beam properties ....................................................... 104

Table 9: DDC \#2 XTRACT input column properties.................................................... 105

Table 10: Super hybrid XRACT input column properties.............................................. 108

Table 11: Super hybrid XRACT input beam properties ................................................ 109

Table 12: DDC \#1 day of testing properties (Chang, Hutchinson, and Englekirk 2007) 113

Table 13: DDC \#1 material test data (Chang, Hutchinson, and Englekirk 2007) .......... 113

Table 14: DDC \#2 material test results (SEQAD 1993) ............................................... 118

Table 15: Super hybrid day of testing properties (Chang, Hutchinson, and Englekirk

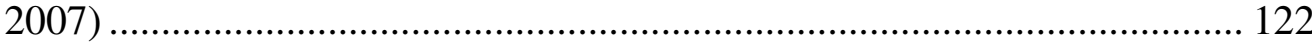

Table 16: Super hybrid material test data (Chang, Hutchinson, and Englekirk 2007) ... 122 


\section{List of Figures}

Figure 1: Classification of precast ductile frames (Englekirk 2003) .................................. 3

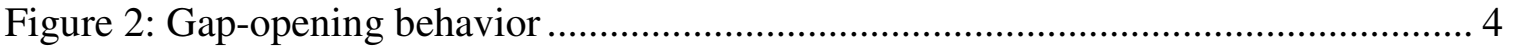

Figure 3: Pure hybrid system (a) seismic elements (b) construction elements................... 5

Figure 4: (a) Deformed shape of beams after testing, (b) Unit \#1, pure hybrid system, at 2.8\% drift (MacRae and Priestley 1994)...................................................... 6

Figure 5: Isometric view of DDC system (Englekirk 2003) ........................................... 7

Figure 6: DDC connection - shear transfer mechanism (Englekirk 2003)........................ 8

Figure 7: Joint elevation of Pankow \#4 at $0.67 \%$ drift (Chang, Hutchinson, and Englekirk 2007) ..................................................................................... 10

Figure 8: Partial joint elevation of Pankow \#4 at 5.35\% drift (Chang, Hutchinson, and Englekirk 2007) ………............................................................................. 11

Figure 9 : Joint elevation of Pankow \#4 at 7.07\% drift (Chang, Hutchinson, and

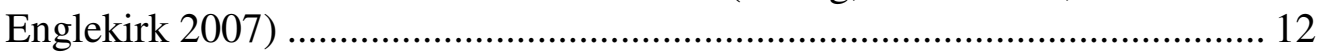

Figure 10: Isometric view of the super hybrid joint (Englekirk 2003) ............................ 13

Figure 11: Force-displacement hysteretic loop approximations at 2\% (Chang, Hutchinson, and Englekirk 2007) and (Stanton, Day, and MacRae 1999).... 15

Figure 12: Force-displacement hysteretic loop approximations at 3-3.5\% (Chang, Hutchinson, and Englekirk 2007) and (Stanton, Day, and MacRae 1999)..... 16

Figure 13: Force-displacement hysteretic loop approximations at 5\% (Chang Hutchinson, and Englekirk 2007) and (Stanton, Day, and MacRae 1999).... 17

Figure 14: Pure hybrid force-displacement hysteretic loop approximations at $2 \%, 3 \%$, and 5\% drift (Stanton, Day, and MacRae 1999)]....

Figure 15: DDC force-displacement hysteretic loop approximations at 2\%,3\%, and 5\% drift (Chang, Hutchinson, and Englekirk 2007)] .................................... 18

Figure 16: Super hybrid force-displacement hysteretic loop approximations at $2 \%$, $3.5 \%$, and 5\% drift (Chang, Hutchinson, and Englekirk 2007)....

Figure 17: Interior unbonded post-tensioned beam-column sub-assemblage fiber model (El Sheikh et al.1997)

Figure 18: Confined and unconfined concrete stress-strain curves from (Mander et al. 1988)

Figure 19: Schematic elevation of the DDC \#1 test specimen (Chang Hutchinson, and

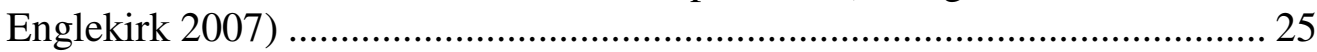

Figure 20: Force-displacement hysteretic loop approximations for DDC \#1 ………...... 26

Figure 21: Schematic elevation of the DDC \#2 test specimen (SEQAD 1993) ............... 26

Figure 22: Force-displacement hysteretic loop approximations for DDC \#2 …………... 27

Figure 23: Schematic elevation of a five-story moment frame building ………….......... 28

Figure 24: Test configuration and boundary conditions ................................................ 29

Figure 25: Model configuration and boundary conditions for DDC \#1 and DDC \#2 2..... 30

Figure 26: Typical fiber element cross section ............................................................. 32

Figure 27: Cantilevered beam moment diagram with various fiber segments ................. 34

Figure 28: Cantilevered beam end displacement verses load scale factor ......................... 35

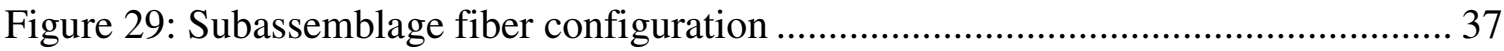

Figure 30: Rigid end zones for beam-column joint modeling (Elwood et al. 2007) ........ 38 
Figure 31: Fiber model joint configuration....................................................................... 39

Figure 32: Force-displacement backbone curves for the DDC \#1 fiber model with varying rigidity of the joint

Figure 33: Force-displacement backbone curves for the DDC \#2 fiber model with

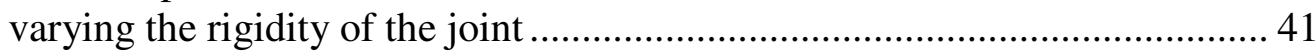

Figure 34: Modeling aspects of the ductile rod .................................................... 42

Figure 35: Force-displacement backbone curves for the fiber model DDC \#1 with varying ductile rod lengths.

Figure 36: Force-displacement backbone curves for the fiber model DDC \#2 with varying ductile rod lengths.

Figure 37: Force-displacement backbone curves for the fiber model DDC \#2 with various numbers of fiber elements along the length of the ductile rod........... 45

Figure 38: Lumped Plasticity subassemblage configuration

Figure 39: Force-displacement backbone curve for the lumped plasticity model DDC \#2 with varying the nonlinear hinge properties .......................................... 50

Figure 40: Force-displacement backbone curve for the lumped plasticity model DDC \#2 with varying the nonlinear hinge location ............................................ 51

Figure 41: Subassemblage nomenclature and geometry ............................................. 53

Figure 42: DDC ductile rod geometry and stress................................................... 54

Figure 43: Force-displacement backbone curve for the DDC \#1 fiber model relative to

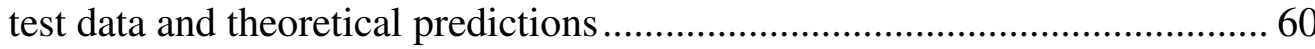

Figure 44: Force-displacement backbone curve for the DDC \#2 fiber model relative to test data and theoretical predictions

Figure 45: Force-displacement backbone curve for the DDC \#1 lumped plasticity model to test data and theoretical predictions

Figure 46: Force-displacement backbone curve for the DDC \#2 lumped plasticity model relative to test data and theoretical predictions

Figure 47: Force-displacement backbone curve for the lumped plasticity DDC \#1 model relative to test data and theoretical predictions

Figure 48: Force-displacement backbone curve for the ETABS model of DDC \#2 relative to test results and theoretical predictions

Figure 49: Schematic elevation of the Pankow \#2 super hybrid test specimen (Chang Hutchinson, and Englekirk 2007) ........................................................ 73

Figure 50: Super Hybrid force-displacement hysteretic loop approximations ................ 74

Figure 51: Constitutive relationship of post-tensioned steel strand ............................. 75

Figure 52: Force-displacement backbone curve for the fiber model of the super hybrid relative to the test results and theoretical predictions ................................... 76

Figure 53: Interaction diagram from XTRACT of the super hybrid column .................. 98

Figure 54: DDC \#1 approximate confined concrete beam constitutive properties......... 102

Figure 55: DDC \#1 approximate unconfined concrete beam properties ........................ 102

Figure 56: DDC \#1 approximate confined concrete column properties ........................ 102

Figure 57: DDC \#1 approximate unconfined concrete column properties .................... 103

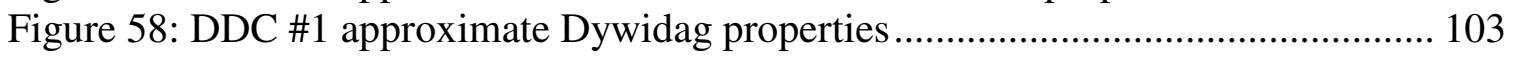

Figure 59: DDC \#1 approximate ductile rod properties ............................................ 103

Figure 60: DDC \#2 approximate confined concrete beam constitutive properties......... 106 
Figure 61: DDC \#2 approximate confined concrete column constitutive properties ..... 106

Figure 62: DDC \#2 approximate unconfined concrete beams and column properties ... 106

Figure 63: DDC \#2 approximate Dywidag properties ............................................... 107

Figure 64: DDC \#2 approximate longitudinal column steel reinforcement properties .. 107

Figure 65: DDC \#2 approximate ductile rod properties ........................................... 107

Figure 66: Super hybrid approximate confined concrete beam properties .................... 110

Figure 67: Super hybrid approximate confined concrete column properties .................. 110

Figure 68: Super hybrid approximate unconfined concrete beam properties ................ 110

Figure 69: Super hybrid approximate unconfined concrete column properties.............. 111

Figure 70: Super hybrid approximate unconfined concrete slab properties .................. 111

Figure 71: Super hybrid approximate longitudinal column reinforcement properties ... 111

Figure 72: Super hybrid approximate Dywidag properties.................................... 112

Figure 73: Super hybrid approximate ductile rod properties ..................................... 112

Figure 74: DDC \#1 beam elevation (Chang, Hutchinson, and Englekirk 2007) ............ 113

Figure 75: DDC \#1 section cut 1/SK-5 through the beam (Chang, Hutchinson, and

Englekirk 2007) ................................................................................ 114

Figure 76: DDC \#1 section cut 2/SK-5 through the beam (Chang, Hutchinson, and Englekirk 2007) ................................................................................. 114

Figure 77: DDC \#1 column elevation (Chang, Hutchinson, and Englekirk 2007)........ 115

Figure 78: DDC \#1 section cut 1/SK-4 through the column (Chang, Hutchinson, and

Englekirk 2007) ................................................................................ 116

Figure 79: DDC \#1 section cut 2/SK-4 through the column (Chang, Hutchinson, and Englekirk 2007) ............................................................................ 116

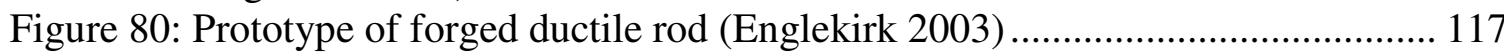

Figure 81: DDC \#1 test data (Chang, Hutchinson, and Englekirk 2007) ...................... 117

Figure 82: Isometric view of a DDC joint similar to DDC \#2 (Englekirk 2003) .......... 119

Figure 83: DDC \#2 ductile rod geometry (Englekirk 2003) ........................................ 119

Figure 84: Relationship between stress and strain for the ductile rod in Figure 83....... 120

Figure 85: DDC \#2 force-displacement hysteretic data (SEQAD 1993)....................... 120

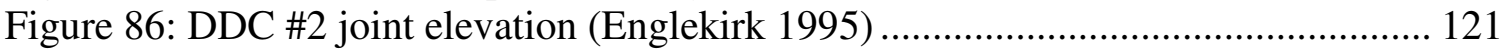

Figure 87: DDC \#2 plan view of the column at the ductile rod elevation in the joint (Englekirk 1995)

Figure 88: Super hybrid column elevation (Chang, Hutchinson, and Englekirk 2007) . 123

Figure 89: Super hybrid section cut 1/SK-5 through the column (Chang, Hutchinson, and Englekirk 2007).

Figure 90: Super hybrid section cut 2/SK-5 through the column (Chang, Hutchinson, and Englekirk 2007).

Figure 91: Super hybrid section cut 1/SK-4 through the column (Chang, Hutchinson, and Englekirk 2007)

Figure 92: Super hybrid south beam elevation (Chang, Hutchinson, and Englekirk 2007)

Figure 93: Super hybrid section cut 1/SK-9 through the south beam (Chang, Hutchinson, and Englekirk 2007)

Figure 94: Super hybrid section cut 2/SK-9 through the south beam (Chang, Hutchinson, and Englekirk 2007) 
Figure 95: Super hybrid plan of the north beam at the pinned end connection (Chang, Hutchinson, and Englekirk 2007)

Figure 96: Super hybrid north beam elevation (Chang, Hutchinson, and Englekirk 2007)

Figure 97: Super hybrid section cut 1/SK-6 through the north beam (Chang, Hutchinson, and Englekirk 2007)

Figure 98: Super hybrid section cut 2/SK-6 through the north beam (Chang, Hutchinson, and Englekirk 2007)

Figure 99: Super hybrid section cut 2/SK-7 through the north beam (Chang, Hutchinson, and Englekirk 2007).

Figure 100: Super hybrid force-displacement hysteretic data (Chang, Hutchinson, and Englekirk 2007) 129

Figure 101: Super hybrid material tests (Chang, Hutchinson, and Englekirk 2007)..... 130 


\section{Nomenclature}

\begin{tabular}{ll} 
ACI & American Concrete Institute \\
AISI & American Iron and Steel Institute \\
ASCE & American Society of Civil Engineers \\
ASTM & American Society for Testing and Material \\
CBC & California Building Code \\
$C 1$ & Half of the length of the column within the joint, in. \\
$C 2$ & Half of the length of the beam within the joint, in. \\
DB & Dywidag bars \\
DDC & Dywidag ductile connector \\
DOT & Day of Test \\
DR & Ductile rod \\
$f_{c}$ & Compressive strength of concrete, ksi \\
FEMA & Federal Emergency Management Agency \\
$f_{u}$ & Ultimate strength, ksi \\
$f_{y}$ & Yield strength, ksi \\
$\mathrm{h}_{\mathrm{b}}$ & Height of the beam, in. \\
IBC & International Building Code \\
$I_{e f f}$ & Effective moment of inertia, in \\
$I_{g}$ & Gross moment of inertia, in \\
$K_{I N I T I A L}$ & Initial stiffness, kips/in. \\
$L_{b}$ & Length of the beam, in. \\
$L_{c r}$ & Plastic hinge length, in. \\
LP & Lumped plasticity \\
$M_{c r}$ & Moment at tensile rupture of the concrete, kip-in. \\
$M_{n}$ & Nominal moment capacity at yielding of the ductile rods, kip-in. \\
$M_{n-D B}$ & Nominal moment capacity at yielding of the Dywidag reinforcement bars, \\
PT & kip-in. \\
UBC & Post Tensioned \\
$\gamma$ & Uniform Building Code \\
$\gamma_{c r}$ & Drift ratio, \% \\
$\gamma_{y}$ & Drift at tensile rupture of the concrete, $\%$ \\
$\Delta$ & Drift at yielding of the ductile rods, $\%$ \\
$\varepsilon_{\mathrm{y}}$ & Displacement, in. \\
$\theta$ & Yield strain, in./in. \\
$\Phi$ & Rotation, rad/in. \\
& Curvature, radian \\
\hline &
\end{tabular}




\subsection{INTRODUCTION}

Over the past fifty years, structural engineering has experienced significant technological advancement. During the mid-twentieth century, structural engineering involved procedures such as hand calculations of moment distribution and drafting with a T-square. Today, a large portion of structural engineering is accomplished on the computer with the help of structural analysis programs. With this new medium for making design decisions comes a need to understand how structural systems should be modeled on the computer. In particular, this report focuses on the computer modeling of the Dywidag ductile connector (DDC) frame, a type of precast system.

\subsection{Advantages of Precast Frame Systems}

Research on precast systems has been motivated by the immense advantages found in these systems relative to their monolithic, cast-in-place counter parts (Priestley 1991). Precast systems require less formwork than monolithic systems. In addition, some precast manufactures are able to apply architectural finishes to the precast structural elements, therein eliminating additional cladding costs for the building owner. Less insitu pouring, formwork construction, and additional facade construction can lead to a quicker erection time, reduced material cost, and better quality control. Another reason precast frames are more desirable than monolithic concrete frames is due to their structural performance. Precast moment frames can be designed to respond similar to or more favorably than a monolithic concrete ductile moment frame (Cheok and Stone 1993). 
With these construction and structural performance advantages, why aren't there more precast systems in the seismic regions of the United States? According to Nigel Priestley (1991), organizer of the Precast Seismic Structural Systems (PRESS) Research Program,

To a considerable extent, the reason for the lack of advancement of precast structural systems in the United States can be attributed to uncertainty about their seismic performance... The codes require confirmation of the suitability of new designs by satisfaction of performance criteria provided by expensive and timeconsuming structural testing. This requirement inhibits innovation and has forced research and design practice into a narrow focus of reinforced [monolithic] concrete emulation instead of expanding the scope to take advantage of the strengths and differences of precast construction.

\subsection{Precast Frame Systems}

Precast frame systems can be divided into four categories according to the connection location of the precast elements and the plastic hinge region. These four categories are shown in Figure 1. Category (a), (c), and (d) are precast frames that are designed to behave like monolithic moment frames with plastic hinges occurring in the beam. Each of these three categories differs according to the shape of the precast elements used. Category (a) consists of precast elements that come in a cruciform shape. Category (c) consists of multi-story column elements and single-span beam elements. Category (d) consists of single-story column elements and multi-span beam elements. 


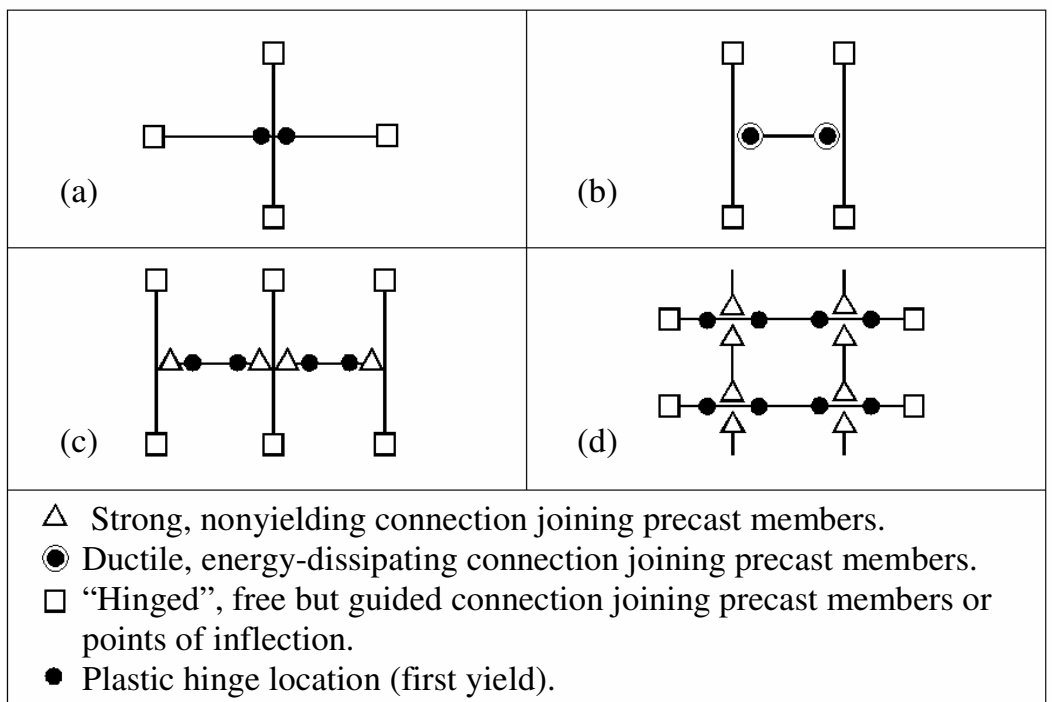

Figure 1: Classification of precast ductile frames (Englekirk 2003)

Category (b) consists of the same types of precast elements as category (c); however, category (b) is designed to have plastic hinges occur at the beam-column interface, where the precast elements meet. Category (b) is more commonly known as a gap-opening system, and it is under this category that the DDC system is classified.

\subsection{Gap-opening Frame Systems}

The joint behavior of a gap-opening system is shown graphically in Figure 2. 


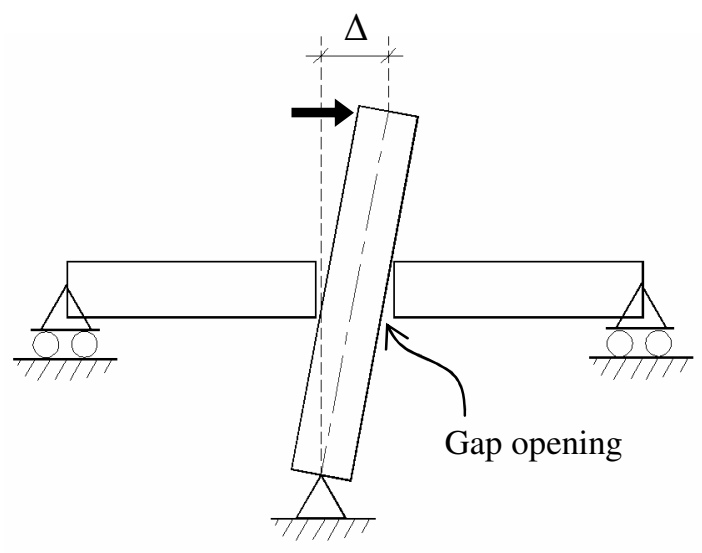

Figure 2: Gap-opening behavior

The gap-opening system is characterized by the opening of the beam-column interface which permits drift in the system with minimal damage to the main structural elements. This system has been studied in the United States since the early 1990's. The first gapopening system to evolve was the pure hybrid system. In the mid 1990's the Dywidag Ductile Connector (DDC) System was developed, and almost a decade later came the development of the super hybrid system in the early twenty-first century. The sections to follow describe the configuration, construction methods, and behavioral characteristics of the three gap-opening frame systems.

\subsubsection{Pure Hybrid Systems}

The pure hybrid frame is one type of gap-opening system that gets its name from its combined use of mild steel and post-tensioning (PT) strands. Throughout a seismic response, the PT strands are designed to remain elastic; the mild steel is designed to yield and act as the energy dissipating element. The PT strands provide a restoring force which tends to move the system back towards its original position after the frame has been displaced by lateral forces (El-Sheikh, et al. 1997). Also, due to the compression forces 
imposed on the joint by the PT strands, shear transfer occurs in the concrete through friction at the beam-column interface. The typical configuration of a pure hybrid joint is shown in Figure 3(a).

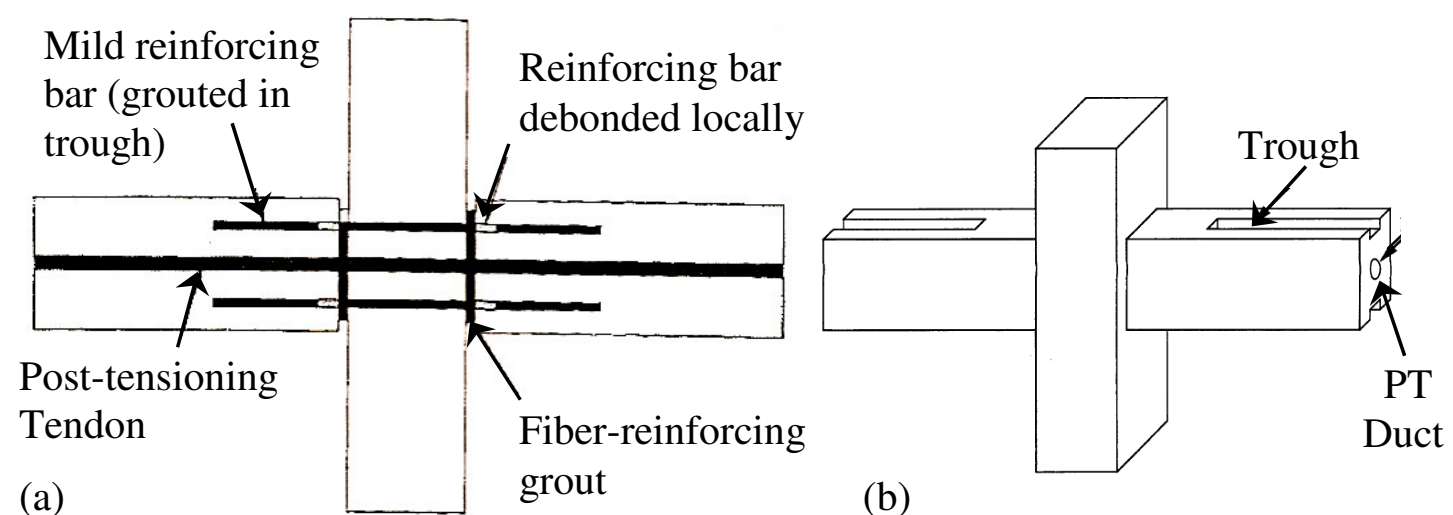

Figure 3: Pure hybrid system (a) seismic elements (b) construction elements (Hawileh, Tabatabai, and Rahman 2006) (Cheok and Stone 1993)

The pure hybrid system is constructed on site by first erecting the precast columns. Then, the beams are shored in place while the mild steel is fed through the columns and beams via the trough access areas, shown in Figure 3(b). The mild steel is either fully or partially grouted. The beam-column interface is grouted with fiber-reinforced grout. After adequate curing, the PT strands are fed through the PT duct, see Figure 3(b), and post tensioned. 


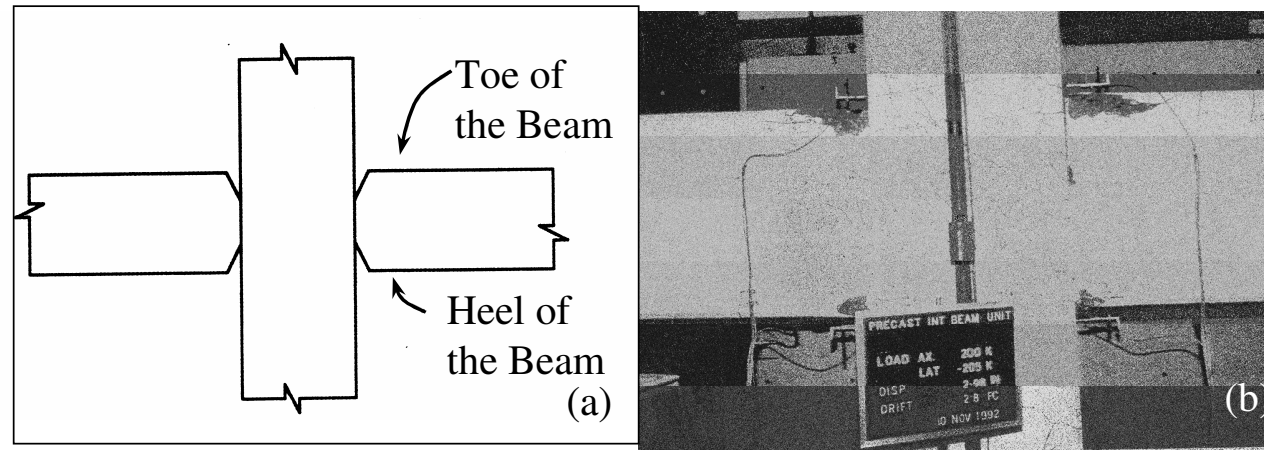

Figure 4: (a) Deformed shape of beams after testing, (b) Unit \#1, pure hybrid system, at $2.8 \%$ drift (MacRae and Priestley 1994)

The observed behavior of the pure hybrid system is crushing of the toe of the concrete beam as the drift demand increases; this behavior is shown in Figure 4(a) and (b). Failure is due to $25 \%$ strength degradation of the system.

\subsubsection{Dywidag Ductile Connector Systems}

The DDC system is a type of gap-opening frame that uses a Dywidag ductile connector as the main energy dissipating element, as opposed to typical reinforcing bars used by the pure hybrid system. An isometric view of the DDC joint is shown in Figure 5. 


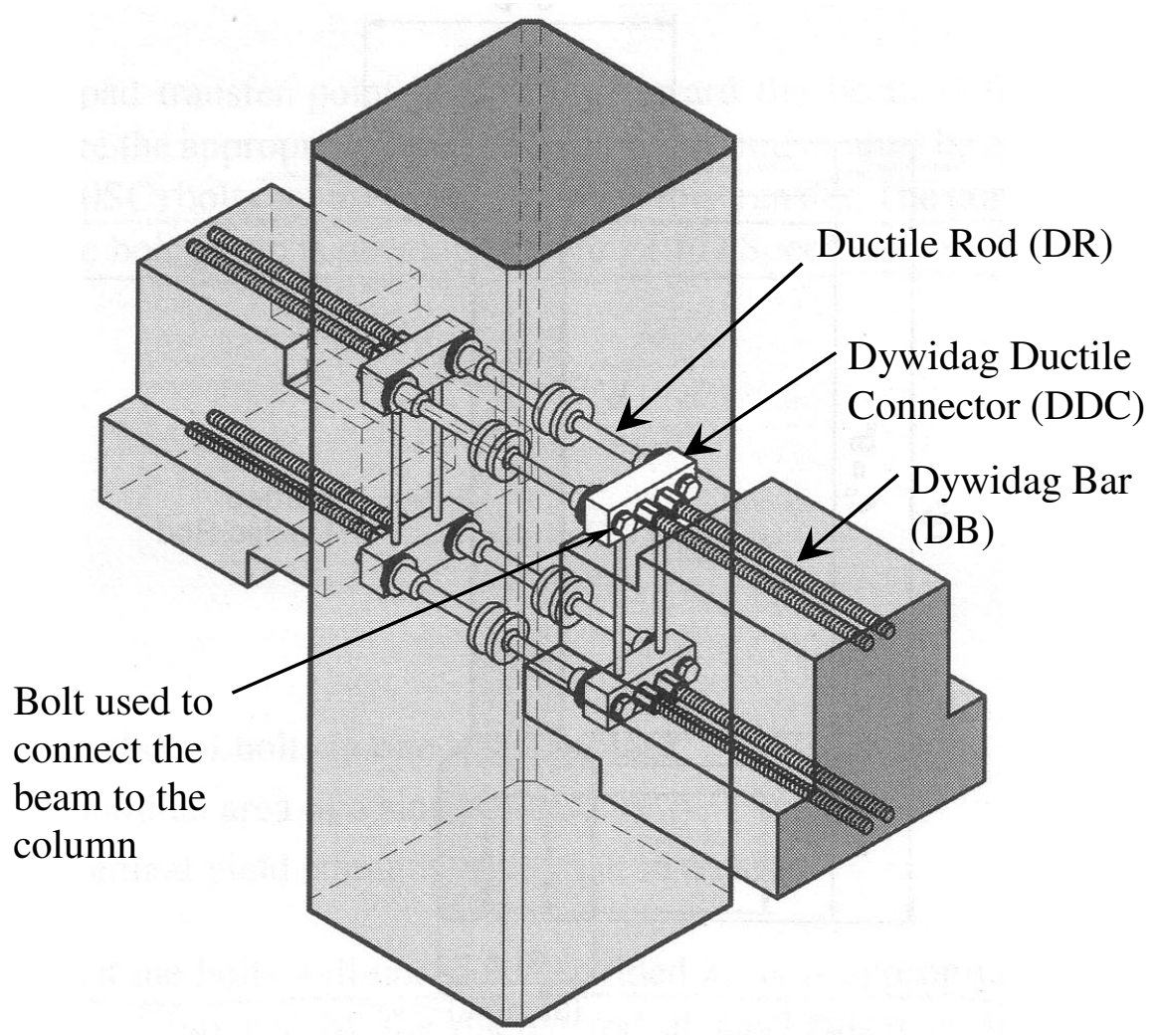

Figure 5: Isometric view of DDC system (Englekirk 2003)

The DDC system is constructed by first erecting the columns. Then, the beams are erected and the bolts, labeled in Figure 5, are tightened to the ductile rods (DR) by threading them through the steel block, also known as the Dywidag ductile connector. Structural grouting is not required since the steel blocks are designed to transfer all of the shear force across the beam-column interface. The ductile rods use a combination of bond strength and bearing area to distribute lateral forces through the joint. This load path is shown in Figure 6. 


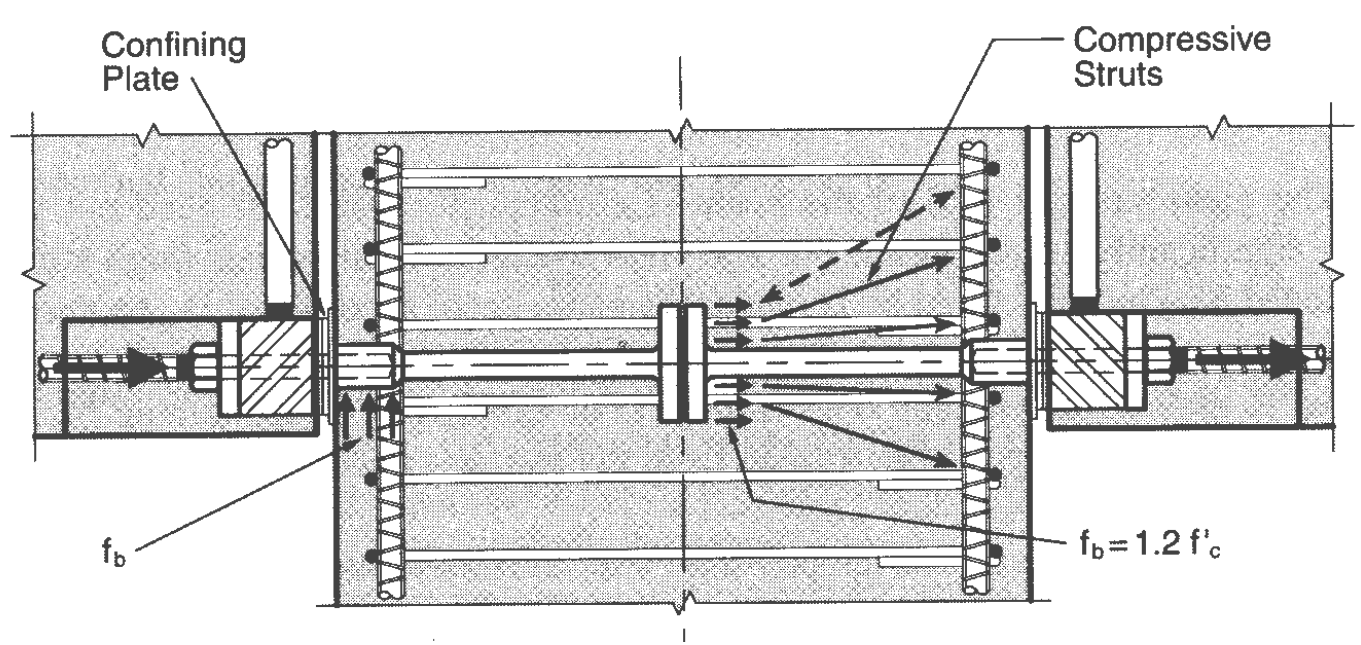

Figure 6: DDC connection - shear transfer mechanism (Englekirk 2003)

The development of the [DDC] assemblage... was motivated by a desire to improve the postyield behavior of concrete ductile frames... The adaptation of the ductile connection concept to precast concrete is logical, because it allows postyield deformations to be accommodated where members are joined...The Achilles heel of a properly conceived ductile frame beam has always been the toe (no pun intended) of the frame beam where large compressive and shear stresses combine (Englekirk 2003).

The elongated reinforcing bars within the beam tend to buckle due to the cyclic tensile overstraining caused by lateral loading. Therefore, the DDC system solves these problems with the following alterations:

(1) Relocating the yielding element to within the joint as to provide it with nondeteriorating lateral support, (2) allowing for the strain in the toe region of the beam to be controlled, and (3) transferring shear in the joint by means of friction between the steel block and steel washer (Englekirk 2003). 
Observations of the progressive behavior of a DDC test specimen are summarized in

Table 1.

Table 1: The observed behavior in the Pankow \#4 DDC system subassemblage (Chang, Hutchinson, and Englekirk 2007)

\begin{tabular}{|c|c|}
\hline Stage & Observations Noted by Chang and Hutchinson \\
\hline 1 & $\begin{array}{c}\text { At a drift of } \gamma=0.67 \% \text {, flexural cracks extended approximately } 1 / 2 \text { of the } \\
\text { length of the beams. Compression cracks developed in the column at the } \\
\text { beam-column interface and two shear cracks in each direction developed } \\
\text { within the joint at a coarse spacing of approximately } 24 \text { inches. [An image of } \\
\text { Pankow \#4 at this stage is shown in Figure 7.] }\end{array}$ \\
\hline 2 & $\begin{array}{l}\text { At theoretical yield, } \gamma=0.88 \% \text {, the ductile rods approach the end of their elastic } \\
\text { range; the column face experiences tension cracking which extends above and } \\
\text { below the joint. }\end{array}$ \\
\hline 3 & $\begin{array}{c}\text { At a drift of } \gamma=2.65 \% \text {, spalling of the tension zones at the face of the column } \\
\text { and along the beam-column interface was observed. As well, tightly spaced } \\
\text { shear cracks (approximately } 6 \text { inches on center) developed within the joint } \\
\text { region. }\end{array}$ \\
\hline 4 & $\begin{array}{l}\text { At a drift of } \gamma=5.35 \% \text {, pull out of the DDC was observed in the gaps } \\
\text { developed at the beam-column interface. [An image of Pankow \#4 at this stage } \\
\text { is shown in Figure 8.] }\end{array}$ \\
\hline 5 & $\begin{array}{l}\text { Although regions of spalling and exposed reinforcing steel and DDC were } \\
\text { observed, the specimen performed markedly well and remained stable with no } \\
\text { steel buckling or fracture observed during the imposed loading to a drift of } \gamma= \\
7.07 \% \text {. No strength degradation were observed. [An image of Pankow \#4 at } \\
\text { this stage is shown in Figure 9.] }\end{array}$ \\
\hline
\end{tabular}

As can be seen in Figure 7, minimal cracking occurs in the specimen after $0.67 \%$

drift. 


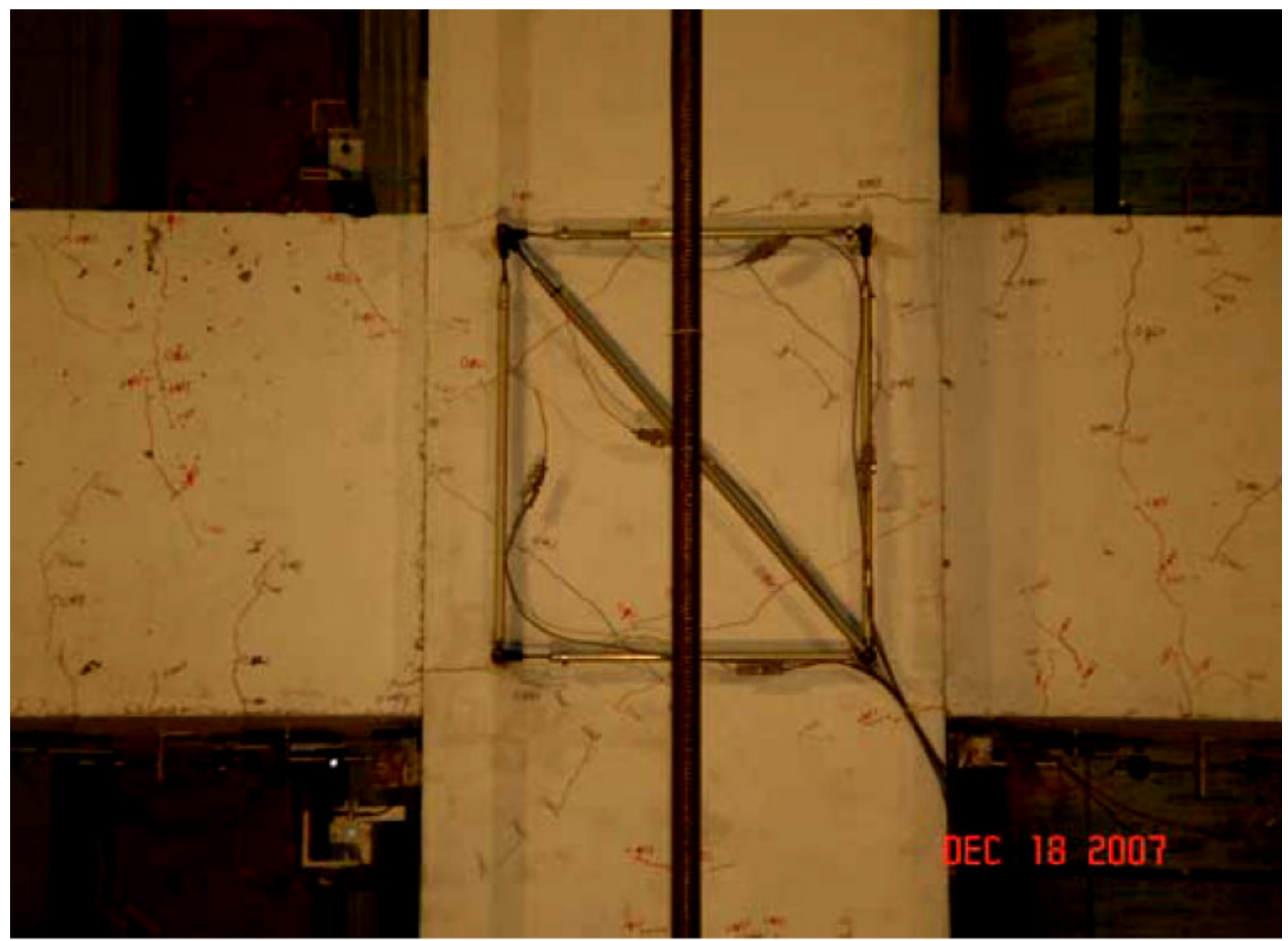

Figure 7: Joint elevation of Pankow \#4 at 0.67\% drift (Chang, Hutchinson, and Englekirk 2007)

Figure 7 shows the pre-yield condition of the specimen. Figure 8 shows the condition of the specimen after it was subjected to a drift of 5.35\%. At this point, the specimen had already yielded the ductile rods and the Dywidag reinforcement in the beam. 


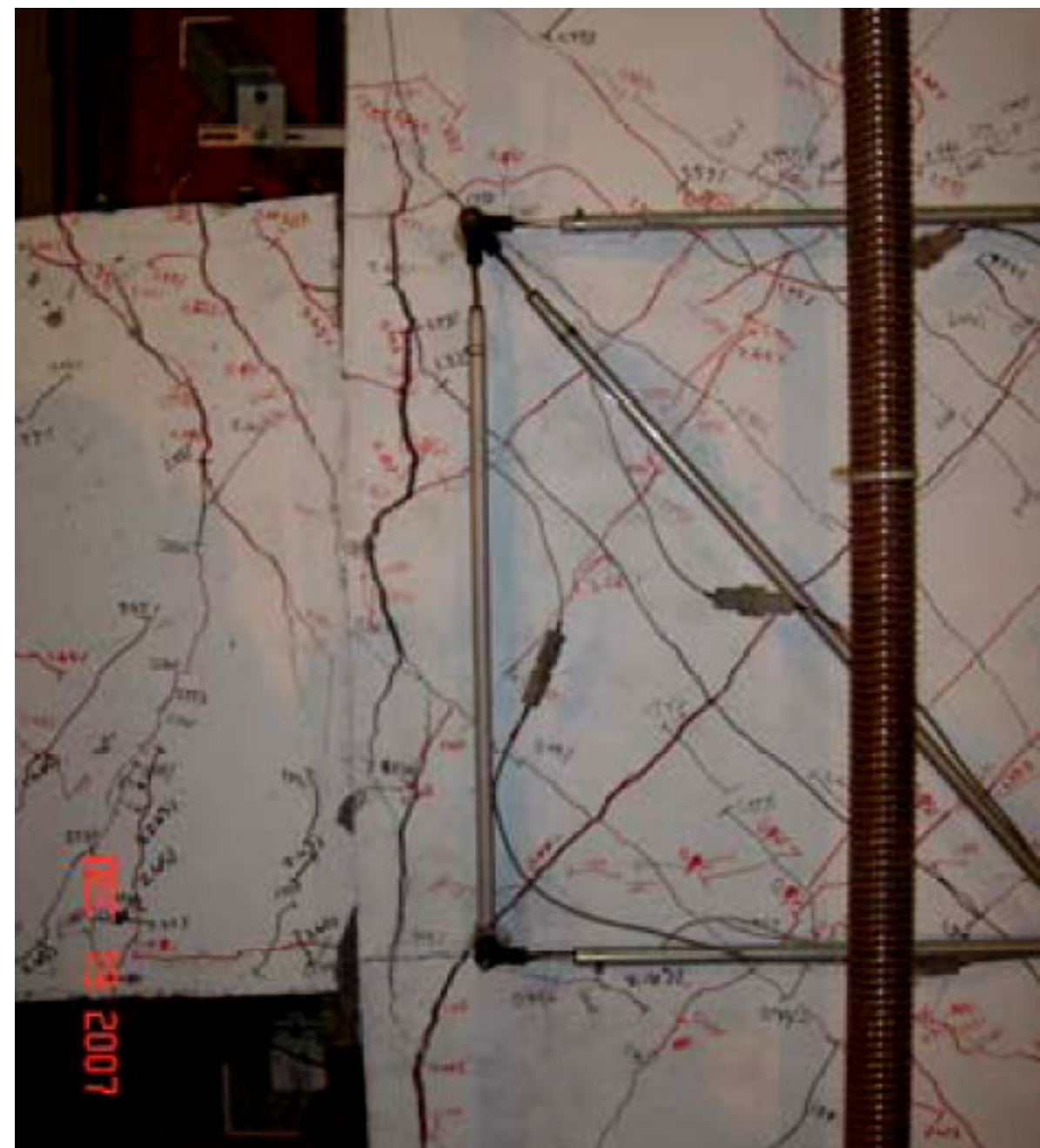

Figure 8: Partial joint elevation of Pankow \#4 at 5.35\% drift (Chang, Hutchinson, and Englekirk 2007)

In contrast to Figure 8, Figure 9 shows the condition of the specimen after the cracking and spalling has eliminated continuous lateral support along the Dywidag bars and therefore the bars have buckled. The DDC system does not completely eliminate buckling of the beam reinforcement, but it does increase the subassemblage drift levels associated with buckling of these bars. 


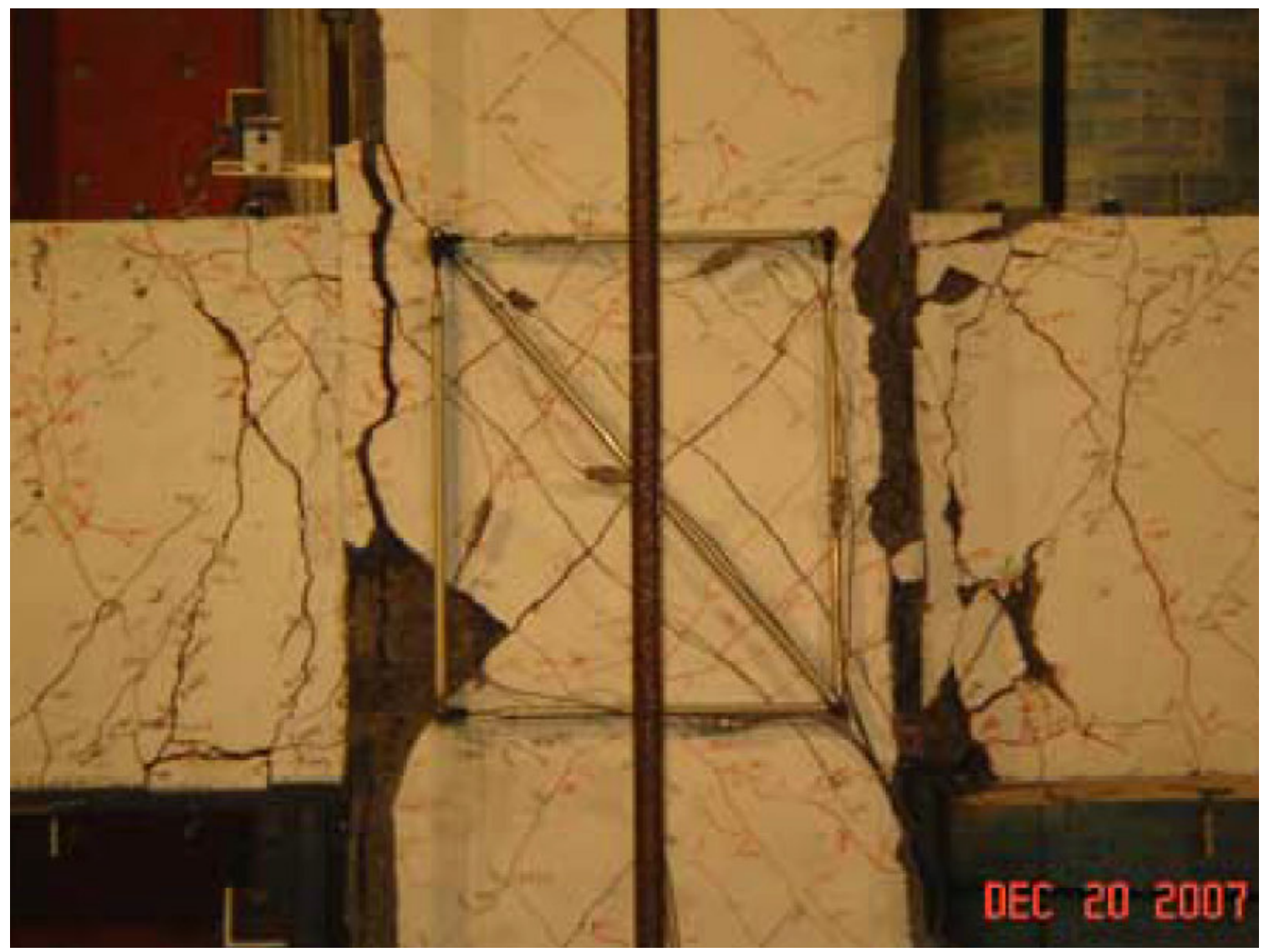

Figure 9 : Joint elevation of Pankow \#4 at $7.07 \%$ drift (Chang, Hutchinson, and Englekirk 2007)

The buckling of the beam reinforcement near the beam-column interface is slightly visible, from the Figure 9 elevation, through the small flare out of the ends of the concrete beams.

A more recent evolutionary turn for the family of precast gap-opening frames was the development of the super hybrid system which incorporates aspects of both the DDC and pure hybrid systems. 


\subsubsection{Super Hybrid Systems}

The super hybrid system refers to the gap-opening frame that uses a DDC as the main energy dissipating element, and PT strands as the restoring force within the system. The super hybrid frame eliminates the extensive grouting required to construct the pure hybrid system, as well as reduces member sizes required of the DDC system when designed under monolithic moment frame code provisions. The configuration of a super hybrid joint is shown in Figure 10.

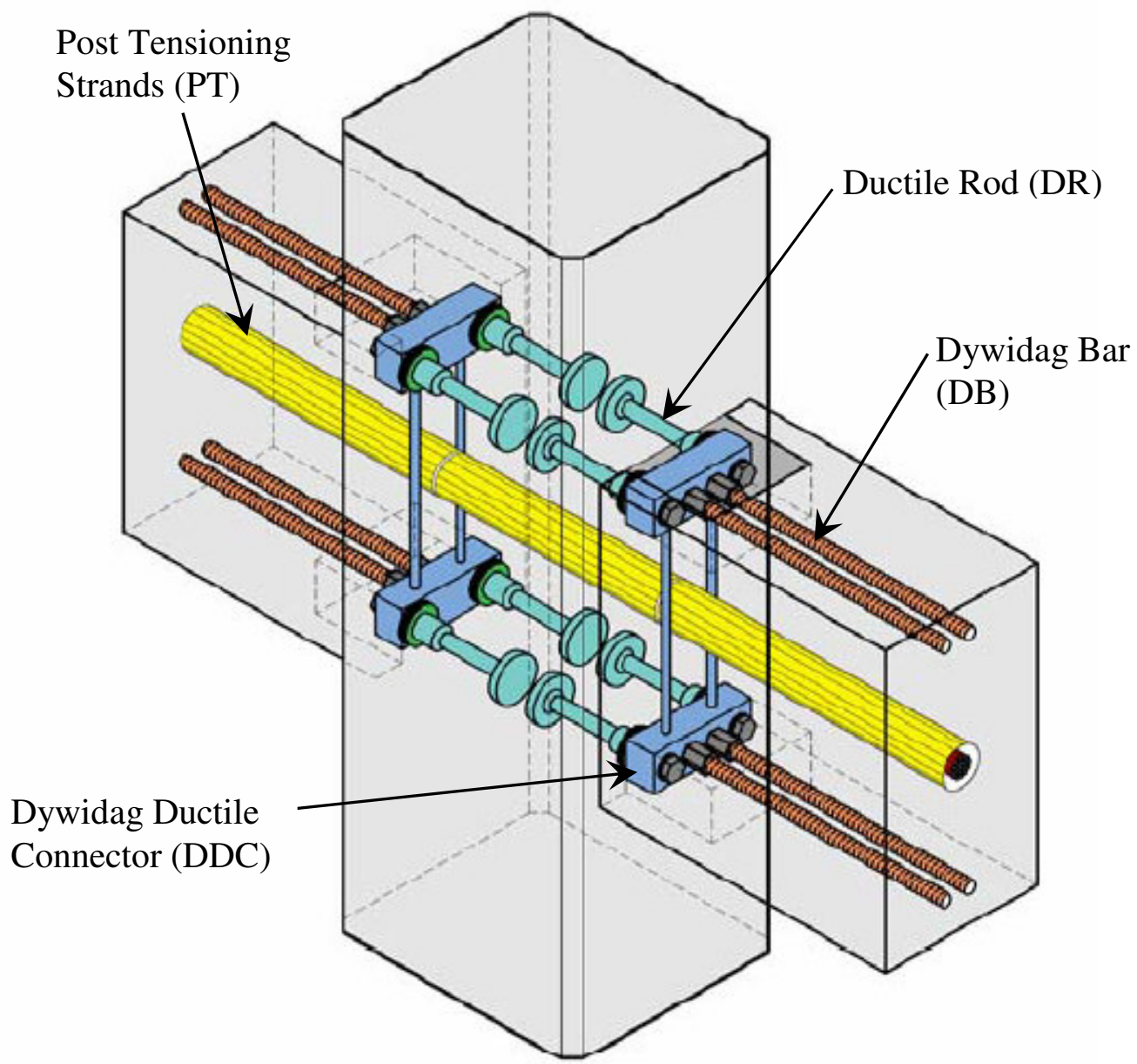

Figure 10: Isometric view of the super hybrid joint (Englekirk 2003) 
The super hybrid erection process is analogous to that of the DDC system except for the additional feeding and tensioning of the PT. The progressive behavior of the super hybrid system is similar to the DDC. The only super hybrid test conducted thus far showed failure of the joint via buckling of the Dywidag bar portion of the DDC, at around $7 \%$ drift.

Each of these gap-opening frame systems has unique physical traits though they all share the same gap-opening behavior. Taking a closer look at the hysteretic test results of these systems helps shed light on the behavioral differences between them.

\subsubsection{Advantages and Disadvantages in the Gap-Opening Systems}

The advantages and disadvantages of each gap-opening system depend on the system's seismic performance and constructability. As mentioned in the previous section, the pure hybrid system requires shoring, which makes it a less desirable gapopening system from a construction stand point. This section will focus on the performance-based advantages and disadvantages.

Figure 11 shows the approximate normalized hysteretic loops of the DDC, pure hybrid, and super hybrid systems at $2 \%$ drift. Around $2 \%$ drift the pure hybrid specimen shows desirable results. The energy dissipation is present and comparable in all specimens. The pure hybrid specimen has a greater pinching effect than the other specimens, and therefore, it experiences less residual drift. 


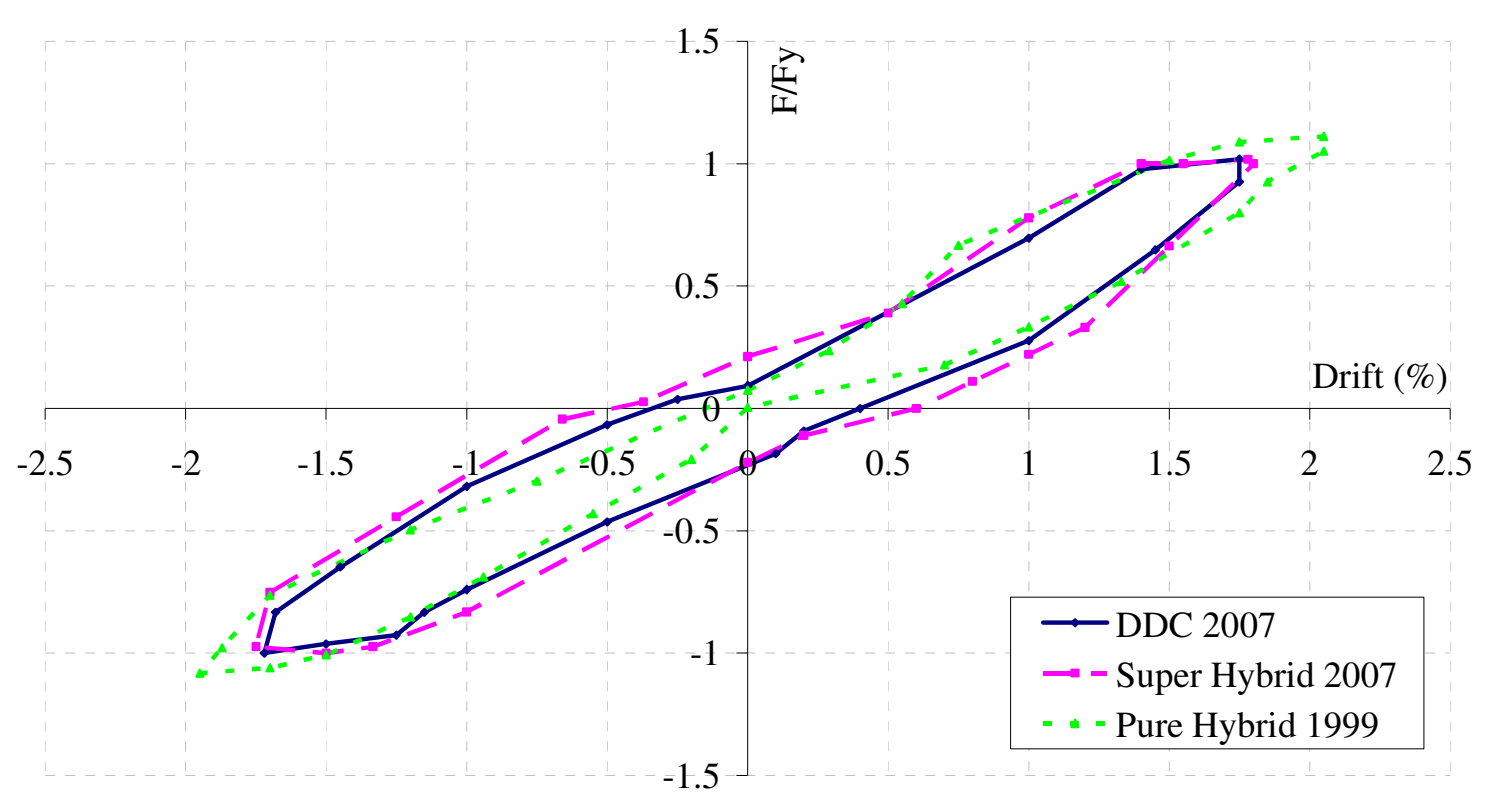

Figure 11: Force-displacement hysteretic loop approximations at 2\% (Chang, Hutchinson, and Englekirk 2007) and (Stanton, Day, and MacRae 1999)

Figure 12 shows the approximate hysteretic loops of each system at 3-3.5\% drift. At this drift ratio, the residual drift has roughly doubled, relative to the $2 \%$ loops, for the DDC and super hybrid specimens. The energy dissipation in the DDC and super hybrid specimens is greater than that of the pure hybrid specimen. 


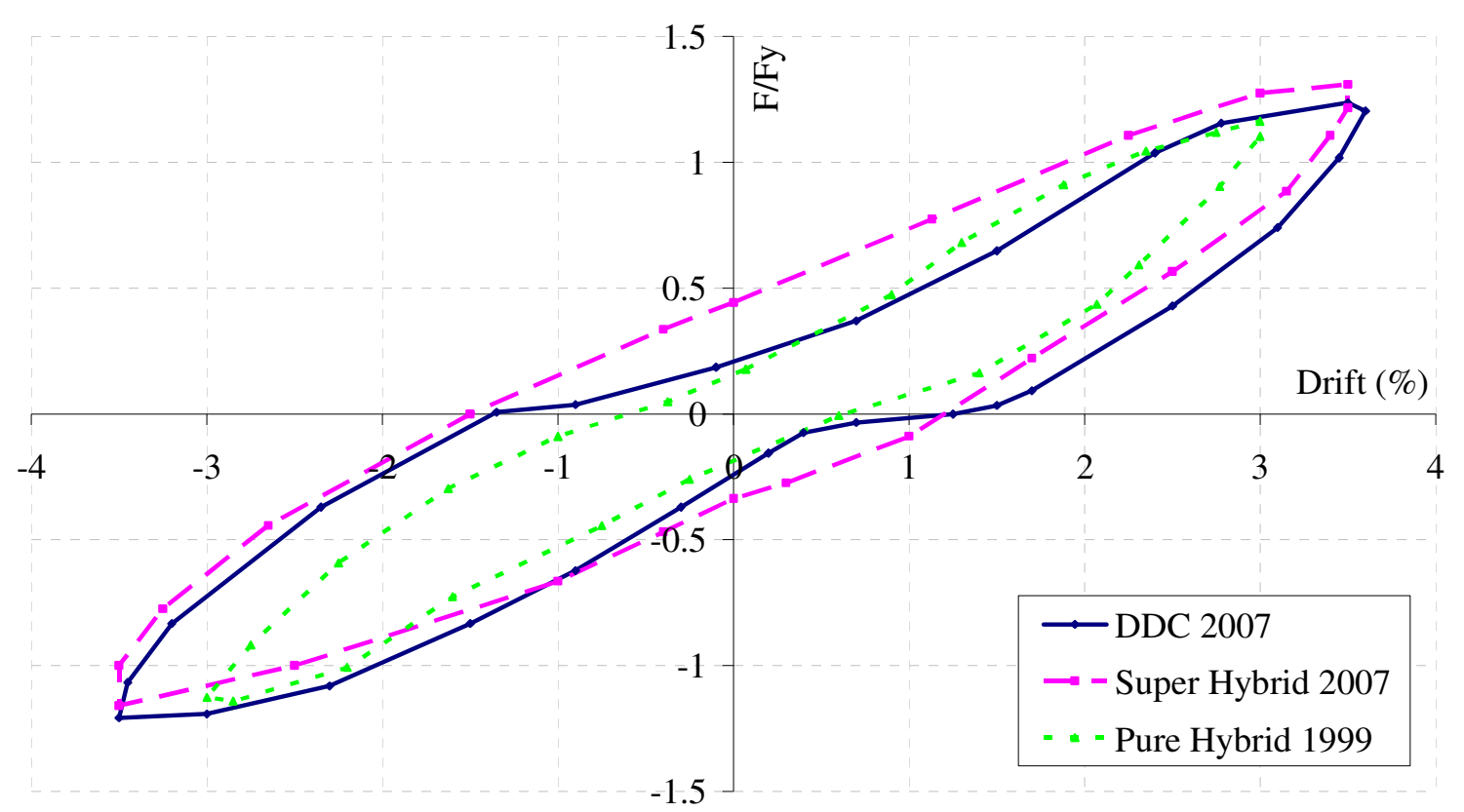

Figure 12: Force-displacement hysteretic loop approximations at 3-3.5\% (Chang, Hutchinson, and Englekirk 2007) and (Stanton, Day, and MacRae 1999)

Figure 13 shows the approximate hysteretic loops of each specimen at 5\% drift. At this level of drift, the relative energy dissipation is distinctly different in the DDC and super hybrid specimens relative to the pure hybrid specimen. At $5 \%$ drift the pure hybrid subassemblage decreases in strength to about $75 \%$ of its capacity, and thus has reached failure. 


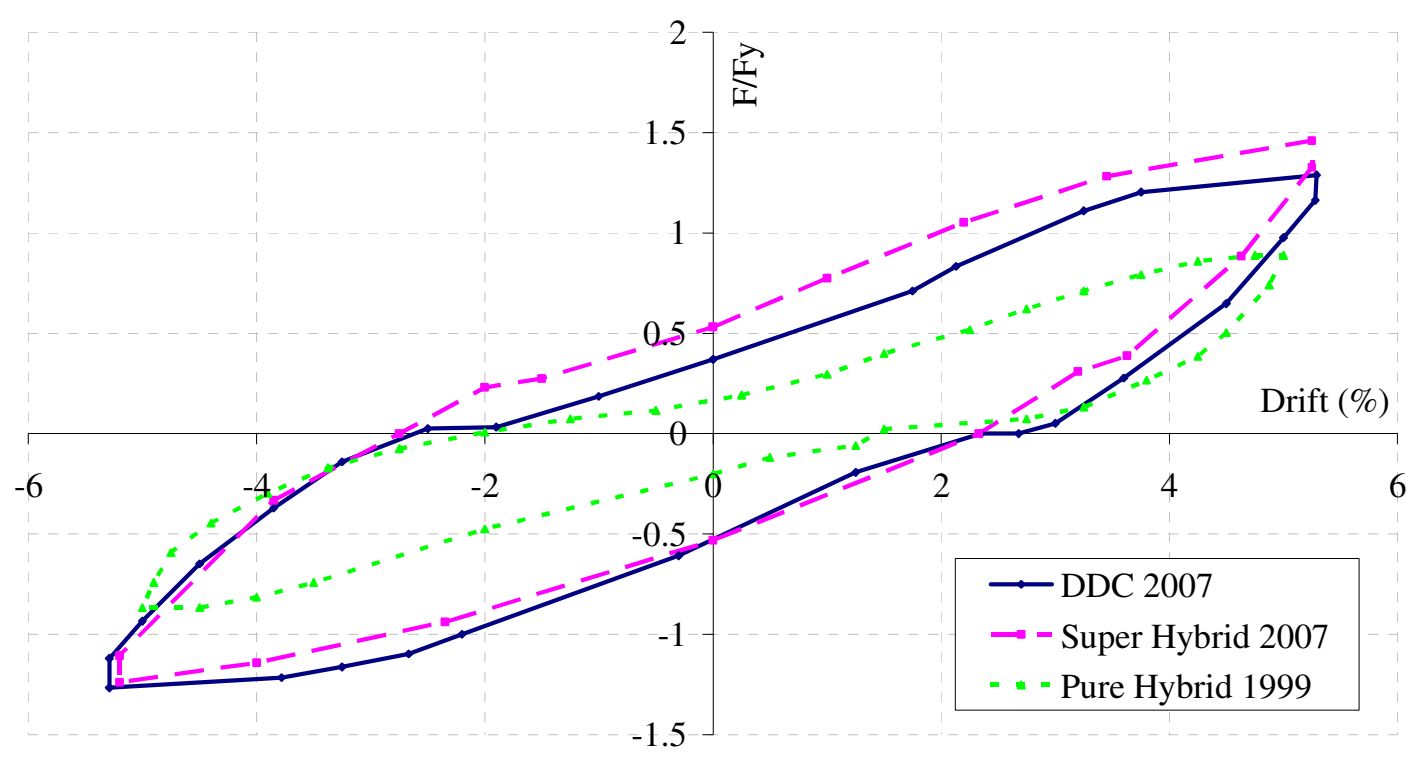

Figure 13: Force-displacement hysteretic loop approximations at 5\% (Chang, Hutchinson, and Englekirk 2007) and (Stanton, Day, and MacRae 1999)

The degradation in strength of the pure hybrid system is more visually apparent in Figure 14 which only shows the various hysteretic loops of the pure hybrid system.

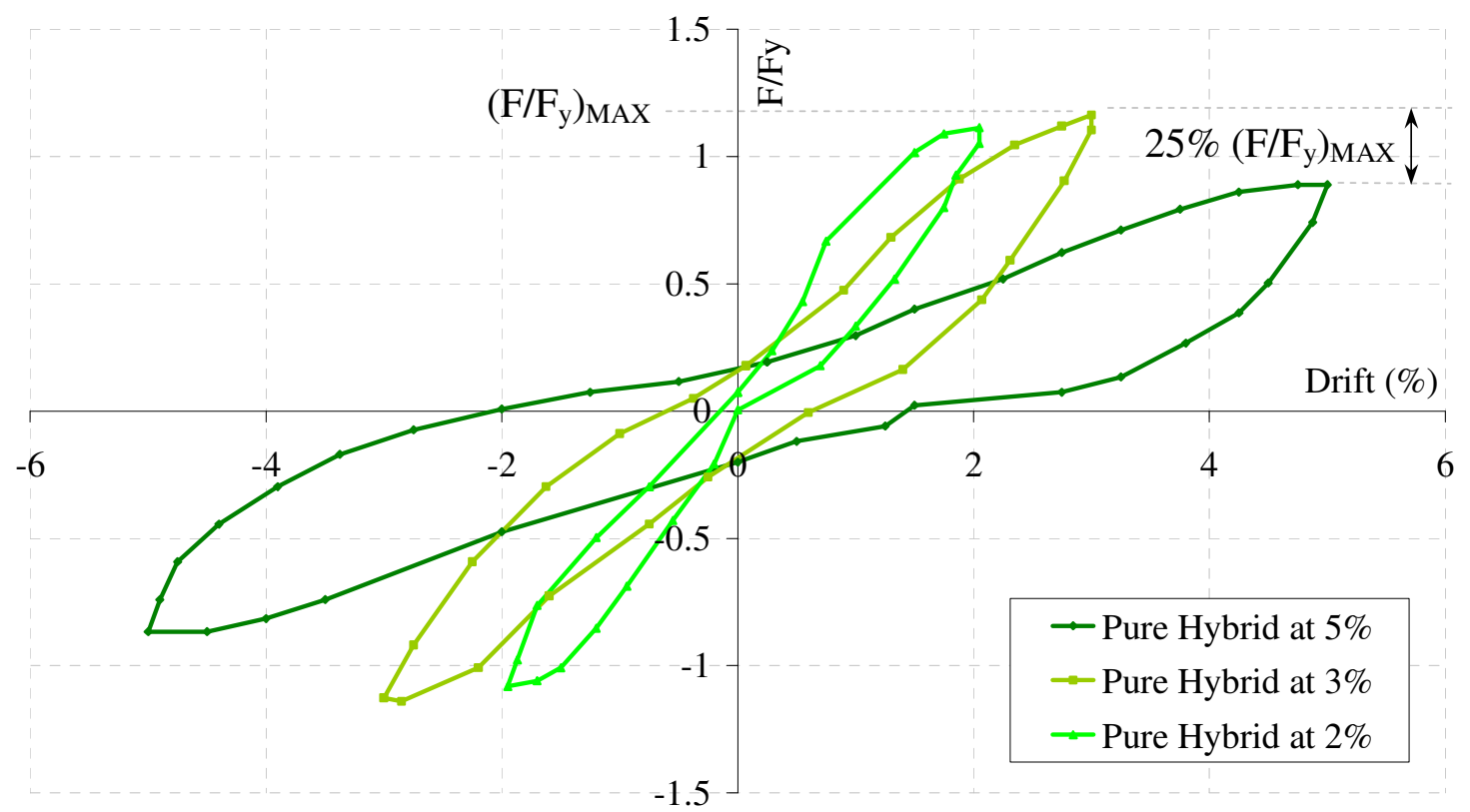

Figure 14: Pure hybrid force-displacement hysteretic loop approximations at 2\%, 3\%, and 5\% drift (Stanton, Day, and MacRae 1999)] 
In contrast to the pure hybrid specimen, degradation in strength from $2 \%$ to $5 \%$ drift is not present in the DDC system and the super hybrid system. Both systems' test results are shown in Figure 15 and Figure 16 respectively.

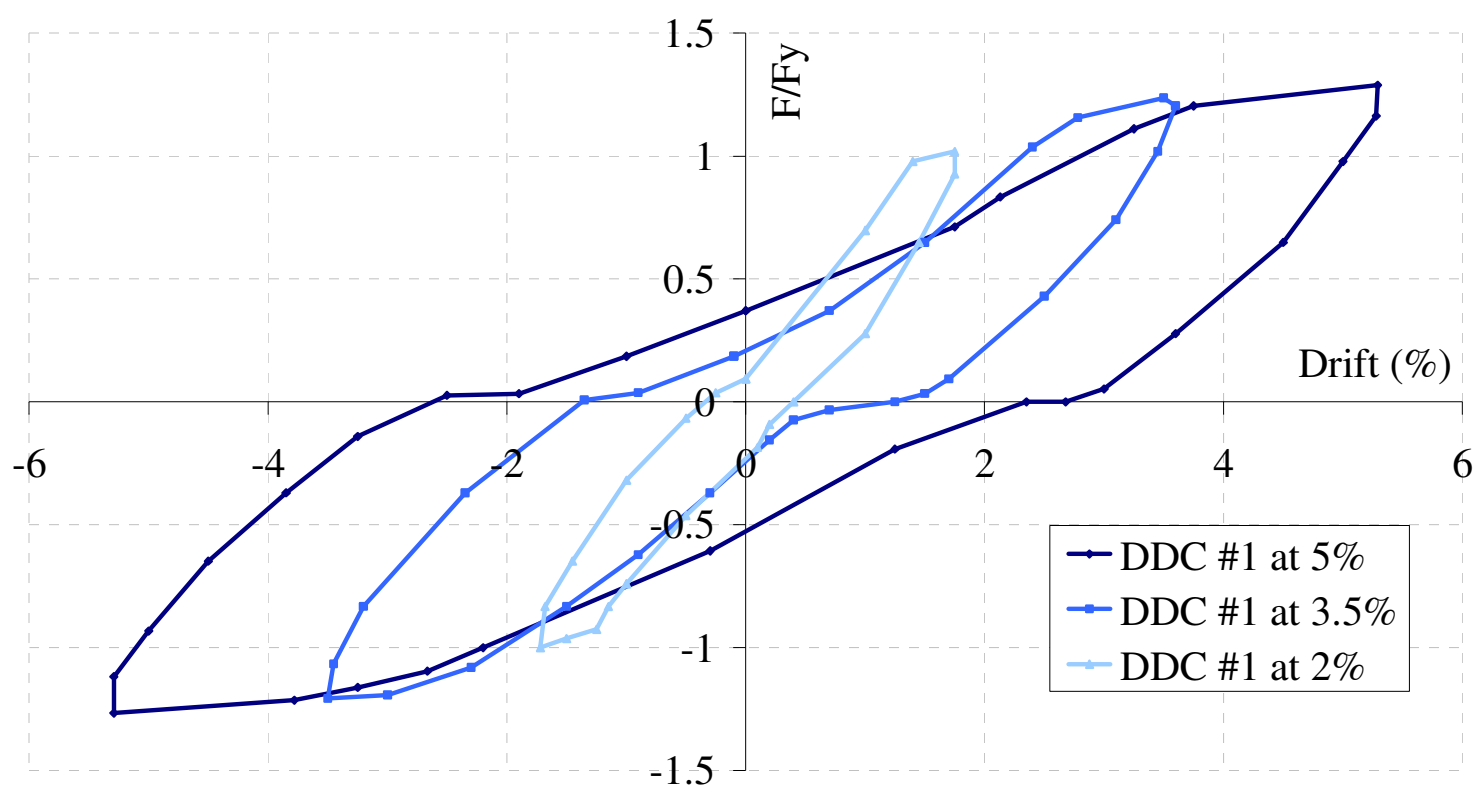

Figure 15: DDC force-displacement hysteretic loop approximations at 2\%, 3\%, and 5\% drift (Chang, Hutchinson, and Englekirk 2007)]

A disadvantage of the DDC and super hybrid systems is the greater levels of residual drift compared to the pure hybrid system.

Though the behavior of the DDC specimen and super hybrid specimen appear to be very similar, they differ in their subassemblage composition, besides just the presence or absence of PT. 


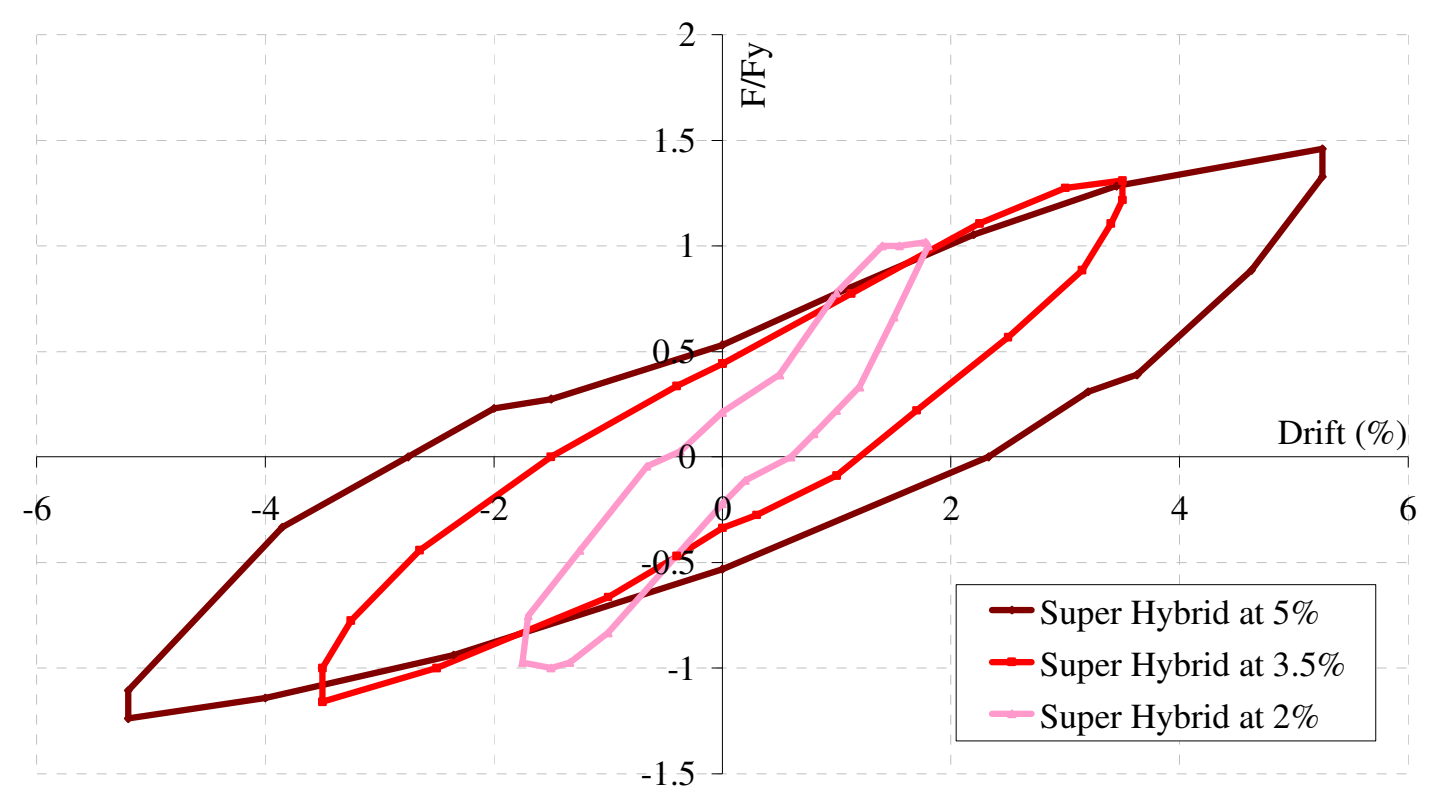

Figure 16: Super hybrid force-displacement hysteretic loop approximations at 2\%, 3.5\%, and 5\% drift (Chang, Hutchinson, and Englekirk 2007)

The super hybrid specimen, results shown in Figure 16, had a total of 8 ductile rods within the joint compared to 12 ductile rods within the joint of the DDC specimen. With four less ductile rods, less steel is used in the joint and in adjacent members.

As previously mentioned, when looking at the gap-opening systems from a constructability stand point, the DDC and super hybrid systems require less erection time than the pure hybrid system, but still maintain the same advantages over a monolithic frame as the pure hybrid system. As well, the DDC and super hybrid systems show minimal signs of strength degradation at drift levels over $4 \%$.

The Northridge earthquake caused a significant amount of damage in steel frame buildings and subsequent research suggests that it will be difficult to attain postyield story drifts of 3 percent in steel ductile frames. Story drifts of 3.5 percent in concrete frames produce considerable distress and this is also the case in 
structural steel subassemblies. The ductile connector [DDC] is not only easily capable of exceeding these levels of story drift but does so without damaging the system (Englekirk 1995).

With the above mentioned level of potential demand on structural systems in Southern California, as well as the advantages of the DDC and super hybrid systems, some engineers in the region have tried to incorporate these systems into building practice.

\subsection{Current Industry Practices}

Design codes in the United States such as the Uniform Building Code (UBC), International Building Code (IBC), and the American Concrete Institute Code (ACI) permit the design of precast structures in high seismic zones via three routes.

The first route requires the design of precast structures to emulate the behavior of a comparable monolithic concrete structure in terms of strength and toughness. For example, the Hollywood Highlands building uses the DDC as the primary lateral system; however, the design procedures followed chapter 16, chapter 19, and chapter 21 of the 2001 California Building Code (CBC) under the category of special moment resisting frame. The general seismic demand and capacity design for the DDC is the same as designing a monolithic moment frame. Taking this design approach results in larger member sizes than are necessary (Chen 2007).

The second route for design permits a new type of lateral system, but requires experimental and analytical evidence verifying satisfactory behavior of the precast systems under simulated seismic loading (Celik and Sritharan, 2004). This route requires 
a substantial amount of time, effort, and money, and, for these reasons, is typically not the approach taken.

The third route requires the design of a hybrid system that fits within the parameters set by the Standard ACI T1.2-03, which is titled Special Hybrid Moment Frames Composed of Discretely Jointed Precast and Post-Tensioned Concrete Members. The T1.2-03 provides detailed guidelines for the mechanism requirements for the pure hybrid frame. "This limits the type of hybrid frame acceptable by this specific code, to those frames whose design characteristics do not exceed the bounds of the properties of the pure hybrid specimens used in the validation tests for code ACI T1.2-03" (Hawkins and Ghosh 2004). Due to such limitations, design engineers have been denied permission to use the ACI T1.2-03 code for the design of a super hybrid system.

Due to the lack of testing on super hybrid and DDC frames, and the relatively new nature of the systems, attempts to use these systems outside the monolithic code sections have failed (Chen 2007). With the recent testing and research done at UCSD on the DDC and super hybrid systems, the implementation of these systems into practice is becoming more plausible via the second route previously mentioned.

\subsection{The Project Statement}

As the Dywidag ductile connector and super hybrid systems reach industry, the design engineer will need to model these systems using structural analysis software. This report provides two examples of tested DDC specimens that were each modeled in PERFORM-3D and ETABS. The experimental backbone curve for each test specimen 
was compared to the corresponding analytical pushover curves. Preceding these results is a discussion on the parameters to consider when creating a lumped plasticity model (ETABS) and a fiber model (PERFORM-3D).

The fiber modeling focuses on providing a means to study the joint behavior as the parameters of the system are changed. This fiber modeling uses finite element analysis on beam elements containing multiple fibers to determine the internal forces of the system. Each fiber is analyzed individually at its mid-span and mid-height. The results produce a piecewise approximation of the internal forces along each member within the system. This approach is a valuable method for researching the DDC system, as it is more cost effective than testing numerous system configurations. As well, fiber modeling is a tool which can greatly effect design decisions by helping the engineer better understand the effects of varying parameters of the system.

The lumped plasticity modeling provides the design engineer with a means for modeling a three-dimensional building with a DDC system. The lumped plasticity model uses elastic members in conjunction with nonlinear moment-rotation hinges. With such a model, the engineer has the tools to get acceptable global demand forces within a reasonable time frame.

This project provides modeling suggestions for both the fiber models and the lumped plasticity models used to predict the seismic behavior of the DDC precast concrete system. 


\subsection{LITERATURE REVIEW}

The first portion of this project involves creating an analytical model of the DDC system. Several pieces of literature helped guide the development and assessment of the DDC analytical models created for this project. The most influential researcher paper for this project was that of the work done at Lehigh University which describes the process of creating an analytical fiber model for a pure hybrid system. El-Sheikh et al. (1997) designed a subassemblage model in DRAIN-2DX, the precursor to PERFORM-3D. As seen in Figure 17, the El-Sheikh et al. work used fiber elements to model various portions of the beam-column elements.

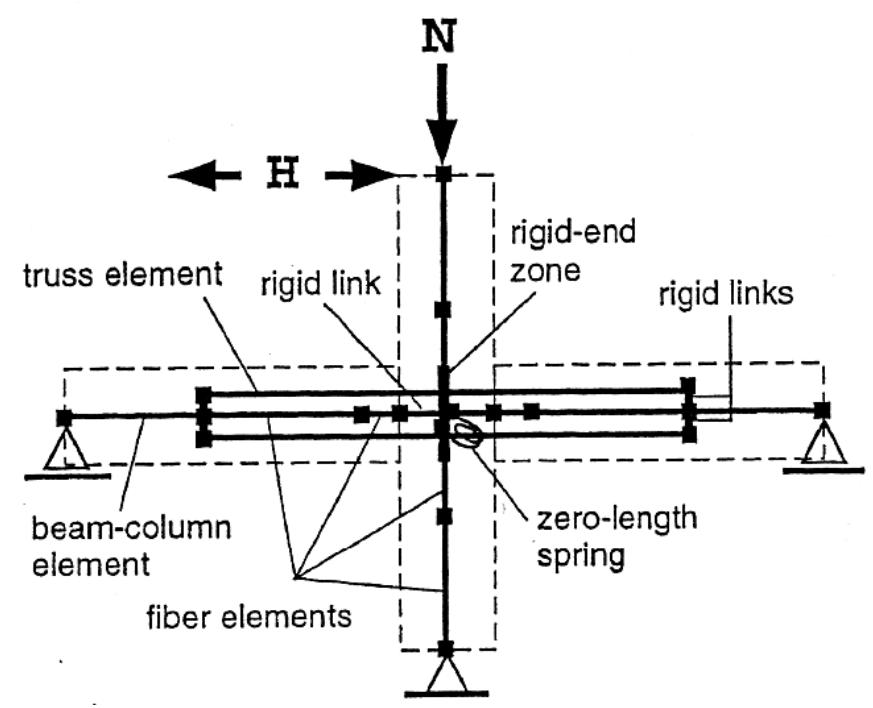

Figure 17: Interior unbonded post-tensioned beam-column sub-assemblage fiber model (El Sheikh et al.1997)

Their study laid the ground work for the idea of using a fiber model for the DDC models created during this project.

The uniaxial stress-strain relationship, for materials within the system, is required to define the behavior for each fiber within the fiber elements of a model. 
Various models have been used in the past to mimic the stress-strain properties of structural materials. For this project, the stress-strain model developed by Mander et al. (1988) was used to define the constitutive properties necessary for modeling the concrete members. Figure 18 labels some of the characteristics of Mander's Model.

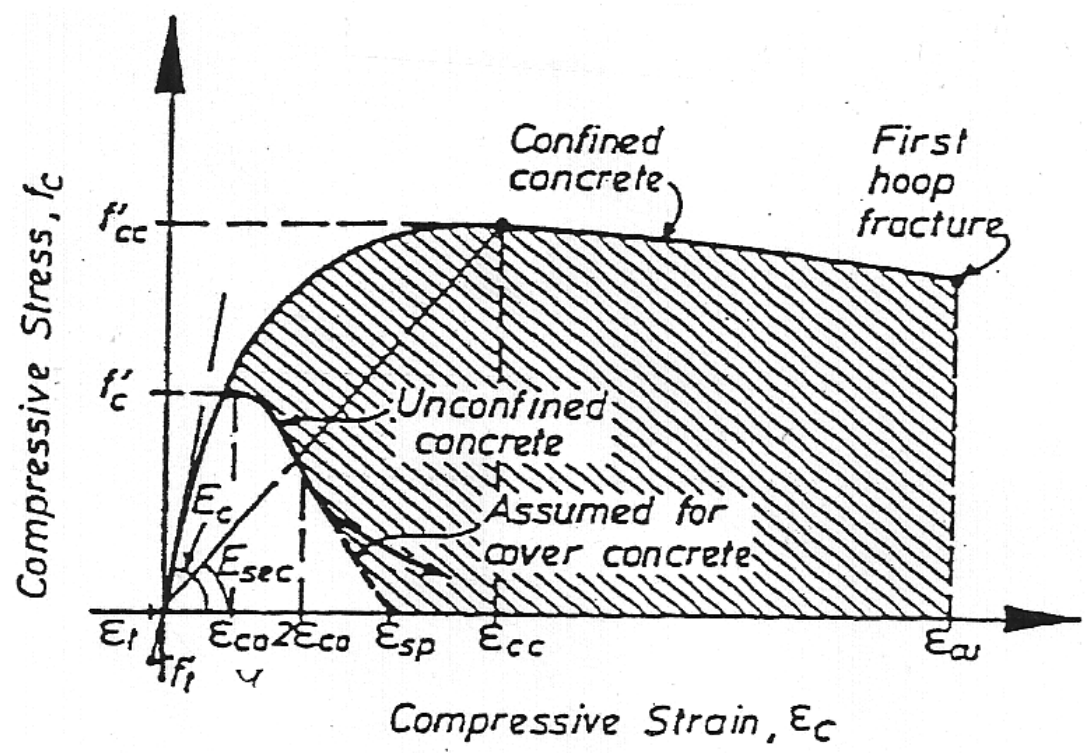

Figure 18: Confined and unconfined concrete stress-strain curves from (Mander et al. 1988)

The above mentioned Mander's stress-strain models were used in the DDC fiber model to define the confined and unconfined concrete properties within the beams and columns.

After the fiber models were created, they were blindly tested against their corresponding sets of experimental data. The two DDC test specimens modeled are Pankow \#4 and SEQAD \#1. Figure 19 shows an elevation of the Pankow \#4 specimen, which is referred to as DDC \#1. 


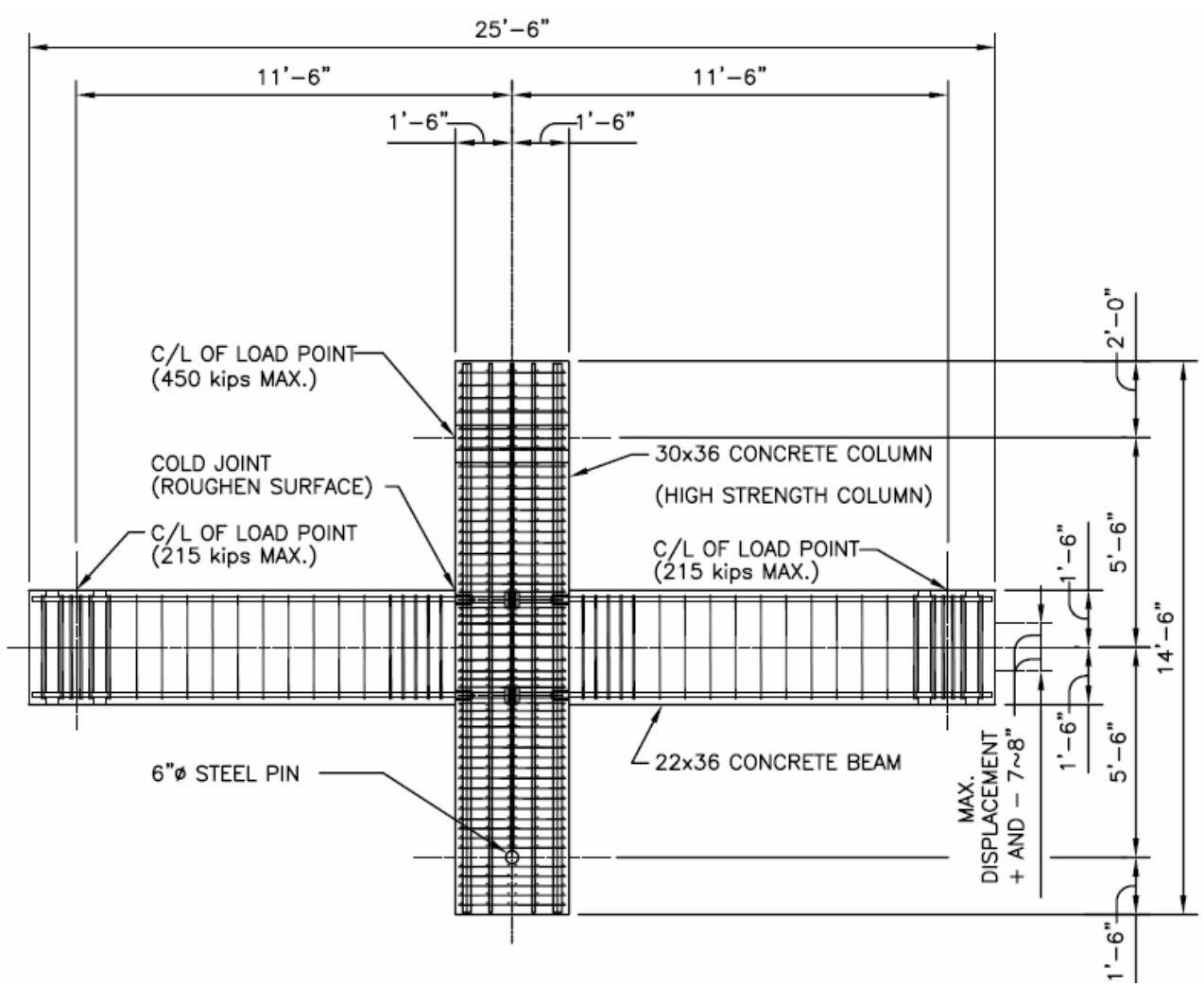

Figure 19: Schematic elevation of the DDC \#1 test specimen (Chang Hutchinson, and Englekirk 2007)

More details of DDC \#1, such as reinforcement size and spacing, are provided in Appendix G. An approximation of the hysteretic test data for DDC \#1 is shown in Figure 20; the actual test results are shown in Appendix G. 


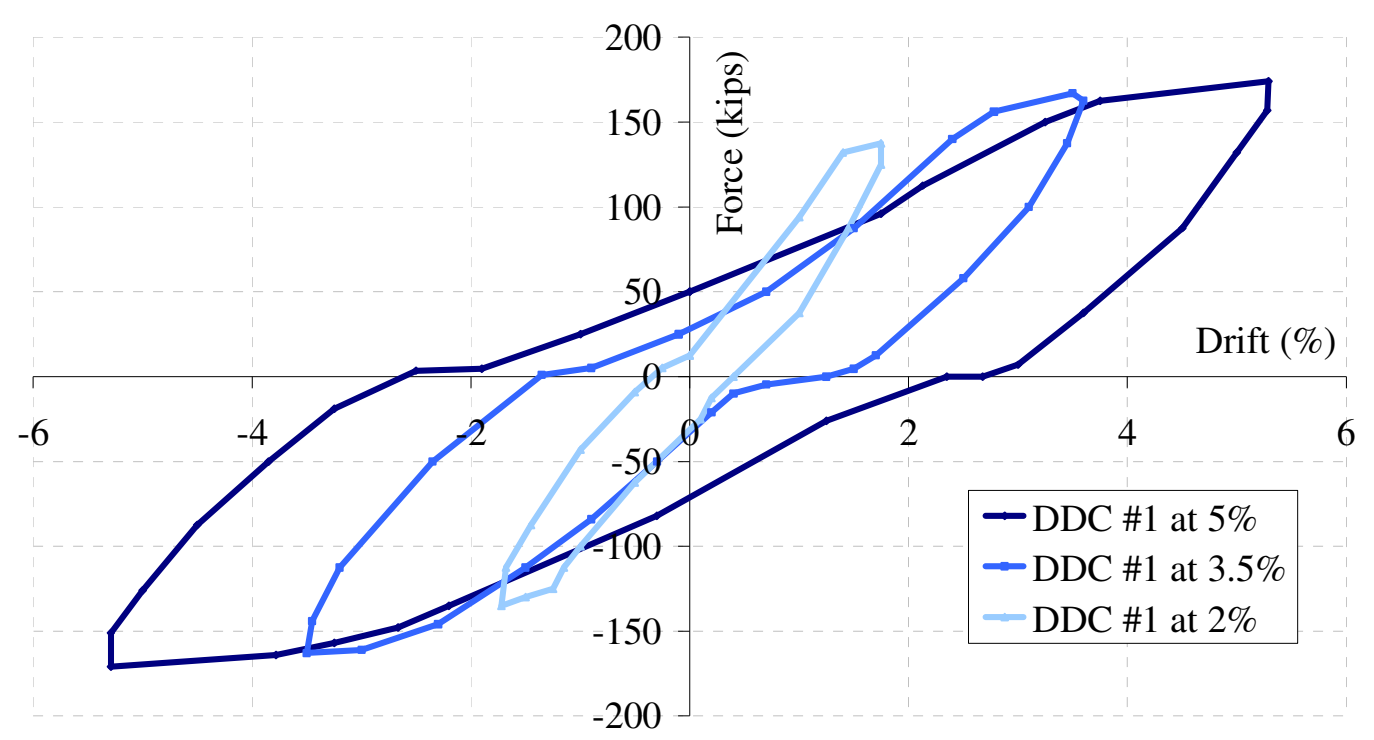

Figure 20: Force-displacement hysteretic loop approximations for DDC \#1

The second specimen modeled is SEQAD \#1, and is referred to as DDC \#2.

This DDC specimen was tested by Structural Earthquake Analysis and Design

Consulting Engineers, Inc. (SEQAD). The elevation of DDC \#2 is shown in Figure 21.

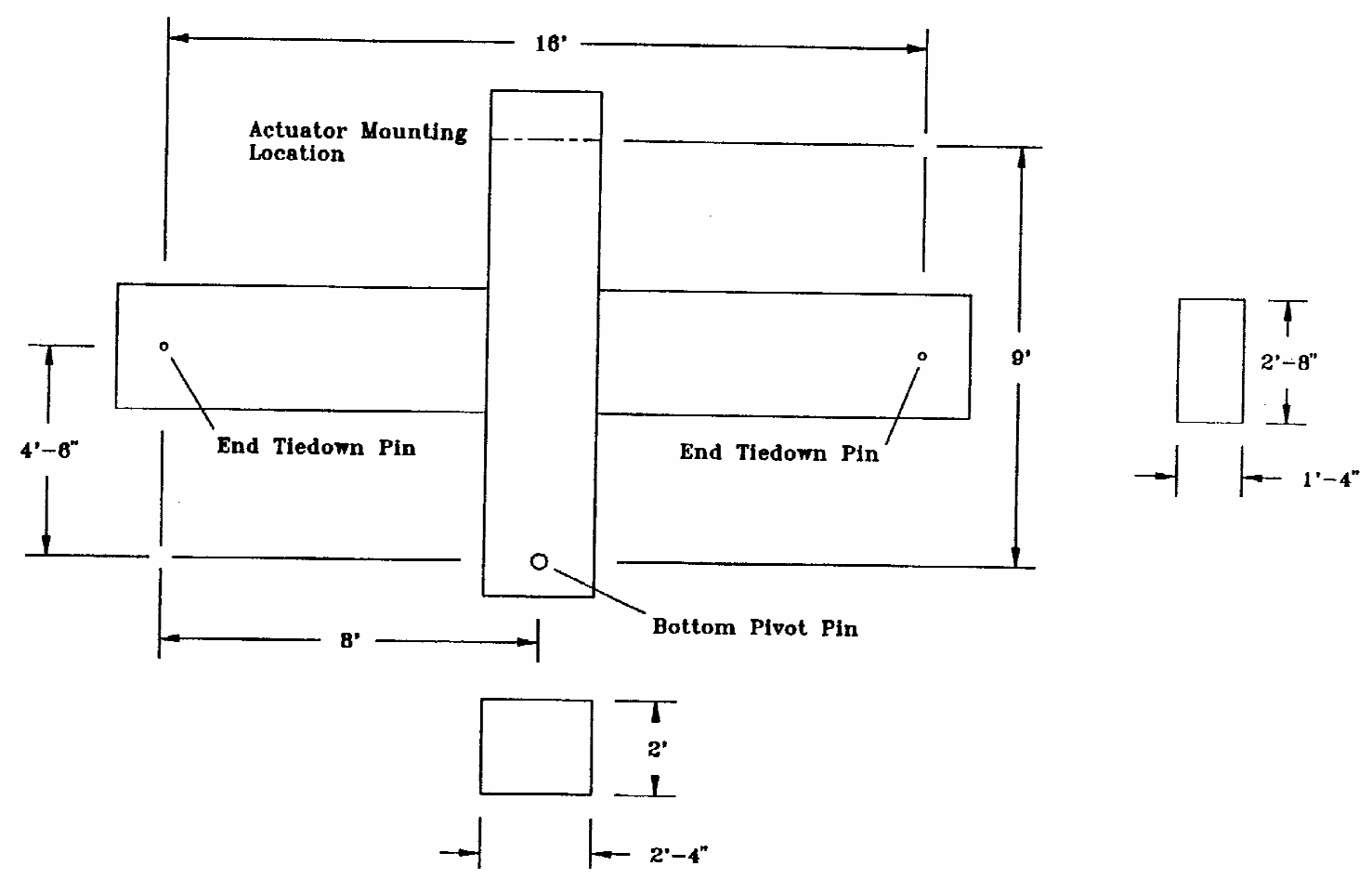

Figure 21: Schematic elevation of the DDC \#2 test specimen (SEQAD 1993) 
An approximation of the hysteretic test data for DDC \#2 is shown in Figure 22. The actual test results, as well as specimen details such as reinforcement layout, are provided in Appendix H.

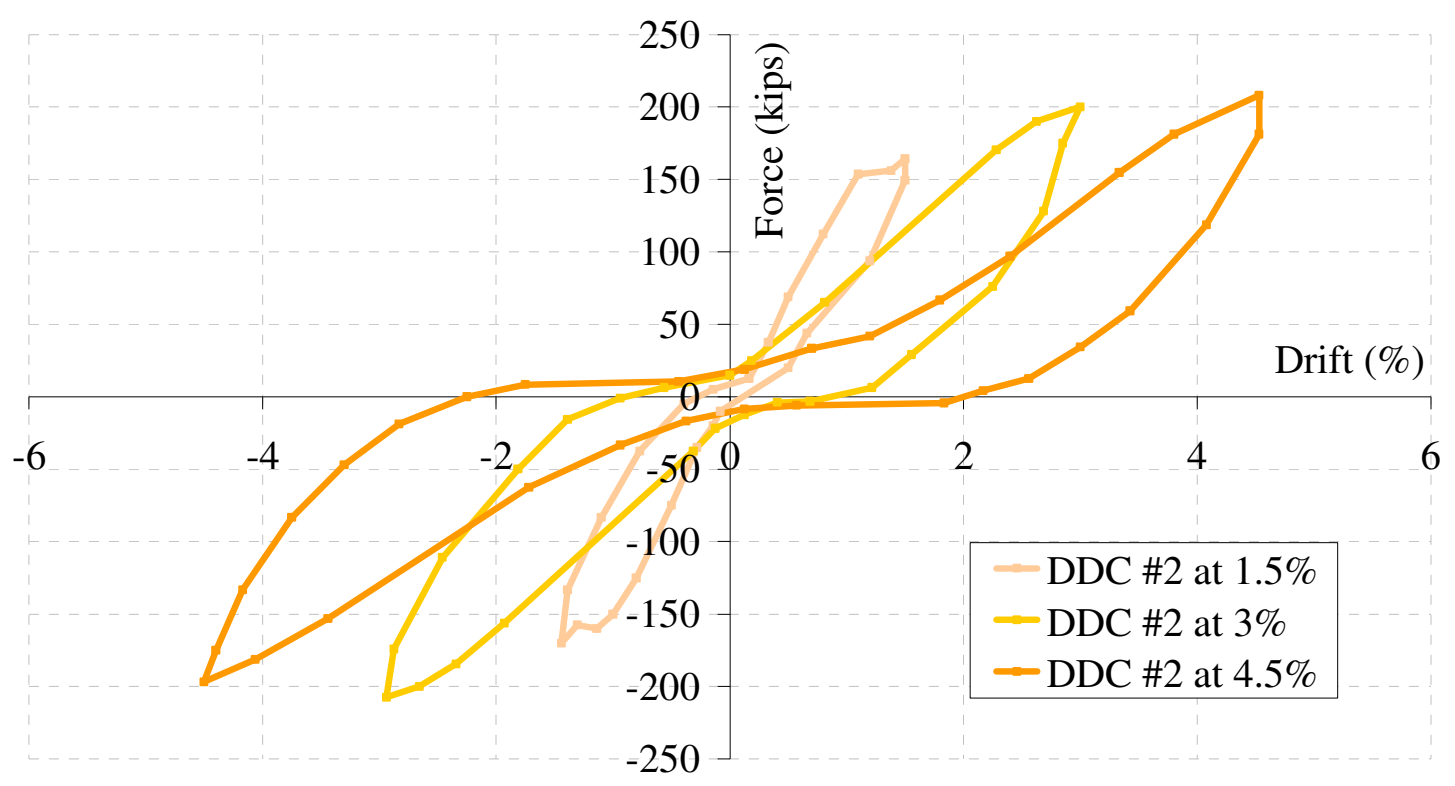

Figure 22: Force-displacement hysteretic loop approximations for DDC \#2.

More of the El-Sheikh et al. paper as well as a study conducted by Elwood et al. (2007) are mentioned in Section 3.0 as their content is discussed in greater detail and parallels some of the studies conducted for this project. 


\subsection{MODEL DESIGN AND ASSUMPTIONS}

In the process of modeling DDC \#1 and DDC \#2 many assumptions were made. Some assumptions are standard practice, where as others are recently developed techniques. Along with modeling the DDC specimens, some small parametric studies were conducted.

\subsection{Boundary Conditions}

The specimens studied are typical interior frame elements as shown in Figure 23.

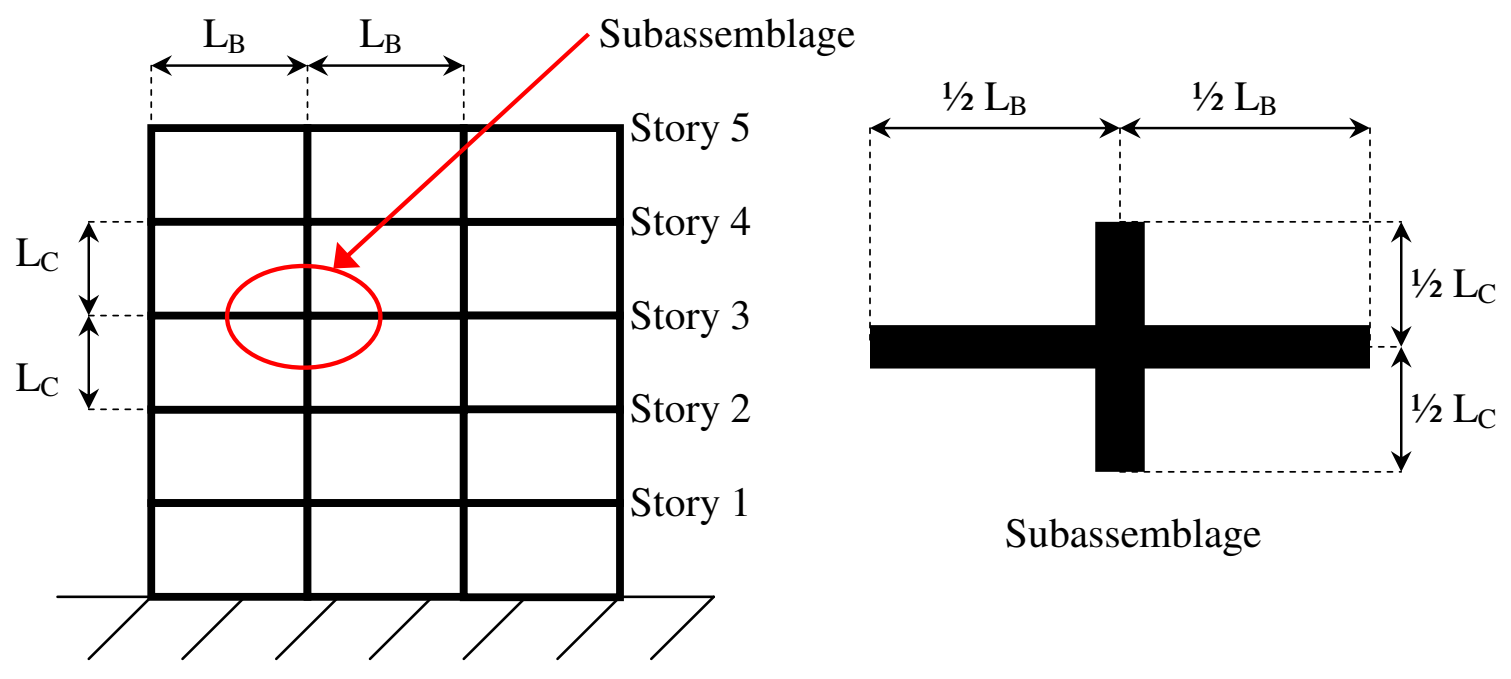

Figure 23: Schematic elevation of a five-story moment frame building

The subassemblage is a cruciform shape which spans from the mid-point of the beams and has a height extending from the mid-point of each column; the subassemblage terminates at the theoretical inflection points of the frame. 
In the case of the global geometry of the subassemblages, DDC \#1 and DDC \#2 were tested and restrained in different ways. Figure 24 shows the loading locations and boundary conditions for both test specimens.

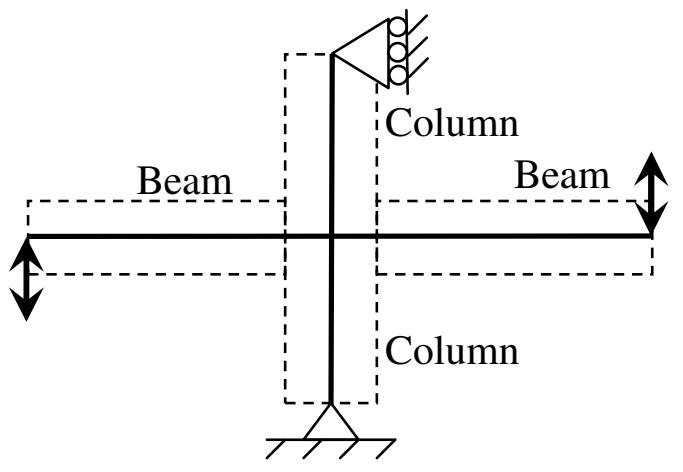

DDC \#1

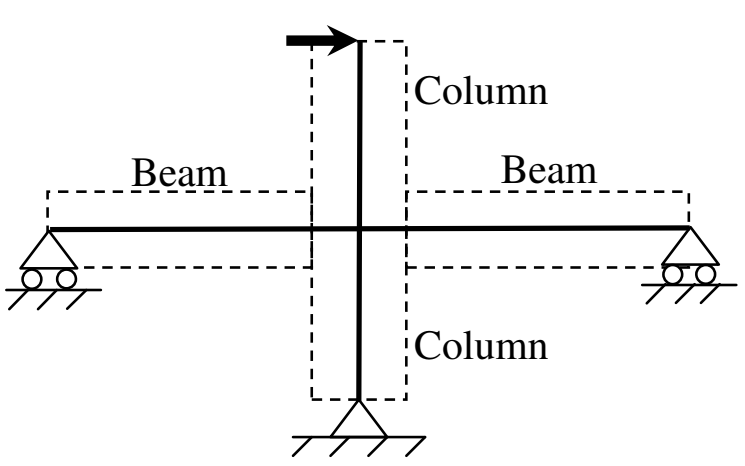

DDC \#2

Figure 24: Test configuration and boundary conditions

The force-displacement output from each test varies. For DDC \#1 the test data collected at UCSD is a graph of the beam shear verses the drift between the beam ends. For DDC \#2 the test data collected by SEQAD is a graph of the column shear verses the drift between the column ends. Figure 25 shows the boundary conditions and applied loading location for the computer models. 


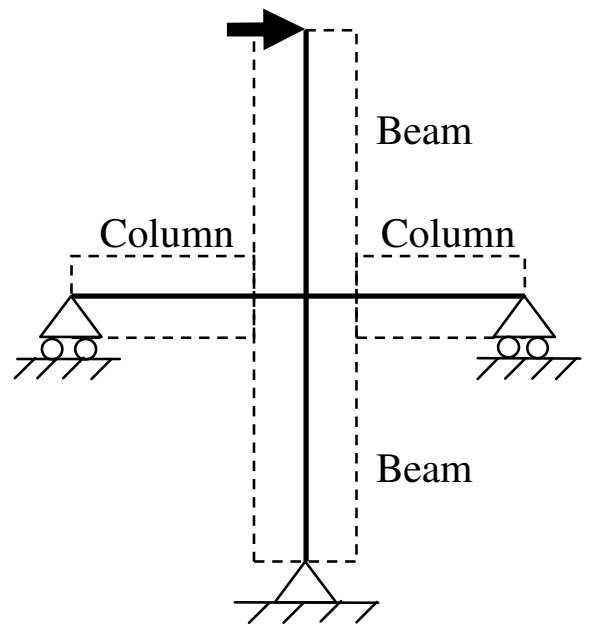

DDC \#1

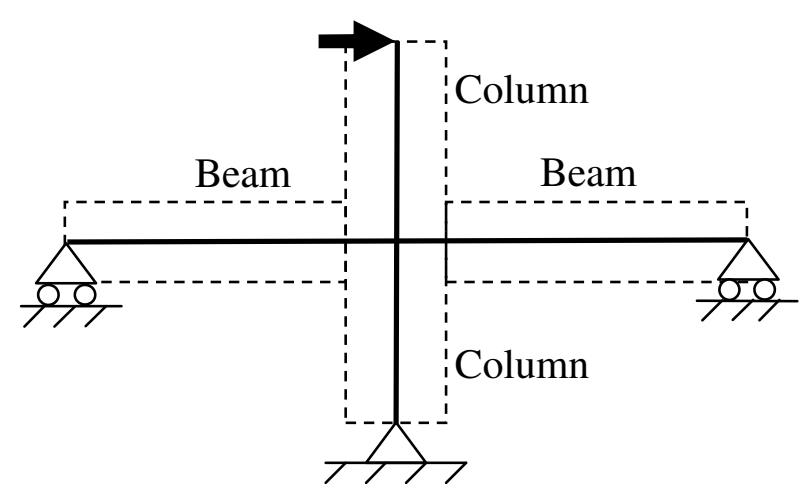

DDC \#2

Figure 25: Model configuration and boundary conditions for DDC \#1 and DDC \#2

The configuration for DDC \#1 was rotated $90^{\circ}$ from the test configuration to improve the efficiency of the data collection process.

\subsection{Various Parameters}

For DDC \#1 and DDC \#2, the effects of self weight, column axial load, and P- $\Delta$ effects are negligible. This is not to say that these aspects should be ignored for threedimensional building analyses of this system, but for the subassemblages studied in this report, these various modeling parameters do not significantly affect the joint behavior.

\subsection{Fiber Model (PERFORM-3D)}

\subsubsection{The Gap-Opening}

The beam-column interface, where the gap-opening occurs, shown in Figure 2, is a defining trait of gap-opening systems. At this interface, there is shear transfer through the DDC, the steel block, as well as flexural strength provided by the ductile rods and 
compressive concrete. Since the steel block is designed to remain elastic, the main modeling concern at this interface is the lack of deformation compatibility due to the gapopening. The process of gap opening and closing under the action of flexural loading is captured in the fiber elements by having an increase in the number of fibers subjected to tension as the loading increases, and a decrease in the number of fibers subjected to tension as the loading decreases.

The important aspect of this gap-opening behavior in PERFORM-3D is the ultimate tensile strain in the material properties. The ultimate tensile strain value should be relatively large in order to allow the analysis of the system to continue well past the point in which a fiber has lost all its strength. For example, Figure 54 shows the confined concrete beam properties for DDC \#1. At 0.012 strain the fiber with this assigned material characteristics would have no more strength; however, it is still permitted to increase in strain up to $0.5 \mathrm{in} . / \mathrm{in}$. in order to allow for large deformations, an essential characteristic for the gap-opening interface.

\subsubsection{Fiber Elements}

Fiber elements were decided upon as a means to model not just the gap-opening, but also the inelastic regions of the beams and columns. A typical cross section for a fiber element is shown in Figure 26. 


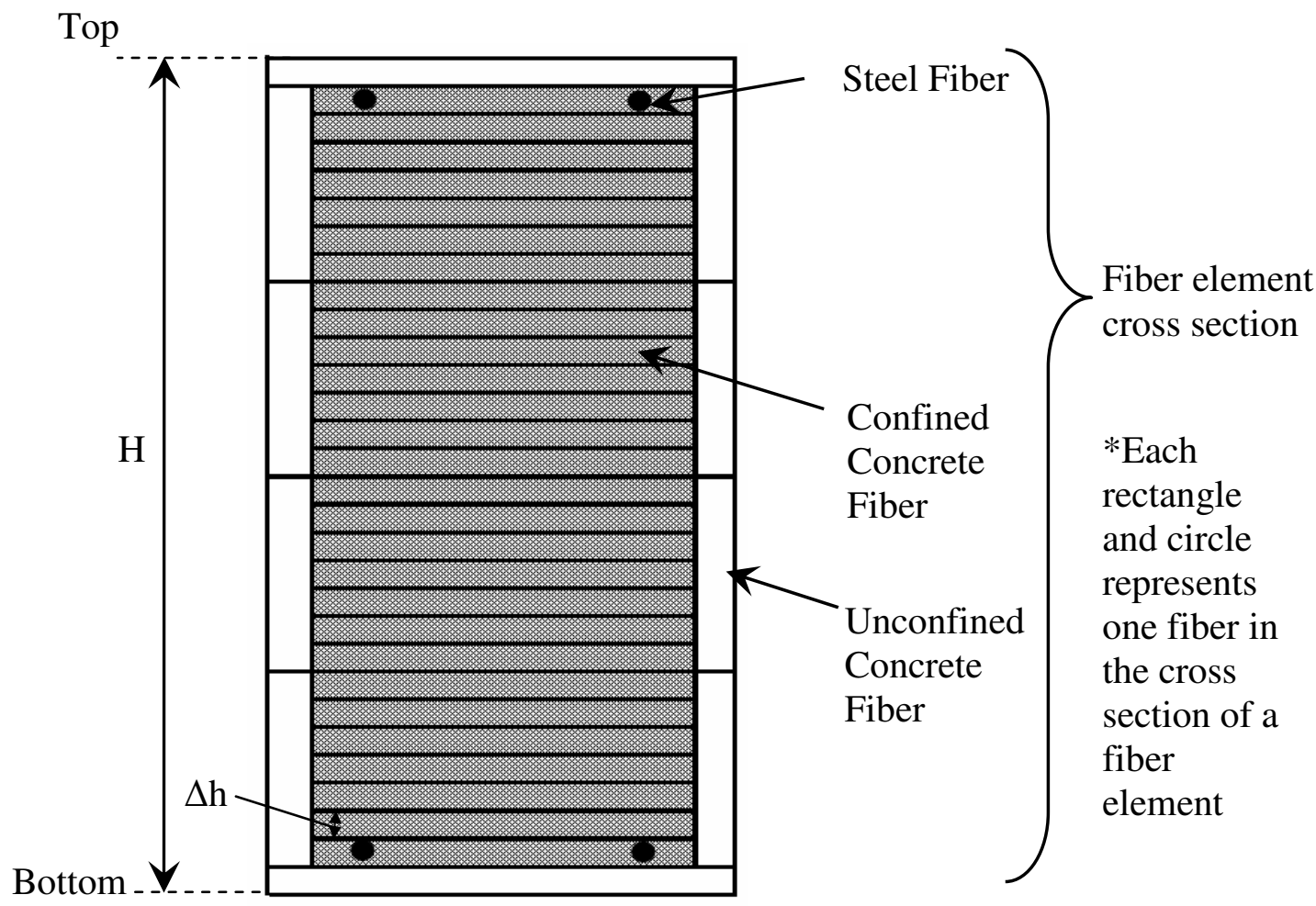

Figure 26: Typical fiber element cross section

A study by El-Sheikh et al. (1997) concluded the following about fiber element cross sections:

1. The number of fibers has a negligible effect on the moment capacity of the beam.

2. An increase in the number of fibers reduces the ultimate rotation capacity due to the crushing of the confined concrete, up to a certain limit where the ultimate rotation becomes almost constant. It is adequate to assume $\Delta \mathrm{h} / \mathrm{H}=0.02$ to achieve good accuracy. [Refer to Figure 26.]

3. Dividing the unconfined cover concrete at the top and bottom edges of the crosssection into more than one fiber does not affect the accuracy of the analysis. 
4. A coarse distribution of fibers may be used for concrete types other than spiral confined concrete.

DDC \#1 and DDC \#2 have no spirally confined concrete, and even though the ElSheikh et al. results say coarser fiber spacing is acceptable for other forms of confined concrete, the height of the confined fibers was decided upon using the $\mathrm{s}_{\mathrm{H}}^{\mathrm{H}}$ ratio. Therefore, the confined concrete fiber heights should be $0.64 \mathrm{in}$. and $0.72 \mathrm{in}$; a height of 0.5in. was chosen for ease of construction.

The fiber element length is an aspect of fiber modeling equally important to the analysis as sizing the fibers within the fiber element. Each fiber element has constant behavior across its length which is determined according to the demands at mid-span of the fiber element. Therefore, a beam composed of several fiber elements will have a cross-sectional moment of inertia, curvature and so on that varies in a stepwise fashion across the length of the beam. The fiber segment, where the moment is at its maximum, is an important fiber element in determining the moment capacity of the beam. When comparing the two cantilever beams in Figure 27, the maximum moment, $\mathrm{M}_{\mathrm{MAX}}$, is better approximated by the 8-segment fiber beam rather than the 4-segment fiber beam due to the location, along the moment diagram, that $\mathrm{M}_{1}$ is defined. 

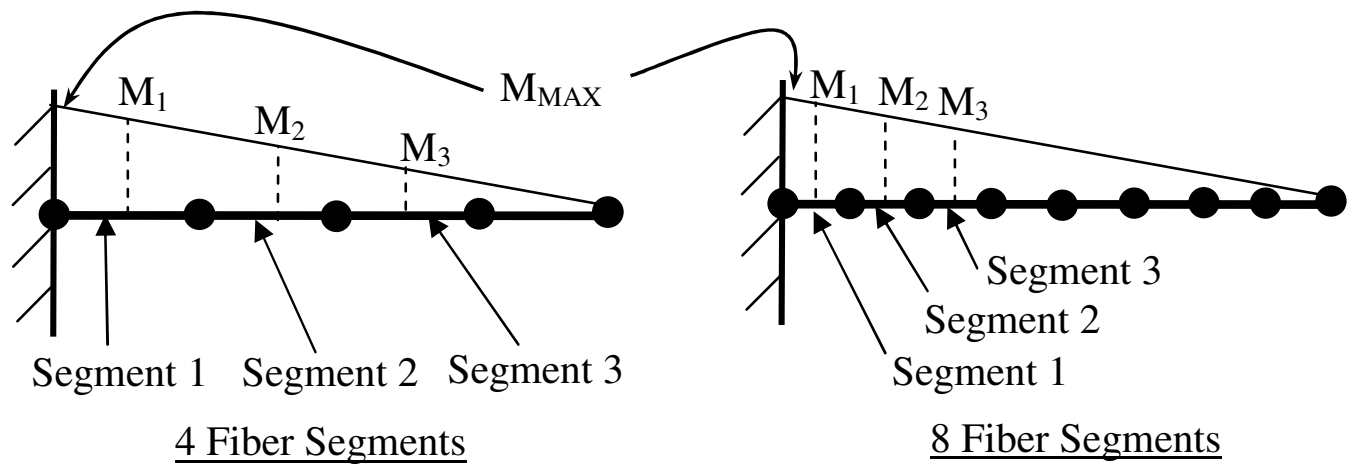

Figure 27: Cantilevered beam moment diagram with various fiber segments According to the 1997 study by El-Sheikh et al., the following was concluded regarding fiber segment length:

1. The moment capacity increases as the first segment length decreases.

2. The ultimate rotation, defined by the crushing of confined concrete, is proportional to the first segment length.

This Lehigh University research concluded the above mentioned correlations between capacity and fiber element length for an unbonded post-tensioned frame. Their research also focused on creating an equation to calculate the plastic hinge length of the beam $\left(\mathrm{L}_{\mathrm{cr}}\right)$ which could then be used as the length of the first fiber segment.

MacRae and Priestley (1994) reported that, "the plastic hinge length may be computed as $0.08 \mathrm{~L}_{\mathrm{B}}$, in the absence of a more realistic empirically based equation". For the unbonded post-tensioned specimen modeled by Lehigh University researchers, the $\mathrm{L}_{\mathrm{cr}}$ length was calculated as 1.8in. verses 7.2in. using the MacRae and Priestley approach. Since the DDC specimens are not post-tensioned nor are they ordinary RC frames, these 
results act only as guidelines in determining the first segment length within the DDC model.

A small study was conducted on a 138in. cantilevered beam with load applied at its free end. The beam had similar properties and geometry to the DDC \#1 beam. There were five fiber models of this beam created using 2, 4, 8, 16, 32, and 64 fiber elements per beam with uniform fiber element length. As the applied load was increased from zero to 150 kips, the displacement over the loading history was recorded as can be seen in Figure 28.

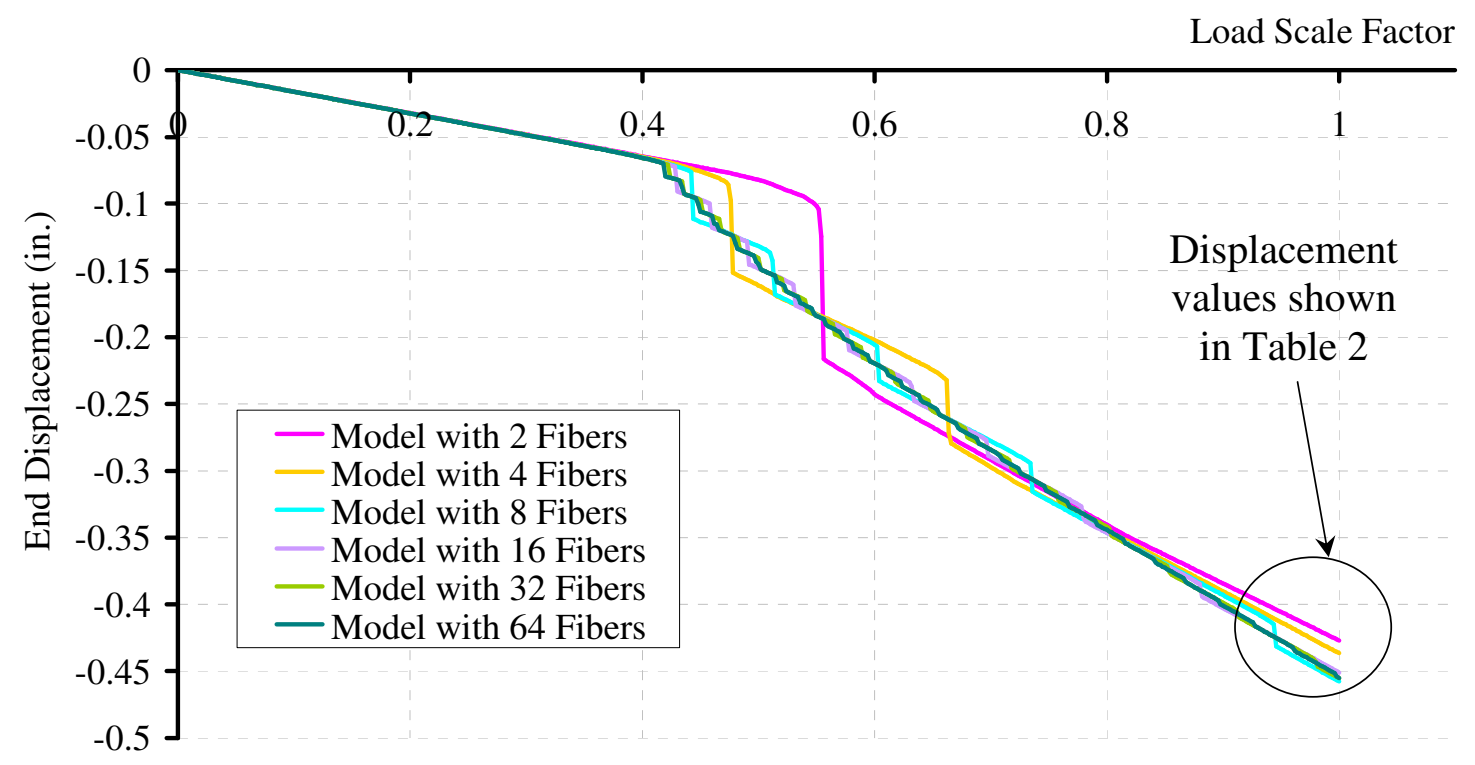

Figure 28: Cantilevered beam end displacement verses load scale factor

All of the cantilevered beam models show the same response up to about 20 kips which is expected since the demand load is still within the elastic range of the beams. As the load increases, the beam behaviors go nonlinear and the difference in beam response becomes 
apparent. Table 2 shows the free end displacement of each beam at an applied load of 150 kips.

Table 2: Cantilevered fiber beam study results at a load factor of one

\begin{tabular}{|c|c|c|c|c|}
\hline $\begin{array}{c}\text { Beam } \\
\text { No. }\end{array}$ & $\begin{array}{c}\text { \# of } \\
\text { Fibers }\end{array}$ & $\begin{array}{c}\text { Fiber Length } \\
\text { (in.) }\end{array}$ & $\Delta_{\max }$ (in.) & $\begin{array}{c}\text { Percent error relative } \\
\text { to beam no. 7 }\end{array}$ \\
\hline $1^{1}$ & 1 & 138 & -4.60 & - \\
\hline 2 & 2 & 69 & -0.427 & $6.15 \%$ \\
\hline 3 & 4 & 34.5 & -0.436 & $4.18 \%$ \\
\hline 4 & 8 & 17.3 & -0.458 & $0.66 \%$ \\
\hline 5 & 16 & 8.63 & -0.451 & $0.88 \%$ \\
\hline 6 & 32 & 4.31 & -0.455 & $0 \%$ \\
\hline $7^{2}$ & 64 & 2.16 & -0.455 & $0 \%$ \\
\hline
\end{tabular}

${ }^{1}$ Beam No. 1's results are not shown in the graphs because the displacement was large relative to the other beams.

${ }^{2}$ The minimum fiber length permitted in PERFORM-3D is 2 in.

Though the displacement results in Table 2 show the 8 -fiber beam to produce a closer displacement to the 64-fiber beam than the 16-fiber beam, the behavior over the loading history is not as accurate for the 8-fiber beam relative to the 16-fiber beam. The number of fibers to choose for a member depends on the desired accuracy of the results. In this case, there is no need to increase the number of fibers over a member length to anything beyond 32 fibers because the difference is trivia.

Since the majority of the inelastic behavior occurs along half of the beam length, another brief fiber length study was conducted to determine what variation of fiber lengths to use across the columns and beams of the specimens. The final fiber configuration chosen for all the fiber models is shown in Figure 29. 


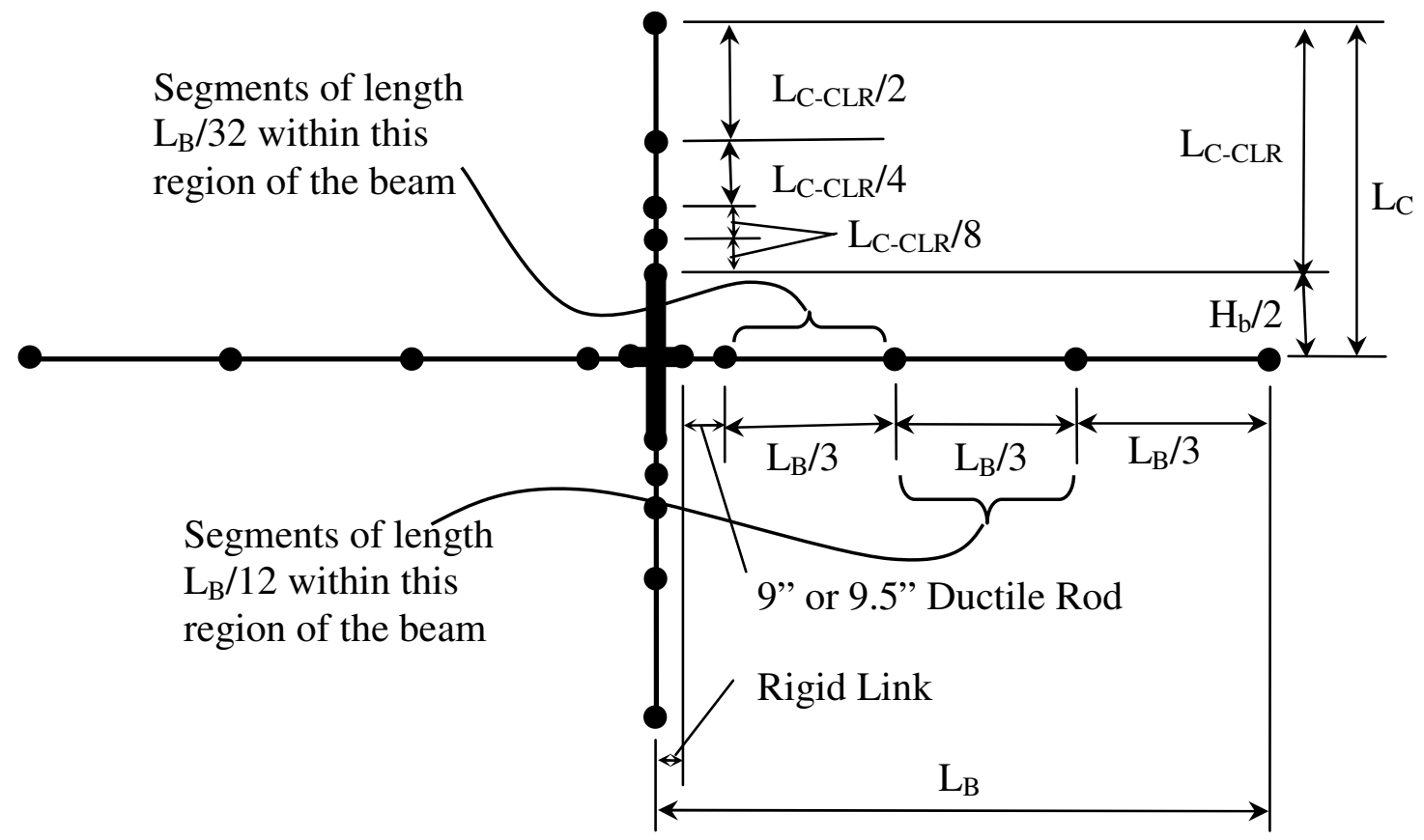

Figure 29: Subassemblage fiber configuration

The subassemblage is composed entirely of fiber beam-column elements, except for two locations within the joint which are modeled as rigid; the rigid zones are discussed in the following sections. The fiber segment length decreases along the member where it is closer to the joint, as more cracking occurs in this region.

\subsubsection{Joint Modeling}

The document titled ASCE/SEI Standard 41-06 Seismic Rehabilitation of Existing Buildings, recommends that the beam-column joints of a monolithic reinforced concrete moment frame, “...be represented as a stiff or rigid zone...”, pg. (159) of (ASCE 2007). However, in an article presented at the annual meeting of the Los Angeles Tall Buildings Structural Design Council, this decision was reevaluated. 
"Tests have demonstrated that beam-column joints can experience significant shear deformations even prior to yielding of the longitudinal reinforcement within the joint. Affects of these shear deformations can be approximated by extending the beam or column flexibility into the joint in the analytical model" (Elwood et al. 2007).

Elwood et al. propose using the ratio of the nominal moment capacity of the column to the beam in order to determine the rigid link lengths. Their recommendations are shown in Figure 30.

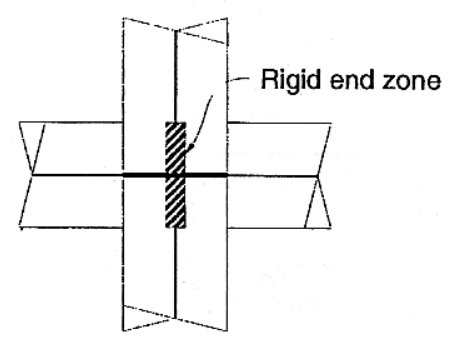

a) $\Sigma M_{n d} \Sigma M_{n b}>1.2$

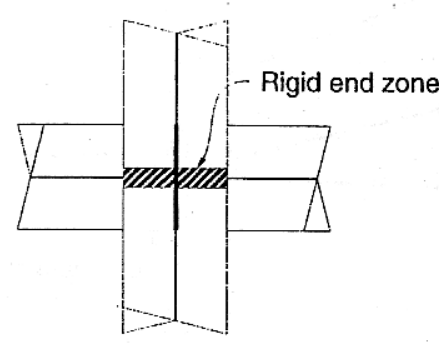

b) $\Sigma M_{n d} \Sigma M_{n b}<0.8$

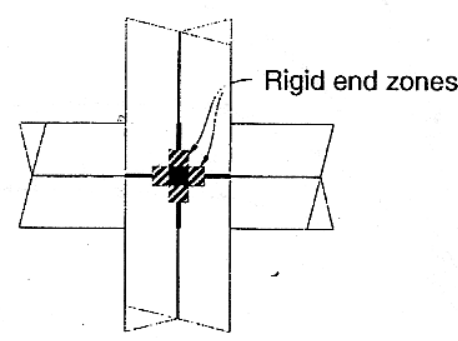

c) $0.8 \leq \Sigma M_{n d} \Sigma M_{n b} \leq 1.2$

Figure 30: Rigid end zones for beam-column joint modeling (Elwood et al. 2007)

When applying this concept to DDC \#1 and DDC \#2, the ratio of the moment capacity of the column to the ductile rod connector was used. This ratio was used instead of the column to beam ratio as the beam capacity does not fully reach the joint as the ductile rod connectors act as a fuse to limit the demand the beam can impose on the joint. The ratios of DDC\#1 and DDC \#2 were near or above 1.2, and thus the joints were modeled as shown in Figure 30(a), with a fully rigid column and a flexible beam within the joint. Calculations for determining the moment capacity ratios are provided in 
Appendix A and Appendix B. Figure 31 shows the rigid links within the fiber models against the backdrop of a test specimen joint.

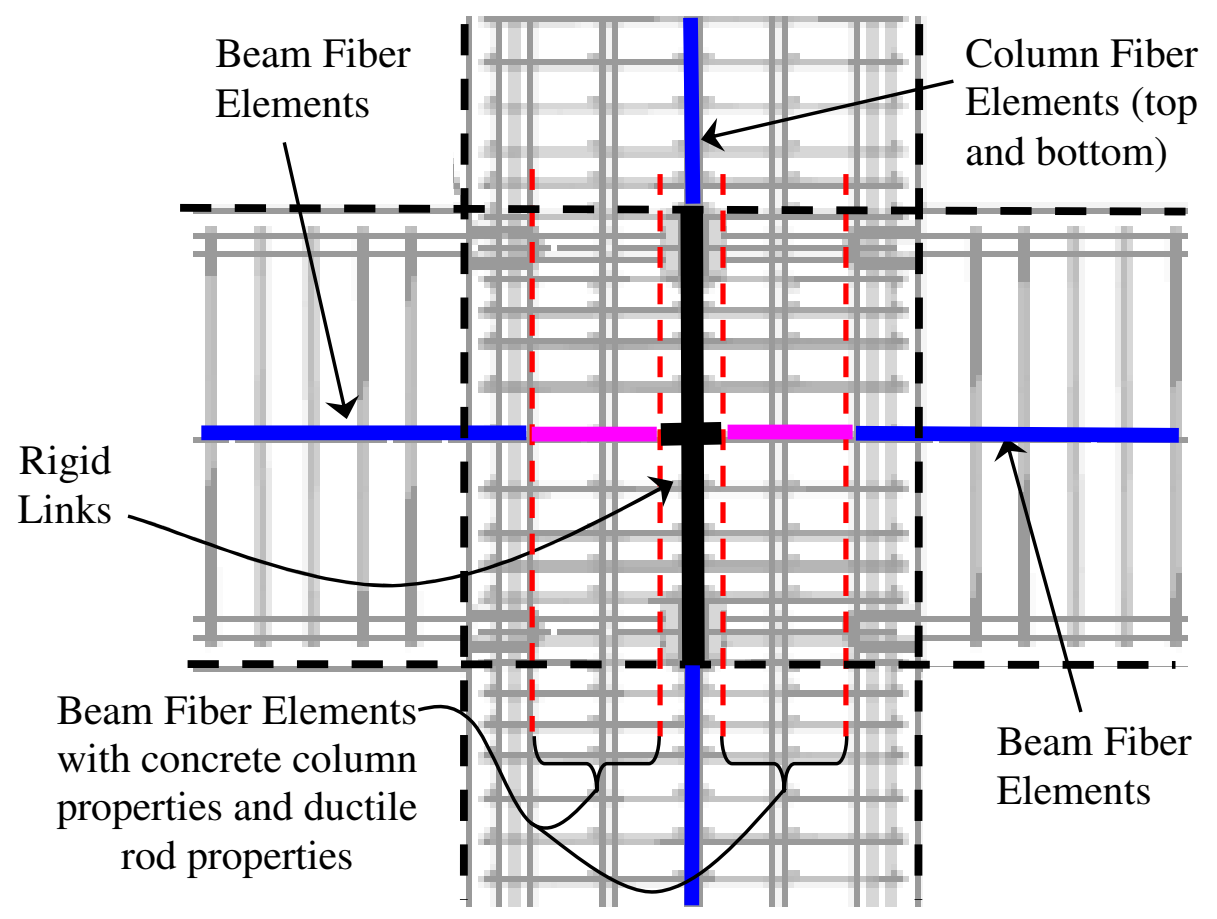

Figure 31: Fiber model joint configuration

The final fiber model joint configuration was tested against two other fiber models with fully flexible and fully rigid joints. The result for the DDC \#1 fiber model is shown in Figure 32. 


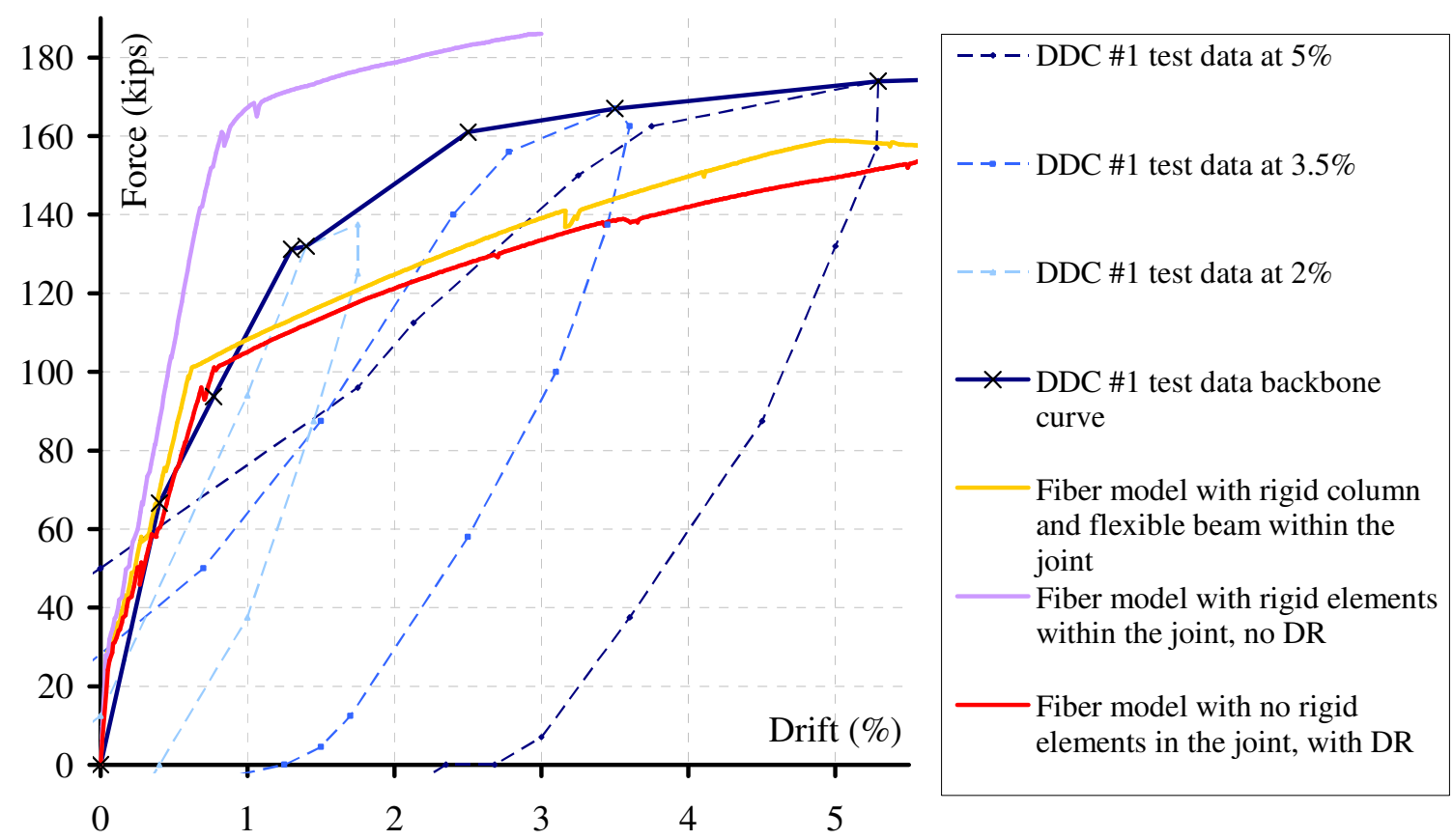

Figure 32: Force-displacement backbone curves for the DDC \#1 fiber model with varying rigidity of the joint

By making the beam and column lengths within the joint fully rigid, the initial stiffness and the capacity of the system increased. There is a small difference in the results between the fully-flexible-joint fiber model and the rigid-column-joint fiber model. These results graphically demonstrate the small contribution the portion of the column within the joint has on the subassemblage stiffness. This same test was performed on DDC \#2 and the fiber model result is shown in Figure 33. 


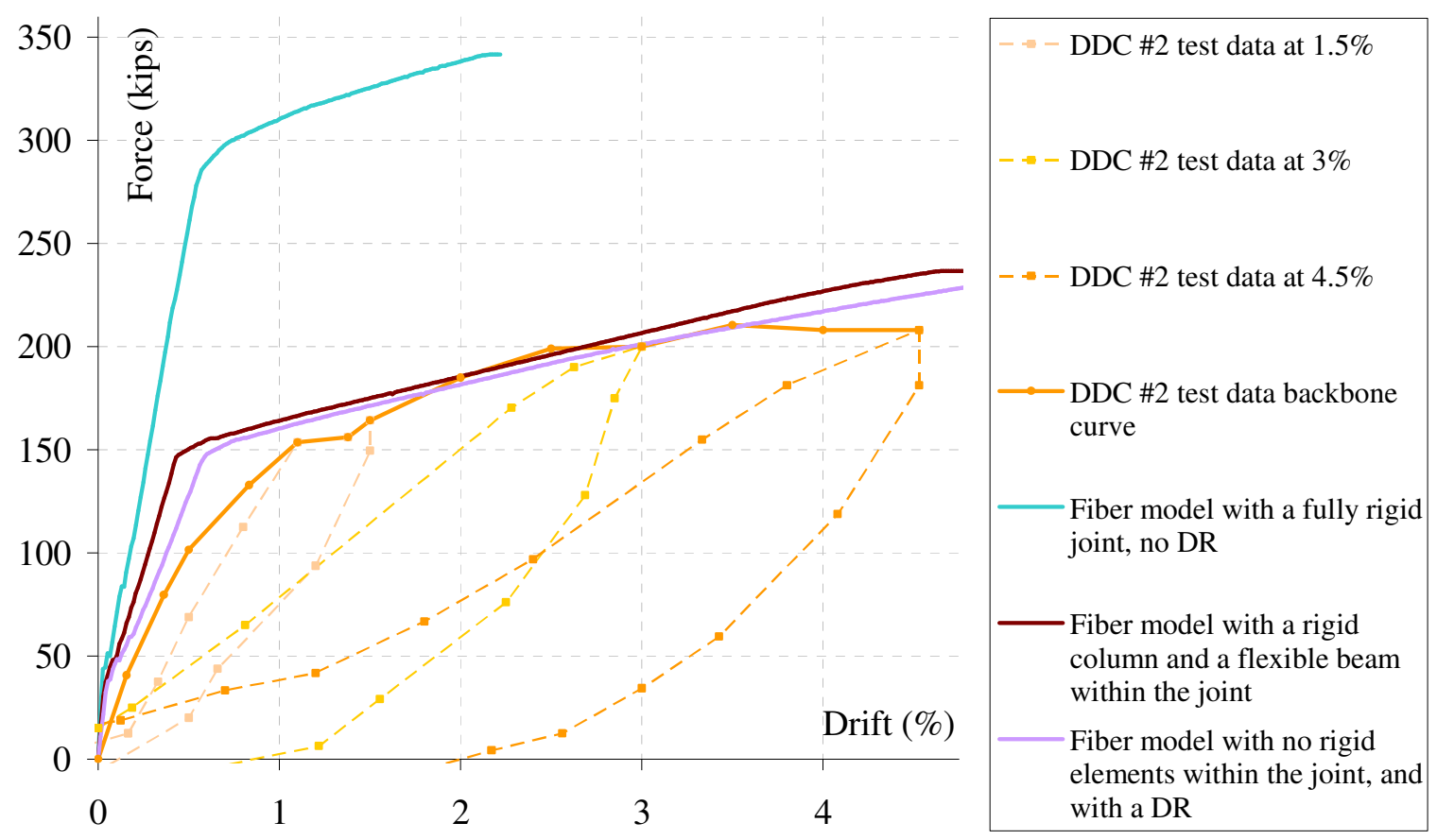

Figure 33: Force-displacement backbone curves for the DDC \#2 fiber model with varying the rigidity of the joint

Both results from DDC \#1 and DDC \#2 validate the applicability of this rigid joint calculation to the DDC systems.

\subsubsection{Ductile Rod Modeling}

The ductile rod is the region of the DDC designed to yield in response to lateral loading. Thus, the constitutive and geometric properties of the ductile rod play a substantial role in the behavior of this system. The ductile rod stress-strain and geometric properties for each test specimen are provided in Appendix G and Appendix H. As well, the PERFORM-3D approximations of the stress-strain properties can be found in Appendix D and Appendix E.

The ductile rods are modeled as fibers within the specific fiber elements shown as the pink segments in Figure 31. Taking a closer look at the ductile rod in Figure 34, the 
only portion of the ductile rod being modeled is the slender shank portion of the hardware. The head portion of the ductile rod is modeled as rigid; refer to the horizontal black segment at the center of the joint in Figure 31. The threaded connection portion of the ductile rod is ignored. In place of this segment of column is a beam fiber segment which contains concrete beam fibers and Dywidag fibers. Thus, this segment is modeled as a continuation of the beam. Modeling this segment with beam properties as opposed to column properties has shown to have a minimal effect on the analysis results.

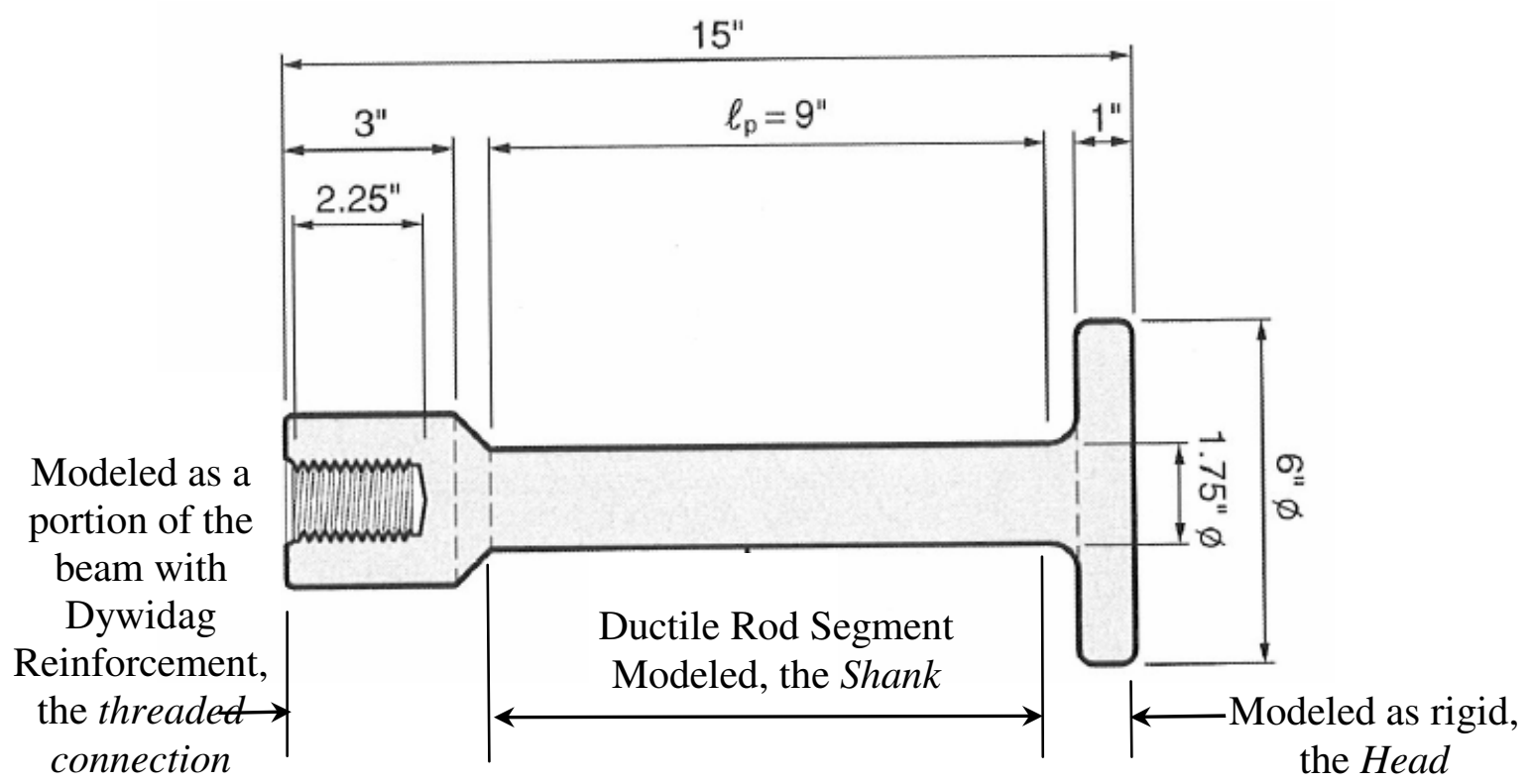

Figure 34: Modeling aspects of the ductile rod

Another aspect of the ductile rod that appears to have a substantial effect on the behavior of the DDC system is the modeled length of the ductile rod. A study was conducted on DDC \#1 and DDC \#2 where the respective fiber models were assigned ductile rod shank lengths of 2in., 3.5in., 5.5in., 7.5in., and 9.5in. The results from this study are shown in Figure 35 and Figure 36. 

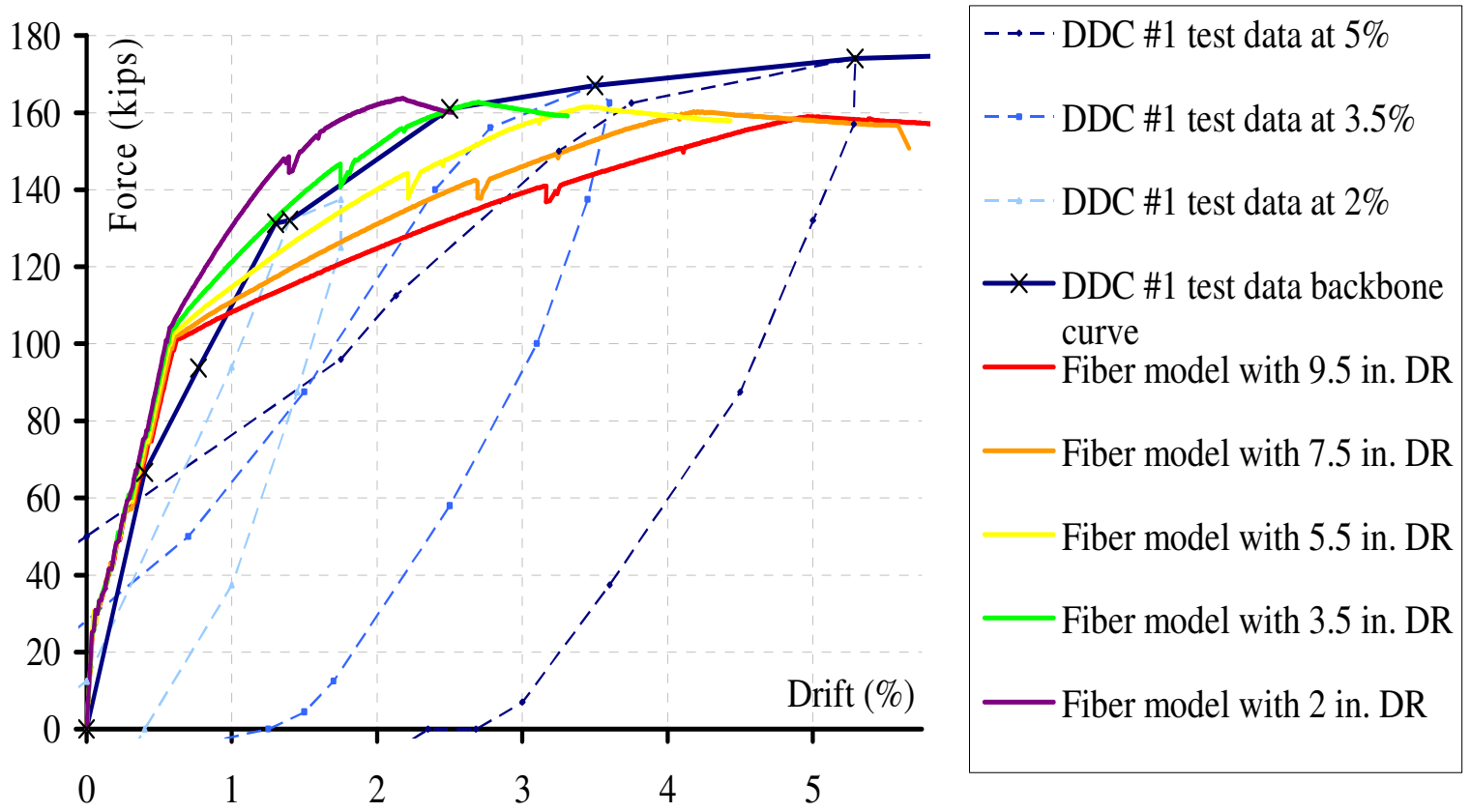

Figure 35: Force-displacement backbone curves for the fiber model DDC \#1 with varying ductile rod lengths

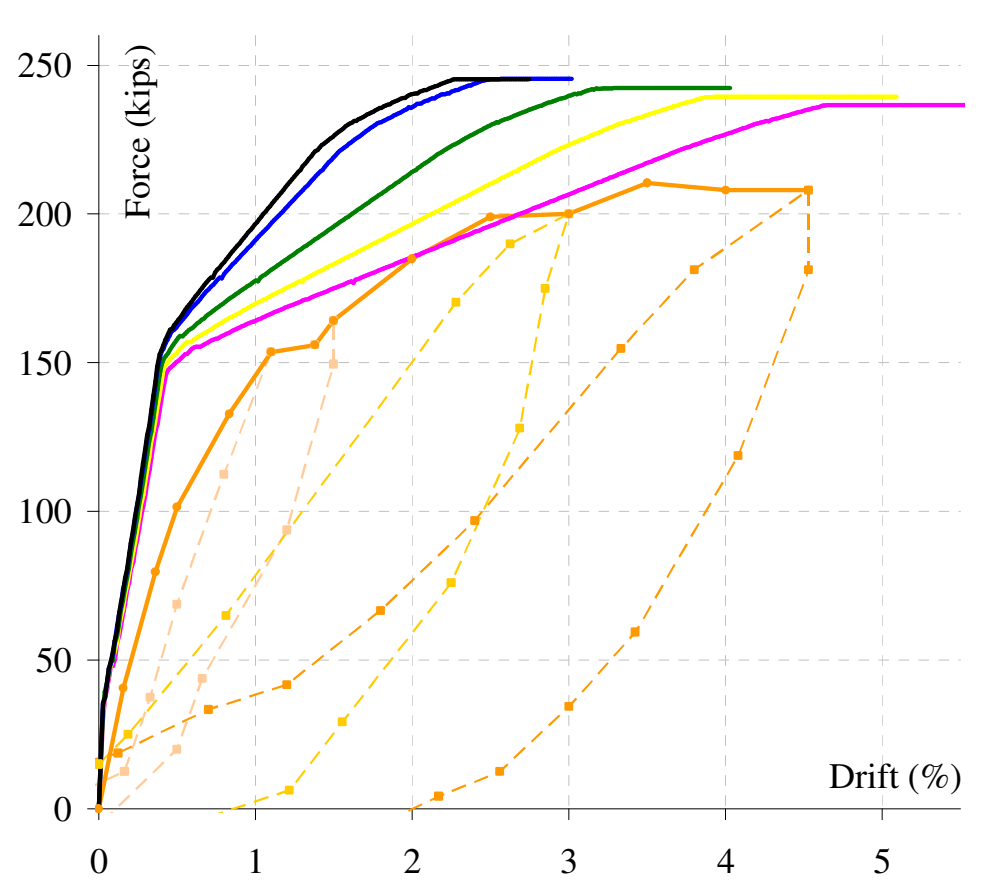

DDC \#2 test data at $1.5 \%$

DDC \#2 test data at $3 \%$

DDC \#2 test data at $4.5 \%$

DDC \#2 test data backbone curve

Fiber model with 9.5 in. DR

Fiber model with 7.5 in. DR

— Fiber model with 5.5 in. DR

- Fiber model with 3.5 in. DR

Figure 36: Force-displacement backbone curves for the fiber model DDC \#2 with varying ductile rod lengths

Figure 35 and Figure 36 show that as the modeled length of the ductile rod decreases, the secondary stiffness of the system increases. As well, the yielding of the 
Dywidag threaded bars shift to an earlier point in the pushover analysis from about $4.5 \%$ to $2.2 \%$ drift. From Figure 35 it appears as if modeling the ductile rod as having a length of $3.5 \mathrm{in}$. to $5.5 \mathrm{in}$. produces more approximate results. Since this is an uncalibrated analysis, the shorter ductile rod lengths are not used in the creation of the blind prediction fiber model results. What is hypothesized from these results is that perhaps the ductile rod only becomes debonded from the concrete column for a portion of its length, and thus has a smaller effective shank length than the geometric length. From this report, nothing regarding the debond length of the ductile rod can be concluded; however, it is recommended that this topic be explored further.

The last study associated with the ductile rod relates to the number of fiber elements used to represent the ductile rod. In this study the ductile rod was modeled using the following variations: (1) 9.5in. fiber element, (2) 4.75in. fiber elements, (3) 3.16in. fiber elements, and (4) $2.375 \mathrm{in}$. fiber elements. This brief study was only conducted on DDC \#2. The results from this study are shown in Figure 37. 


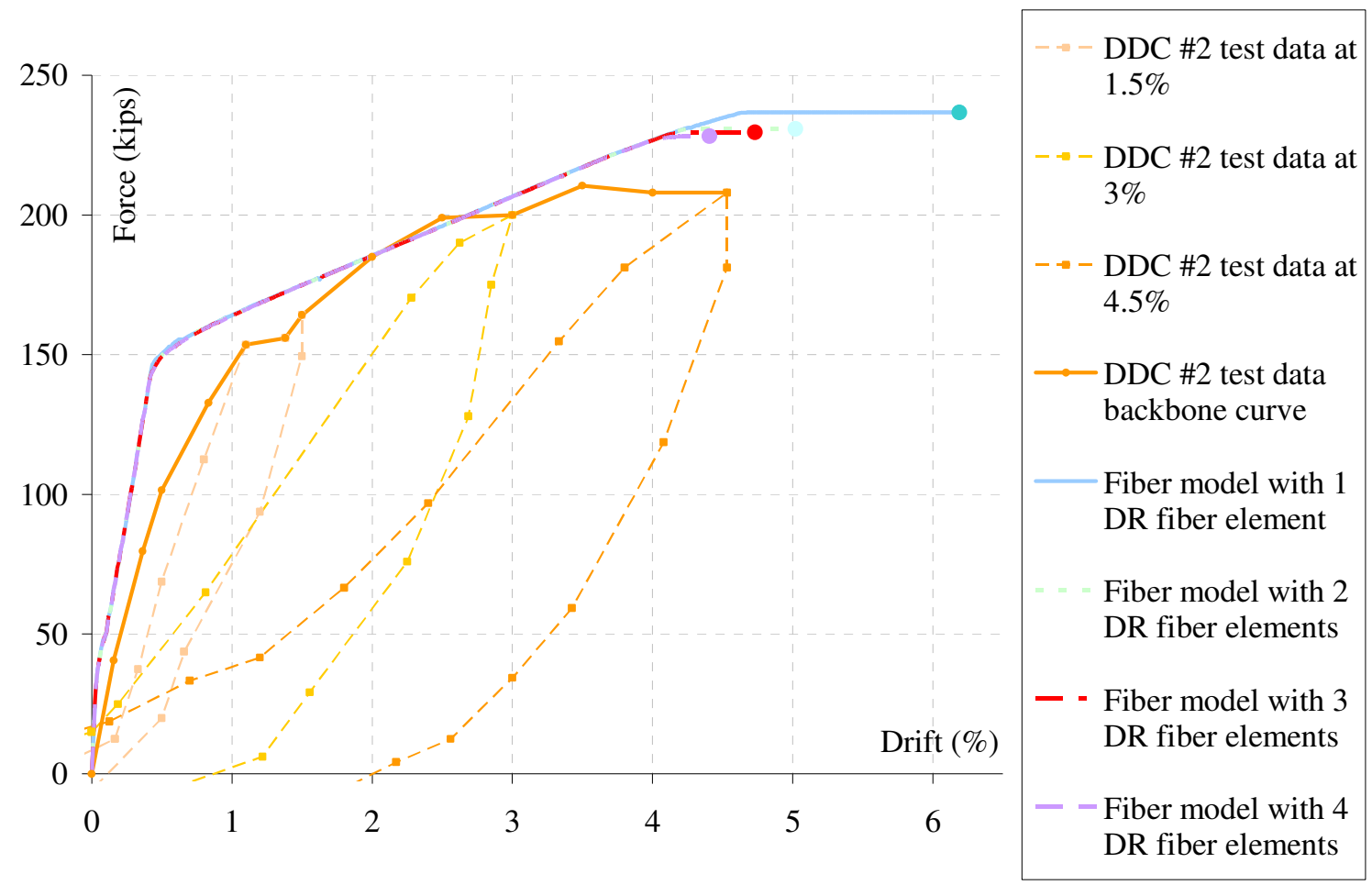

Figure 37: Force-displacement backbone curves for the fiber model DDC \#2 with various numbers of fiber elements along the length of the ductile rod

As Figure 37 shows, when the number of ductile rod fiber elements increase over the DR shank length, the ultimate curvature of the system decreases. For the blind prediction fiber model of each system, only one fiber was used across the entire length of the ductile rod shank, as there is no reason to substantiate doing otherwise.

Overall, the ductile rod plays perhaps the most significant role in the behavior of the DDC system and more research into the number of fibers and/or the lengths of fibers used in modeling the ductile rod is recommended.

\subsubsection{Concrete Members}

As mentioned earlier, the concrete members are modeled using several fiber elements. All fiber elements have the same cross section along a member though they 
vary in length. This means the fiber models ignore the increase in transverse reinforcement around the beam ends; this aspect of modeling was not within the scope of modeling research for this project.

The concrete member properties for each specimen can be found in Appendix G and Appendix H. Mander's model, shown in Figure 18, was used to determine the concrete material properties (Mander et al. 1988). The material approximations are shown in Appendix D and Appendix E. The major discrepancy with using Mander's model is that it is not applicable to high strength concrete, which is found in some members of the specimens. Since this discrepancy exists with the column and due to the minimal contribution the column has on the flexibility of the subassemblage, this approach was considered acceptable for this project.

\subsection{Lumped Plasticity Model (ETABS)}

The structural analysis software, ETABS, is considered by many to be a more commonly used program than PERFORM-3D in the structural engineering industry. However, ETABS analysis capabilities are more limited than PERFORM-3D. For example, fiber elements are not incorporated into the ETABS interface. There are two many reasons for exploring modeling capabilities of the DDC system in ETABS: (1) to determine an acceptable method for modeling the DDC system in an office environment where the design engineer only has access to ETABS, and (2) to determine an acceptable method for modeling a DDC building in order to get global design forces. The ETABS subassemblage configuration is shown in Figure 38. Similar to the fiber models, the 
lumped plasticity models have a rigid link along the column length within the joint. As opposed to using fiber elements to capture the subassemblage stiffness, two other techniques were applied.

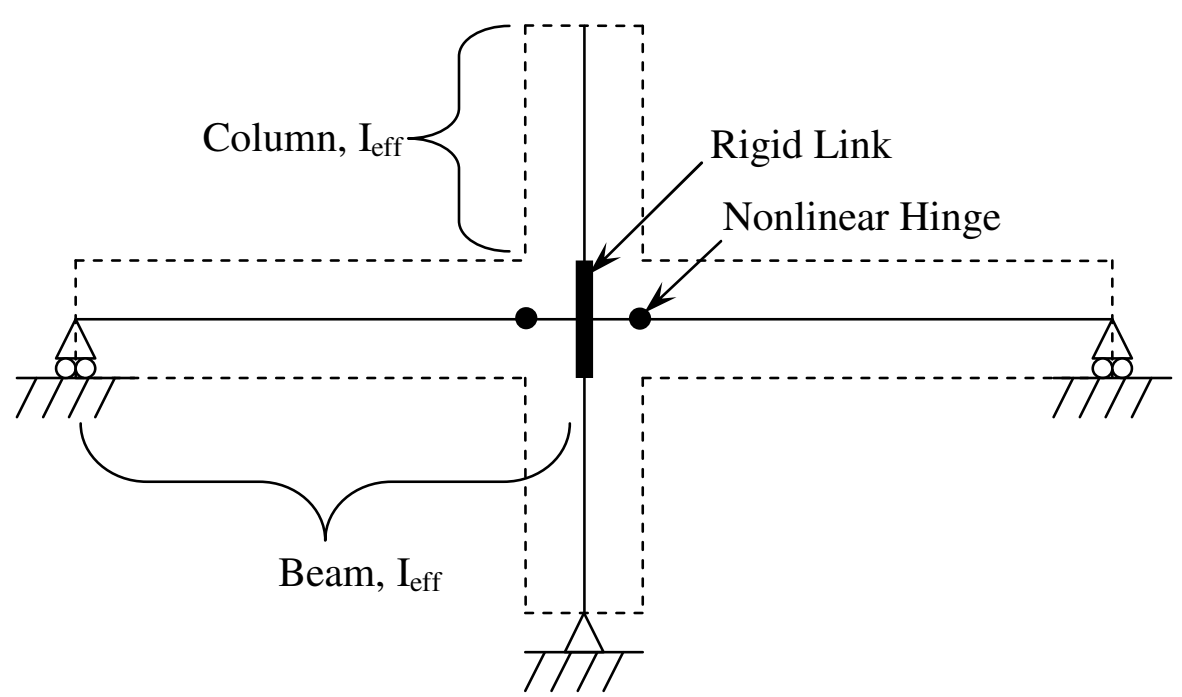

Figure 38: Lumped Plasticity subassemblage configuration

First, the members were modeled with an effective stiffness. The effective stiffness was determined by running a moment-curvature analysis on each member. The results from analyzing each member of DDC \#1 and DDC \#2 gave an average effective stiffness of roughly $30 \%$ of the gross stiffness for every member; this value was used in the lumped plasticity models of DDC \#1 and DDC \#2. In lieu of running a moment-curvature analysis, a design engineer can choose to follow the FEMA 356 recommended effective stiffness values, shown in Table 3; however, these recommendations may give less accurate results than a moment-curvature analysis. 
Table 3: Effective stiffness valued recommended, (Table 6-5) in (ASCE 2000)

\begin{tabular}{|c|c|c|c|}
\hline Component & $\begin{array}{l}\text { Flexural } \\
\text { Rigidity }\end{array}$ & $\begin{array}{c}\text { Shear } \\
\text { Rigidity }\end{array}$ & $\begin{array}{c}\text { Axial } \\
\text { Rigidity }\end{array}$ \\
\hline Beams-nonprestressed & $0.5 \mathrm{E}_{\mathrm{c}} \mathrm{I}_{\mathrm{g}}$ & $0.4 \mathrm{E}_{\mathrm{c}} \mathrm{A}_{\mathrm{w}}$ & - \\
\hline Beams-prestressed & $\mathrm{E}_{\mathrm{c}} \mathrm{I}_{\mathrm{g}}$ & $0.4 \mathrm{E}_{\mathrm{c}} \mathrm{A}_{\mathrm{w}}$ & - \\
\hline $\begin{array}{l}\text { Columns with compression due } \\
\text { to design gravity loads } \geq \\
0.5 \mathrm{~A}_{\mathrm{g}} \mathrm{f}_{\mathrm{c}}\end{array}$ & $0.7 \mathrm{E}_{\mathrm{c}} \mathrm{I}_{\mathrm{g}}$ & $0.4 \mathrm{E}_{\mathrm{c}} \mathrm{A}_{\mathrm{w}}$ & $\mathrm{E}_{\mathrm{c}} \mathrm{A}_{\mathrm{g}}$ \\
\hline $\begin{array}{l}\text { Columns with compression due } \\
\text { to design gravity loads } \leq 0.3 \\
\mathrm{~A}_{\mathrm{g}} \mathrm{f}_{\mathrm{c}} \text { or with tension }\end{array}$ & $0.5 \mathrm{E}_{\mathrm{c}} \mathrm{I}_{\mathrm{g}}$ & $0.4 \mathrm{E}_{\mathrm{c}} \mathrm{A}_{\mathrm{w}}$ & $\mathrm{E}_{\mathrm{s}} \mathrm{A}_{\mathrm{s}}$ \\
\hline \multicolumn{4}{|c|}{$\begin{array}{l}\text { Note: It shall be permitted to take } I_{g} \text { for T-beams as twice the value of } I_{g} \\
\text { of the web along. Otherwise, } I_{g} \text { shall be based on the effective } \\
\text { width as defined in Section } 6.4 .1 .3 \text { [in reference (ASCE 2000)]. } \\
\text { For columns with axial compression falling between the limits } \\
\text { provided, linear interpolation shall be permitted. Alternatively, the } \\
\text { more conservative effective stiffness shall be used. }\end{array}$} \\
\hline
\end{tabular}

The second technique applied to the lumped plasticity model, to help it approximate the nonlinear behavior of a DDC system, is to assign a nonlinear hinge at the beam-column interface, the hinges are shown in Figure 38.

\subsubsection{Nonlinear Hinges}

This technique of applying an effective stiffness to the members and a lumped nonlinear hinge to mimic the plastic hinge region is similar to the approach often used for monolithic concrete frames. However, what sets the DDC system apart is that it has trilinear hinge properties as opposed to bilinear hinge properties because there are two main yield points within the system. The first yield point represents the yielding of the ductile rod; the second yield point represents the yielding of the Dywidag bars. The yield moment and yield rotation calculations are shown in Appendix A and Appendix B. The curvatures for both the Dywidag and the ductile rod were calculated using, Equation 1. 
Equation 1: Concrete T-beam curvature, Eqn. (4.57d) in (Priestley 2007)

$$
\phi=\frac{1.7 \varepsilon_{y}}{h_{b}}
$$

The rotation of one beam was calculated using Equation 2.

Equation 2: Concrete beam rotation, Eqn. (4.52) in (Priestley 2007)

$$
\theta=\frac{\phi \times L_{b}}{6}
$$

The ultimate rotation of the nonlinear hinge was taken from test data. Both Equation 1 and Equation 2 were used to determine the rotation of the beam at yielding of the ductile rod and yielding of the Dywidag bars. Figure 39 shows the difference in using Equation 2 to calculate the Dywidag rotation verses using the test data to determine the rotation of the subassemblage at yielding of the Dywidag bars.

Figure 39 graphically demonstrates how Equation 2 does not account for the plastic rotation in the ductile rod when calculating the rotation of the beam at yielding of the Dywidag bars. The curve labeled "Blind model with $\mathrm{I}_{\mathrm{eff}}$ and a Bilinear Curve (partially based on test data)" uses the hysteretic test data to determine the rotation of the subassemblage at yielding of the Dywidag bars; yielding of the ductile rod was determined theoretically using Equation 2. Using the test results, to determine the yield rotation of the specimen, produces a better approximation of system behavior, as can be seen in Figure 39, but it is not a realistic route for the typical design engineer as it involves experimental testing. One aspect of future research may involve creating an equation to determine the rotation of the DDC system at yielding of the Dywidag bars with simultaneous plastic hinging of the ductile rods and gap-opening. 


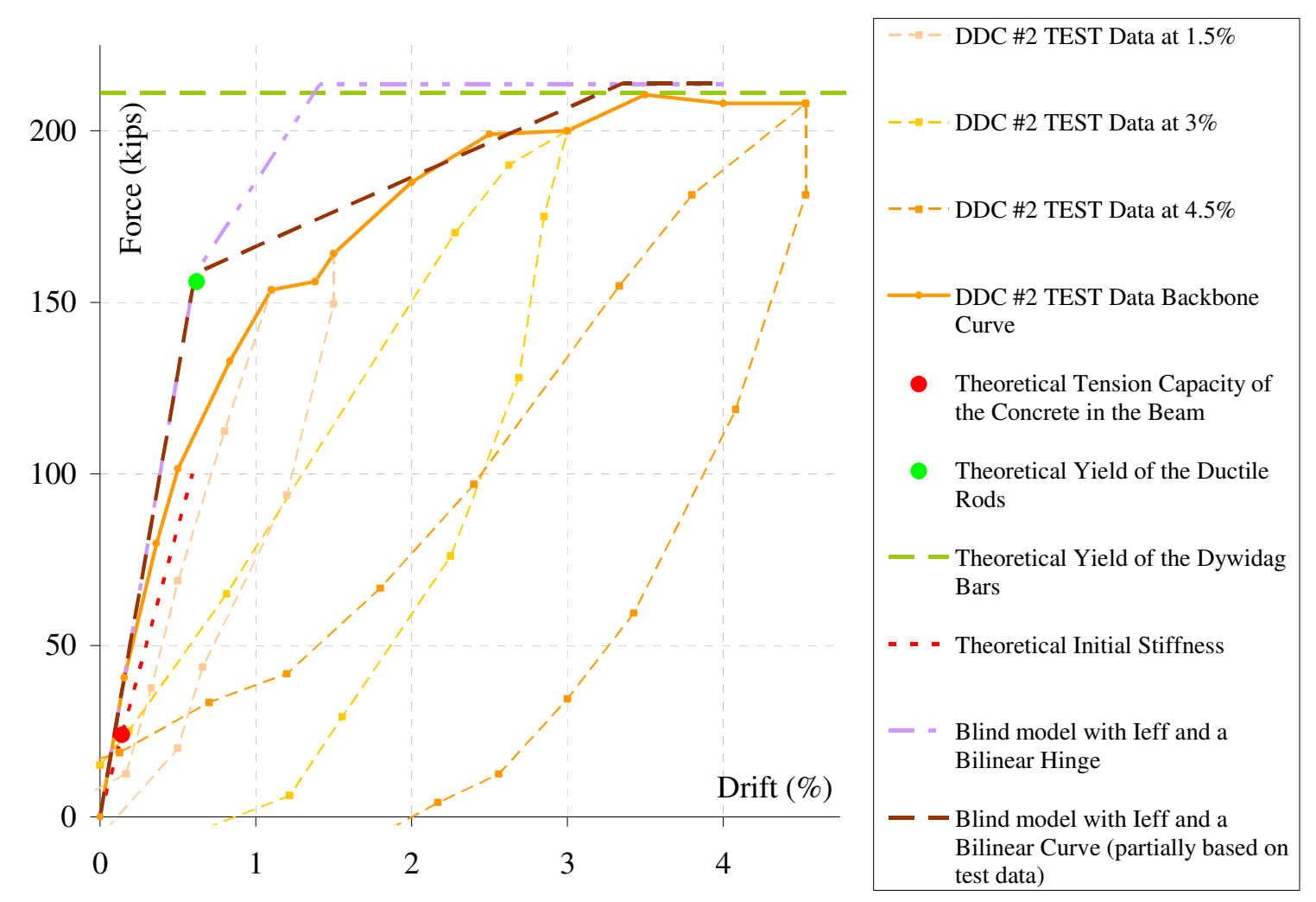

Figure 39: Force-displacement backbone curve for the lumped plasticity model DDC \#2 with varying the nonlinear hinge properties

The ETABS nonlinear hinge lumps two separate inelastic events, which occur over various lengths, into one zero-length hinge location. In actuality, the ductile rod yields slightly closer to the center of the joint than the yielding of the Dywidag bars. Each yield event can be idealized as an elastic perfectly-plastic (EPP) curve. When combining both EPP curves into one, the new curve is trilinear with zero stiffness after the second yield event has occurred. A small study was conducted to determine if lumping the yielding events makes a difference in the ETABS approximation. Figure 40 shows the results of moving the location of the nonlinear hinge from the center of the joint to the beam-column interface. 


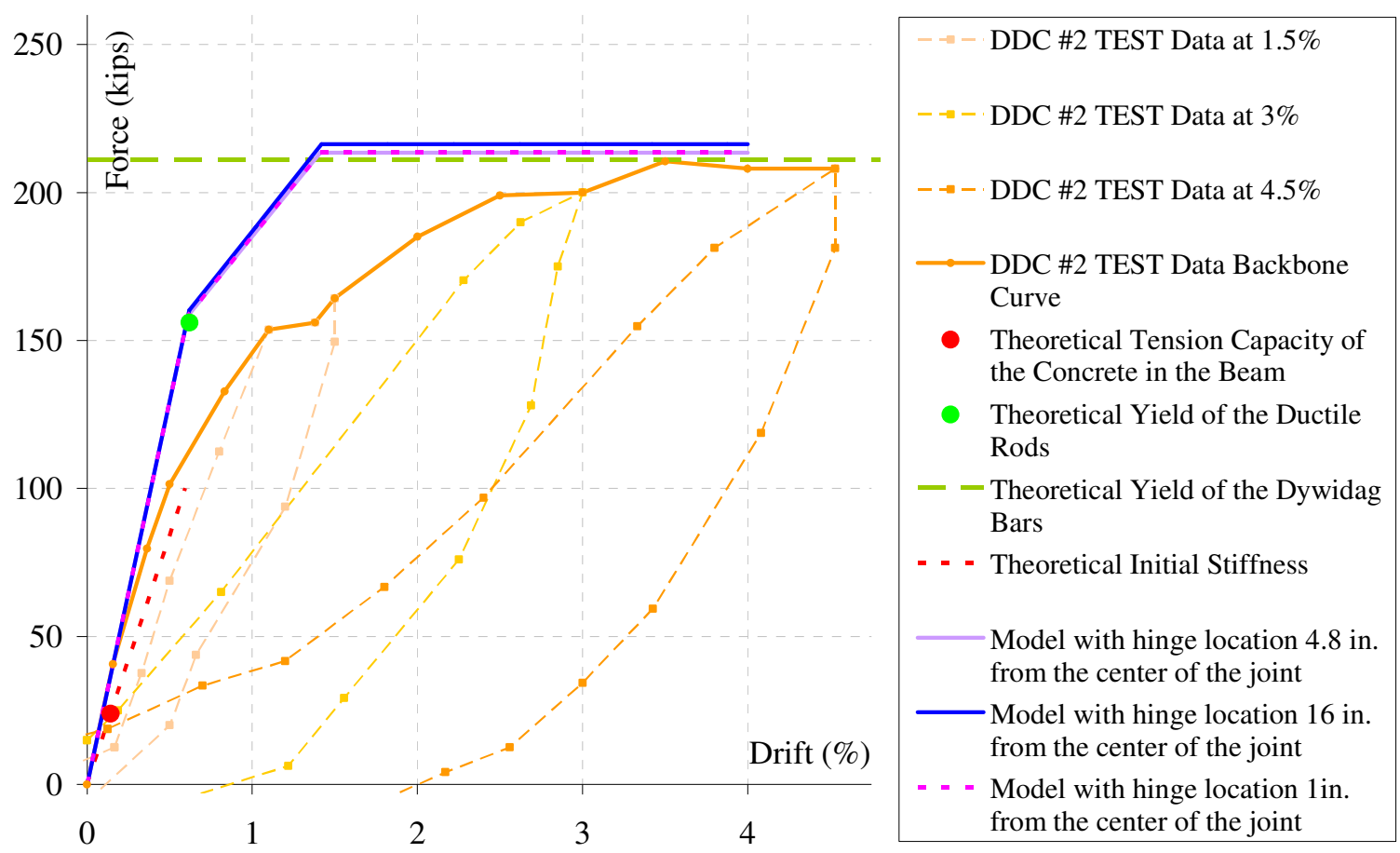

Figure 40: Force-displacement backbone curve for the lumped plasticity model DDC \#2 with varying the nonlinear hinge location

The results show that varying the location of the nonlinear hinge from the center of the joint to the face of the joint does not have a substantial effect on the results. Therefore, consolidating both nonlinear events into one hinge is an acceptable approach for approximating the inelastic properties of the DDC joint. 


\subsection{THEORETICAL PREDICTIONS}

Along with creating a fiber model and lumped plasticity model of each test specimen, theoretical predictions of specimen behavior were calculated. The following values were predicted:

- Initial stiffness, $K_{I N I T I A L}$.

- Moment in the beam at the tensile rupture of the concrete beam, $M_{c r}$, and the associated drift, $\gamma_{c r}$.

- Nominal moment capacity of the ductile rods, $M_{n \text {. }}$, and the associated drift, $\gamma_{y}$

- Nominal moment capacity of the beam with Dywidag reinforcement bars, $M_{n-D B}$

All hand calculations mentioned above, for DDC \#1 and DDC \#2, can be found in Appendix A and Appendix B respectively.

\subsection{Initial Stiffness}

The initial stiffness was determined by means of virtual work. First, standard nomenclature for the subassemblage was established and is shown in Figure 41. 


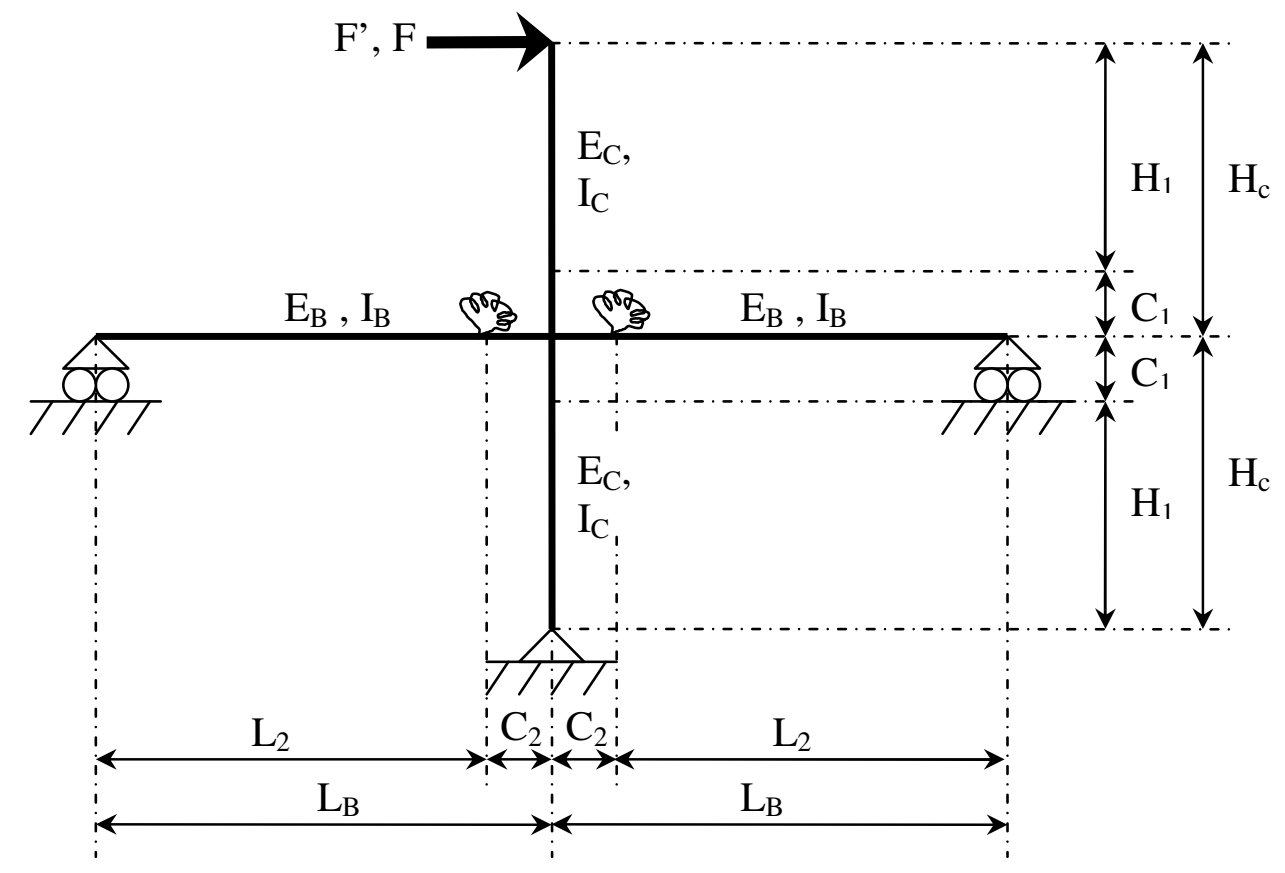

Figure 41: Subassemblage nomenclature and geometry

Equation 3 and Equation 4 describe the displacement of the subassemblage due to the beams and the column respectively.

Equation 3: Displacement of the subassemblage due to the beams

$$
\Delta_{B E A M S}=\frac{2}{E_{B} I_{B}}\left(\frac{1}{3}\right)\left(F^{\prime} \times H_{c}\right)\left(F \times H_{c}\right)\left(L_{B}\right)
$$

Equation 4: Displacement of the subassemblage due to the column

$$
\Delta_{\text {COLUMN }}=\frac{2}{E_{c} I_{c}}\left(\frac{1}{3}\right)\left(F^{\prime} \times H_{c}\right)\left(F \times H_{c}\right)\left(H_{c}\right)
$$

The DDC rods act as inelastic truss elements that form a force-couple near the beamcolumn interface. The properties of the rods were incorporated into the stiffness calculation. Determining the stiffness of the ductile rods in the elastic range required one of the basic principles of material mechanics, described in Equation 5, axial deformation. 
Equation 5: Elastic axial displacement

$$
\Delta=\frac{P \times L}{A \times E}
$$

where,

$P=$ axial load.

$L=$ length of the axial member.

$A=$ cross sectional area of the member.

$E=$ modulus of elasticity of the member.

The relationship between axial deformation and rotation in the elastic range is defined using a combination of system geometry and small displacement theory; refer to Figure 42 and Equation 6.

Equation 6: Displacement and rotation relationship in the ductile rods

$$
\Delta=\frac{d}{2} \Phi
$$

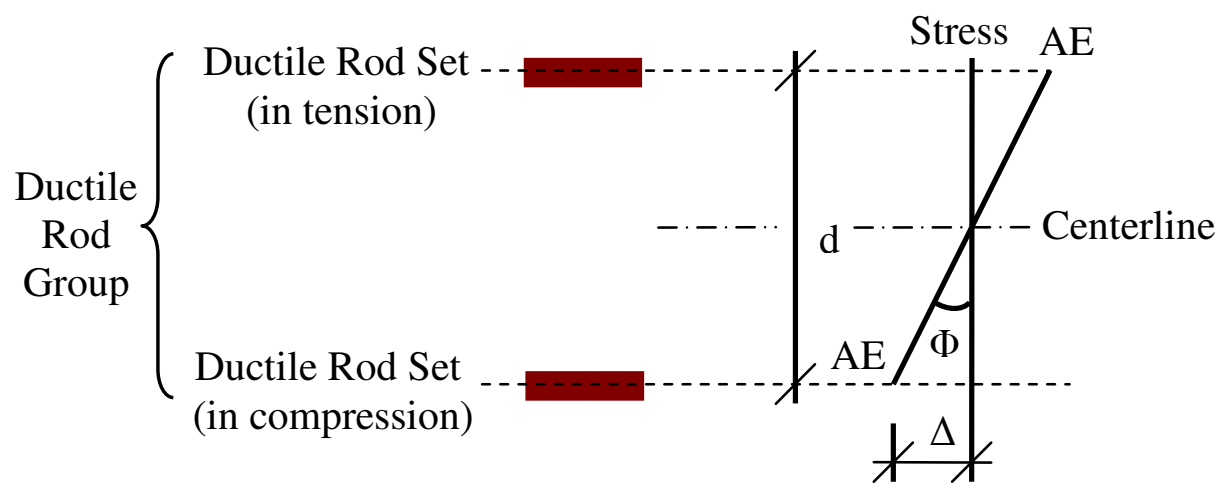

Figure 42: DDC ductile rod geometry and stress

Combining Equation 5 and Equation 6 forms the moment equation of the ductile rod group in terms of rotation, see Equation 7. 
Equation 7: Moment-rotation relationship in the ductile rods

$$
M=F \times d=(\underbrace{\frac{N \times A \times E}{2 \times L} \times d^{2}}_{K_{\text {SPRING }}}) \times \Theta
$$

where,

$A=$ cross-sectional area of one ductile rod.

$N=$ number of ductile rods.

$E=$ modulus of elasticity of the ductile rods.

$L=$ length of the shank portion of the ductile rod.

$d=$ distance between the compression and tension sets of ductile rods.

The contribution of the ductile rods to the global stiffness is analogous to adding a rotational spring at each beam-to-column interface as is shown in Figure 41. The portion of the global displacement due to the spring is described in Equation 8, where $K_{S P R I N G}$ is defined in Equation 7.

Equation 8: Ductile rod rotational spring stiffness

$$
\begin{aligned}
& \Delta_{\text {ROTATIONAL_SPRING }}=\frac{M \times M^{\prime}}{K_{\text {SPRING }}} \\
& \text { where, } \\
& M=\text { actual moment seen by the spring. } \\
& M^{\prime}=\text { virtual moment seen by the spring. }
\end{aligned}
$$

The summation of Equation 3, Equation 4, and Equation 8 result in the subassemblage stiffness of a DDC system, refer to Equation 9.

Equation 9: DDC subassemblage stiffness

$$
\Delta_{\text {DDC }}=\Delta_{\text {BEAMS }}+\Delta_{\text {COLUMN }}+\Delta_{\text {ROTATIONAL_SPRING }_{-}}
$$

The spring permits much more drift within the system and thus greatly reduces the subassemblage stiffness relative to an equivalent monolithic system. The shear deformation within the system was not included as its effects on the system are insignificant relative to the ductile rod's rotational spring. 


\subsection{Moment at Tensile Rupture of the Concrete Beam}

The moment in the beam that is associated with the tensile rupture of the concrete is determined using Equation 10.

Equation 10: Cracking moment

$$
M_{c r}=\frac{f_{r} I_{g}}{y_{t}}, \text { Eqn. (9-9) in (ACI 2005) }
$$

where,

$f_{r}=7.5 \sqrt{f^{\prime}}$, modulus of rupture of the concrete,

Eqn. (9-10) in (ACI 2005).

$f^{\prime}{ }_{c}=$ compressive strength of the concrete.

$I_{g}=$ gross moment of inertia of the beam cross-section.

$y_{t}=$ distance from the centroidal axis of the gross cross section, neglecting reinforcement, to the tension face.

The subassemblage displacement at the cracking moment was calculated for DDC \#1 using Equation 11.

Equation 11: Cracking displacement for DDC \#1

$$
\Delta_{c r}=\frac{V_{b}}{K_{\text {INITIAL }}}
$$

where,

$V_{b}=\frac{M_{c r}}{\ell_{b-C L R}}$, beam shear.

$K_{\text {INITIAL }}=$ initial stiffness of the subassemblage.

$\ell_{b-C L R}=$ clear distance from the pinned support of the beam to the face of the joint.

DDC \#1 test results provide the beam shear verses beam drift where as DDC \#2 test results provide the column shear verses the column drift. For this reason, there are two different equations to describe the cracking displacement for DDC \#1 and DDC \#2. The 
subassemblage displacement at the cracking moment for DDC \#2 was calculated using

Equation 12.

Equation 12: Cracking displacement for DDC \#2

$$
\Delta_{c r}=\frac{M_{c r} \times \ell_{b}}{\ell_{b-C L R} \times \ell_{c} \times K_{\text {INITIAL }}}
$$

where,

$\ell_{b}=$ distance from the pinned support of the beam to the center of the joint.

$\ell_{b-C L R}=$ clear distance from the pinned support of the beam to the face of the joint.

$\boldsymbol{\ell}_{c}=$ distance from the pinned support of the column to the center of the joint.

$K_{\text {INITIAL }}=$ initial stiffness of the subassemblage.

\subsection{Nominal Moment and Drift at Yielding of the Ductile Rods}

The nominal moment capacity of the ductile rod was calculated using Equation 13.

Equation 13: Nominal moment capacity of the ductile rod connectors

$$
M_{n}=N T_{y}\left(d-d^{\prime}\right), \text { Eqn. (2.1.73) in (Englekirk 2003) }
$$

where,

$N=$ number of ductile rods.

$T_{y}=A \times F_{y}$, the axial force which causes yielding of the ductile rod.

$A=$ cross-sectional area of one ductile rod.

$F_{y}=$ yield stress of the ductile rod.

$d=$ distance from the centroid of the tensile ductile rod group to the extreme compression fibers.

$d^{\prime}=$ distance from the centroid of the compressive ductile rod group to the extreme compression fibers.

The subassemblage displacement was calculated using the yield rotation, refer to Equation 14. 
Equation 14: Yield rotation of a concrete frame subassemblage

$$
\begin{gathered}
\theta_{y}=\frac{0.5 \varepsilon_{y} L_{b}}{h_{b}}, \text { Eqn. (4.58a) in (Priestley et al. 2007) } \\
\text { where, } \\
\varepsilon_{y}=F_{y} / E, \text { yield strain of the ductile rod. } \\
F_{y}=\text { yield stress of the ductile rod. } \\
E=\text { modulus of elasticity of the ductile rod. } \\
L_{b}=\text { full horizontal length of the subassemblage from one } \\
\quad \text { beam end to the other. } \\
h_{b}=\text { cross-sectional height of the beam. }
\end{gathered}
$$

The yield displacement was then calculated using Equation 15 .

Equation 15: Displacement of the subassemblage

$$
\Delta=\theta_{y} \times H
$$

where,

$\theta_{y}=$ yield rotation.

$H=$ total height of the subassemblage from the top of the column to the column base.

*Note: DDC \#1 test results provide the beam shear vs. beam drift where as DDC \#2 test results provide the column shear vs. the column drift. For this reason, the $H$ value in Equation 15 may vary.

\subsection{Nominal Moment at Yielding of the Dywidag Bars}

The nominal moment capacity of the Dywidag bars within the beam was calculated using Equation 16.

Equation 16: Nominal moment capacity of the beam with Dywidag bars

$$
M_{n}=A_{s} F_{y}(d-a / 2)
$$

where,

$A_{s}=$ total area of all tensile Dywidag bars.

$F_{y}=$ yield stress of the ductile rod.

$d=$ distance from the centroid of the tensile ductile rod group to the extreme compression fibers. 


$$
\begin{aligned}
& a=\frac{A_{s} F_{y}}{0.85 f_{c}^{\prime} b} \text {, depth of the concrete compression block } \\
& \text { according to the Whitney stress block theory. } \\
& f_{c}^{\prime}=\text { compressive strength of the concrete. } \\
& b=\text { width of the beam cross-section. }
\end{aligned}
$$

All of the hand calculated results for both the DDC \#1 and DDC \#2 are shown in Table 4.

Table 4: Theoretical predictions for the DDC subassemblage test specimens

\begin{tabular}{|c|c|c|c|c|c|c|}
\hline $\begin{array}{c}\text { DDC } \\
\text { System }\end{array}$ & $\begin{array}{c}K_{\text {INITIAL }} \\
(\mathrm{kips} / \mathrm{in})\end{array}$ & $\begin{array}{c}M_{c r}, \text { Moment } \\
\text { at Tensile } \\
\text { Rupture of the } \\
\text { Concrete } \\
\text { Beam (kip*in) }\end{array}$ & $\begin{array}{c}\gamma_{c r}, \\
\text { Tensile } \\
\text { Rupture } \\
\text { Drift (\%) }\end{array}$ & $\begin{array}{c}M_{n}, \\
\text { Nominal } \\
\text { Moment } \\
(\text { kip*in) }\end{array}$ & $\begin{array}{c}\gamma_{y}, \\
\text { Yield } \\
\text { Drift } \\
(\%)\end{array}$ & $\begin{array}{c}M_{n-D B}, \\
\text { Nominal } \\
\text { Moment for } \\
\text { the Dywidag } \\
\text { Bars (kip*in) }\end{array}$ \\
\hline$\# 1$ & 180.3 & 2642 & $0.0525 \%$ & 12,772 & $0.794 \%$ & 18,930 \\
\hline$\# 2$ & 156 & 1,101 & $0.142 \%$ & 7,217 & $0.621 \%$ & 9,710 \\
\hline
\end{tabular}

The values shown in Table 4 were used to determine the forces in the beams and column at each yielding event. It is the member forces, drifts, and initial stiffness which are plotted in the results section for each specimen. 


\subsection{MODELING RESULTS}

A static push-over analysis was run for each test specimen using a fiber model and a lumped plasticity model to determine the approximate backbone curve of the DDC systems. In the analyses, a monotonic, steadily-increasing lateral load was applied to the structure, until a predetermined limit state was reached. All modeling results were plotted up until a $25 \%$, or greater, reduction in ultimate strength occurred in the modeling results.

\subsection{Fiber Model Results (PERFORM-3D)}

Figure 43 shows the results from the fiber model of DDC \#1 as it compares to the theoretical predictions, see Table 4, and test data.

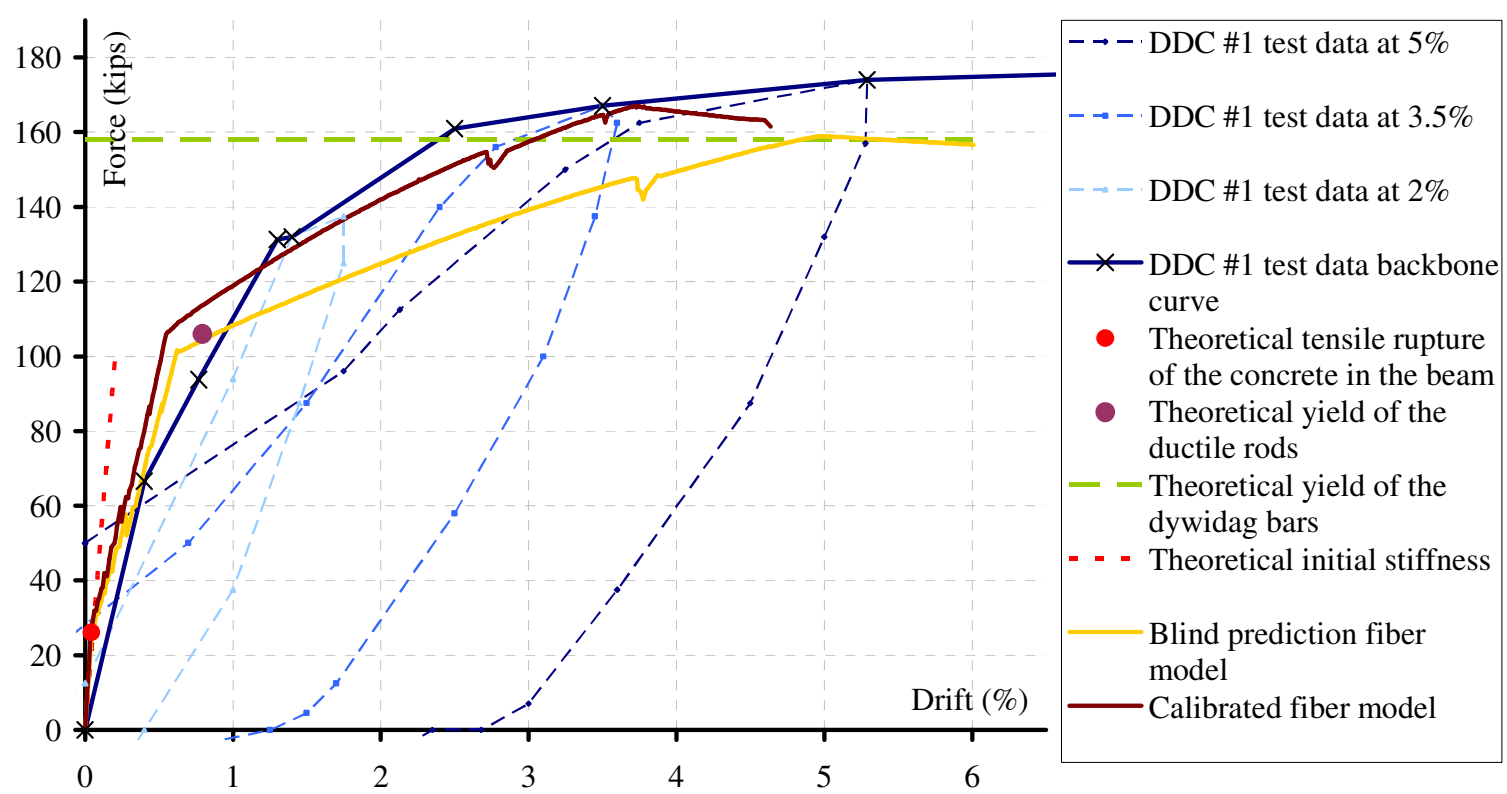

Figure 43: Force-displacement backbone curve for the DDC \#1 fiber model relative to test data and theoretical predictions 
Figure 44 shows the results from the fiber model of DDC \#2 as it compare to the theoretical predictions and test data.
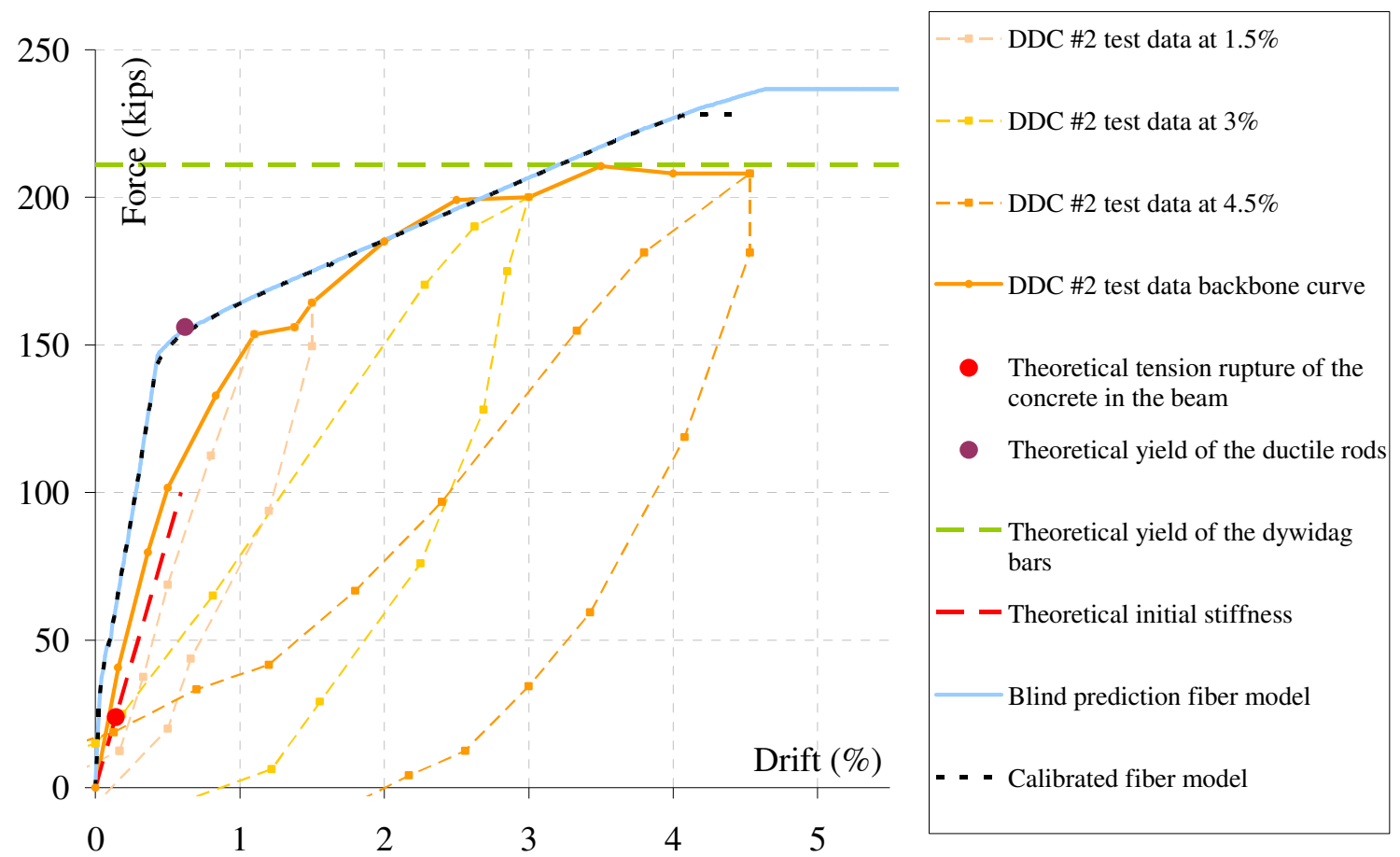

Figure 44: Force-displacement backbone curve for the DDC \#2 fiber model relative to test data and theoretical predictions

Both calibrated models use two fiber elements over a shorter ductile rod length of roughly $2 / 3$ of the actual ductile rod length in order to better approximate the test data. Though both models differ based on their over and under estimation of system capacities, both models show four distinct slopes along their analysis curves: (1) the initial elastic stiffness at pretensile rupture of the concrete, (2) the secondary stiffness at preyielding of the steel, (3) the tertiary stiffness at post ductile rod yielding but preyielding of the Dywidag bars, and (4) the quaternary stiffness at post Dywidag bar yielding. Both models have a decrease in stiffness around the predicted tensile rupture of the concrete. Moving farther along the curves, both models show the greatest loss in stiffness around 
the predicted yield of the ductile rods. In addition, both model's system strength continues to increase to, at least, yielding of the Dywidag bars.

Some discrepancies in the models relative to their corresponding test specimens can be seen. The DDC \#2 blind fiber model reaches ultimate strength over 20 kips higher than its calculated shear force capacity in the column, 211 kips, associated with yielding of the Dywidag bars. On the other hand, DDC \#1 under estimates the test specimen's ultimate shear force strength of 174 kips by 30 kips. As well, the DDC \#1 blind fiber model has an initial stiffness closer to the theoretical prediction; where as DDC \#2 does not.

\subsection{Lumped Plasticity Model Results (ETABS)}

Figure 45 shows the results from the lumped plasticity model of DDC \#1 as it compares to theoretical predictions and test data. 


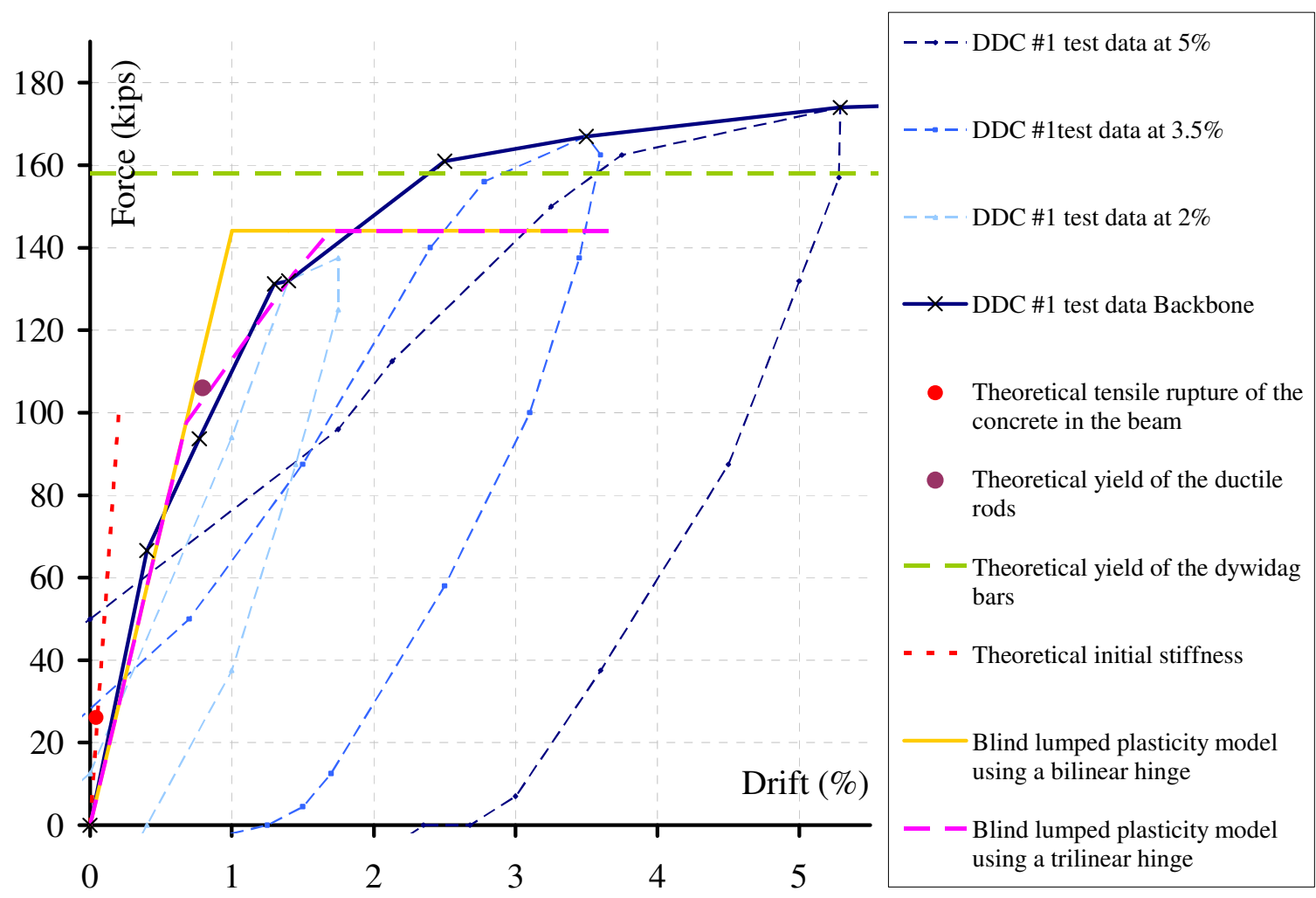

Figure 45: Force-displacement backbone curve for the DDC \#1 lumped plasticity model to test data and theoretical predictions

Figure 46 shows the results from the lumped plasticity model of DDC \#2 as it compares to theoretical predictions and test data. 


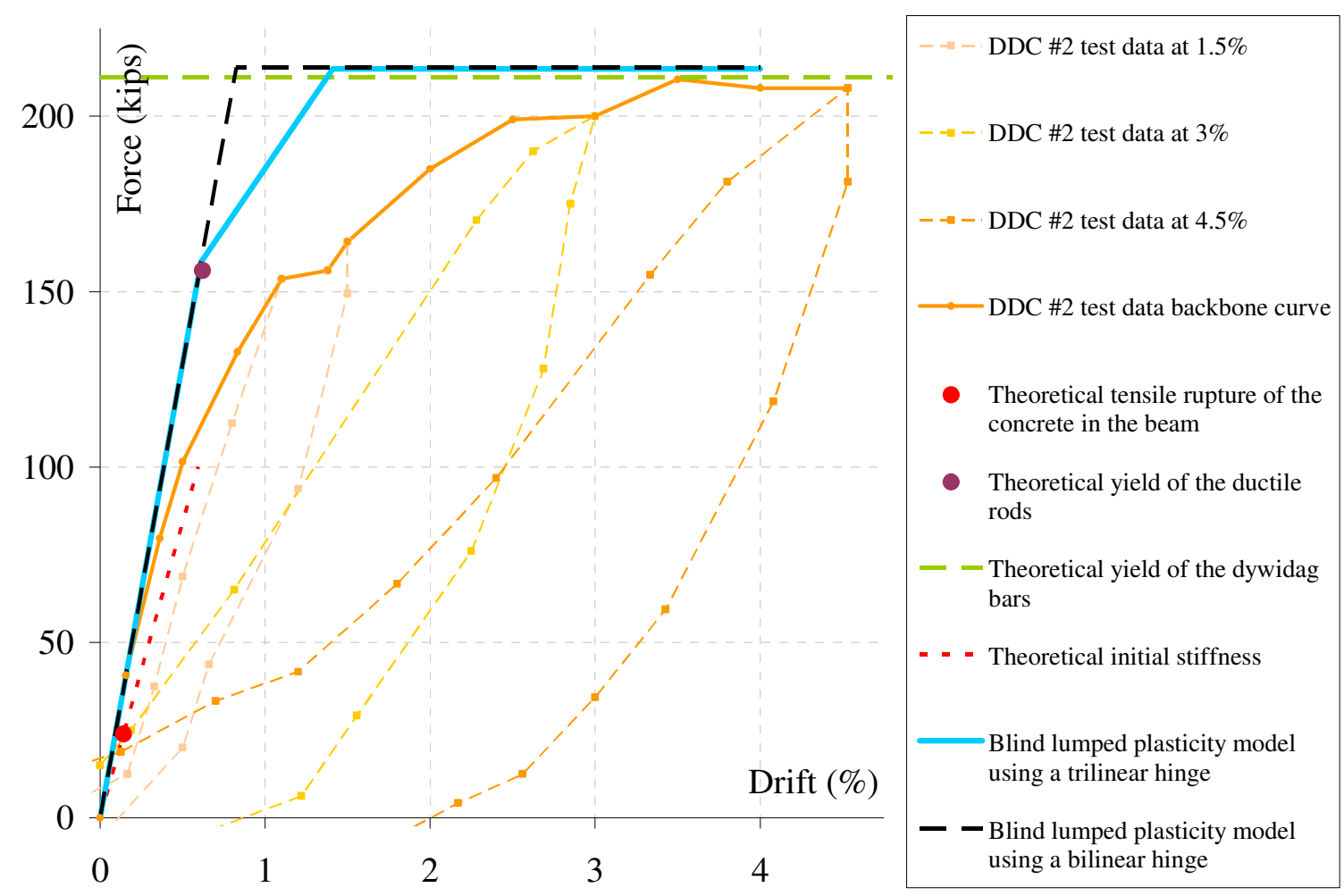

Figure 46: Force-displacement backbone curve for the DDC \#2 lumped plasticity model relative to test data and theoretical predictions

An all encompassing results graph of the trilinear lumped plasticity model approximation, the fiber model approximation, the theoretical predictions, and the specimen test data are shown for DDC \#1 and DDC \#2 in Figure 47 and Figure 48 respectively. 


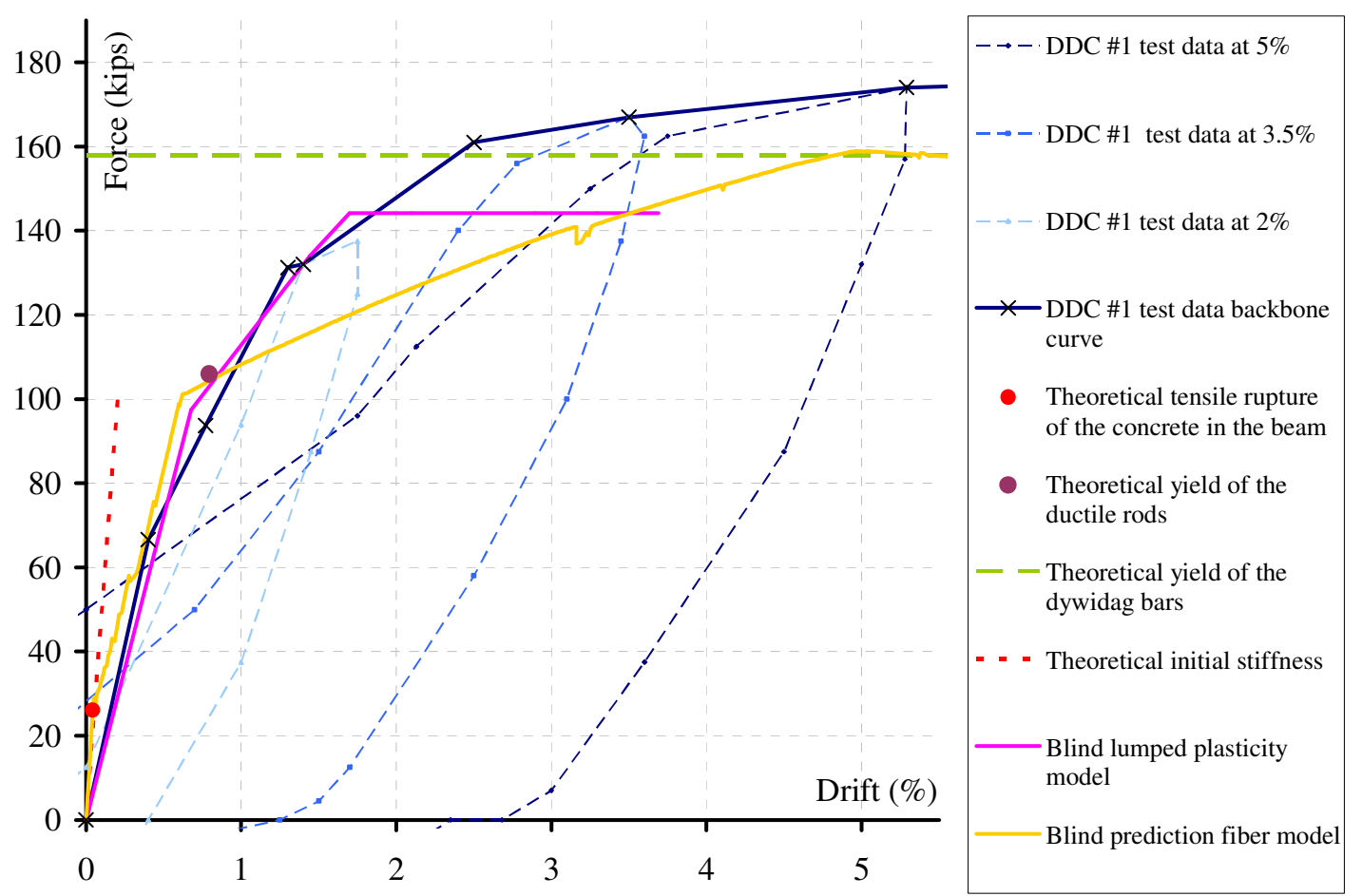

Figure 47: Force-displacement backbone curve for the lumped plasticity DDC \#1 model relative to test data and theoretical predictions

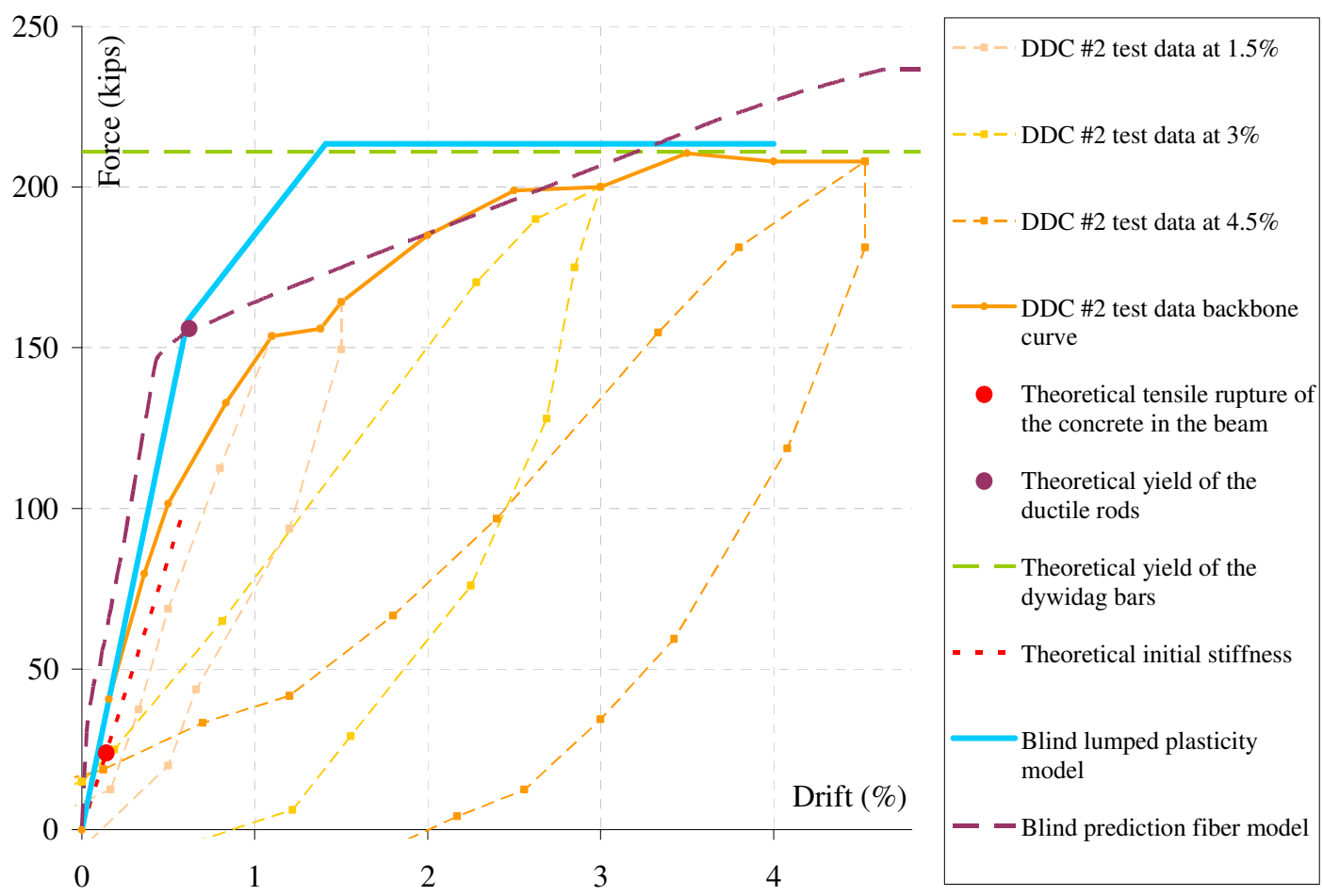

Figure 48: Force-displacement backbone curve for the ETABS model of DDC \#2 relative to test results and theoretical predictions 


\subsection{SUMMARY, CONCLUSION, AND FUTURE WORK}

This report describes the results of research on the modeling of the Dywidag ductile connector (DDC) system. The research areas covered by this report include the analytical modeling and behavior of beam-column subassemblages under lateral load, theoretical means for predicting the system behavior, the use of fiber elements to model the system's characterize and study the system behavior, and the development of a lumped plasticity model which can be used in DDC building models to determine global frame behavior. This section summarizes the results, presents the conclusions from the previous sections, and mentions potential areas of future research.

\subsection{Structural Behavior of Dywidag Ductile Connector Joints}

\subsubsection{Summary}

A summary of the structural behavior of the Dywidag ductile connector system, which was determined by (Chang, Hutchinson, and Englekirk 2007) is as follows:

1. Failure of the specimen occurs at the point of buckling of the Dywidag bars within the beam after cracking and spalling around the beam toe and heel has occurred.

2. The main modes of deformation in the DDC joint are gap-opening and shear cracking. 
3. There are two yielding points within the system. This first being the ductile rods, located within the joint, and the second being the Dywidag bars, which act as the longitudinal reinforcement within the beam.

4. The specimen may experience pull-out of the DDC at large drifts. This is mitigated by increasing the transverse volumetric ratio of reinforcement within the joint.

5. The specimens tested have shown no signs of strength degradation up to $4.5 \%$ drift.

\subsubsection{Conclusion}

The main conclusions regarding the structural system behavior of DDC joints are:

1. Gap-opening under flexure is the desired mode of deformation and allows for the strain in the toe region of the beam to be controlled.

2. The ductile rod moves the location of the yielding from the beam to within the joint where it has nondeteriorating lateral supported (Englekirk 2003).

3. Shear forces are transferred by friction from steel to steel across the beam-column interface. The load path travels from the face of the ductile rod to the beam transfer block via a set of shim plates. The pretensioning of the bolt activated this frictional load transfer (Englekirk 2003). 


\subsection{Fiber Model (PERFORM-3D)}

\subsubsection{Summary}

The fiber model, described in Section 3.3 was used to model the Dywidag ductile connector specimens. PERFORM-3D fiber beam-column elements were used to represent both the gap-opening under flexure, and the nonlinear inelastic behavior of the concrete in the members and joint. The beam-column joint is not modeled as fully rigid to account for some of the shear deformation that occurs in the joint. Only a fiber element of a length equivalent to that of the ductile rod shank is modeled with ductile rod fibers; other fibers within this fiber element have the confined concrete column constitutive properties. The inelastic behavior in the test specimen is concentrated at the end of the beam near the gap opening at the beam-column interface; this plastic hinge length is unknown. Shorter fiber lengths were required along the member where high demands existed. The portion of the column within the joint was modeled as fully rigid, with minimal change to the system behavior. The DDC \#1 and DDC \#2 fiber models seemed to under estimate the yield drift of the system. As well, the fiber models are not consistent in approximating the shear force in the members at ultimate force demand. The fiber model provides a reasonable estimate of the force-displacement backbone curve for the DDC system, but more time and research could produce better results.

\subsubsection{Conclusion}

Studies of the fiber model and its modeling parameters lead to the following conclusions: 
1. The confined concrete fibers, with the maximum strain, should be modeled with a height of approximately $2 \%$ of the beam height (El-Sheikh et al.1997).

2. The unconfined concrete fibers may be more coarsely distributed over the cross section as shown in Figure 26 (El-Sheikh et al. 1997).

3. The number of fiber segments used to model the beams and column should decrease in length as the member gets closer to the joint, as demand values and curvature variation increases. The recommended fiber segment configuration is shown in Figure 31, but a more in-depth study is recommended.

4. The joint rigidity should be modeled according to the recommendations by (Elwood et al. 2007). Rather than use a capacity ratio of column-to-beam, as Elwood recommends for monolithic frames, the capacity ratio of column to ductile-rod set should be used; the ductile rod set is the fuse which limits the applied moment the beam can crank into the joint. Thus far, this approach has led to a rigid column and flexible beam arrangement within the joint.

5. The ductile rods are modeled as fibers within a fiber element of which is the length of the ductile rod shank. Concrete properties within this fiber segment are based on the confined concrete column region. The head of the ductile rod is modeled as rigid, where as the rest of the joint and ductile rod is modeled using fiber elements with the properties of the beam.

6. Dividing the ductile rod fiber element into multiple fiber segments reduces the ultimate rotation of the system without altering the stiffness characteristics.

7. Shortening the ductile rod fiber segment decreases the ultimate rotation while also increasing the post-yield stiffness of the system. 


\subsection{Lumped Plasticity Model (ETABS)}

\subsubsection{Summary}

The lumped plasticity (LP) model, described in Section 3.4 is used to model the Dywidag ductile connector system for global structural system analysis. Elastic concrete members with effective stiffness values are used to represent the nonlinear inelastic behavior of the concrete members. The nonlinear hinge, located at the beam-column interface, is used to represent yielding of the ductile rod and yielding of the Dywidag bars. Similar to the fiber model, the lumped plasticity model's beam-column joint is not modeled as fully rigid as to account for some of the shear deformation that occurs in the joint. The nonlinear hinge properties are assigned according to nominal moment capacities of the ductile rods and Dywidag bars. The rotations are determined via monolithic frame curvature and rotation calculations. The lumped plasticity model can be used to perform a nonlinear pushover analysis. The DDC \#1 and DDC \#2 lumped plasticity models seemed to under estimate the yield drift of the system. Similar to the fiber model, the lumped plasticity model does not show consistency in approximating the shear force in the members at ultimate force demands. Similar to the their corresponding fiber models, the LP simplified model of DDC \#1 under estimated the ultimate strength of the system and the LP model of DDC \#2 over estimated the ultimate strength of the system. The LP model provides an acceptable estimate of the force-displacement backbone curve for the DDC system. 


\subsubsection{Conclusion}

Studies of the lumped plasticity (LP) model and its modeling parameters have led to the following conclusions:

1. The moment-rotation behavior of the joint is essentially an inelastic trilinear curve with discontinuities at the point of ductile rod yielding and Dywidag bar yielding.

2. The nonlinear hinge can be defined using yield rotation calculations for conventional monolithic concrete moment frames; though, this is where the majority of the model inaccuracies occur. The difficulty lies in predicting the yield rotation, since Equation 2 does not account for gap-opening and plastic rotation in the system. These inadequacies led to a large underestimation of yield rotation.

3. The same procedures were used for the fiber model and the LP model in determining the joint rigidity.

4. The LP models under estimate the ductile rod yield rotation for both DDC \#1 and DDC \#2. The LP model underestimates the strength of DDC \#1 while over estimating the strength of DDC \#2. 


\subsection{Future Work}

\subsubsection{Dywidag Ductile Connector System}

Throughout this report the need for more research in various aspects of the DDC system became apparent. The following is a list of suggested future research topics to explore:

1. Determine the debond length of the ductile rod in a test specimen when cyclically loaded within the system.

2. A more in-depth study on defining the various fiber lengths across a member.

3. Define the plastic hinge length in the DDC system.

4. Create a simplified methodology to characterize the rotation of the system due to gap-opening.

5. Create an equation to approximate the rotation of the system at yielding of the Dywidag bars that would incorporate rotation due to gap-opening and plastic hinging of the ductile rods.

6. Determine why the simplified model underestimated the strength of DDC \#1 while it over estimated the strength of DDC \#2.

7. Study the effects of the reinforcement ratio on the over or under estimation of the fiber model.

\subsubsection{Super Hybrid System}

The super hybrid system is a relatively new type of lateral system, which has several benefits. In order to incorporate this system into practice, more needs to be 
understood about the system behavior. For this reason, it is highly recommended that future research involve the analytical modeling of the super hybrid system using the fiber and the lumped plasticity modeling approaches previously mentioned in this report.

A fiber model of the super hybrid system, shown in Figure 49, was modeled.

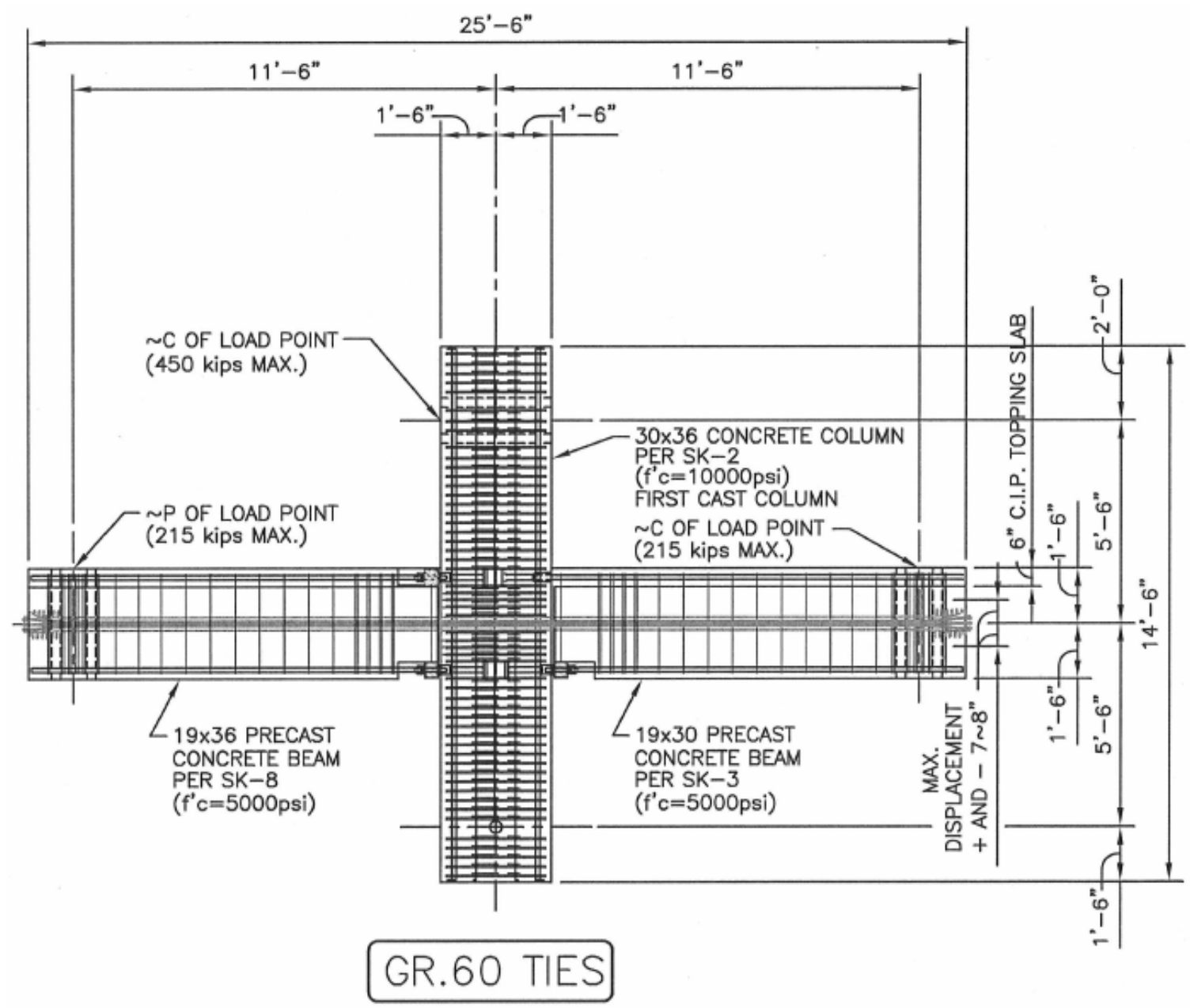

Figure 49: Schematic elevation of the Pankow \#2 super hybrid test specimen (Chang Hutchinson, and Englekirk 2007)

More details of the specimen are provided in Appendix I. An approximation of the super hybrid hysteretic test data is shown in Figure 50. The actual test results are shown in Appendix I. 


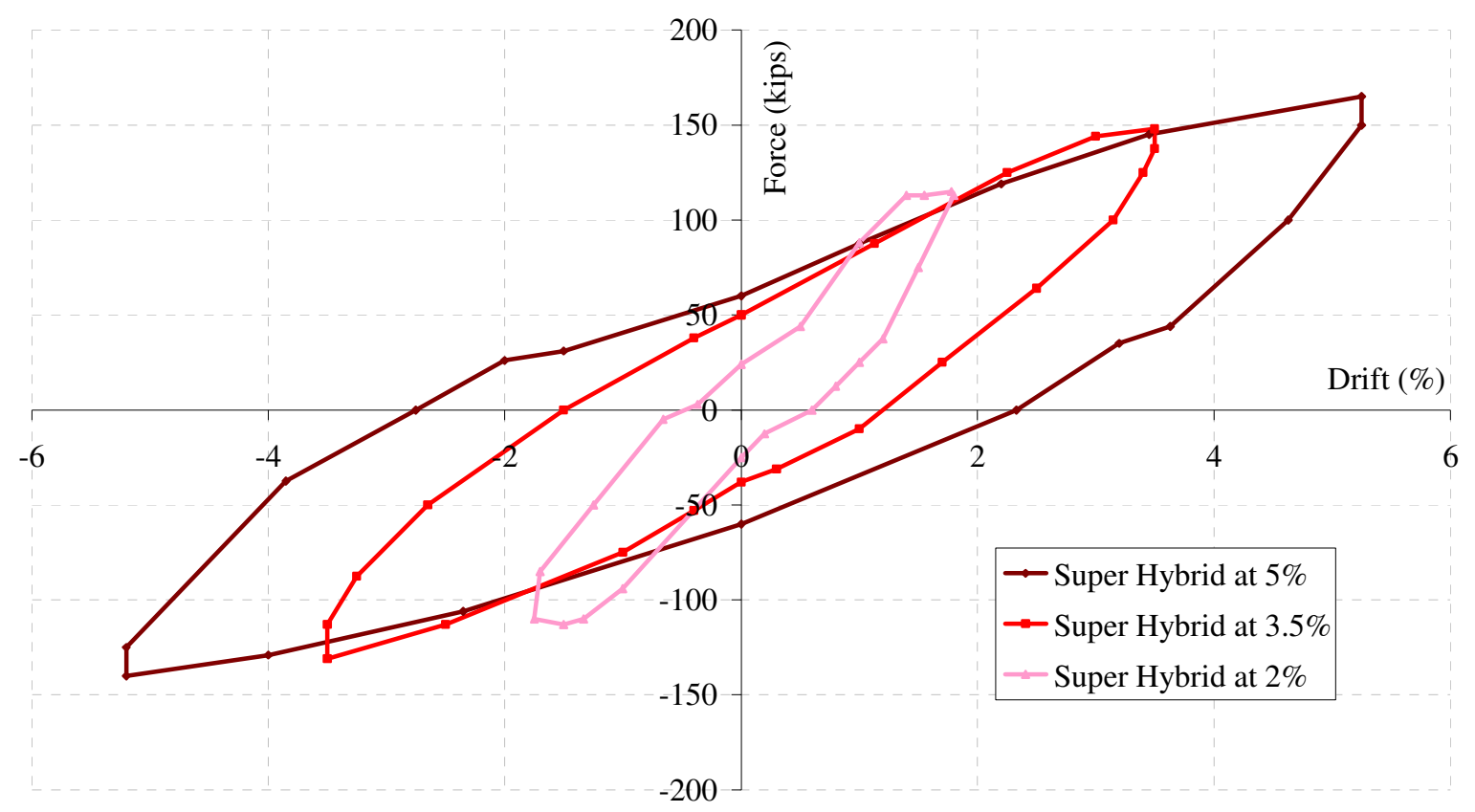

Figure 50: Super Hybrid force-displacement hysteretic loop approximations

Only a fiber model was created of this super hybrid specimen. The system used the same modeling techniques as the DDC systems.

The major differences in the super hybrid specimen versus the DDC specimen are the beam cross sections, the number of ductile rods, and the presence of post tensioned (PT) strands. However, only major modeling difference between the super hybrid specimen and the DDC specimens is the presence of the PT.

The PT was modeled as a truss element connected to the specimen at both beam ends. A compressive loading strain was applied to the truss in order to mimic the compressive PT forces. The truss element was assigned the idealized constitutive properties of the PT steel (grade 270), refer to Figure 51. 


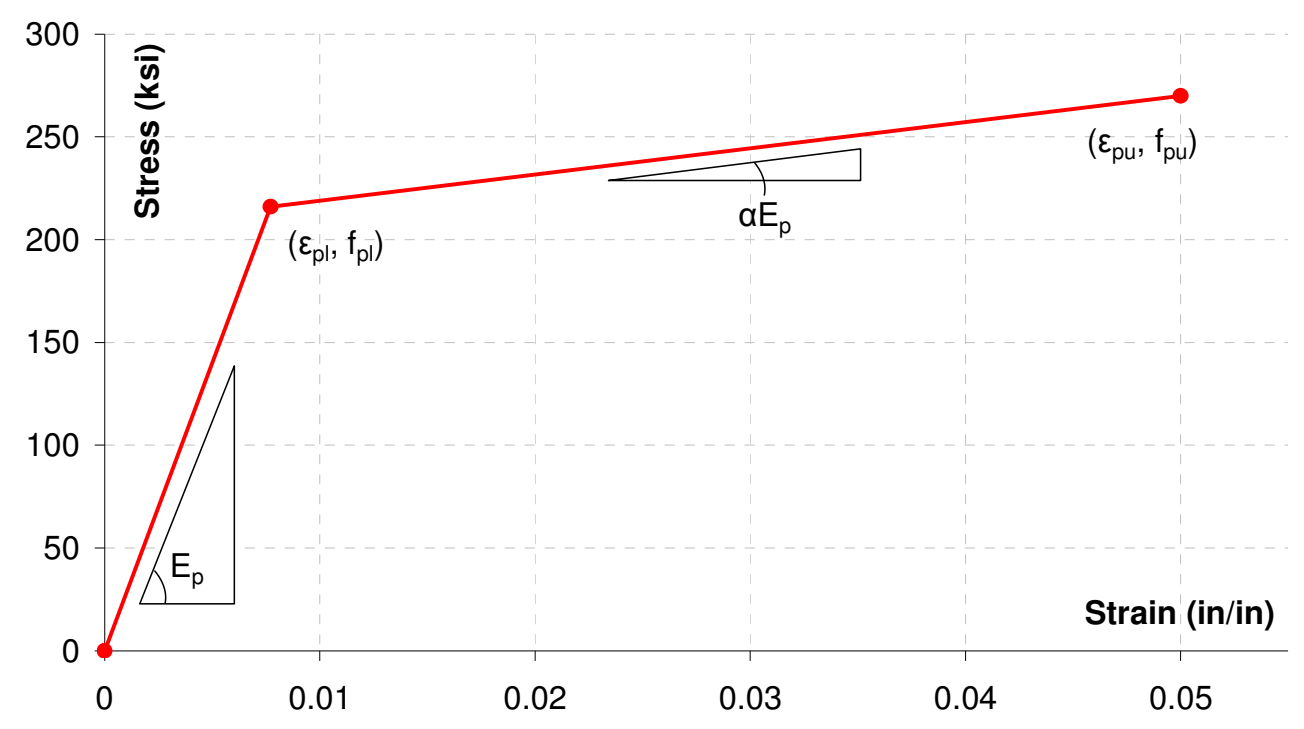

Figure 51: Constitutive relationship of post-tensioned steel strand

Table 5 provides the values associated with the variables in Figure 51.

Table 5: PT Steel Properties

PT Properties for grade 270 strand

\begin{tabular}{|r|l|}
\hline $\mathrm{E}_{\mathrm{p}}=$ & $28,000 \mathrm{ksi}$ \\
\hline$\varepsilon_{\mathrm{pu}}=$ & 0.05 \\
\hline $\mathrm{f}_{\mathrm{pu}}=$ & $270 \mathrm{ksi}$ \\
\hline $\mathrm{f}_{\mathrm{pl}}=$ & $0.8 \mathrm{f}_{\mathrm{pu}}$ \\
\hline
\end{tabular}

The strain load applied to the truss bar was determined using Equation 17 since the initial PT force was within the elastic range of the PT strands.

Equation 17: Elastic axial strain

$$
\varepsilon=\frac{P}{A \times E}
$$

where,

$P=$ axial load, 450 kips.

$A=$ cross sectional area of the member, $3.11 \mathrm{in}^{2}$.

$E=$ modulus of elasticity of the member.

Therefore, the loading strain applied to the bar was -0.00517 in./in. This technique for modeling PT using a truss element and strain loading is similar to the method used in the 
report by (El Sheikh et al. 1997). The constitutive properties and approximations for the super hybrid specimen can be found in Appendix I and Appendix F respectively. The theoretical results, shown in Figure 52, are calculated in Appendix C. The pushover analysis results of the super hybrid fiber model are shown in Figure 52.

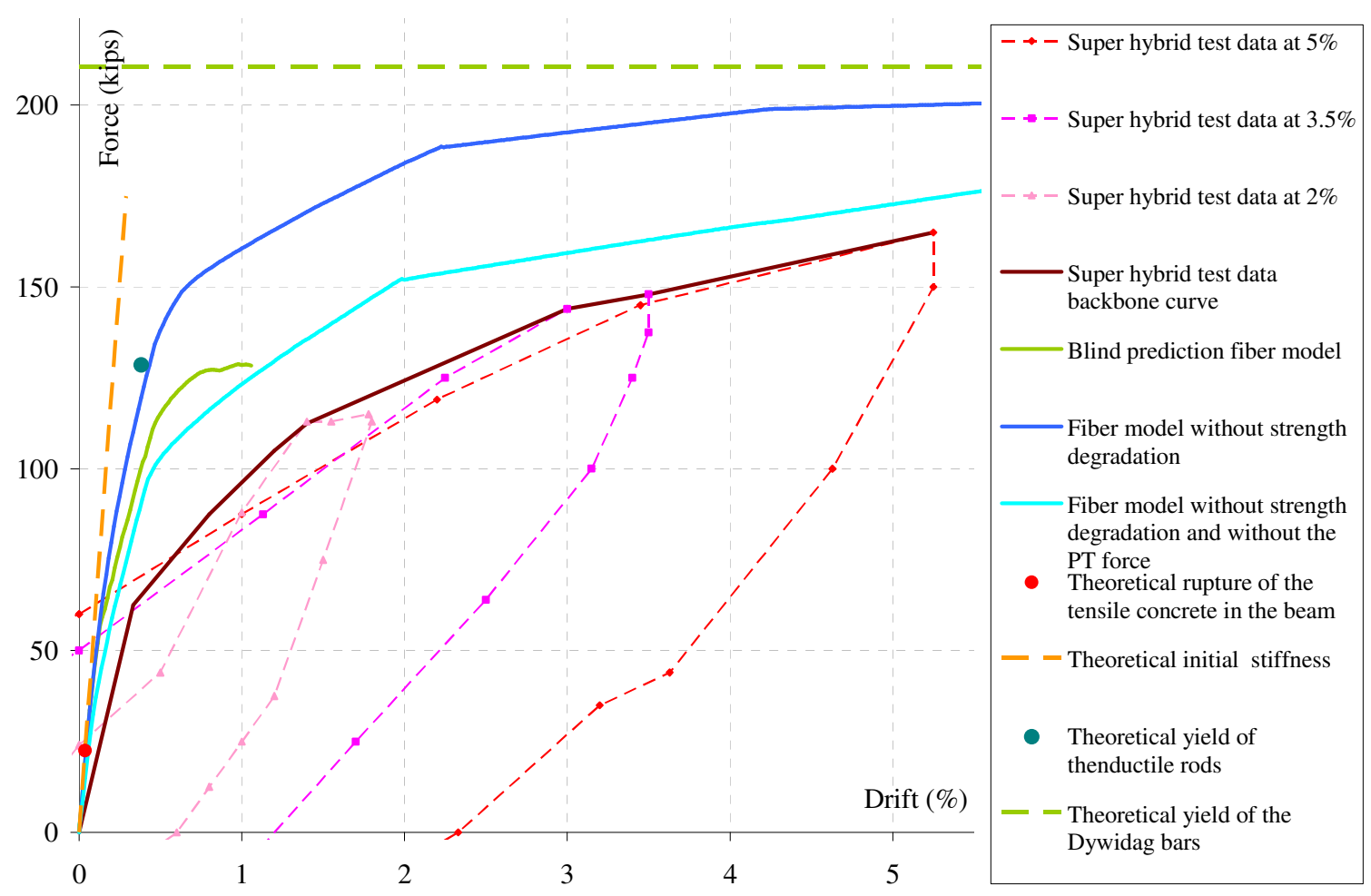

Figure 52: Force-displacement backbone curve for the fiber model of the super hybrid relative to the test results and theoretical predictions

The theoretical stiffness was calculated for the super hybrid as if it were a monolithic system. This theoretical stiffness matches the super hybrid fiber model results but not the test data. As well, the force associated with theoretical yielding of the Dywidag bars is 1.3 times the force associated with the strength capacity of the test specimen.

The blind prediction fiber model of the super hybrid failed at $1 \%$ drift as the fiber model experiences a decrease in system strength of over $25 \%$. When the super hybrid 
fiber model was run such that no fibers experienced strength degradation, the fiber model behavior did not reach failure until after a drift of 5\%, refer to Figure 52. When the super hybrid model was run once more with no strength degradation and no PT force applied, the results were closest to the test data's backbone curve. 


\section{REFERENCES}

\section{Cited References}

ACI Committee 318. 2005. Building Code Requirements for Structural Concrete (ACI 318-05) and Commentary (ACI 318R-05). Farmington Hills, MI: ACI.

ASCE. Prestandard and Commentary for the Seismic Rehabilitation of Buildings. (FEMA 356) and Commentary (FEMA 356-C). Washington, D.C., 2000.

ASCE. Seismic Rehabilitation of Existing Buildings (ASCE/SEI 41-06). Structural Engineering Institute. American Society of Civil Engineers. Reston, VA, 2007.

Celik, O.; and Sritharan, S., An Evaluation of Seismic Design Guidelines Proposed for Precast Concrete Hybrid Frame Systems. ISU-ERI-Ames Report ERI-04425, Iowa State University, Ames, IA, January, 2004.

Chadwell, C., "XTRACT User Guidelines," Version 3.0.8. TRC. www.imbsen.com. 2007.

Chang, B.; Hutchinson, T.; and Englekirk, R., "Charles Pankow Foundation Sponsored Beam/Column Subassembly Testing Program”. Interim Report. October 30, 2007.

Chang, B.; Hutchinson, T.; and Englekirk, R., "Charles Pankow Foundation Sponsored Beam/Column Subassembly Testing Program”. Interim Report \#2. December 19, 2007.

Chen, Richard. Interview with author, December 17, 2007.

Cheok, G.; and Stone, W., "Performance of 1/3-Scale Model Precast Concrete BeamColumn Connections Subjected to Cyclic Inelastic Loads - Report No. 3," NISTIR 5246, National Institute of Standards and Technology, Gaithersburg, MD, August, 1993.

Elwood, K.; Matamoros, A,; Wallace, J.; Lehman, D.; et al, "Update to ASCE/SEI 41 Concrete Provisions," 2007Annual Meeting of the Los Angeles Tall Buildings Structural Design Council, Los Angeles, California, May 2007.

El-Sheikh, M,; Pessiki, S.; Sause, R.; Lu, L.-W.; and Kurama, Y., "Seismic Analysis, Behavior, and Design of Unbonded Post-Tensioned Precast Concrete Frame,"Earthquake Engineering Research Report, Report No. EQ-97-02, Lehigh University, Bethlehem, Nov. 1997. 
Englekirk, R., “The Development and Testing of a Ductile Connector for Assembling Precast Concrete Beams and Columns," PCI Journal, Vol. 40, No. 2, March-April 1995, pp. 36-51.

Englekirk, R., Seismic Design of Reinforced and Precast Concrete Buildings. John Wiley and Sons, Inc. Hoboken, New Jersey, 2003.

Englekirk, R., "Design and Behavior of the Super Hybrid System," 2007

Precast/Prestressed Concrete Institute 53rd Annual Convention, Phoenix, Arizona, October 2007.

Hawkins, N.; and Ghosh, S., "Requirements for the use of PRESSS Moment Resisting Frames,” PCI Journal, Vol. 49, No. 2, Mar.-April 2004, pp. 98-103.

Hawileh, R.; Tabatabai, H.; Rahman, A.; and Amro, A., "Non-dimensional Design Procedures for Precast, Prestressed Concrete Hybrid Frames," PCI Journal, Vol. 51, No. 5, Sept.-Oct. 2006, pp. 110-130.

MacRae, G. and Priestley, M.J.N., "Precast Post-Tensioned Ungrouted Concrete BeamColumn Subassemblage Tests," Report No. SSRP 94/10, Department of Applied Mechanics and Engineering Science, University of California San Diego, CA March 1994.

Mander, J.; Priestley, M.; and Park, R, “Theorical Stress-Strain Model for Confined Concrete," Journal of Structural Engineering, American Society of Civil Engineers, Vol. 114, No. 8, Aug 1988a, pp. 1804-1826.

Nakaki, S.; Englekirk, R.; and Plaehn, J., "Ductile Connectors for a Precast Concrete Frame," PCI Journal, Vol. 39, No. 5, Sept.-Oct. 1994, pp. 46-59.

Priestley, M.J.N., “Overview of PRESSS Research Program,” PCI Journal, Vol. 36, No. 4, July-Aug. 1991, pp.50-57.

Priestley, M.J.N.; Tao, J.R., "Seismic Response of Precast Prestressed Concrete Frames with Partially Debonded Tendons," PCI Journal, Vol.38, No. 1, Jan.-Feb. 1993, pp. 58-66.

Priestley, M.J.N.; Calvi, G.M.; Kowalsky, M.J., Displacement-Based Seismic Design of Structures. Istituto Universitario di Studi Superiori di Pavia (IUSS) Press. Pavia, Italy, 2007.

SEQAD Consulting Engineers, "Precast Ductile Connector Beam-Column Test," Report No. 93-02, Solana Beach, CA March 1993. 
Stanton, J.; Day, S.; and MacRae, G., "Testing of Hybrid Frame Interior, Exterior, and Corner Beam-Column Specimens," Report No.98195-2700, Department of Civil and Environmental Engineering, University of Washington, WA 1999.

\section{Additional References}

Adachi, Masato; and Nishiyama, Minehiro, "Hysteretic Behavior of Precast PostTensioned Beam-Column Joint Assemblage". Transactions of the Japan Concrete Institute, Vol. 19, 1997, pp.211-218.

Cheok, G.; and Lew, H.S., "Performance of 1/3-Scale Model Precast Concrete BeamColumn Connections Subjected to Cyclic Inelastic Loads," NISTIR 4433, National Institute of Standards and Technology, Gaithersburg, MD, Oct., 1990.

Cheok, G.; and Lew, H. S., "Performance of 1/3-Scale Model Precast Concrete BeamColumn Connections Subjected to Cyclic Inelastic Loads - Report No. 2," NISTIR 4589, National Institute of Standards and Technology, Gaithersburg, MD, June, 1991.

Cheok, G.; and Stone, W., "Performance of 1/3-Scale Model Precast Concrete BeamColumn Connections Subjected to Cyclic Inelastic Loads - Report No. 4," NISTIR 94045, National Institute of Standards and Technology, Gaithersburg, MD, June, 1994.

Cheok, G.; Stone, W.; and Nakaki, S., "Simplified Design Procedure for Hybrid Precast Concrete Connections," NISTIR 5765, National Institute of Standards and Technology, Gaithersburg, MD, February, 1996.

Englekirk, R., “An Innovative Design Solution for Precast Prestressed Concrete Buildings in High Seismic Zones," PCI Journal, Vol. 41, No. 4, July-Aug. 1996, pp. 44-53.

Englekirk, R., "Design-Construction of The Paramount - A 39-Story Precast Prestressed Concrete Apartment Building," PCI Journal, Vol. 47, No. 5, July-Aug. 2002, pp. 56-72.

"Northridge Earthquake January 17, 1994 Preliminary Reconnaissance Report," Earthquake Engineering Research Institute, pp. 40.

Iverson, J.K., and Hawkins, N.M., "Performance of Precast/Prestressed Concrete Building Structures During Northridge Earthquake," PCI Journal, Vol. 39, No. 2, Mar.-Apr. 1994, pp. 38-55. 
Park, R., "A Perspective on the Seismic Design of Precast Concrete Structures in New Zealand,” PCI Journal, May-June 1995, pp. 40-60.

PERFORM 3-D Nonlinear Analysis and Performance Assessment for 3D Structures User Guide, Version 4, Computers and Structures Inc., Aug. 2006.

Popovics, S., "A Numerical Approach to Complete Stress-Strain Curves for Concrete," Cement and Concrete Research, Vol. 3, No. 5, Sept. 1973, pp. 583-599.

Raynor, D.; Lehman, D.; and Stanton, J., "Bond-Slip of Reinforcing Bars Grouted in Ducted,” ACI Journal, Vol. No., Sept-Oct. 2002, pp. 568-576. 


\section{APPENDICES}

\section{Appendix A}

\section{DDC \#1 Initial Stiffness}

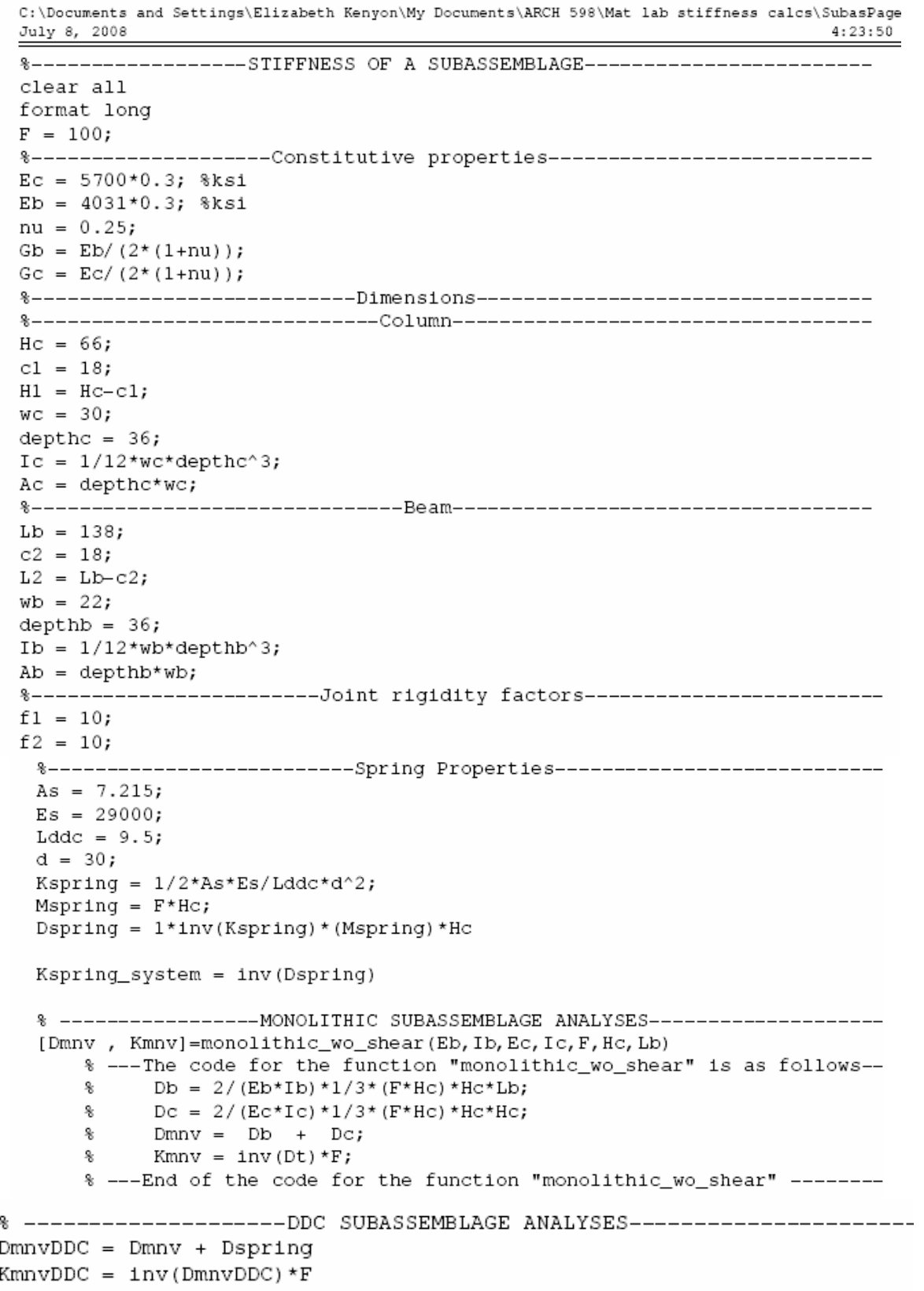




\section{MATLAB OUTPUT}

Kspring_system $=14.1$ (kips/in.), spring stiffness

Dmnv $=0.483$

(in.), Displacement of the monolithic system using $\mathrm{I}_{\mathrm{eff}}=0.3 \mathrm{I}_{\mathrm{g}}$ for both members

$\mathrm{Kmnv}=207$ (kips/in.), Stiffness of the monolithic system using $\mathrm{I}_{\text {eff }}=0.3 \mathrm{I}_{\mathrm{g}}$ for both members

DmnvDDC $=0.555$

KmnvDDC $=180.3$ (in.), Displacement of the DDC system

\section{DDC \#1 Column Shear at the Tension Rupture of the Concrete}

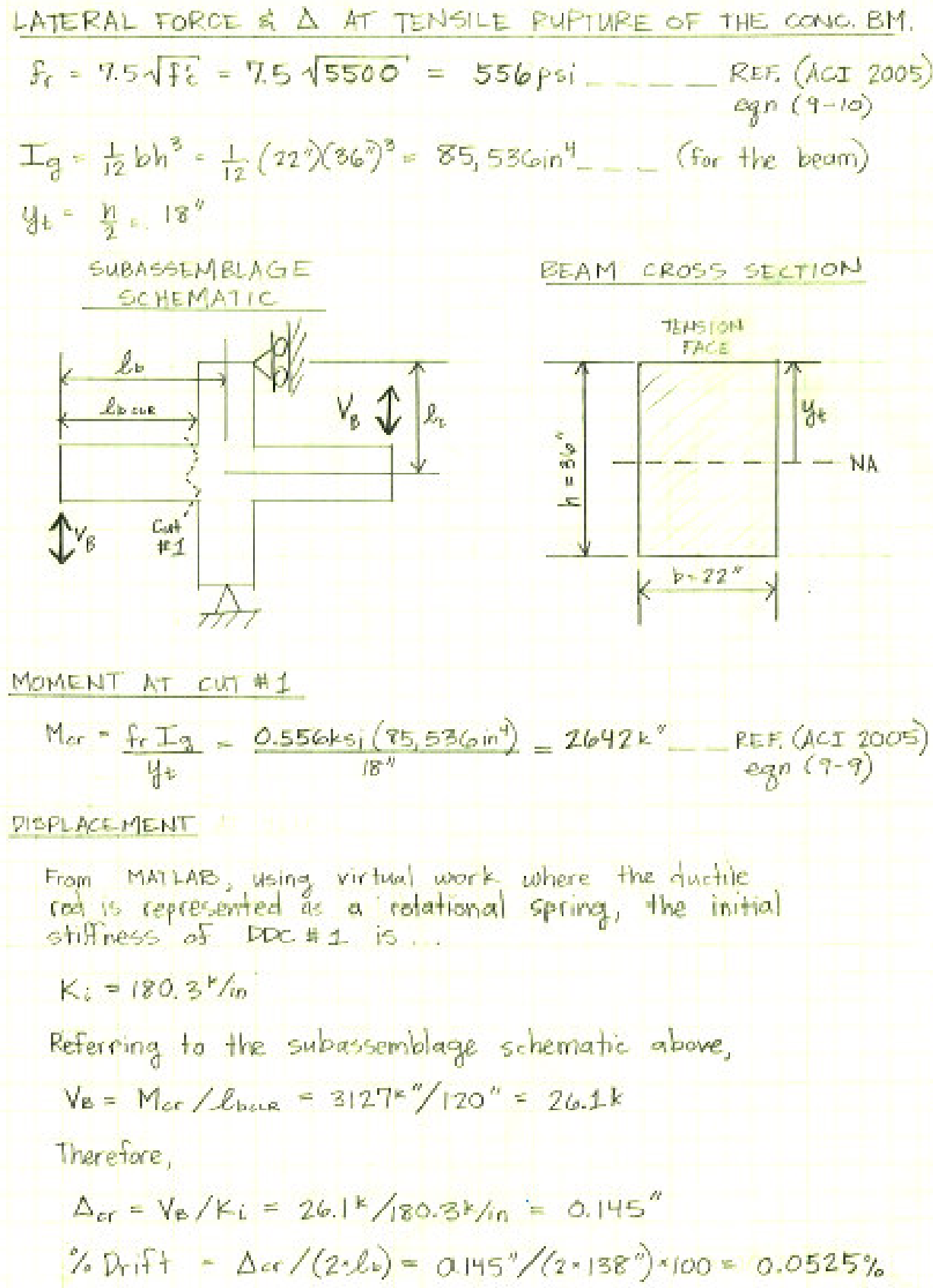




\section{DDC \#1 Column Shear at Yielding of the Ductile Rods}

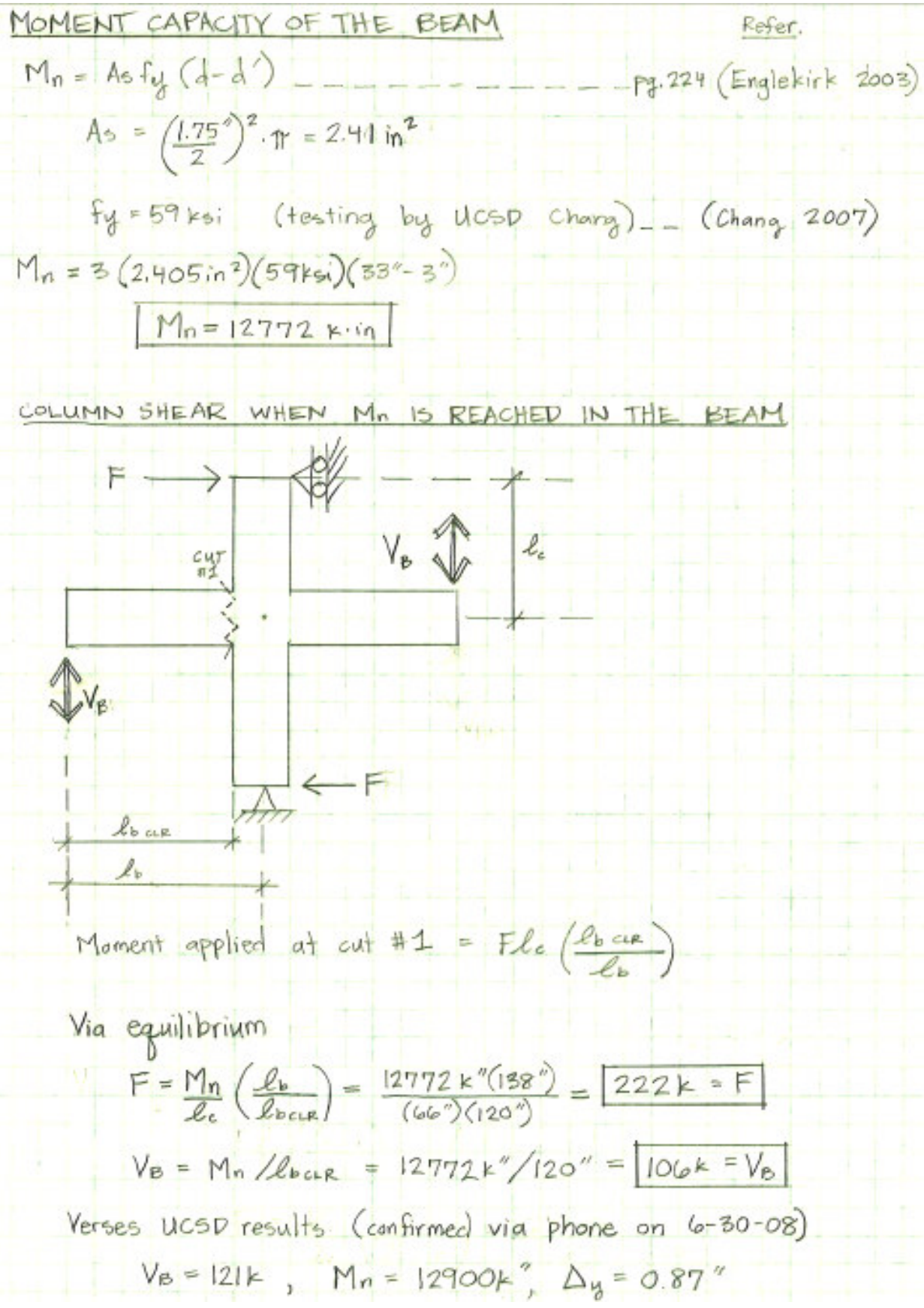




\section{DDC \#1 Predicted Displacement at Yield}

$$
\begin{aligned}
& \text { SUBASSEMBLAGE DISPLACEMENT } \\
& \varepsilon_{y}=\frac{f_{y}}{E}=\frac{60 \mathrm{ksi}}{29000 \mathrm{ksi}}=0.00207
\end{aligned}
$$

\section{DDC \#1 Column Shear at Yielding of the Dywidag Bars}

$$
\begin{aligned}
& \text { MOMENT CAPACITY AT YIELDING OF THE } \\
& \text { DYWIDAG BARS } \\
& M_{n}=A_{s} f y(d-a / 2) \\
& A_{s}=(3 \text { bars })\left(\frac{1.375^{\prime \prime}}{2}\right)^{2} \pi=4.45 \text { in }^{2} \\
& f y=142 k s i \\
& d=33^{\prime \prime} \\
& a=\frac{A_{s f y}}{0.85 b f^{\prime} c}=\frac{4.4547 \mathrm{in}^{2}(142 \mathrm{ksi})}{0.85(5.5 \mathrm{ksi})\left(22^{\prime \prime}\right)}=6.15^{\prime \prime} \\
& M_{n}=4.4547 \mathrm{in}^{2}\left(142 k_{51}\right)\left(33^{\prime \prime}-6.15^{\prime \prime} / 2\right) \\
& M_{Y-D D R}=18930 k^{\prime \prime} \\
& F_{B M}=\frac{M_{n}}{l_{\text {bCR }}}=\frac{18930 k^{\prime \prime}}{120^{\prime \prime}} \\
& F_{B M}=158 \mathrm{~K} \\
& F_{\text {COL }}=\frac{M_{n}}{l_{c}}\left(\frac{l_{b}}{l_{b C L R}}\right)=\frac{18930 k^{\prime \prime}}{66^{\prime \prime}}\left(\frac{138^{\prime \prime}}{120^{\prime \prime}}\right) \\
& F_{\text {COL }}=330 k
\end{aligned}
$$




\section{DDC \#1 Determining Rigid Link Length}

RIGID LINK LENGTH W/IN JOINT

MOMENT CAPACITY

OF THE COLUMN

* A rough $M_{n}$ is needed therefore a simiplified approach to calculating moment capacity will be

used - no axial load or compression steel included

$M_{n}=A_{s} f_{y}(d-2 / 2)$

$$
\begin{aligned}
A_{s} & =(4) \# 11+(4) \# 8 \\
& =5\left(1.56 \mathrm{in}^{2}\right)+4\left(0.79 \mathrm{in}^{2}\right) \\
& =10.96 \mathrm{in}^{2}
\end{aligned}
$$

(2) $\# \|(8$ TOTAL)

(2) \#8(14 TOTAL $)$

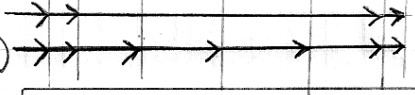

$f y=60 \mathrm{ksi}$

$a=\frac{A s f y}{0.85 f^{\prime} \mathrm{cb}}=\frac{1096 \mathrm{in}^{2}(60 \mathrm{ksi})}{0.85(10.0 \mathrm{ksi})\left(30^{\prime \prime}\right)}=2.57 \mathrm{in}$

$M_{n}=10.96 \mathrm{in}^{2}(60 \mathrm{ksi})\left(32.5^{\prime \prime}-2.571 / 2\right)$

$$
M_{n_{\text {COL }}}=20,527 k^{\prime \prime}
$$

RATIO OF MOMENTS@THE JOINT

$$
\frac{M_{n_{C O L}}}{M_{n_{B M}}}=\frac{20527 k^{\prime \prime}}{12772 k^{\prime \prime}}=1.61
$$

Since $\frac{M_{\text {niou }}}{M_{r_{B M}}}>1.2$ then reference' (Elwood et al 2007) recommends modeling the column as fully rigid w/in the joint is the beam as fully flexible.

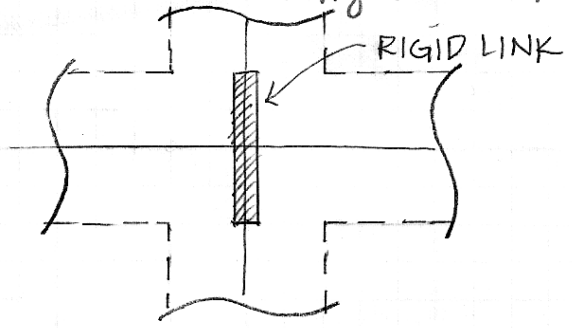




\section{DDC \#1 ETABS Nonlinear Hinge Properties}

PEFINING THE FRANIE NONLINEAR HINGE PROPERTIES

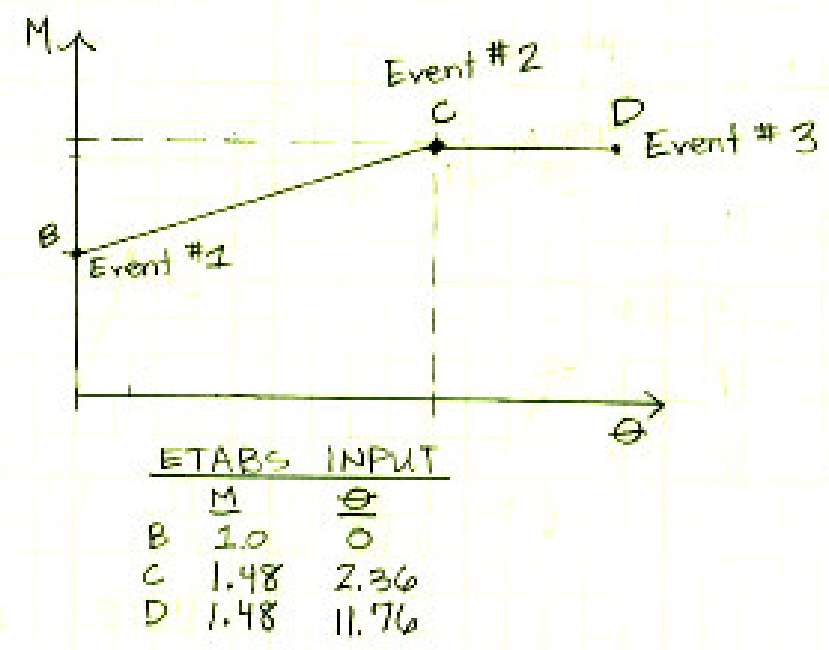

Event \#1-yieiding of the ductile rod

$$
\begin{aligned}
& M_{2}=12772 k^{\prime \prime} \quad \text { REF. } \\
& \phi_{y}=1.7 \varepsilon_{y} / h_{c}-1.7(0.00207) / 36^{\prime \prime}=0.0000978^{\mathrm{rad} / / \mathrm{in}} \text { (Priestley 2007) } \\
& \theta_{y B}=\theta_{2}=\phi_{y} L_{b} / 6=(0.0000178)\left(138^{N} \times 2\right) / 6=0.0045 \mathrm{rd} \operatorname{egn}(4.52)
\end{aligned}
$$

Event ti 2 - yielding of the dywidag bars

$$
M_{3}=18930 \mathrm{k}^{\prime \prime}
$$

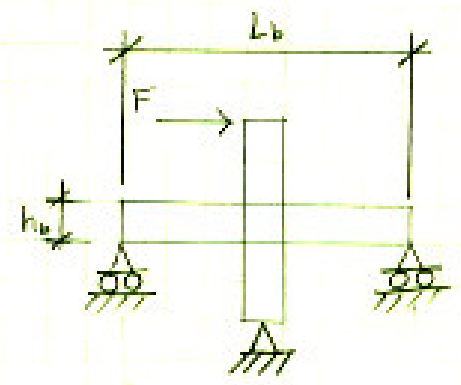

$$
\begin{aligned}
& \phi_{3}=1.7 \varepsilon_{y} / h_{c}=1.7(0.00489) / 36^{\prime \prime}=0.000231 \ldots e q n(4.57 d) \\
& \theta_{3}=\phi_{3} L_{6} / 6 \ldots \ldots \text { eqn }(4,52) \\
& \left.=(0.000231 \mathrm{rod} / \mathrm{s}) / 276^{\circ}\right) / 6 \\
& =0,0106 \mathrm{rad} \text {. } \\
& +\varepsilon_{y_{b}}=\frac{f_{y}}{E}=\frac{142 \mathrm{ks}}{29000 \mathrm{ksi}}=0.00489
\end{aligned}
$$

Event \#3-expected max, drift

$\%$ DRIFT $=5.29$

$\theta_{4}=0.0529$ 


\section{Appendix B}

\section{DDC \#2 Initial Stiffness}

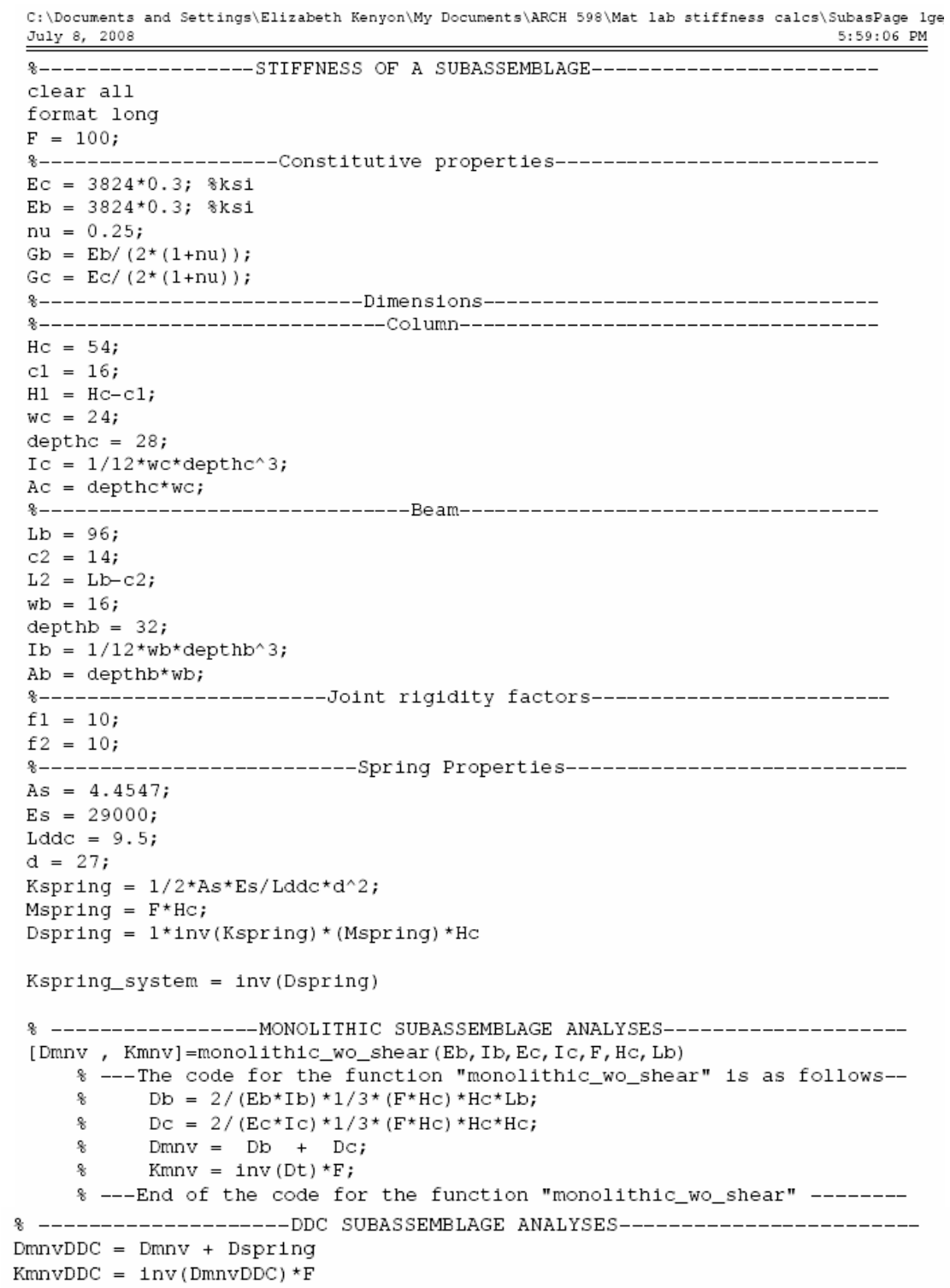

Kspring_system $=17.0$

Dmnv $=0.581$

$\mathrm{Kmnv}=172$

DmnvDDC $=0.640$

KmnvDDC $=156$

\section{OUTPUT}

(kips/in.), spring stiffness

(in.), Displacement of the monolithic system using $\mathrm{I}_{\mathrm{eff}}=0.3 \mathrm{I}_{\mathrm{g}}$ for both members

(kips/in.), Stiffness of the monolithic system using $\mathrm{I}_{\mathrm{eff}}=0.3 \mathrm{I}_{\mathrm{g}}$ for both members (in.), Displacement of the DDC system (kips/in.), Stiffness of the DDC system 


\section{DDC \#2 Column Shear at the Tension Rupture of the Concrete}

LATERAL FORCE \& $\triangle$ AT TENSILE RUPTURE OF THE BM $f_{r}=7.5 \sqrt{f_{c}^{\prime}}=7.5 \sqrt{4500}=403 p 5 i \ldots$ REF. (ACI 2005) eqn $(9-10)$ $I_{y}=\frac{1}{12} b h^{3}=\frac{1}{12}\left(16^{\circ}\right)\left(32^{\prime}\right)^{3}=43,69 / \mathrm{in}^{4} \ldots$ (for the beam) $y_{t}=h / 2=16^{\prime \prime}$ SUBASSEMBLAGE STIFFNESS

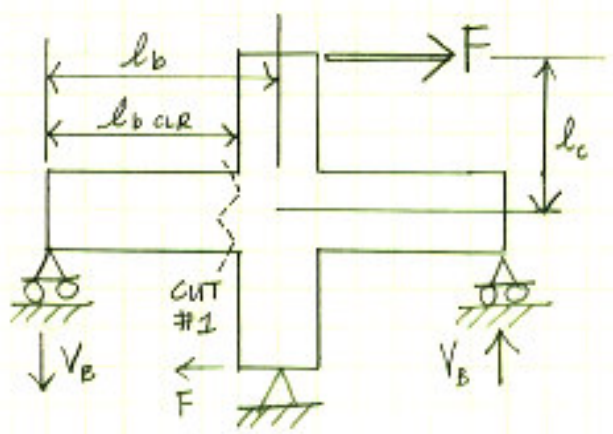

BEAM CROSS SECTION

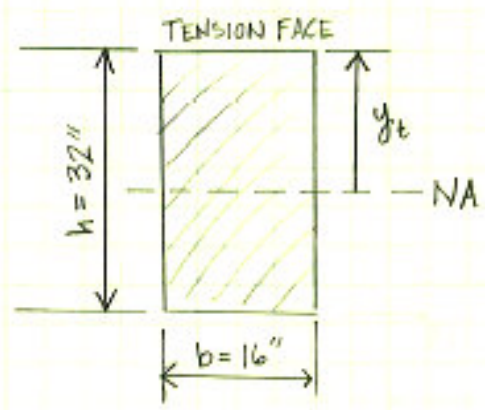

MOMENT AT CUT \#1

$$
M_{c r}=\frac{f_{r} I_{g}}{y_{t}}=\frac{0.403 k \operatorname{si}\left(43,69 \mathrm{lin}^{4}\right)}{16^{\prime \prime}}=1,101 \mathrm{k}^{\prime \prime}, \ldots \operatorname{REF} \cdot(\operatorname{ACl} 2005)
$$

\section{DISPLACEMENT}

From MATLAB, using virtual work where the ductile rod is represenied as a ratutional spring, the initial stiffness of DDC\#1 is...

$$
K_{i}=156 \mathrm{k} / \mathrm{in}
$$

Referring to the subassemblage schematic above,

$$
F=\operatorname{Mer}\left(\ell_{b} / \ell_{b c L R}\right) / \ell_{c}=1100.5 k^{\prime \prime}\left(96^{\prime \prime} / 82^{\prime \prime}\right) / 54^{\prime \prime}=23.9 \mathrm{~K}
$$

Therefore,

$$
\begin{aligned}
& \Delta c r=F / K_{i}=23.9 \mathrm{k} /(156 \mathrm{k} / \mathrm{in})=0.153^{\prime \prime} \\
& \% D R I F T=\Delta c r /\left(2 \cdot \ell_{c}\right)=0.153 \%(54 \% 2) \times 100=0.142 \%
\end{aligned}
$$




\section{DDC \#2 Column Shear at Yielding of the Ductile Rods}

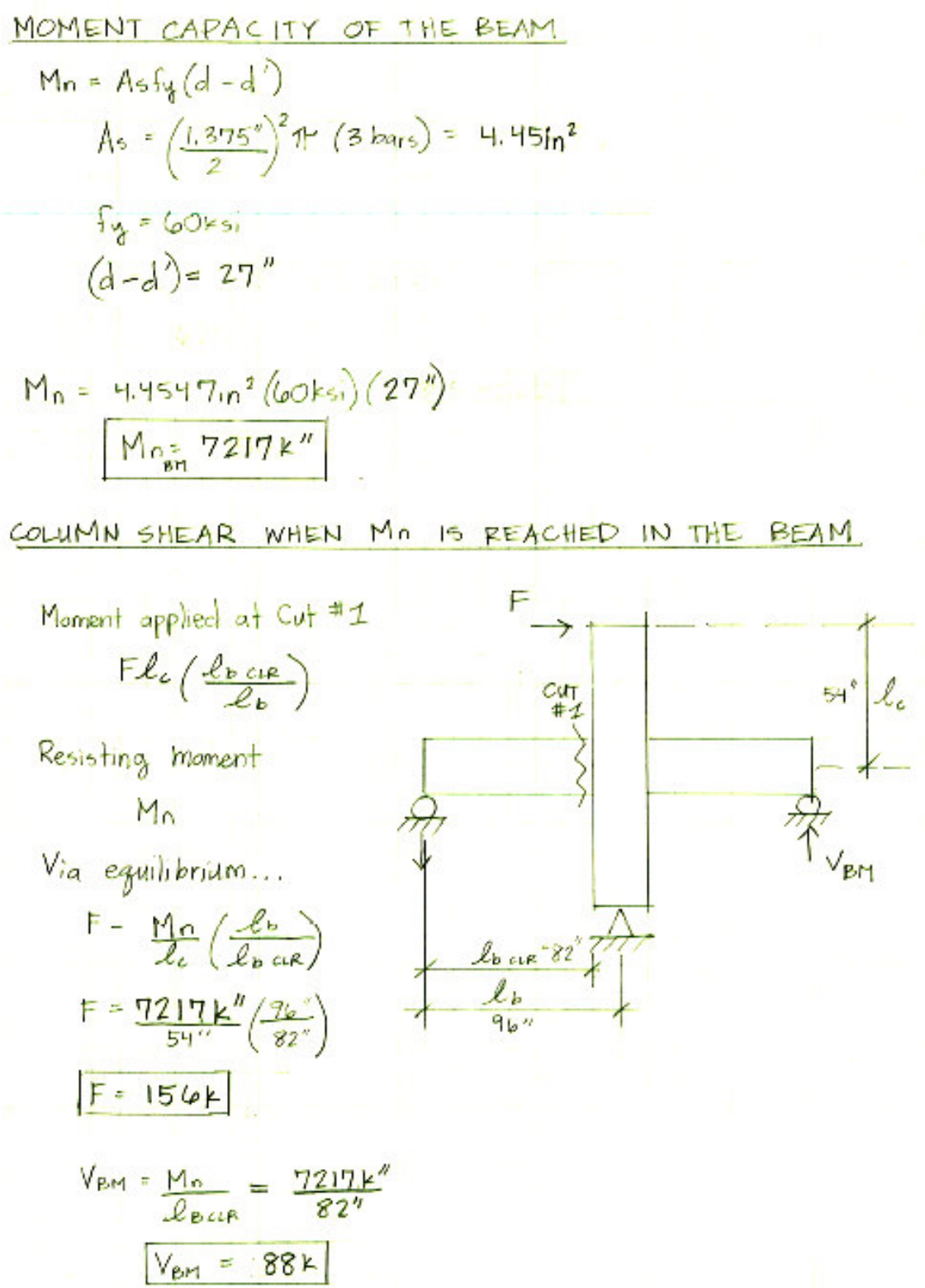




\section{DDC \#2 Predicted Displacement at Yield}

$$
\begin{aligned}
& \text { SUBASSEMBLAGE DISPLACEMENT PREPICTIONS } \\
& \varepsilon_{y}=\frac{f_{y}}{E}=\frac{60 \mathrm{ksi}}{29000 \mathrm{ksi}}=0.00207 \\
& \text { YIELD ROTATION } \\
& \theta_{y}=\frac{0.5 \varepsilon_{y} L_{b}}{h_{b}}=\frac{0.5(0.00207)\left(96^{\prime \prime} \times 2\right)}{32^{\prime \prime}} 0.00621 \mathrm{rad} \text {. ? } \\
& \text { REF. (Priestley 2007) } \\
& \text { eqn. } 4.54 \mathrm{pg} .162 \\
& \Delta_{y}=\theta_{y} l_{c}(z)=0.00621 \mathrm{rad}\left(54^{\prime \prime}\right)(2)=0.671^{\prime \prime} \\
& \% \text { DRIFT }=\Delta y /\left(2 l_{c}\right)=0.671^{\prime \prime} /(2 \times 5411) * 100=0.621 \%
\end{aligned}
$$

\section{DDC \#2 Column Shear at Yielding of the Dywidag Bars}

$$
\begin{aligned}
& \begin{array}{l}
\text { FORCE IN THE COLUMN ASSOCIATED WITH } \\
\text { YIELDING OF THE DYWIDAG BARS }
\end{array} \\
& M_{n}=A_{s} f_{y}(d-3 / 2) \\
& A_{s}=2\left(1.56 \mathrm{in}^{2}\right)=3.12 \mathrm{in}^{2} \\
& \tau \text { \#II size threaded bars } \\
& f_{y}=120 \mathrm{ksi} \\
& d=32-2.5=29.5 \\
& a=\frac{\text { Asfy }}{0.85 f_{c}^{\prime} b}=\frac{3.1 \mathrm{zin}^{2}(140 \mathrm{ksi})}{0.85(4.5 \mathrm{ksi})\left(16^{\prime \prime}\right)}=7.13^{\prime \prime} \\
& M_{n}=3.12 \mathrm{in}^{2}(120 \mathrm{ksi})\left(29.5^{\prime \prime}-7.13^{\prime \prime} / 2\right) \\
& M_{n}=9710^{\prime \prime} k^{\prime \prime} \\
& F_{B M}=\frac{M_{n}}{l_{\text {BCLR }}}=\frac{9710 k^{\prime \prime}}{82^{\prime \prime}}=F_{B M}=118 \mathrm{k} \\
& F_{\text {COL }}=\frac{M_{n}}{l_{c}}\left(\frac{l_{b}}{l_{b C R R}}\right)=\frac{9710 k^{\prime \prime}}{54^{\prime \prime}}\left(\frac{96^{\prime \prime}}{82^{\prime \prime}}\right) \\
& F_{C O L}=211 \mathrm{~K}
\end{aligned}
$$


Appendix

92

DDC \#2 Determining Rigid Link Length

RIGID LINK LENGTH WIN JOINT

MOMENT CAPACITY OF THE COLUMN

* A simplified approach to calculating moment capacity will be used

$$
\begin{aligned}
& M_{n}=A_{s} f_{y}(d-a / 2) \\
& A_{s}=(6)+9 \\
& =6 \mathrm{in}^{2} \\
& f_{y}=60 k s i \\
& a=\frac{\text { Ashy }}{0.85 f_{c} b}=\frac{6 \mathrm{in}^{2}(60 \mathrm{ksi})}{0.85(4.5 \mathrm{ksi})\left(24^{\prime \prime}\right)}=3.92 \mathrm{in} \\
& M_{n} \sim\left(6 \mathrm{in}^{2}\right)(60 \mathrm{ksi})\left(25.5^{\prime \prime}-3.92 \% / 2\right) \\
& M_{n}=8474 k^{\circ}
\end{aligned}
$$

(6) $\# 9$

(12 TONAL)

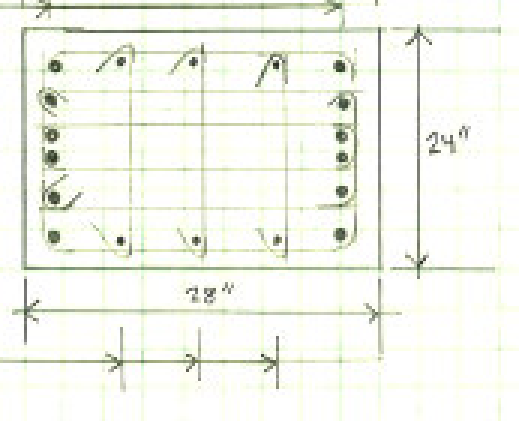

RATIO OF MOMENTS @ THE JOINT

$$
\frac{M_{n_{\text {COL }}}}{M_{n B M}}=\frac{8474 k^{\prime \prime}}{7150 k}=1.19 \sim 1.2
$$

If $\frac{M_{n_{C O L}}}{M_{n_{B M}}}>1.2$ then the article recommends

modeling the colurrin as fully rigid $\mathrm{w} / \mathrm{in}$ the joint \& the beam as fully flexible.

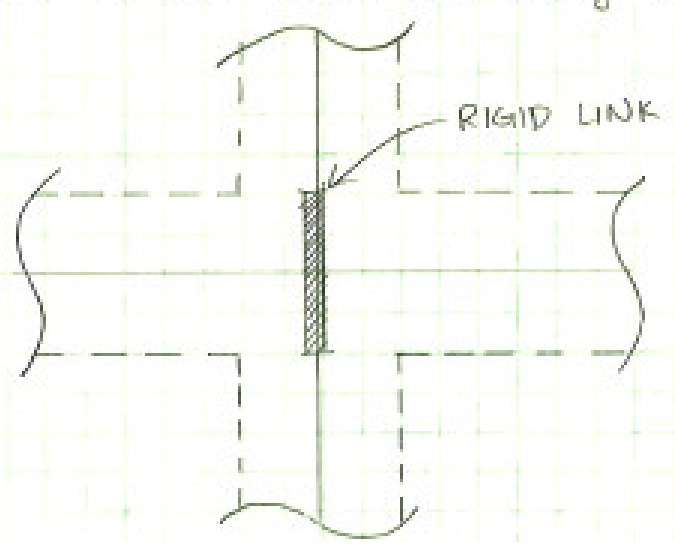




\section{DDC \#2 ETABS Nonlinear Hinge Properties}

DEFINING THE FRAME NON-LINEAR HINGE PROPERTES

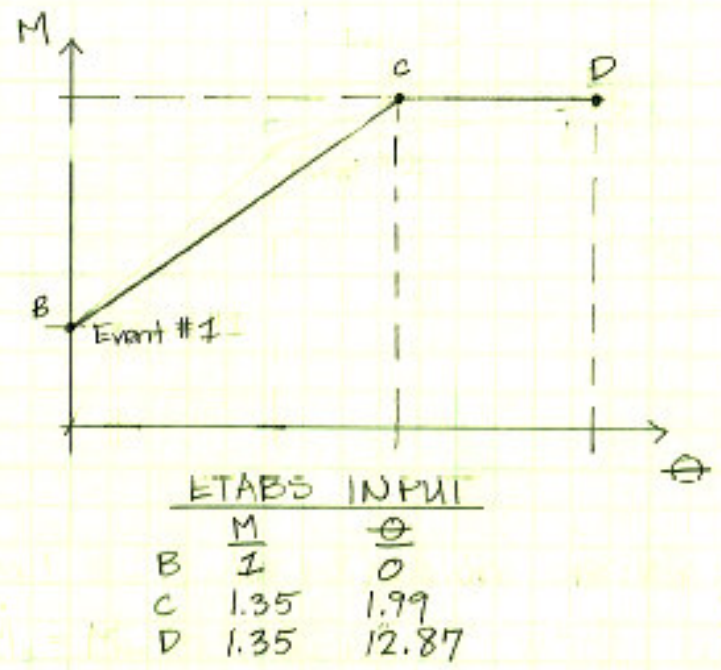

Event ${ }^{*} 2$ - yielding of the ductile rod

$$
M_{2}=7217 k^{\prime \prime}
$$

$$
\begin{aligned}
& \phi_{y}=1.7 \varepsilon_{y} / h_{c}=1.7(0.00207) / 32^{\prime \prime}=0.00011 \frac{\mathrm{rad}}{\mathrm{in}} \ldots \operatorname{eqn}(4.57 \mathrm{~b}) \\
& \theta_{y_{B}}=\theta_{z}=\phi_{y} L_{b} / 6=0.00011\left(96^{\prime \prime} \cdot 2\right) / 6=0.00352 \mathrm{rad} \ldots \operatorname{egn}(4.52)
\end{aligned}
$$

Event \#3-yielding of the dywiddg bars

$$
\begin{aligned}
& M_{3}=9710 \mathrm{k}^{\prime \prime} \\
& L_{b}=192^{\prime \prime} ; h_{b}=32^{\prime \prime} ; \varepsilon_{y}=\frac{f_{y}}{E}=\frac{120 \mathrm{ksi}}{29000 \mathrm{ksi}}=0.00413 \\
& \phi_{3}=1.7 \varepsilon_{y} / h_{c}=1.7(0.00413) / 32^{\circ}=0.000219 \mathrm{rad} / \mathrm{in} \ldots-\operatorname{egn}(4.57 \mathrm{~d}) \\
& \theta_{3}=\phi_{3} L_{b} / 6=(0.000219)\left(192^{\prime \prime}\right) / 6=0.00702 \mathrm{rdd} \ldots \ldots \text { eq }(4.52) \\
& \text { Event } \# 4-\text { expected max drift (rough est.) } \\
& \% \text { DRIFT }=4.53 \% \\
& \theta_{4}=0.0453
\end{aligned}
$$$$
L_{b}=192^{\prime \prime} ; h_{b}=32^{\prime \prime} ; \varepsilon_{y}=\frac{f_{y}}{E}=\frac{120 \mathrm{ksi}_{\mathrm{s}}}{29000 \mathrm{ksi}}=0.00413
$$$$
\theta_{3}=\phi_{3} L_{6} / 6=(0.000219)\left(192^{\prime \prime}\right) / 6=0.00702_{r a d} \ldots . e g n(4.52)
$$ 


\section{Appendix C}

\section{Super Hybrid Initial Stiffness}

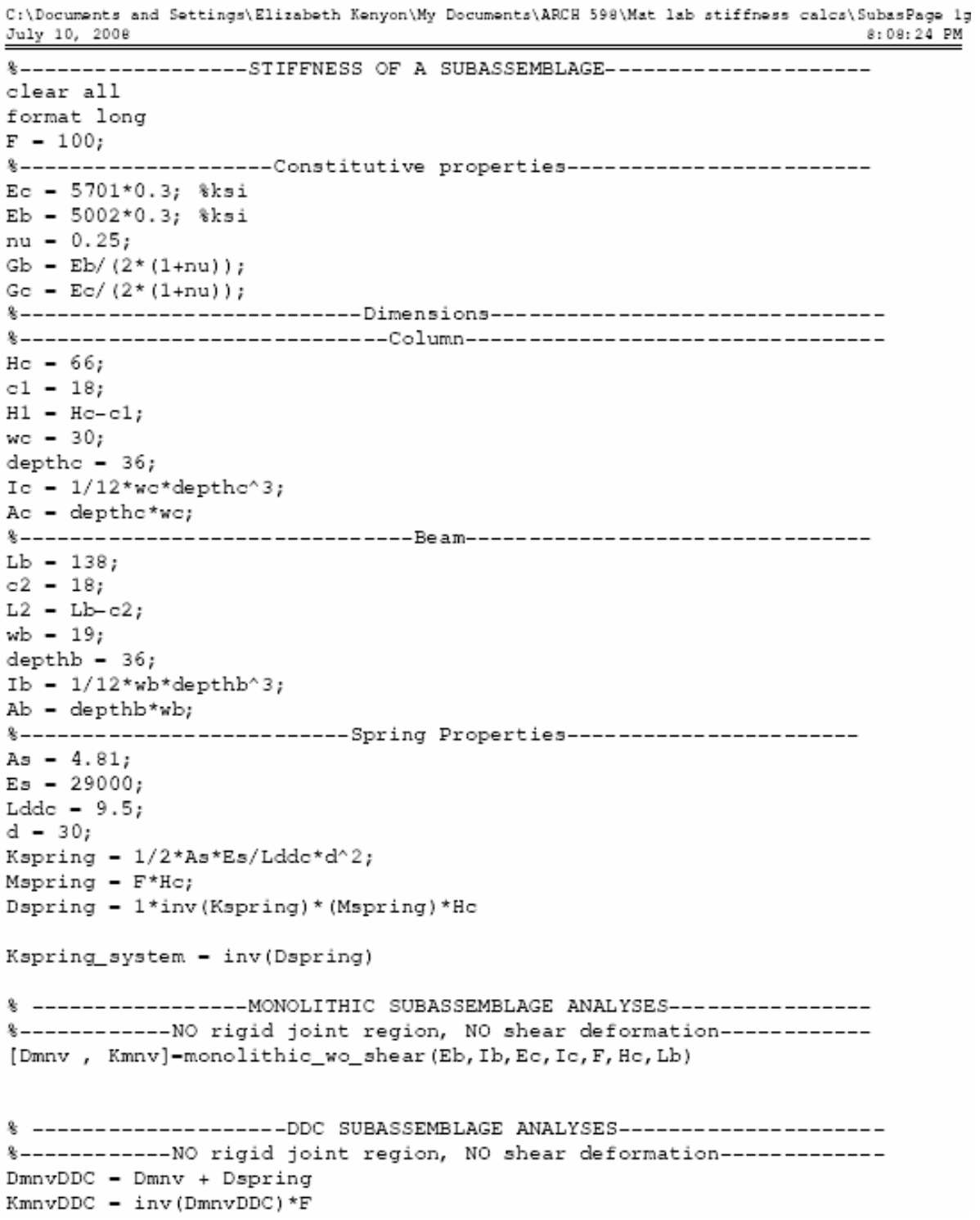

Kspring_system $=15.2$

Dmnv $=0.458$

$\mathrm{Kmnv}=219$

DmnvDDC $=0.524$

KmnvDDC $=191$

\section{OUTPUT}

(kips/in.), spring stiffness

(in.), Displacement of the monolithic system using $\mathrm{I}_{\text {eff }}=0.3 \mathrm{I}_{\mathrm{g}}$ for both members

(kips/in.), Stiffness of the monolithic system using $\mathrm{I}_{\text {eff }}=0.3 \mathrm{I}_{\mathrm{g}}$ for both members

(in.), Displacement of the DDC system

(kips/in.), Stiffness of the DDC system 


\section{$\underline{\text { Super Hybrid Column Shear at the Tension Rupture of the Concrete }}$}

$$
\begin{aligned}
& \text { LATERAL FORCE \& } \triangle \text { AT TENSILE RUPTURE OF THE } \\
& \text { CONCRETE BEAM } \\
& M_{c r}=T_{i} h_{b} \ldots \ldots \ldots \ldots \text { REFERENCE } \\
& \frac{6}{6} \quad \text { (Priestley 2007) } \\
& T_{i}=\text { the initial total prestress force }=450^{k} \quad \text { Eqn }(5.67) \\
& h_{b}=\text { beam depth }=36^{\prime \prime} \\
& M_{c r}=\frac{450^{k}\left(36^{\prime \prime}\right)}{6}=2700 k^{\prime \prime} \\
& \text { Using Kinitial }=219 \mathrm{k} / \mathrm{in} \\
& \text { which is calculated earlier an is the stiffness of } \\
& \text { a monolithic system which does not account for } \\
& \text { the prestressing. } \\
& F=\frac{M_{c r}}{l_{b-u R}}=\frac{2700 k^{\prime \prime}}{120^{\prime \prime}}=22.5^{k} \\
& \Delta=\frac{F}{K_{\text {initial }}}=\frac{22.5^{k}}{219 k / \mathrm{in}}=0.103^{\prime \prime} \\
& \% \text { DRIFT }=\frac{\Delta}{L_{b}}=\frac{0.103^{\prime \prime}}{276^{\prime \prime}}=0.000373
\end{aligned}
$$

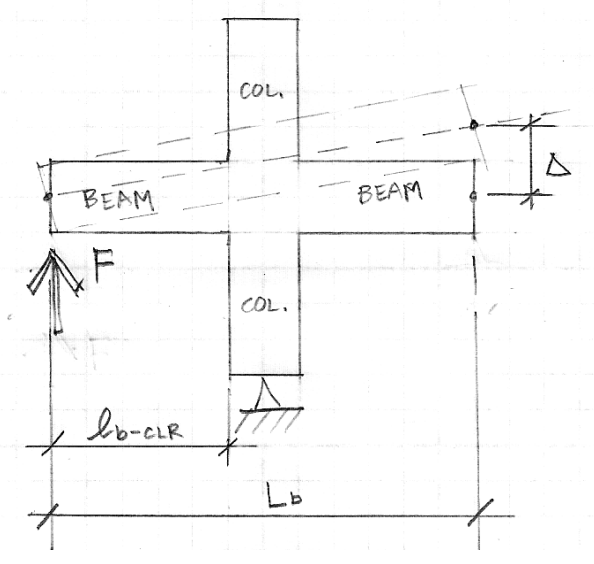




\section{Super Hybrid Column Shear at Yielding of the Ductile Rods}

MOMENT CAPACTIY OF THE BEAM

$$
\begin{aligned}
M_{n}= & A_{s} f_{y}\left(d-d^{\prime}\right)+A_{s p} f_{p e}\left(n / 2-d^{\prime}\right) \\
& A_{s}=2\left(2.4 \mathrm{in}^{2}\right)=4.82 \mathrm{in}^{2} \\
& f_{y}=60 \mathrm{ks} . \\
& \text { According to (Chang, Hutchinson, 专 Englekirk 2007) } \\
& \text { the force on the system due to the PT is } 450 \mathrm{~K}
\end{aligned}
$$$$
\text { Therefore, }
$$$$
A_{\text {spp }} f_{p e}=450 \mathrm{~K}
$$$$
h=36^{\prime \prime}
$$$$
d^{\prime}=3^{\prime \prime}
$$$$
d=33^{\prime \prime}
$$$$
M_{n}=\underbrace{4.8 \operatorname{in}^{2}(60 k-1)\left(33^{\prime \prime}-3^{\prime \prime}\right)}_{M_{s}=8676 k^{\prime \prime}}+\underbrace{450 k\left(36^{\prime \prime} / 2-3^{\prime \prime}\right)}_{M_{P T}=6750 k "}
$$

$\%$ of moment due to the PT $=\frac{M_{P T}}{M_{n}}=43.8 \%$

$$
M_{n}=15426 k^{\prime \prime}
$$

COL./BM SHEAR WHEN Mn IS REACHED IN THE BEAM Via equilitorium,

$$
\begin{gathered}
F=\frac{M_{n}}{l_{c}}\left(\frac{l_{0}}{l_{b C L R}}\right)=\frac{15426 k^{\prime \prime}\left(96^{\prime \prime}\right)}{54^{\prime \prime}\left(82^{\prime \prime}\right)} \\
F=334 k \\
V_{B}=M_{n} / l_{\text {DCLR }}=15426 \mathrm{k}^{\prime \prime} / 82^{\prime \prime} \\
V_{B}=188^{\mathrm{k}}
\end{gathered}
$$

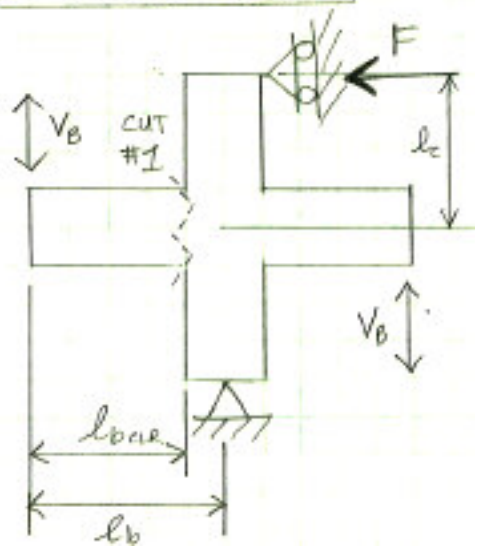




\section{$\underline{\text { Super Hybrid Predicted Displacement at Yield }}$}

\section{SUBASSEMBLAGE YIELD DISPLACEMENT}

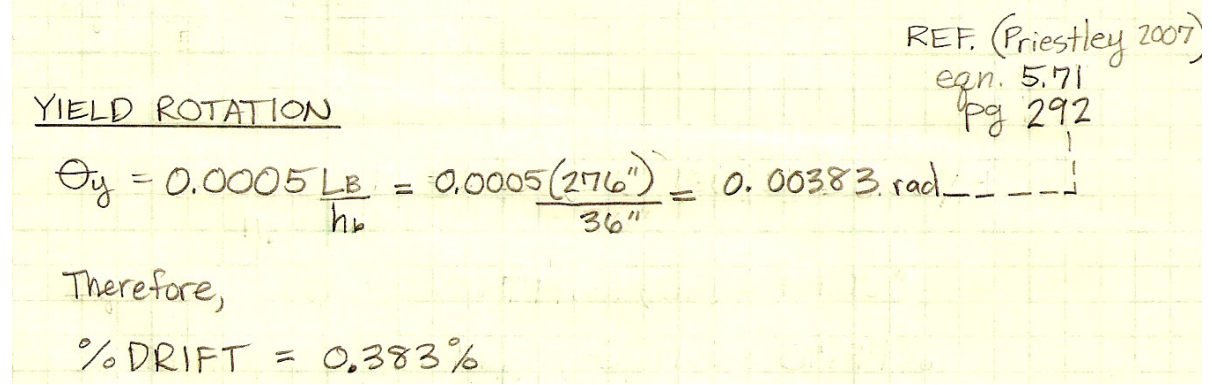

\section{Super Hybrid Column Shear at Yielding of the Dywidag Bars}

$$
\begin{aligned}
& \text { MOMENT CAPACITY AT YIELDING OF THE DYWIDAG BARS } \\
& M_{n}=A_{s} f_{y}(d-a / 2)+A_{s p} f_{p s}(h / 2-a / 2) \\
& \text { * assuming the yield stress is close to initial stress } \\
& \text { after losses does not include the slab in calculation } \\
& A_{s f y}+A_{s p f p s}=0.85 f^{\prime} \mathrm{ab} \\
& a=\frac{A_{s} f y+A s p f p s}{0.85 f^{\prime} c b} \\
& A_{s}=2.4 \mathrm{lin}^{2}(2 \text { bars })=4.82 \mathrm{in}^{2} \\
& f_{y}=140 \mathrm{ksi} \\
& \text { Asp. fps }=450 \mathrm{kip} \\
& f_{C}^{\prime}=7.7 \mathrm{ksi} \\
& b=19^{\prime \prime} \\
& a=\frac{4.82 \mathrm{in}^{2}(140 k s i)+450 k}{0.85(7.7 k s i)\left(19^{\prime \prime}\right)}=9.05^{\prime \prime} \\
& M_{n}=4.82 \mathrm{in}^{2}(140 \mathrm{ksi})\left(33^{\prime \prime}-9.05^{\prime \prime} / 2\right)+450 k\left(36^{\prime \prime} / 2-9.05 \prime / 2\right) \\
& M_{n}=25,279 k^{\prime \prime}
\end{aligned}
$$




\section{Super Hybrid Determining Rigid Link Length}

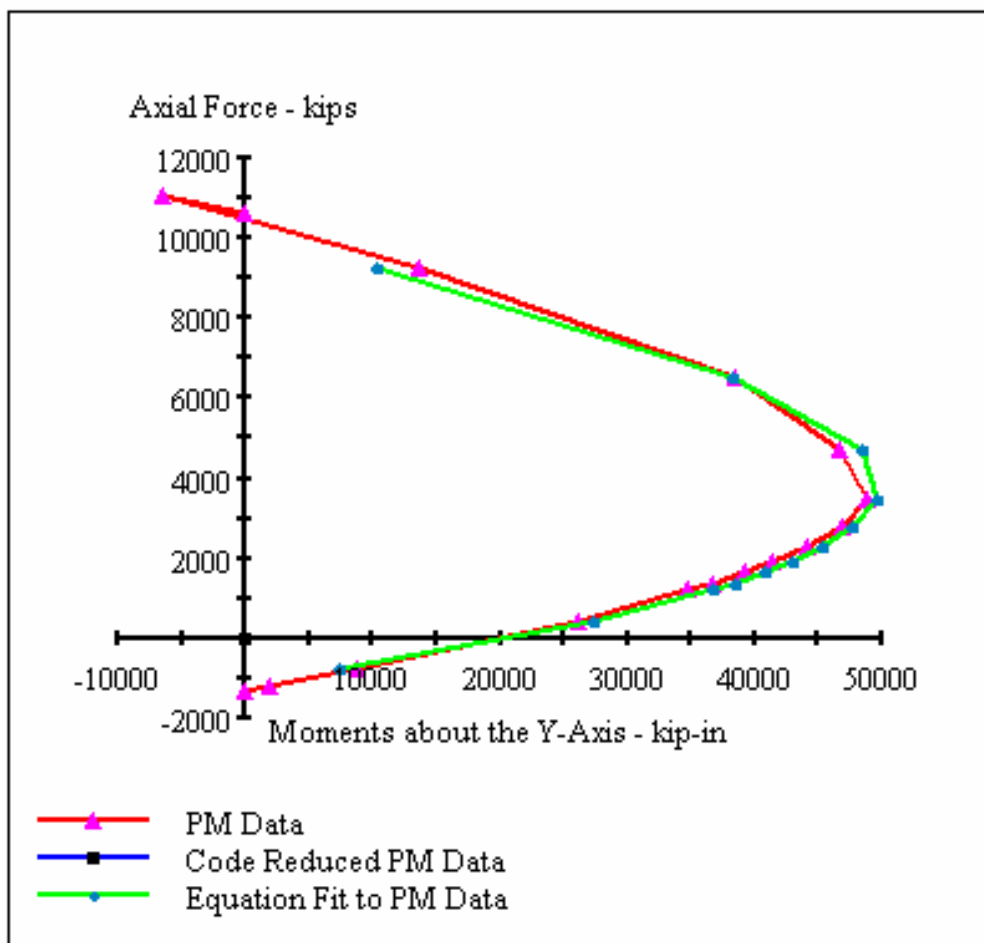

Figure 53: Interaction diagram from XTRACT of the super hybrid column

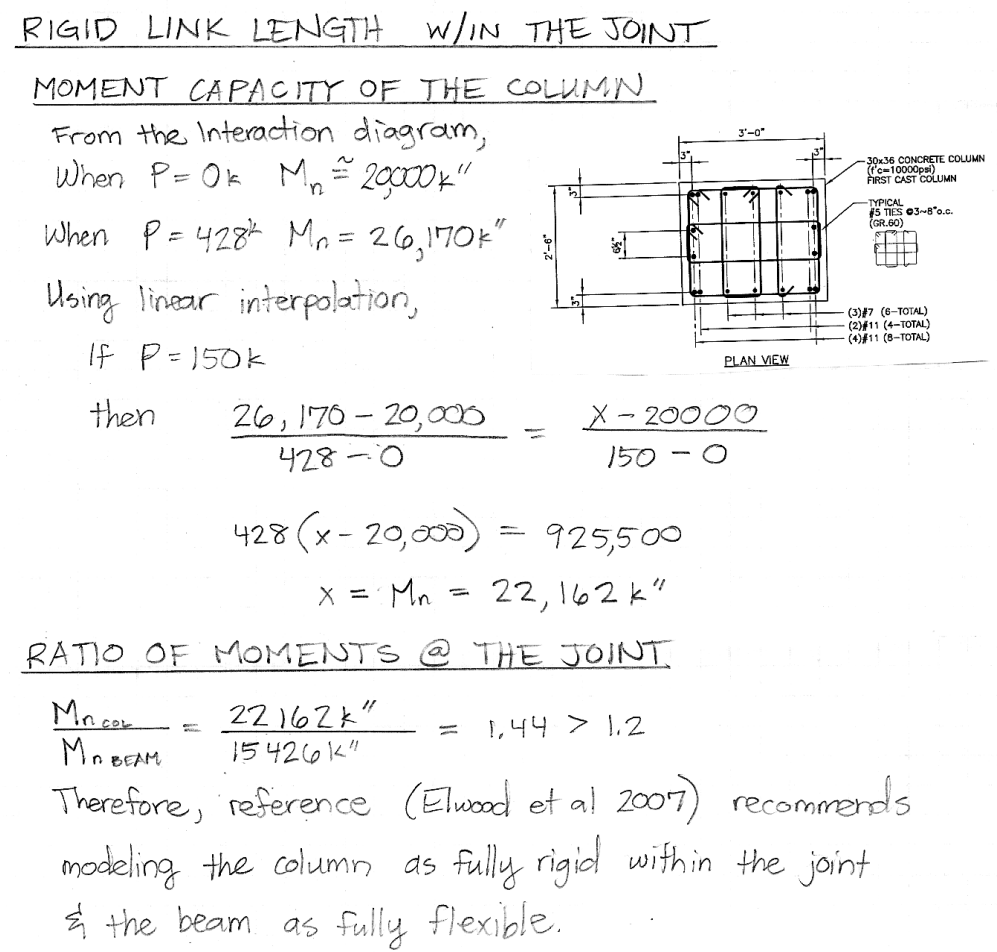




\section{Appendix D}

\section{DDC \#1 XTRACT Input Properties}

Table 6: DDC \#1 XTRACT input beam properties

\begin{tabular}{|c|c|}
\hline Details & DDC \#1 (Pankow \#4) \\
\hline \multicolumn{2}{|c|}{ Confined Concrete Strength Calculation } \\
\hline Type of transverse reinforcing & Rectangular hoops \\
\hline Transverse reinforcing bar yield stress (ksi) & 60 \\
\hline $\mathrm{X}$ transverse reinforcing steel ratio ${ }^{1}$ & 0.0034 \\
\hline $\mathrm{Y}_{\text {transverse reinforcing steel ratio }}{ }^{1}$ & 0.00139 \\
\hline Average distance between tied longitudinal bars (in) ${ }^{2}$ & 17.3 \\
\hline Number of longitudinal bars around core & 6 \\
\hline Confined core area $\left(\mathrm{in}^{2}\right)$ & 627 \\
\hline \multirow[t]{2}{*}{ Tie spacing along member (in) } & (varying) \\
\hline & 8" o.c. \\
\hline 28-Day compressive concrete strength $(\mathrm{ksi})$ & 5.5 \\
\hline Confined concrete strength $(\mathrm{ksi})^{3}$ & 6.049 \\
\hline \multicolumn{2}{|c|}{ Crushing Strain Calculation } \\
\hline Transverse reinforcing steel strain at fracture (in/in) & 0.12 \\
\hline Transverse (volumetric) reinforcing steel ratio ${ }^{4}$ & 0.0048 \\
\hline Crushing strain, $\varepsilon_{\mathrm{cu}}^{3,6}$ & 0.012 \\
\hline \multicolumn{2}{|c|}{ Mander's Confined Concrete Curve Calculation } \\
\hline Tension Strength (ksi) & -0.556 \\
\hline Yield Strain, $\varepsilon_{\mathrm{cy}}{ }^{5}$ & 0.002029 \\
\hline Concrete Elastic Modulus (ksi) $^{7}$ & 4246 \\
\hline \multicolumn{2}{|c|}{ Unconfined Concrete Curve Calculation } \\
\hline Yield Strain $^{5}$ & 0.0014 (default) \\
\hline Crushing Strain $^{6}$ & 0.004 (default) \\
\hline Spalling Strain ${ }^{8}$ & 0.006 (default) \\
\hline Post Crushing Strength ${ }^{9}$ & 0 (default) \\
\hline Failure Strain ${ }^{10}$ & 1 \\
\hline \multicolumn{2}{|l|}{ 1. X Transverse Steel Reinforcing Ratio $\left(\rho_{\underline{x}}\right):$} \\
\hline \multicolumn{2}{|c|}{$\begin{array}{l}\text { The transverse reinforcing ratio in one of the two principal directions. This } \\
\text { ratio can be calculated by taking a 'cut' across the section in the ' } \mathrm{X} \text { direction'. The } \\
\text { ratio may be calculated as follows: }\end{array}$} \\
\hline \multicolumn{2}{|c|}{$\begin{array}{l}\qquad \mathrm{r}_{\mathrm{x}}=\text { (the total area of all transverse steel the cut passed through within a depth } \\
\text { of one transverse reinforcement spacing) } /[(\text { the section dimension in the } \mathrm{X} \\
\text { direction }) *(\text { transverse reinforcement spacing })] \text {. }\end{array}$} \\
\hline 2. Average Distance Between Tied Longitudinal Bars: & \\
\hline
\end{tabular}




\section{Previous Table (cont'.): DDC \#1 XTRACT Input Beam Properties}

\begin{tabular}{|c|}
\hline This is the (perimeter of the core section) / (number of perimeter longitudinal \\
\hline 3. Calculated by XTRACT using Mander's model \\
\hline 4. Transverse (volumetric) reinforcing steel ratio: \\
\hline$\rho=\rho_{x}+\rho_{y}$ \\
\hline 5. Yield Strain $\left(\varepsilon_{\text {cy }}\right)$ \\
\hline $\begin{array}{l}\text { Concrete compression yield strain is typically never used in design; however, } \\
\text { because the limit state of the 'Yield Moment' is controlled by the first yield of any } \\
\text { material, XTRACT requires this parameter. A reasonable value (the default) is } 70 \% \text { of } \\
\text { the strain at peak stress }\left(f_{c c} \text { )- for this project, XTRACT uses the default value. }\right. \\
\text { Because the strain at peak stress for unconfined concrete is typically } .002 \text {, the default } \\
\text { for this parameter becomes } 0.0014 \text {. }\end{array}$ \\
\hline 6. Crushing strain, $\varepsilon_{\mathrm{cu}}$ \\
\hline $\begin{array}{l}\text { Crushing strain is associated with the concrete strain that occurs at the same } \\
\text { time as hoop or transverse reinforcing fracture. If the section satisfies ACI } 318-95 \\
\text { Chapter } 21 \text { design requirements, crushing strain may be assumed at } .015 \text {. If a more } \\
\text { detailed calculation is required, this may be used. To calculate the confined crushing } \\
\text { strain, the user may use the Crushing Strain Calculator or may enter the values directly. } \\
\text { For unconfined crushing strain, the default is assumed to be } 0.004 \text {. This correlates well } \\
\text { for bending failures with some inherent conservatism. The ACI value and lower bound } \\
\text { is typically taken as .003. }\end{array}$ \\
\hline 7. Concrete Elastic Modulus: \\
\hline 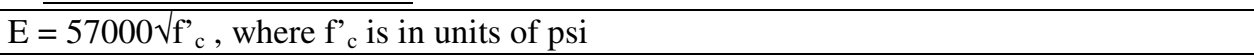 \\
\hline 8. Spalling Strain $\left(\varepsilon_{\mathrm{sp}}\right)$ : \\
\hline Strain at completion of material spalling. Default is 0.006 . \\
\hline 9. Post Crushing Strength $\left(\mathrm{f}_{\mathrm{c} p}\right):$ \\
\hline $\begin{array}{l}\text { Strength of unconfined concrete after spalling. The default value of } 0 \text { is used } \\
\text { in this project. }\end{array}$ \\
\hline 10. Failure Strain: \\
\hline $\begin{array}{l}\text { "Because in analyzing a confined concrete section (section with significant } \\
\text { transverse reinforcement) for its nonlinear behavior, the confined core will typically } \\
\text { have a compression strain capacity that far exceeds that of the cover (or unconfined) } \\
\text { concrete this value can be different than the crushing strain. For unconfined concrete on } \\
\text { a confined concrete section, the strain to end computation (the ultimate limit state) will } \\
\text { be different than the crushing strain. }\end{array}$ \\
\hline $\begin{array}{l}\text { This is the input value that terminates the Moment Curvature analysis: i.e. If } \\
\text { the user was performing a moment curvature analysis of an unconfined section, this } \\
\text { value should be set to .004. If the section is confined and cover spalling is not the } \\
\text { desired quantity to terminate the analysis (the ultimate limit state), then this value } \\
\text { should be set to } 1.0 \text { (or a high number so as to not control failure). Default is } 0.0 \text { so as } \\
\text { to remind the user of the importance of this parameter."(Chadwell 2007). For this } \\
\text { project the failure strain is set to } 1.0 \text {. }\end{array}$ \\
\hline $\begin{array}{l}11 \text { Information provided by reference (SEQAD Consulting Engineers 1993) } \\
{ }^{12} \text { Calculated using the following equation: } \mathrm{f}_{\mathrm{t}}=7.5 \sqrt{\mathrm{f}}{ }_{\mathrm{c}} \text { (ACI 2005): equation (9-10). } \\
{ }^{13} \text { In the case of these variables, information was not provided and engineering judgment } \\
\text { in conjunction with other references was used to determine these values } \\
{ }^{14} \text { Values were used here from the Dywidag material tests conducted in conjunction with } \\
\text { the } 2007 \text { Pankow series testing conducted at UCSD, research done separately from the } \\
\text { SEQAD research } \\
{ }^{*} \text { For all other footnotes see DDC \#1 Appendices }\end{array}$ \\
\hline
\end{tabular}


Table 7: DDC \#1 XTRACT input column properties

\begin{tabular}{|c|c|}
\hline Details & DDC \#1 (Pankow \#4) \\
\hline \multicolumn{2}{|c|}{ Confined Concrete Strength Calculation } \\
\hline Type of transverse reinforcing & Rectangular hoops \\
\hline Transverse reinforcing bar yield stress (ksi) & 75 \\
\hline $\mathrm{X}$ transverse reinforcing steel ratio ${ }^{1}$ & 0.00646 \\
\hline$Y$ transverse reinforcing steel ratio ${ }^{1}$ & 0.00517 \\
\hline Average distance between tied longitudinal bars (in) ${ }^{2}$ & 6.66 \\
\hline Number of longitudinal bars around core & 18 \\
\hline Confined core area $\left(\right.$ in $\left.^{2}\right)$ & 891 \\
\hline \multirow[t]{2}{*}{ Tie spacing along member (in) } & (varying) \\
\hline & 6" o.c. \\
\hline 28-Day compressive concrete strength (ksi) & 9.58 \\
\hline Confined concrete strength $(\mathrm{ksi})^{3}$ & 11.7 \\
\hline \multicolumn{2}{|c|}{ Crushing Strain Calculation } \\
\hline Transverse reinforcing steel strain at fracture (in/in) & 0.12 \\
\hline Transverse (volumetric) reinforcing steel ratio ${ }^{4}$ & 0.01163 \\
\hline Crushing strain, $\varepsilon_{\mathrm{cu}}{ }^{3,6}$ & 0.01652 \\
\hline \multicolumn{2}{|c|}{ Mander's Confined Concrete Curve Calculation } \\
\hline Tension Strength (ksi) ${ }^{12}$ & -0.958 \\
\hline Yield Strain, $\varepsilon_{\mathrm{cy}}{ }^{5}$ & 0.002869 (default) \\
\hline Concrete Elastic Modulus (ksi) $^{7}$ & 5579 \\
\hline \multicolumn{2}{|c|}{ Unconfined Concrete Curve Calculation } \\
\hline Yield Strain ${ }^{5}$ & 0.0014 (default) \\
\hline Crushing Strain $^{6}$ & 0.004 (default) \\
\hline Spalling Strain ${ }^{8}$ & 0.006 (default) \\
\hline Post Crushing Strength $^{9}$ & 0 (default) \\
\hline Failure Strain ${ }^{10}$ & 1 \\
\hline $\mathrm{DC} \# 1 \mathrm{Be}$ & \\
\hline
\end{tabular}




\section{DDC \#1 PERFORM-3D Approximations}

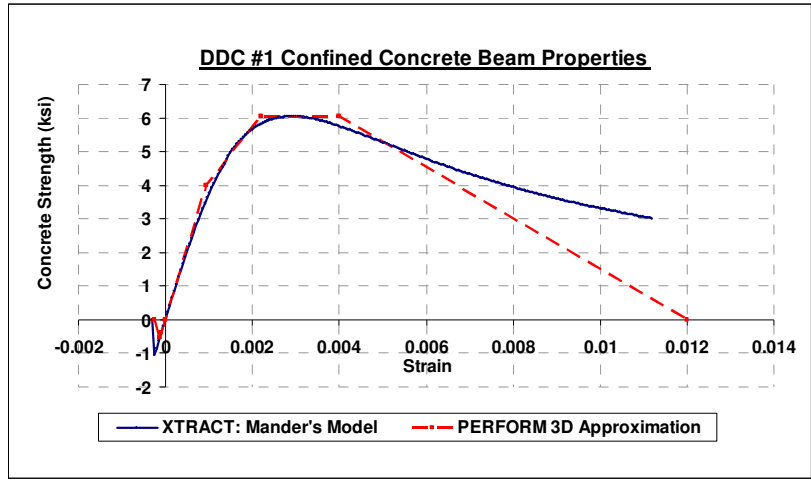

Figure 54: DDC \#1 approximate confined concrete beam constitutive properties

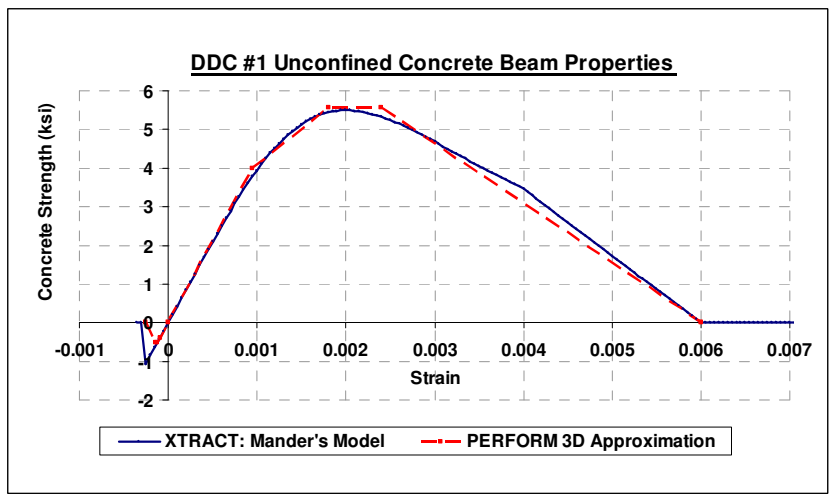

Figure 55: DDC \#1 approximate unconfined concrete beam properties

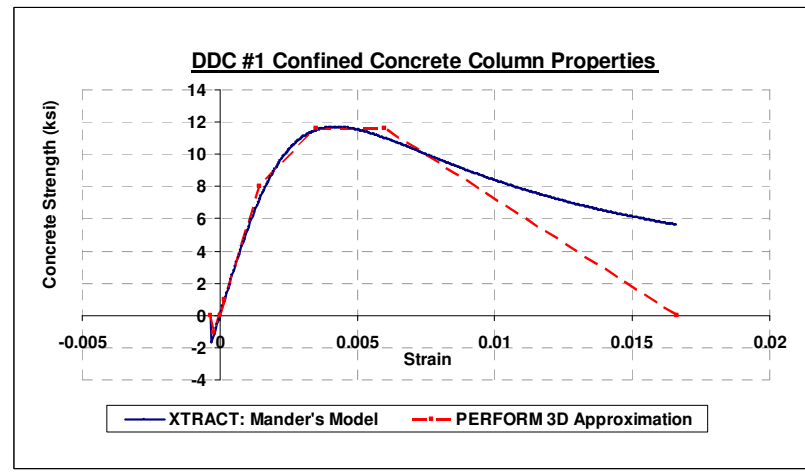

Figure 56: DDC \#1 approximate confined concrete column properties 


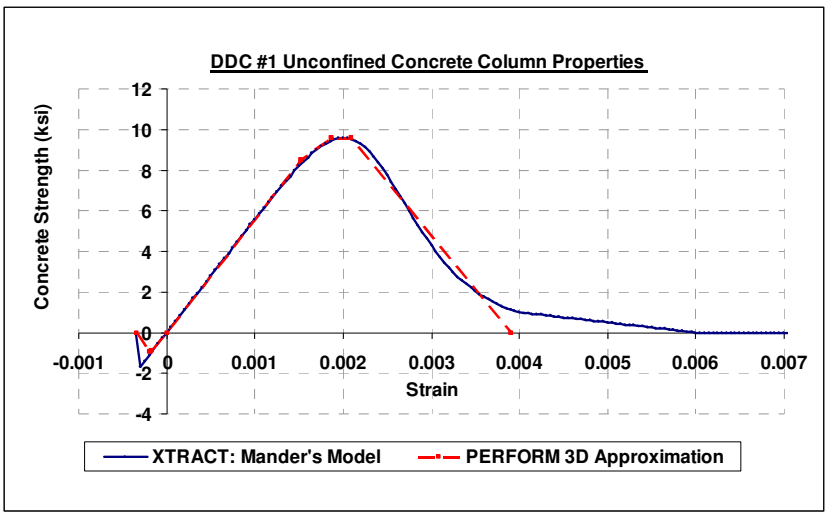

Figure 57: DDC \#1 approximate unconfined concrete column properties

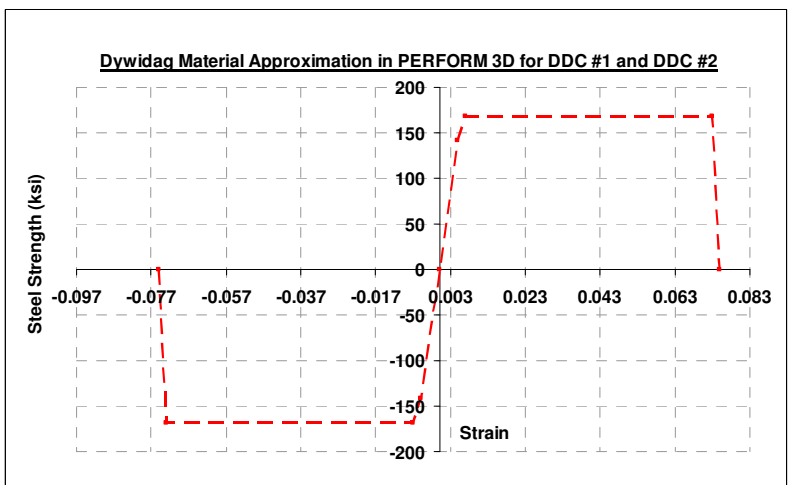

Figure 58: DDC \#1 approximate Dywidag properties

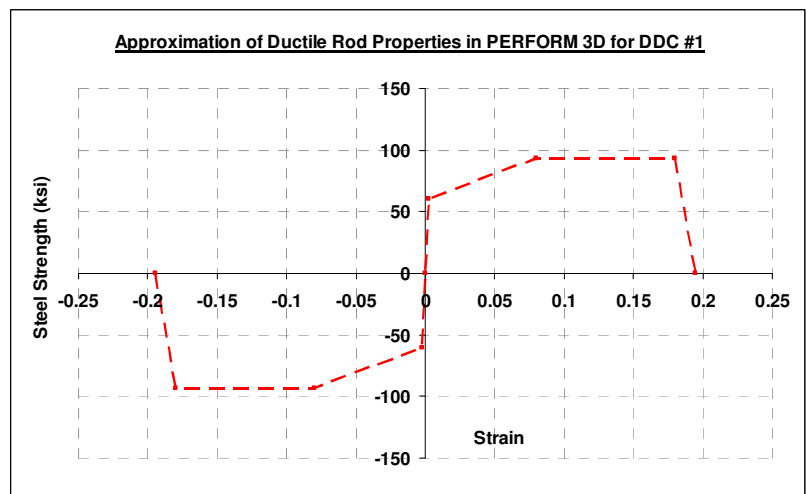

Figure 59: DDC \#1 approximate ductile rod properties 


\section{Appendix E}

\section{DDC \#2 XTRACT Input Properties}

Table 8: DDC \#2 XTRACT input beam properties

\begin{tabular}{|c|c|}
\hline Details & DDC \#2 (SEQAD \#1) \\
\hline \multicolumn{2}{|c|}{ Confined Concrete Strength Calculation } \\
\hline Type of transverse reinforcing & Rectangular hoops \\
\hline Transverse reinforcing bar yield stress $(\mathrm{ksi})^{11}$ & 66 \\
\hline $\mathrm{X}$ transverse reinforcing steel ratio ${ }^{1}$ & 0.00208 \\
\hline $\mathrm{Y}_{\text {transverse reinforcing steel ratio }}{ }^{1}$ & 0.00104 \\
\hline Average distance between tied longitudinal bars (in) ${ }^{2}$ & 21 \\
\hline Number of longitudinal bars around core & 4 \\
\hline Confined core area $\left(\mathrm{in}^{2}\right)$ & 377 \\
\hline \multirow[t]{2}{*}{ Tie spacing along member (in) ${ }^{11}$} & (varying) \\
\hline & 12" o.c. \\
\hline 28-Day compressive concrete strength (ksi) ${ }^{11}$ & 4.5 \\
\hline Confined concrete strength $(\mathrm{ksi})^{3}$ & 4.627 \\
\hline \multicolumn{2}{|c|}{$\begin{array}{l}\text { Crushing Strain Calculation } \\
\end{array}$} \\
\hline Transverse reinforcing steel strain at fracture (in/in) ${ }^{13}$ & 0.18 \\
\hline Transverse (volumetric) reinforcing steel ratio ${ }^{4}$ & 0.00312 \\
\hline Crushing strain, $\varepsilon_{\mathrm{cu}}{ }^{3,6}$ & 0.01522 \\
\hline \multicolumn{2}{|c|}{$\begin{array}{r}\text { Mander's Confined Concrete Curve Calculation } \\
\end{array}$} \\
\hline Tension Strength (ksi) ${ }^{12}$ & -0.402 \\
\hline Yield Strain, $\varepsilon_{\mathrm{cy}}{ }^{5}$ & 0.001598 \\
\hline Concrete Elastic Modulus (ksi) $^{7}$ & 3824 \\
\hline \multicolumn{2}{|c|}{$\begin{array}{l}\text { Unconfined Concrete Curve Calculation } \\
\end{array}$} \\
\hline Yield Strain $^{5}$ & 0.0014 (default) \\
\hline Crushing Strain ${ }^{6}$ & 0.004 (default) \\
\hline Spalling Strain ${ }^{8}$ & 0.006 (default) \\
\hline Post Crushing Strength ${ }^{9}$ & 0 (default) \\
\hline Failure Strain $^{10}$ & 1 \\
\hline \multicolumn{2}{|c|}{$\begin{array}{l}11 \text { Information provided by reference (SEQAD Consulting Engineers } 1993) \\
\left.{ }^{12} \text { Calculated using the following equation: } \mathrm{f}_{\mathrm{t}}=7.5 \sqrt{\mathrm{f}}{ }_{\mathrm{c}} \text { (ACI } 2005\right) \text { : equation }(9-10) \text {. } \\
{ }^{13} \text { In the case of these variables, information was not provided and engineering judgment in } \\
\text { conjunction with other references was used to determine these values } \\
{ }^{14} \text { Values were used here from the Dywidag material tests conducted in conjunction with the } 2007 \\
\text { Pankow series testing conducted at UCSD, research done separately from the SEQAD research } \\
{ }^{*} \text { For all other footnotes see DDC \#1 Beam Properties table }\end{array}$} \\
\hline
\end{tabular}


Table 9: DDC \#2 XTRACT input column properties

\begin{tabular}{|c|c|}
\hline Details & DDC \#2 (SEQAD \#1) \\
\hline \multicolumn{2}{|c|}{ Confined Concrete Strength Calculation } \\
\hline Type of transverse reinforcing & Rectangular hoops \\
\hline Transverse reinforcing bar yield stress $(\mathrm{ksi})$ & 75 \\
\hline $\mathrm{X}$ transverse reinforcing steel ratio & 0.00692 \\
\hline Y transverse reinforcing steel ratio ${ }^{1}$ & 0.00968 \\
\hline Average distance between tied longitudinal bars (in) ${ }^{2}$ & 5.11 \\
\hline Number of longitudinal bars around core & 18 \\
\hline Confined core area $\left(\mathrm{in}^{2}\right)$ & 480 \\
\hline \multirow[t]{2}{*}{ Tie spacing along member (in) } & (varying) \\
\hline & 8" o.c. \\
\hline 28-Day compressive concrete strength (ksi) & 4.5 \\
\hline Confined concrete strength $(\mathrm{ksi})^{3}$ & 6.451 \\
\hline \multicolumn{2}{|l|}{$\begin{array}{ll}\text { Crushing Strain Calculation } \\
\end{array}$} \\
\hline Transverse reinforcing steel strain at fracture (in/in) & 0.09 \\
\hline Transverse (volumetric) reinforcing steel ratio ${ }^{4}$ & 0.0166 \\
\hline Crushing strain, $\varepsilon_{\mathrm{cu}}^{3,6}$ & 0.02 \\
\hline \multicolumn{2}{|c|}{$\begin{array}{l}\text { Mander's Confined Concrete Curve Calculation } \\
\end{array}$} \\
\hline Tension Strength (ksi) ${ }^{12}$ & -0.402 \\
\hline Yield Strain, $\varepsilon_{\mathrm{cy}}{ }^{5}$ & 0.004435 (default) \\
\hline Concrete Elastic Modulus (ksi) $^{7}$ & 3824 \\
\hline \multicolumn{2}{|c|}{ Unconfined Concrete Curve Calculation } \\
\hline Yield Strain $^{5}$ & 0.0014 (default) \\
\hline Crushing Strain ${ }^{6}$ & 0.004 (default) \\
\hline Spalling Strain ${ }^{8}$ & 0.006 (default) \\
\hline Post Crushing Strength ${ }^{9}$ & 0 (default) \\
\hline Failure Strain ${ }^{10}$ & 1 \\
\hline \multicolumn{2}{|c|}{$\begin{array}{l}11 \text { Information provided by reference (SEQAD Consulting Engineers 1993) } \\
{ }^{12} \text { Calculated using the following equation: } \mathrm{f}^{\prime}=7.5 \sqrt{ } \mathrm{f}_{\mathrm{c}} \text { (ACI 2005): equation }(9-10) \text {. } \\
{ }^{13} \text { In the case of these variables, information was not provided and engineering judgment } \\
\text { in conjunction with other references was used to determine these values } \\
\text { in }{ }^{14} \text { Values were used here from the Dywidag material tests conducted in conjunction with } \\
\text { the } 2007 \text { Pankow series testing conducted at UCSD, research done separately from the } \\
\text { SEQAD research } \\
\text { "For all other footnotes see DDC \#1 Beam Properties table }\end{array}$} \\
\hline
\end{tabular}




\section{DDC \#2 PERFORM-3D Approximations}

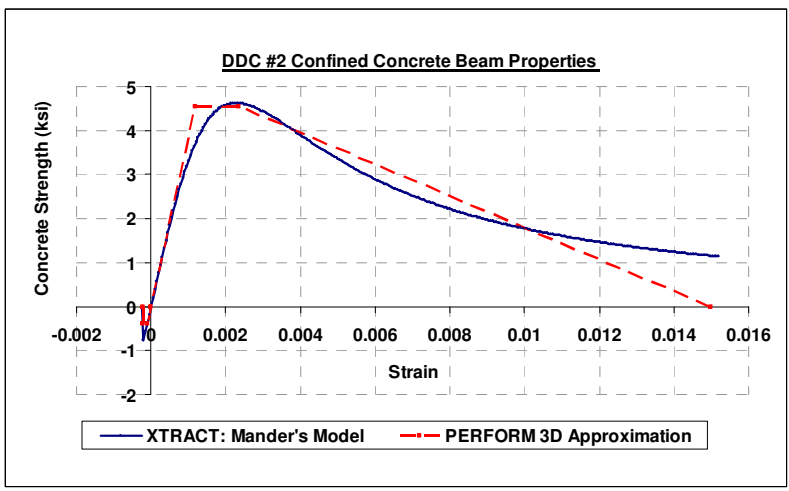

Figure 60: DDC \#2 approximate confined concrete beam constitutive properties

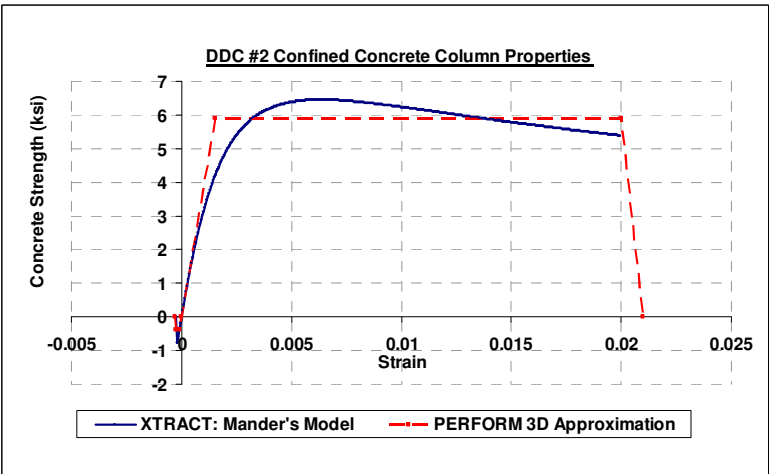

Figure 61: DDC \#2 approximate confined concrete column constitutive properties

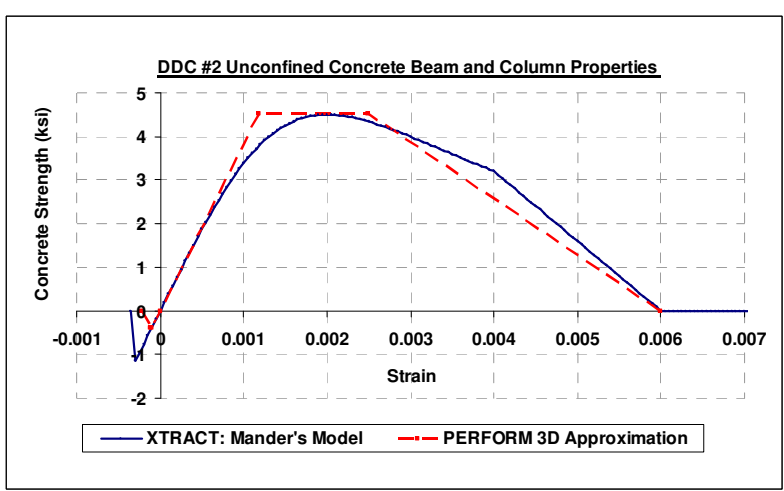

Figure 62: DDC \#2 approximate unconfined concrete beams and column properties 


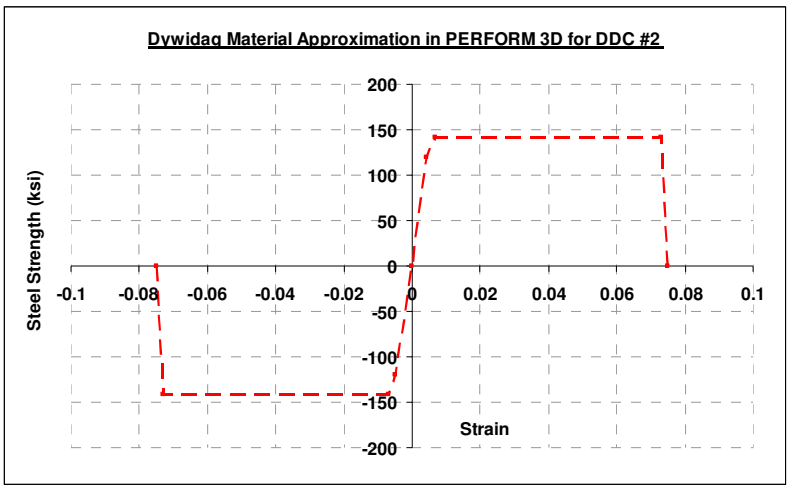

Figure 63: DDC \#2 approximate Dywidag properties

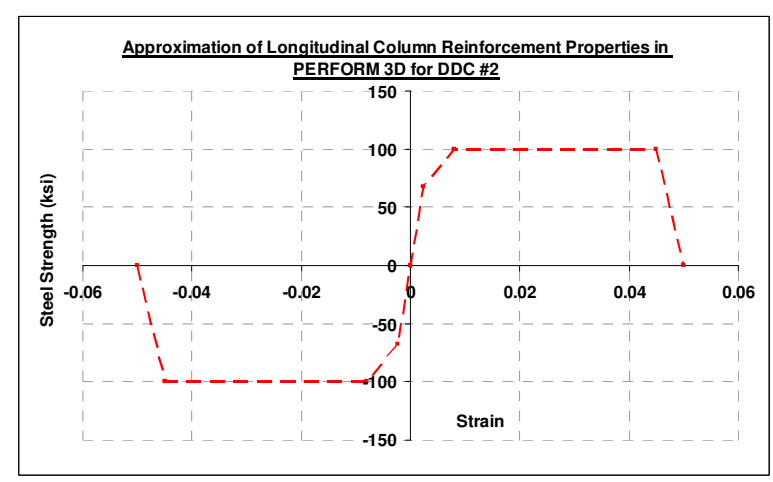

Figure 64: DDC \#2 approximate longitudinal column steel reinforcement properties

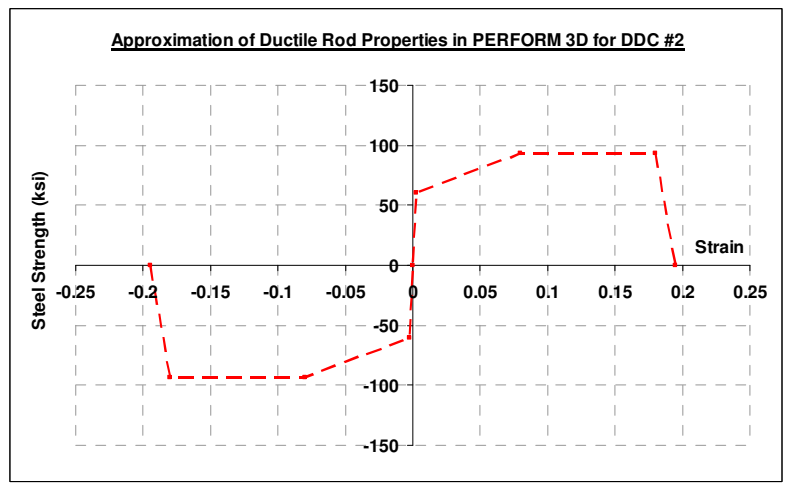

Figure 65: DDC \#2 approximate ductile rod properties 


\section{Appendix F}

\section{Super Hybrid XTRACT Input Properties}

Table 10: Super hybrid XRACT input column properties

\begin{tabular}{|c|c|}
\hline Details & $\begin{array}{c}\text { Super Hybrid } \\
\text { (Pankow \#2) }\end{array}$ \\
\hline \multicolumn{2}{|c|}{ Confined Concrete Strength Calculation } \\
\hline Type of transverse reinforcing & Rectangular hoops \\
\hline Transverse reinforcing bar yield stress (ksi) ${ }^{11}$ & 77 \\
\hline $\mathrm{X}$ transverse reinforcing steel ratio ${ }^{1}$ & 0.00717 \\
\hline Y transverse reinforcing steel ratio ${ }^{1}$ & 0.00689 \\
\hline Average distance between tied longitudinal bars (in) ${ }^{2}$ & 7.7 \\
\hline Number of longitudinal bars around core & 18 \\
\hline Confined core area $\left(\mathrm{in}^{2}\right)$ & 720 \\
\hline \multirow[t]{2}{*}{ Tie spacing along member (in) ${ }^{11}$} & (varying) \\
\hline & 6" o.c. \\
\hline 28-Day compressive concrete strength (ksi) ${ }^{11}$ & 10.25 \\
\hline Confined concrete strength $(\mathrm{ksi})^{3}$ & 12.53 \\
\hline \multicolumn{2}{|c|}{ Crushing Strain Calculation } \\
\hline Transverse reinforcing steel strain at fracture (in/in) ${ }^{13}$ & 0.12 \\
\hline Transverse (volumetric) reinforcing steel ratio ${ }^{4}$ & 0.01406 \\
\hline Crushing strain, $\varepsilon_{\mathrm{cu}}{ }^{3,6}$ & 0.01852 \\
\hline \multicolumn{2}{|c|}{ Mander's Confined Concrete Curve Calculation } \\
\hline Tension Strength (ksi) ${ }^{12}$ & 0.759 \\
\hline Yield Strain, $\varepsilon_{\mathrm{cy}}{ }^{5}$ & 0.00296 \\
\hline Concrete Elastic Modulus (ksi) $^{7}$ & 5771 \\
\hline \multicolumn{2}{|c|}{ Unconfined Concrete Curve Calculation } \\
\hline Yield Strain $^{5}$ & 0.0014 (default) \\
\hline Crushing Strain $^{6}$ & 0.004 (default) \\
\hline Spalling Strain $^{8}$ & 0.006 (default) \\
\hline Post Crushing Strength ${ }^{9}$ & 0 (default) \\
\hline Failure Strain ${ }^{10}$ & 1 \\
\hline \multicolumn{2}{|c|}{$\begin{array}{l}\text { Information provided by reference (SEQAD Consulting Engineers } 1993) \\
{ }^{12} \text { Calculated using the following equation: } \mathrm{f}_{\mathrm{t}}=7.5 \sqrt{\mathrm{f}}{ }_{\mathrm{c}}(\mathrm{ACI} 2005) \text { : equation }(9-10) \text {. } \\
{ }^{13} \text { In the case of these variables, information was not provided and engineering } \\
\text { judgment in conjunction with other references was used to determine these values } \\
{ }^{14} \text { Values were used here from the Dywidag material tests conducted in conjunction } \\
\text { with the } 2007 \text { Pankow series testing conducted at UCSD, research done separately } \\
\text { from the SEQAD research } \\
{ }^{*} \text { For all other footnotes see DDC \#1 Beam Properties table }\end{array}$} \\
\hline
\end{tabular}


Table 11: Super hybrid XRACT input beam properties

\begin{tabular}{|c|c|}
\hline Details & $\begin{array}{c}\text { Super Hybrid } \\
\text { (Pankow \#2) }\end{array}$ \\
\hline \multicolumn{2}{|c|}{ Confined Concrete Strength Calculation } \\
\hline Type of transverse reinforcing & Rectangular hoops \\
\hline Transverse reinforcing bar yield stress (ksi) & 64 \\
\hline $\mathrm{X}$ transverse reinforcing steel ratio ${ }^{1}$ & 0.0035 \\
\hline$Y$ transverse reinforcing steel ratio ${ }^{1}$ & 0.00815 \\
\hline Average distance between tied longitudinal bars (in) ${ }^{2}$ & 14.6 \\
\hline Number of longitudinal bars around core & 8 \\
\hline Confined core area $\left(\mathrm{in}^{2}\right)$ & 435 \\
\hline \multirow[t]{2}{*}{ Tie spacing along member (in) } & (varying) \\
\hline & 6"o.c. \\
\hline 28-Day compressive concrete strength (ksi) & 7.7 \\
\hline Confined concrete strength $(\mathrm{ksi})^{3}$ & 8.54 \\
\hline \multicolumn{2}{|l|}{$\begin{array}{l}\text { Crushing Strain Calculation } \\
\end{array}$} \\
\hline Transverse reinforcing steel strain at fracture (in/in) & .12 \\
\hline Transverse (volumetric) reinforcing steel ratio ${ }^{4}$ & 0.00535 \\
\hline Crushing strain, $\varepsilon_{\mathrm{cu}} 3,6$ & 0.0107 \\
\hline \multicolumn{2}{|c|}{$\begin{array}{ll}\text { Mander's Confined Concrete Curve Calculation } \\
\end{array}$} \\
\hline Tension Strength (ksi) ${ }^{12}$ & 0.658 \\
\hline Yield Strain, $\varepsilon_{\mathrm{cy}}^{5}$ & 0.00216 \\
\hline Concrete Elastic Modulus (ksi) ${ }^{7}$ & 5002 \\
\hline \multicolumn{2}{|c|}{$\begin{array}{c}\text { Unconfined Concrete Curve Calculation } \\
\end{array}$} \\
\hline Yield Strain ${ }^{5}$ & 0.0014 (default) \\
\hline Crushing Strain ${ }^{6}$ & 0.004 (default) \\
\hline Spalling Strain ${ }^{8}$ & 0.006 (default) \\
\hline Post Crushing Strength ${ }^{9}$ & 0 (default) \\
\hline Failure Strain ${ }^{10}$ & 1 \\
\hline \multicolumn{2}{|c|}{$\begin{array}{l}\text { Unconfined Concrete SLAB Curve Calculation } \\
\end{array}$} \\
\hline 28-Day Compressive Strength (ksi) & 3.3 \\
\hline Tension Strength (ksi) & 0.431 \\
\hline Yield Strain ${ }^{5}$ & 0.0014 (default) \\
\hline Crushing Strain ${ }^{6}$ & 0.004 (default) \\
\hline Spalling Strain ${ }^{8}$ & 0.006 (default) \\
\hline Post Crushing Strength $^{9}$ & 0 (default) \\
\hline Failure Strain ${ }^{10}$ & 1 \\
\hline Concrete Elastic Modulus (ksi) & 3274 \\
\hline \multicolumn{2}{|c|}{$\begin{array}{l}\text { I1 Information provided by reference (SEQAD Consulting Engineers 1993) } \\
{ }^{12} \text { Calculated using the following equation: } \mathrm{f}^{\prime}{ }_{\mathrm{t}}=7.5 \sqrt{ } \mathrm{f}_{\mathrm{c}} \text { (ACI 2005): equation }(9-10) \text {. } \\
{ }^{13} \text { In the case of these variables, information was not provided and engineering judgment } \\
\text { in conjunction with other references was used to determine these values } \\
{ }^{14} \text { Values were used here from the Dywidag material tests conducted in conjunction with } \\
\text { the } 2007 \text { Pankow series testing conducted at UCSD, research done separately from the } \\
\text { SEQAD research } \\
{ }^{*} \text { For all other footnotes see DDC \#1 Beam Properties table }\end{array}$} \\
\hline
\end{tabular}




\section{Super Hybrid PERFORM-3D Approximations}

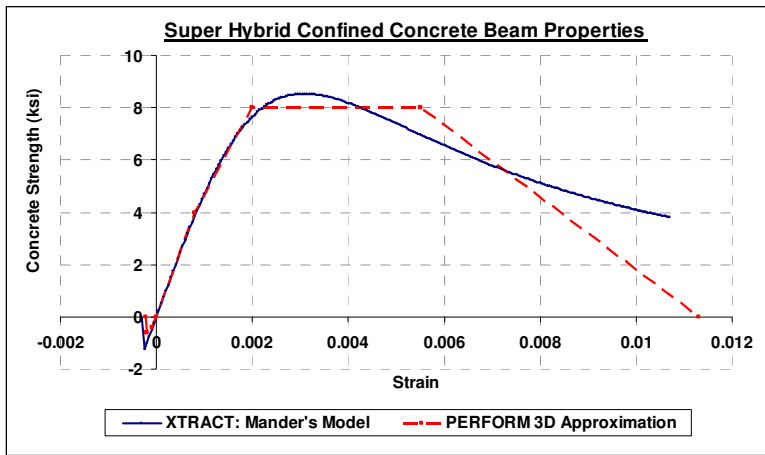

Figure 66: Super hybrid approximate confined concrete beam properties

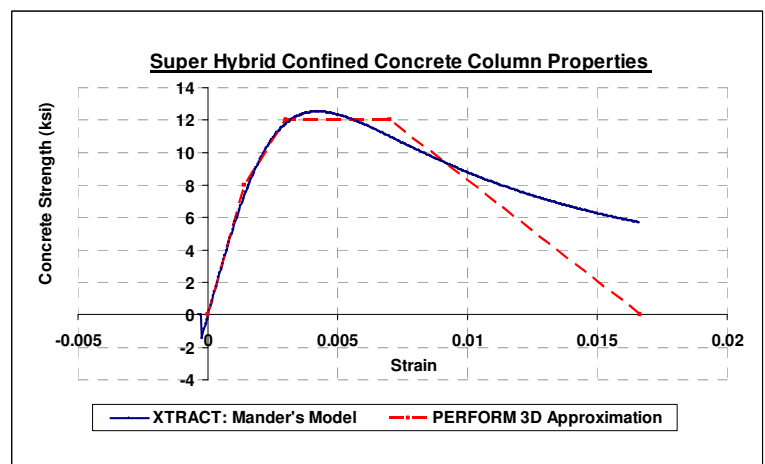

Figure 67: Super hybrid approximate confined concrete column properties

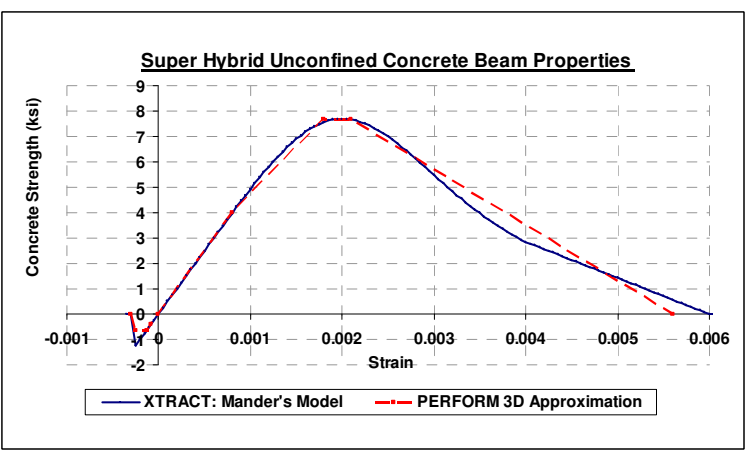

Figure 68: Super hybrid approximate unconfined concrete beam properties 


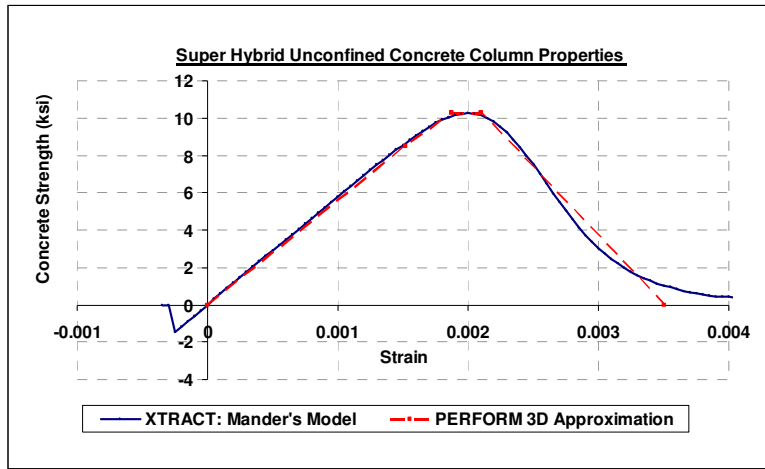

Figure 69: Super hybrid approximate unconfined concrete column properties

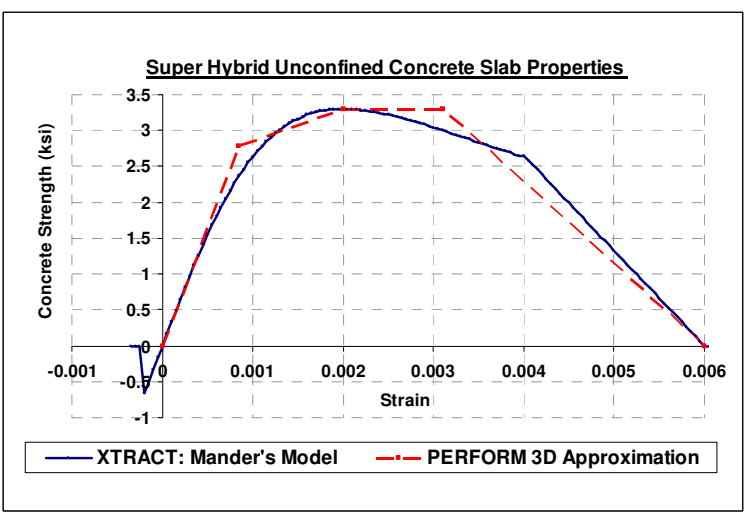

Figure 70: Super hybrid approximate unconfined concrete slab properties

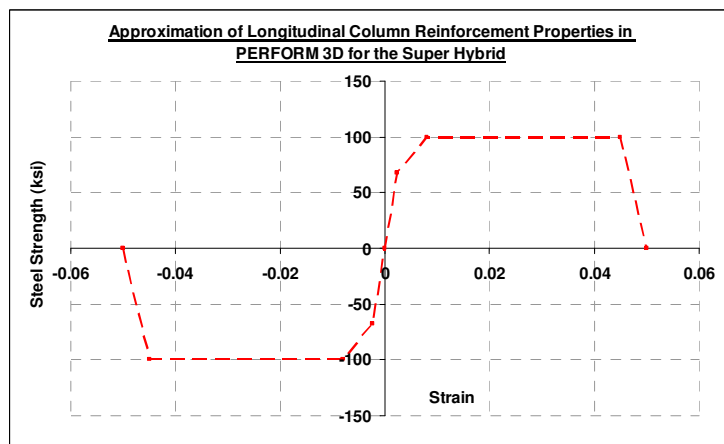

Figure 71: Super hybrid approximate longitudinal column reinforcement properties 


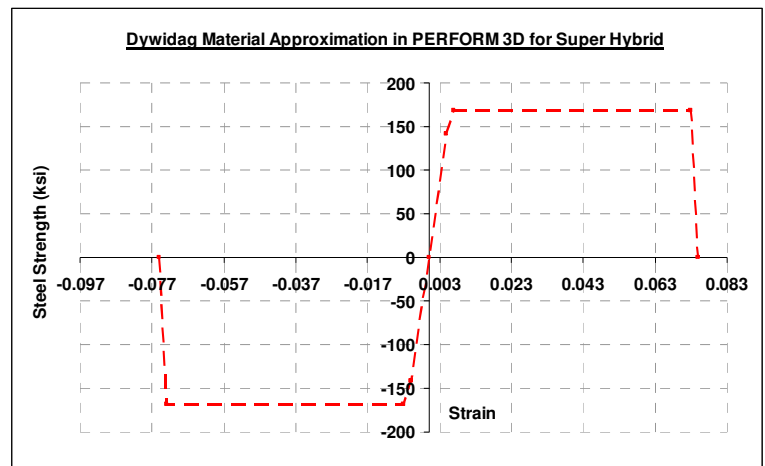

Figure 72: Super hybrid approximate Dywidag properties

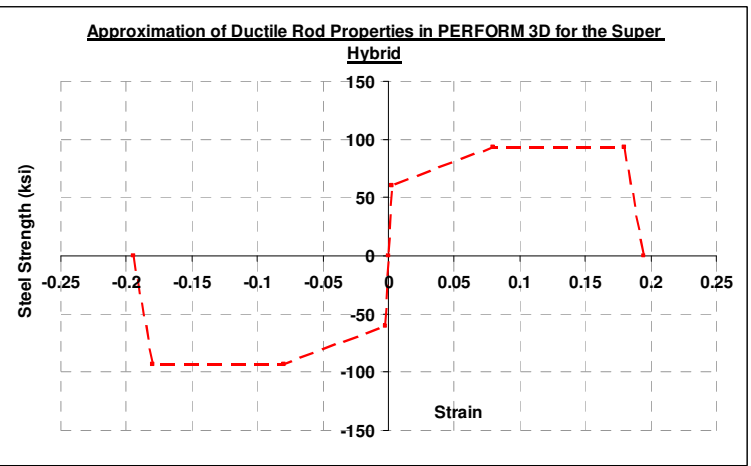

Figure 73: Super hybrid approximate ductile rod properties 


\section{Appendix G}

Table 12: DDC \#1 day of testing properties (Chang, Hutchinson, and Englekirk 2007)

\begin{tabular}{|l|l|c|}
\hline \multicolumn{3}{|c|}{ DDC \#1 DOT Properties Table } \\
\hline \multirow{4}{*}{$\begin{array}{l}\text { Expected strength } \\
\text { values }\end{array}$} & f'c (COLUMN) $(\mathrm{ksi})$ & DDC \#1 (Pankow \#4) \\
\cline { 2 - 3 } & f'c (BEAM) $_{(\mathrm{ksi})}$ & 5 \\
\cline { 2 - 3 } & f'c ${ }_{(\mathrm{SLAB})}(\mathrm{ksi})$ & $\mathrm{n} / \mathrm{a}$ \\
\hline \multirow{2}{*}{$\begin{array}{l}\text { Actual (DOT) } \\
\text { strength values }\end{array}$} & f'c ${ }_{(\mathrm{COLUMN})}(\mathrm{ksi})$ & 9.58 \\
\cline { 2 - 3 } & f'c ${ }_{(\mathrm{BEAM})}(\mathrm{ksi})$ & 5.55 \\
\cline { 2 - 3 } & f'c ${ }_{(\mathrm{SLAB})}(\mathrm{ksi})$ & $\mathrm{n} / \mathrm{a}$ \\
\hline
\end{tabular}

Table 13: DDC \#1 material test data (Chang, Hutchinson, and Englekirk 2007)

\begin{tabular}{|c|c|c|c|c|c|c|}
\hline Description & $\varepsilon_{\mathrm{y}}(\mathrm{in} / \mathrm{in})$ & $\mathrm{f}_{\mathrm{y}}(\mathrm{in} / \mathrm{in})$ & $\varepsilon_{\mathrm{p}}(\mathrm{in} / \mathrm{in})$ & $\mathrm{f}_{\mathrm{p}}(\mathrm{ksi})$ & $\varepsilon_{\text {ult }}(\mathrm{in} / \mathrm{in})$ & $\mathrm{f}_{\text {ult }}(\mathrm{ksi})$ \\
\hline DDC & 0.0039 & 59 & 0.12 & 92 & 0.18 & 89 \\
\hline Baugrids & 0.041 & 86 & 0.046 & 87 & 0.066 & 67 \\
\hline Dywidags & 0.0063 & 142 & 0.069 & 168 & 0.078 & 167 \\
\hline \#11 rebar & - & 70.5 & - & 92 & - & - \\
\hline
\end{tabular}

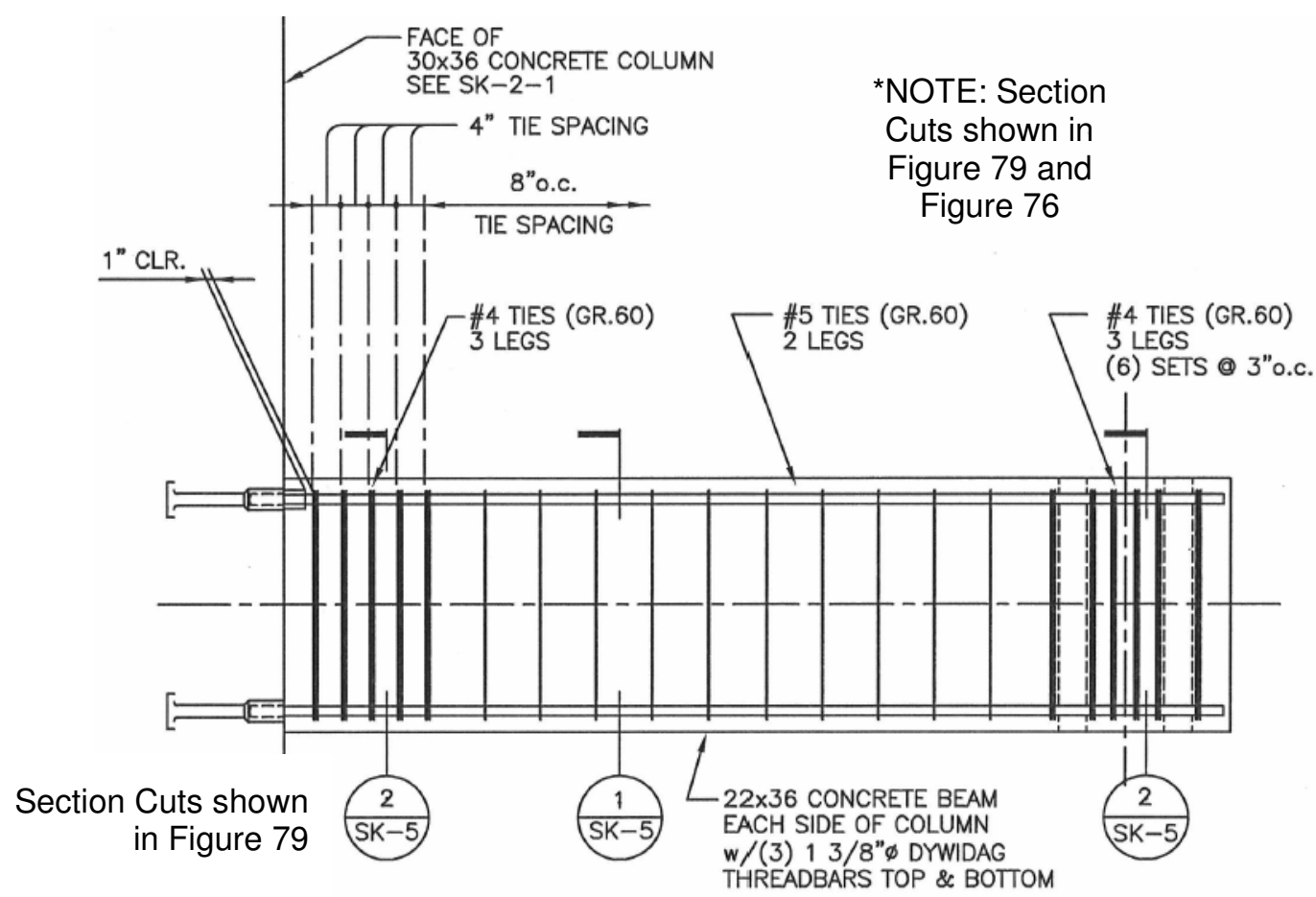

Figure 74: DDC \#1 beam elevation (Chang, Hutchinson, and Englekirk 2007) 


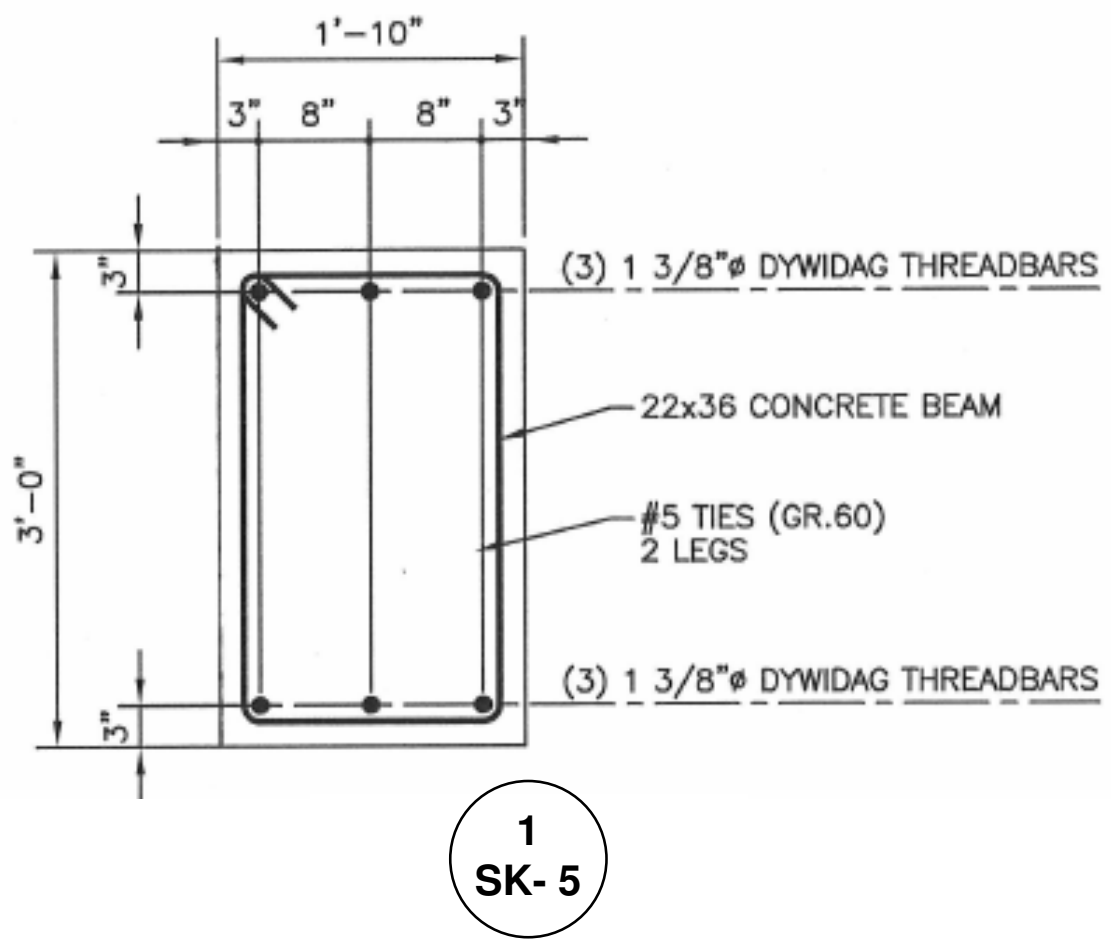

Figure 75: DDC \#1 section cut 1/SK-5 through the beam (Chang, Hutchinson, and Englekirk 2007)

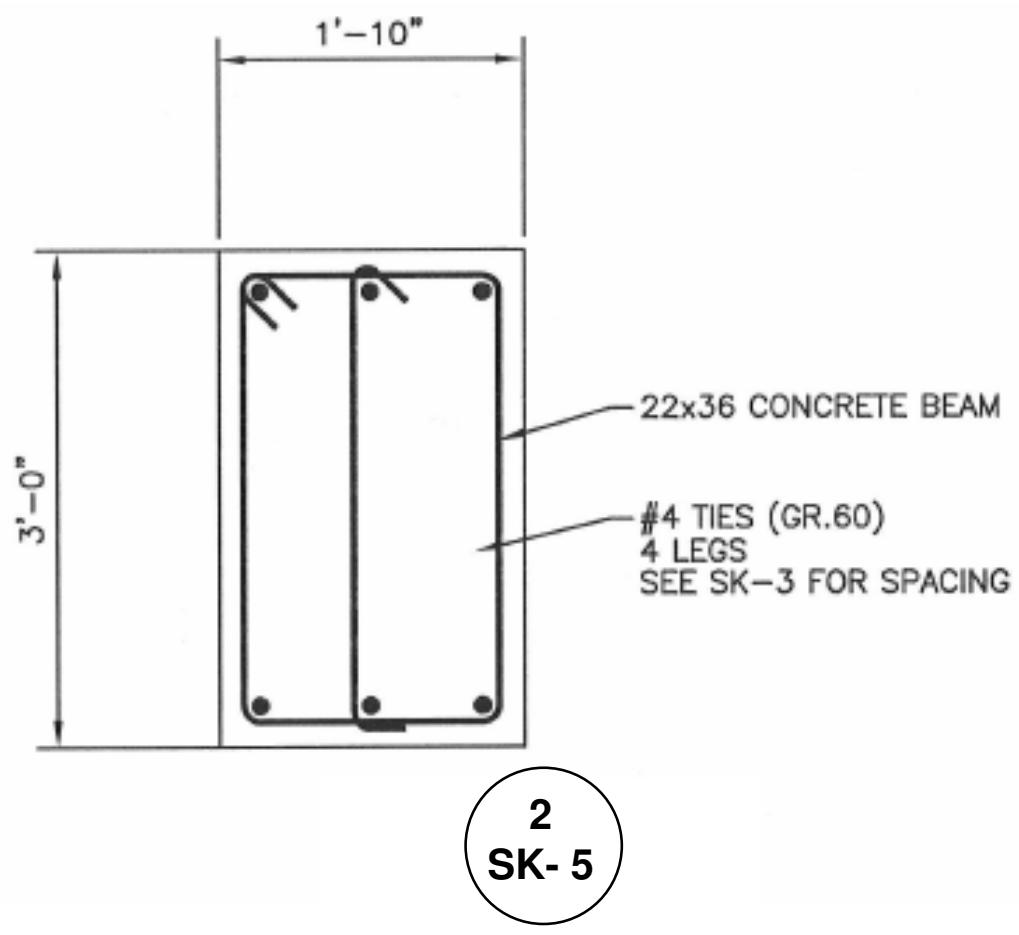

Figure 76: DDC \#1 section cut 2/SK-5 through the beam (Chang, Hutchinson, and Englekirk 2007) 


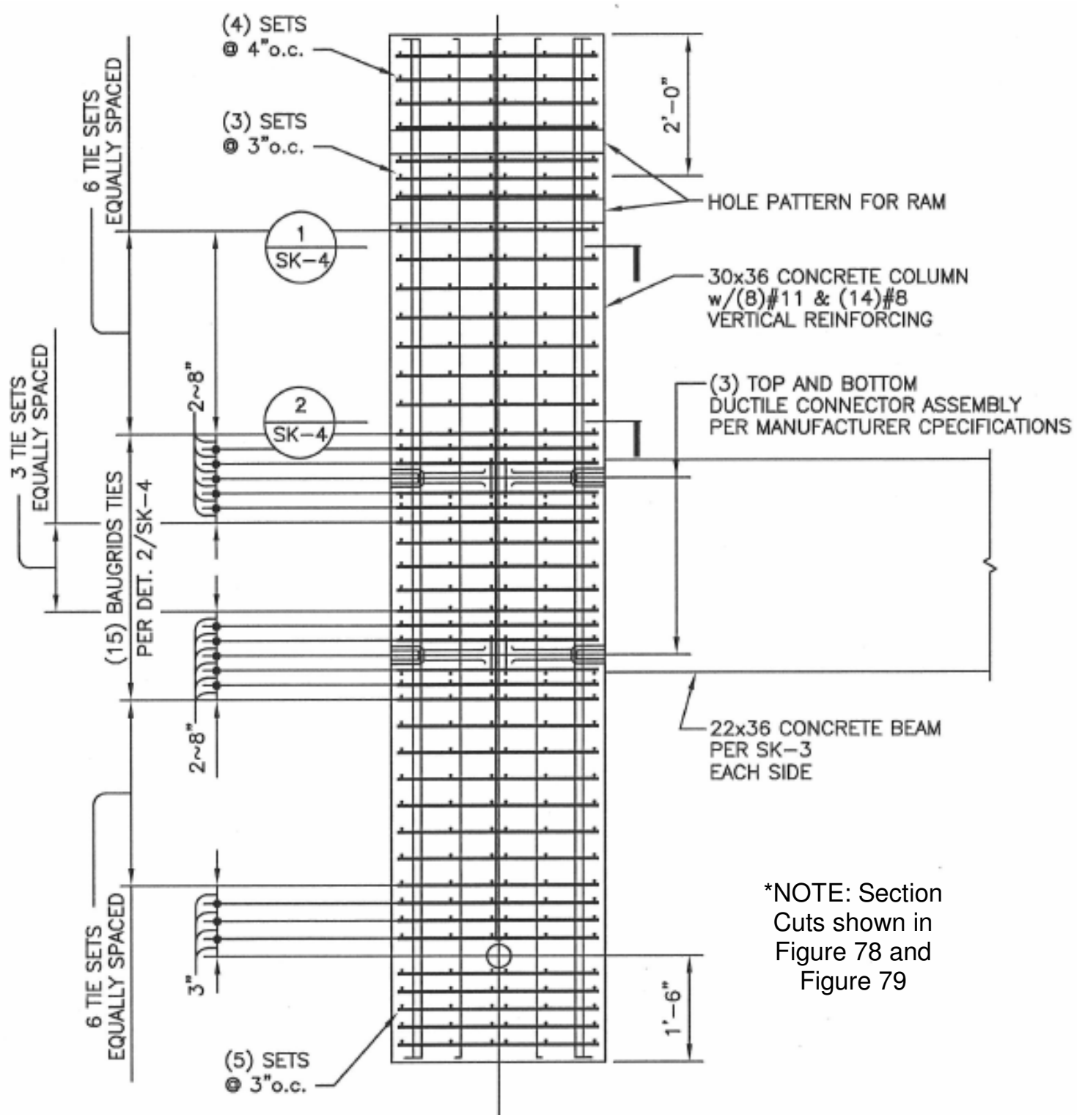

Figure 77: DDC \#1 column elevation (Chang, Hutchinson, and Englekirk 2007) 


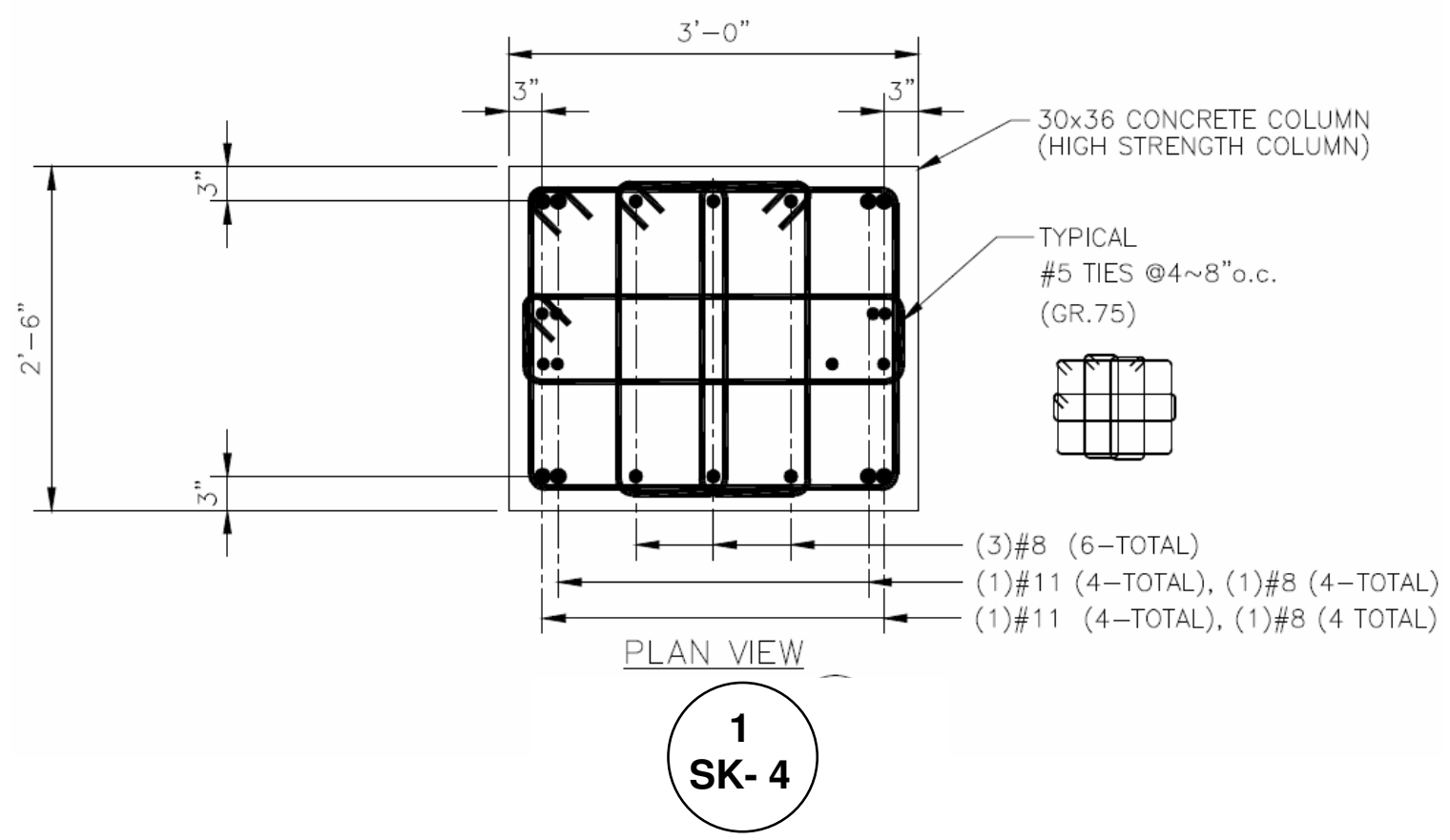

Figure 78: DDC \#1 section cut 1/SK-4 through the column (Chang, Hutchinson, and Englekirk 2007)

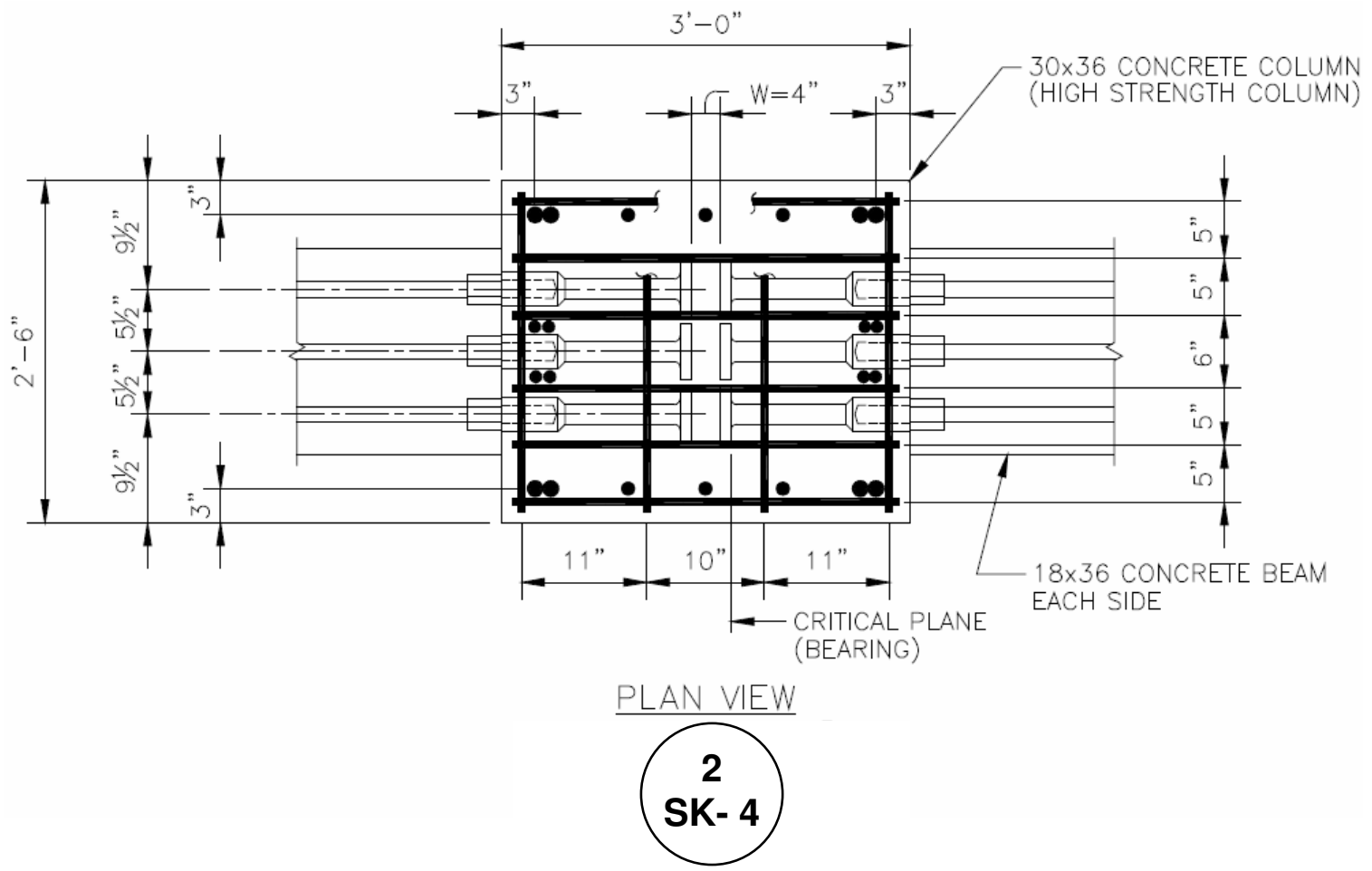

Figure 79: DDC \#1 section cut 2/SK-4 through the column (Chang, Hutchinson, and Englekirk 2007) 


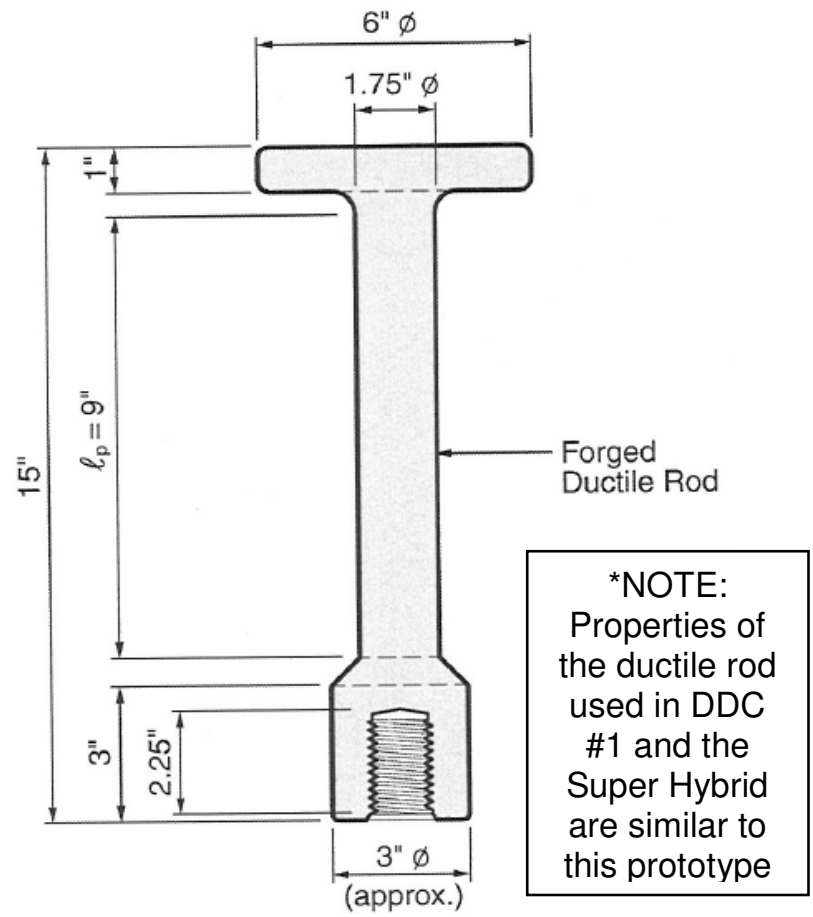

Figure 80: Prototype of forged ductile rod (Englekirk 2003)

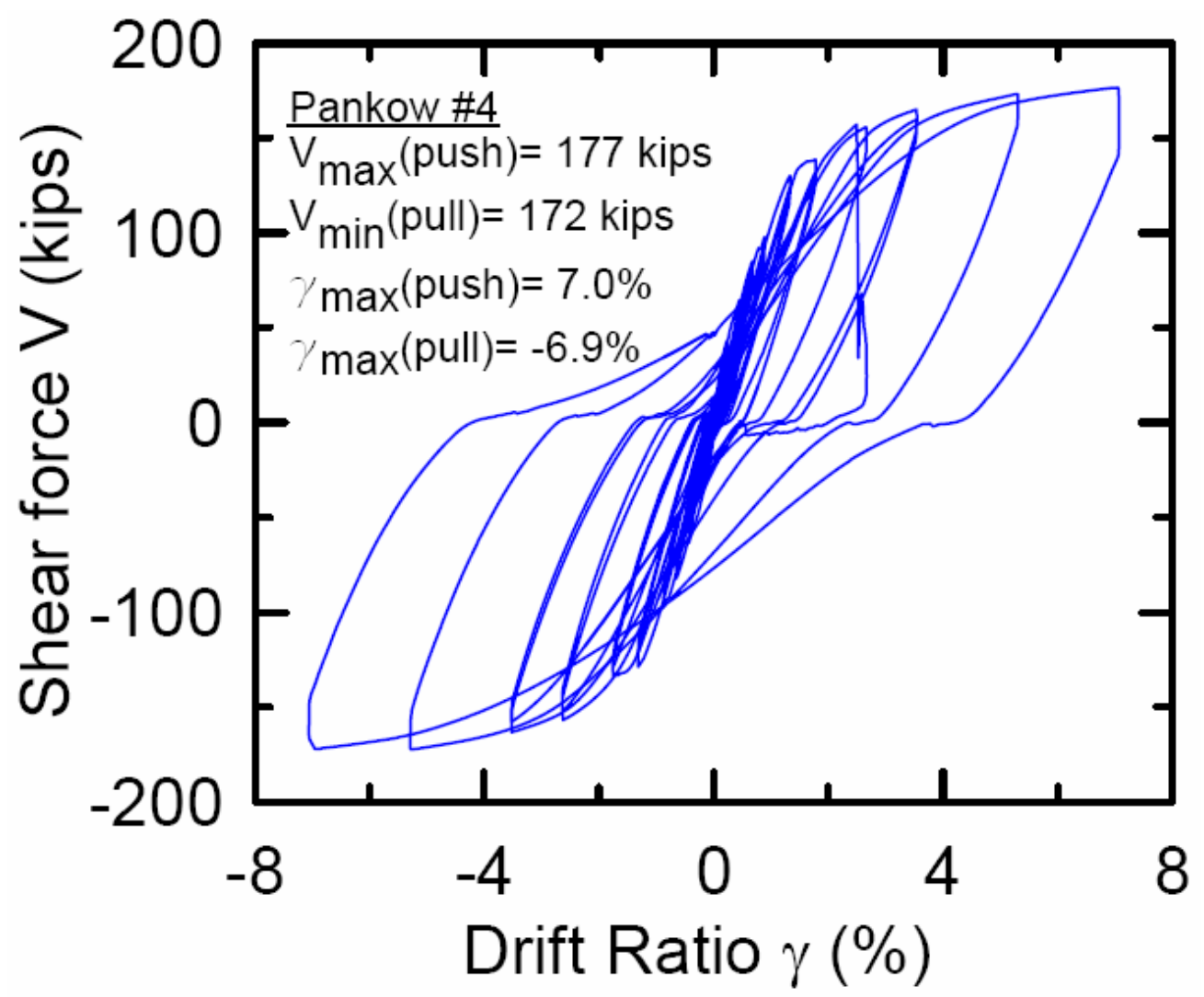

Figure 81: DDC \#1 test data (Chang, Hutchinson, and Englekirk 2007) 


\section{Appendix H}

Table 14: DDC \#2 material test results (SEQAD 1993)

\begin{tabular}{|c|c|c|c|}
\hline \multicolumn{4}{|c|}{ DDC \#2 Test Data Results Table } \\
\hline \multicolumn{4}{|c|}{ Steel Properties } \\
\hline & Bar Size & Yield Strength $\mathrm{f}_{\mathrm{y}}(\mathrm{ksi})$ & $\begin{array}{c}\text { Ultimate Strength } \mathrm{f}_{\mathrm{u}} \\
(\mathrm{ksi})\end{array}$ \\
\hline \multirow{4}{*}{$\begin{array}{l}\text { Reinforcement }^{1} \\
\quad \text { (Grade 60) }\end{array}$} & \#4 & 66.0 & 103 \\
\hline & $\# 5$ & 71.5 & 111 \\
\hline & \#6 & 73.5 & 107 \\
\hline & $\# 8$ & 65.5 & 101 \\
\hline Ductile Link & - & $62^{4}$ & $93.6^{6}$ \\
\hline $\begin{array}{c}\text { Beam } \\
\text { Reinforcement } \\
(\text { Grade } 150)\end{array}$ & $13 / 8 ”$ & $120^{4}$ & $142^{5}$ \\
\hline \multicolumn{4}{|c|}{ Concrete and Joint Grout Properties } \\
\hline \multirow{3}{*}{ Concrete } & & \multicolumn{2}{|c|}{$\mathrm{f}_{\mathrm{c}}{ }_{\mathrm{c}}(\mathrm{ksi})^{2}$} \\
\hline & & \multicolumn{2}{|c|}{4.5} \\
\hline & Batch & \multicolumn{2}{|c|}{$\mathrm{f}_{\mathrm{c}}^{\prime}(\mathrm{ksi})$} \\
\hline \multirow{3}{*}{$\begin{array}{c}\text { Grout }^{3} \text { Minimum } \\
\text { Required Strength } \\
6 \mathrm{ksi}\end{array}$} & $\# 1$ & \multicolumn{2}{|c|}{7.59} \\
\hline & $\# 2$ & \multicolumn{2}{|c|}{7.27} \\
\hline & \#3 & \multicolumn{2}{|c|}{8.07} \\
\hline \multicolumn{4}{|c|}{$\begin{array}{l}{ }^{1} \text { Steel material properties supplied by steel mill. } \\
{ }^{2} \text { Concrete properties determined from } 3 \text { tests. } \\
{ }^{3} \text { Grout - Sikadur } 42 \text {, Grout-Pak }-3 \text { part epoxy grout with Fibermesh Harbourite Polyethylene } \\
3 / 4 " \text { long, } 2 \text { lbs per } 1 \mathrm{yd}^{3} \\
\left.{ }^{4} \text { This number was found in reference (Englekirk } 1995\right) \\
{ }^{5} \text { This value was determined by using a ratio of the Dywidag material tested during the } 2007 \\
\text { Pankow testing (Chang, Hutchinson, and Englekirk, 2007) where } \mathrm{F}_{\mathrm{y}}=140 \mathrm{ksi} \text { and } \mathrm{F}_{\mathrm{u}}=168 \mathrm{ksi} \\
\text { therefore a ratio of } \mathrm{F}_{\mathrm{u}} / \mathrm{F}_{\mathrm{y}}=1.18 \text { and so } \mathrm{F}_{\mathrm{u}} \text { for DDC } \# 2 \text { is } \mathrm{F}_{\mathrm{u}}=1.18 * \mathrm{~F}_{\mathrm{y}}=1.18 * 120 \mathrm{ksi}=142 \mathrm{ksi} \\
{ }^{6} \text { This number was found in reference }(\text { Englekirk } 1995) \text {. Refer to Figure } 4 \text { of this reference. }\end{array}$} \\
\hline
\end{tabular}




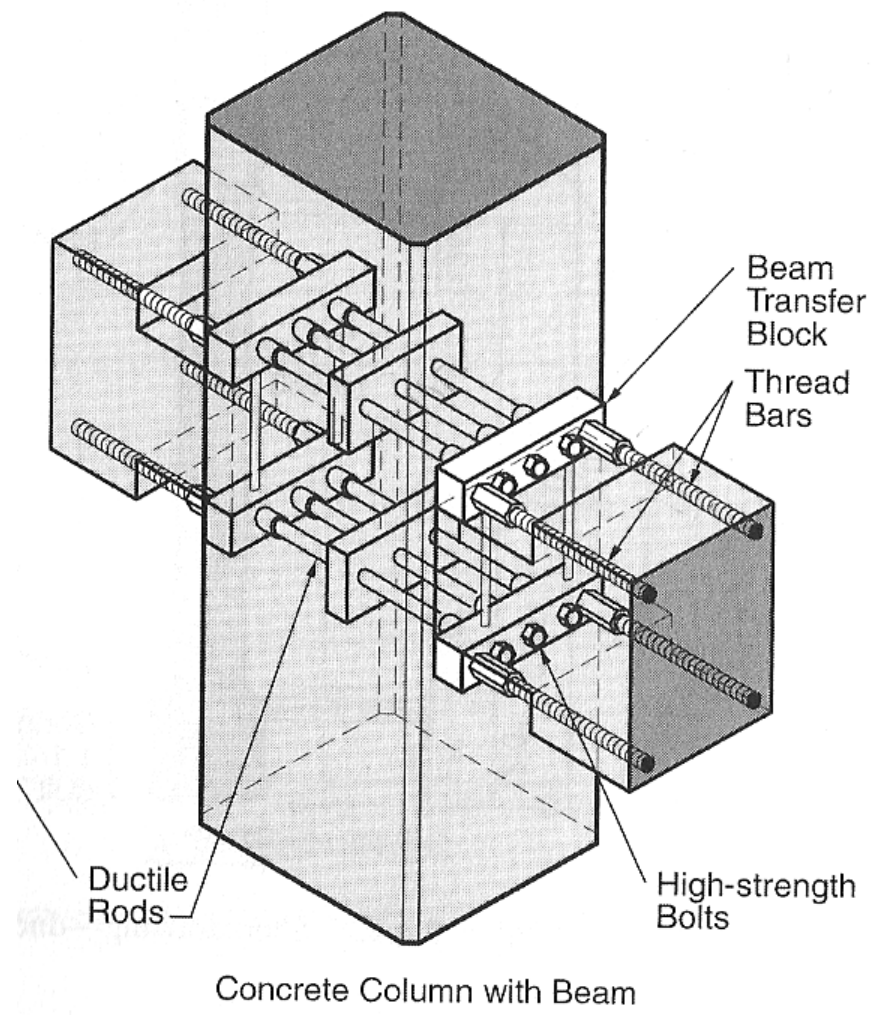

Figure 82: Isometric view of a DDC joint similar to DDC \#2 (Englekirk 2003)

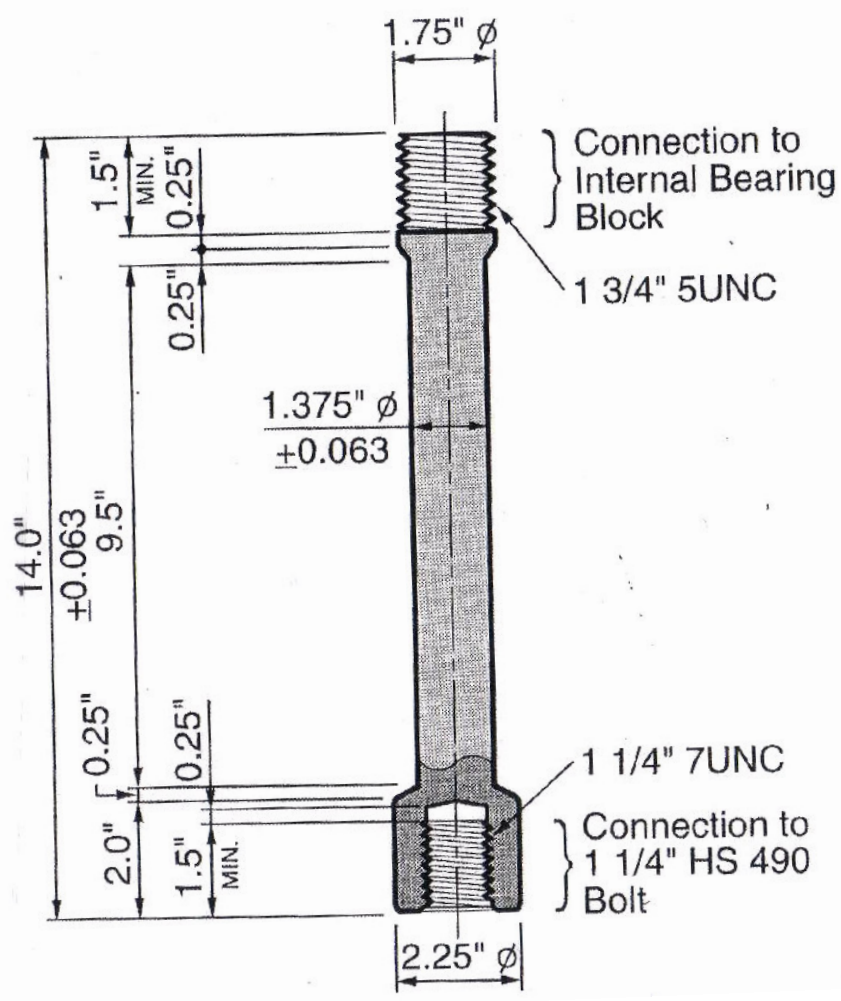

Figure 83: DDC \#2 ductile rod geometry (Englekirk 2003) 


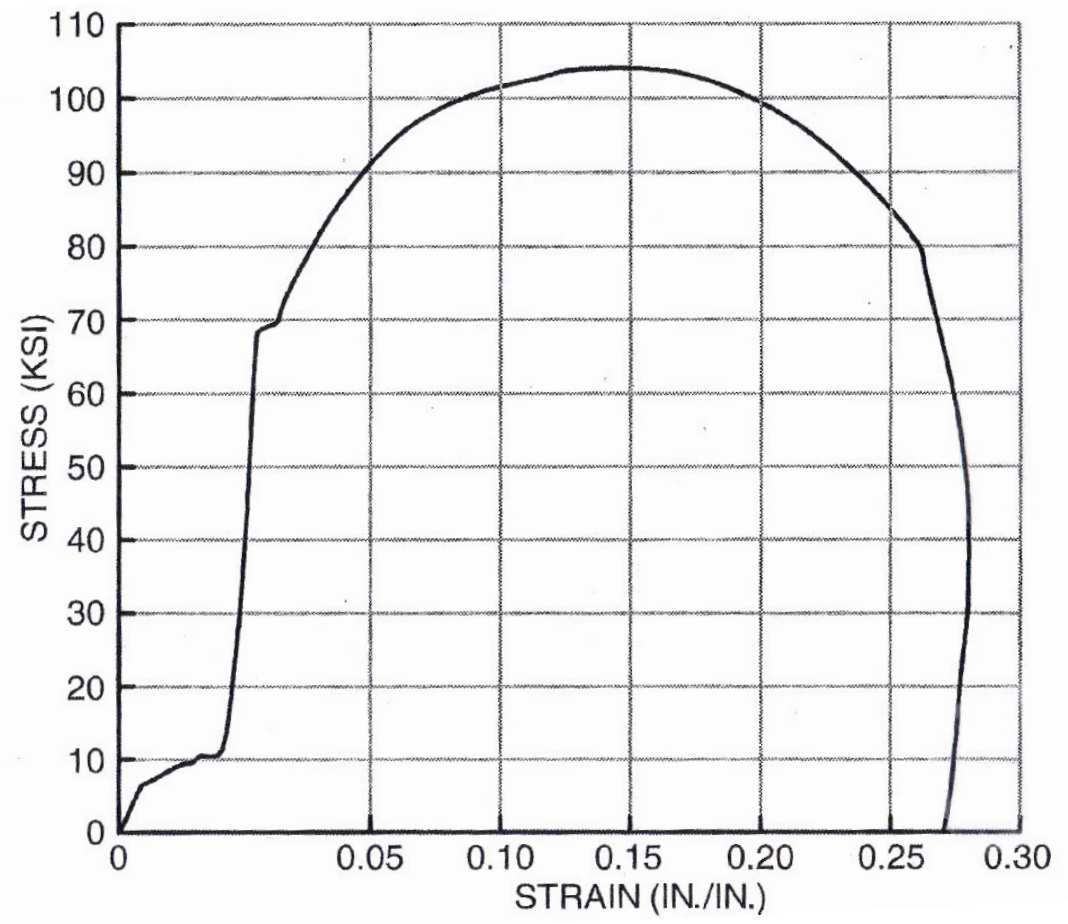

Figure 84: Relationship between stress and strain for the ductile rod in Figure 83

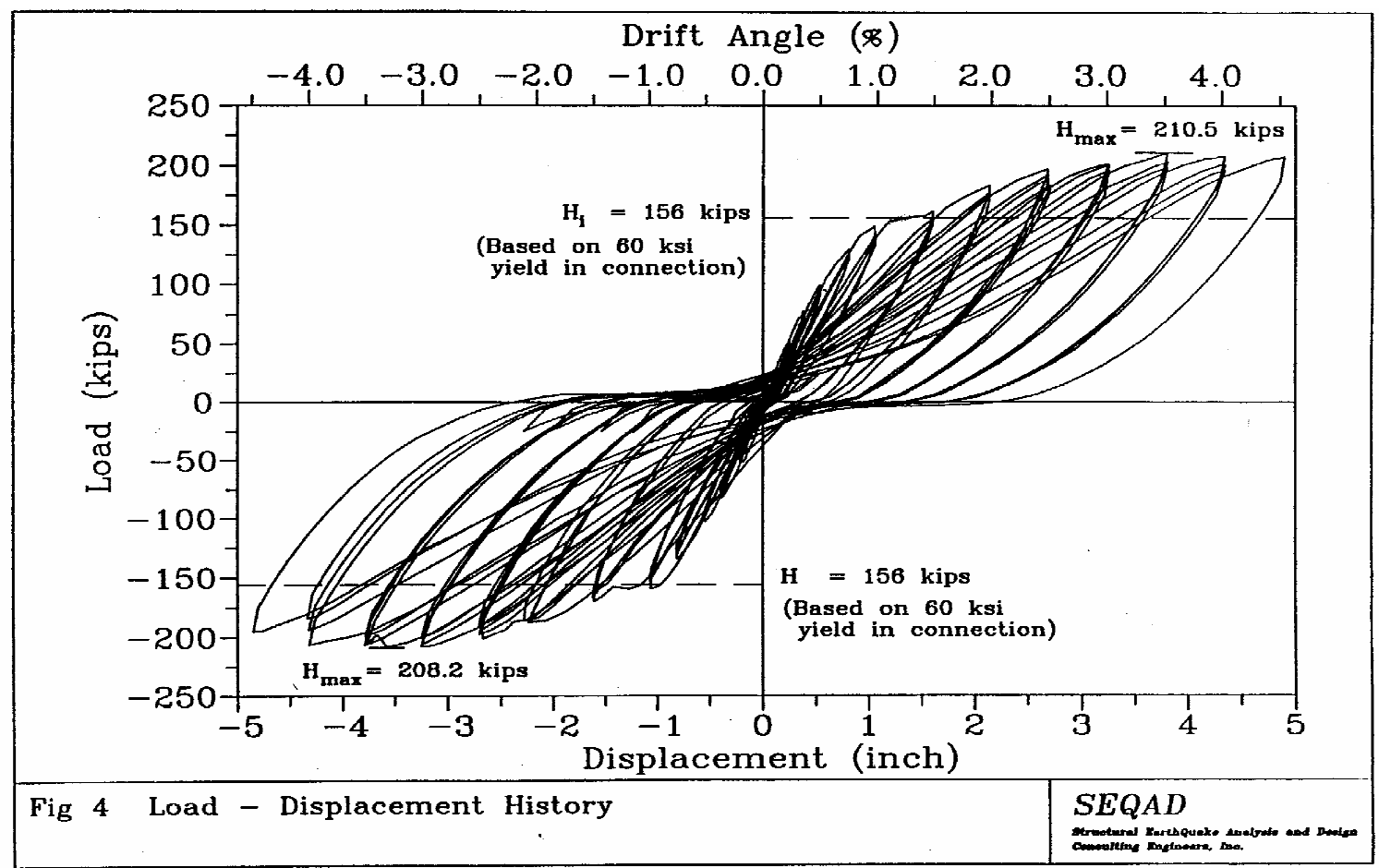

Figure 85: DDC \#2 force-displacement hysteretic data (SEQAD 1993) 


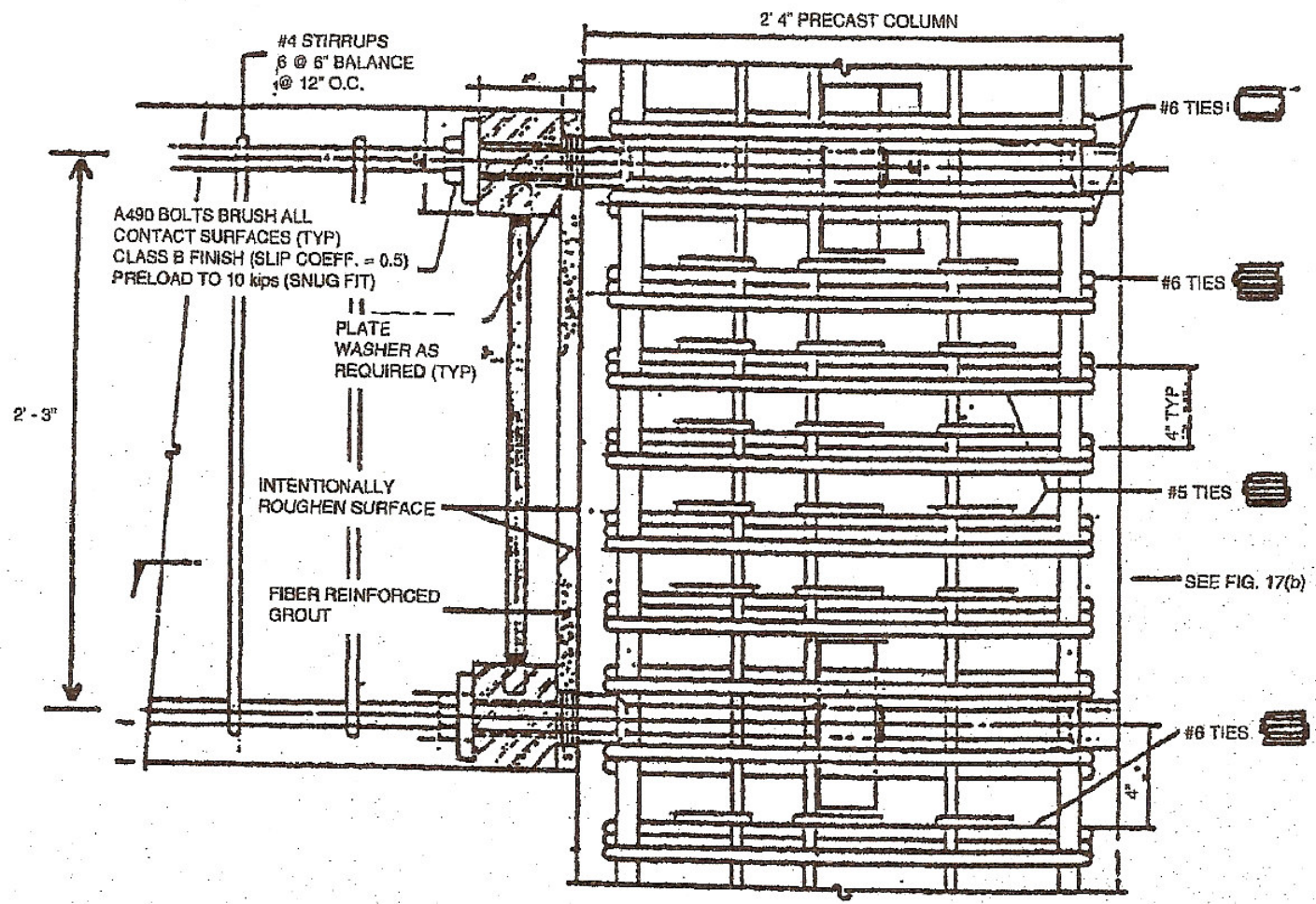

Figure 86: DDC \#2 joint elevation (Englekirk 1995)

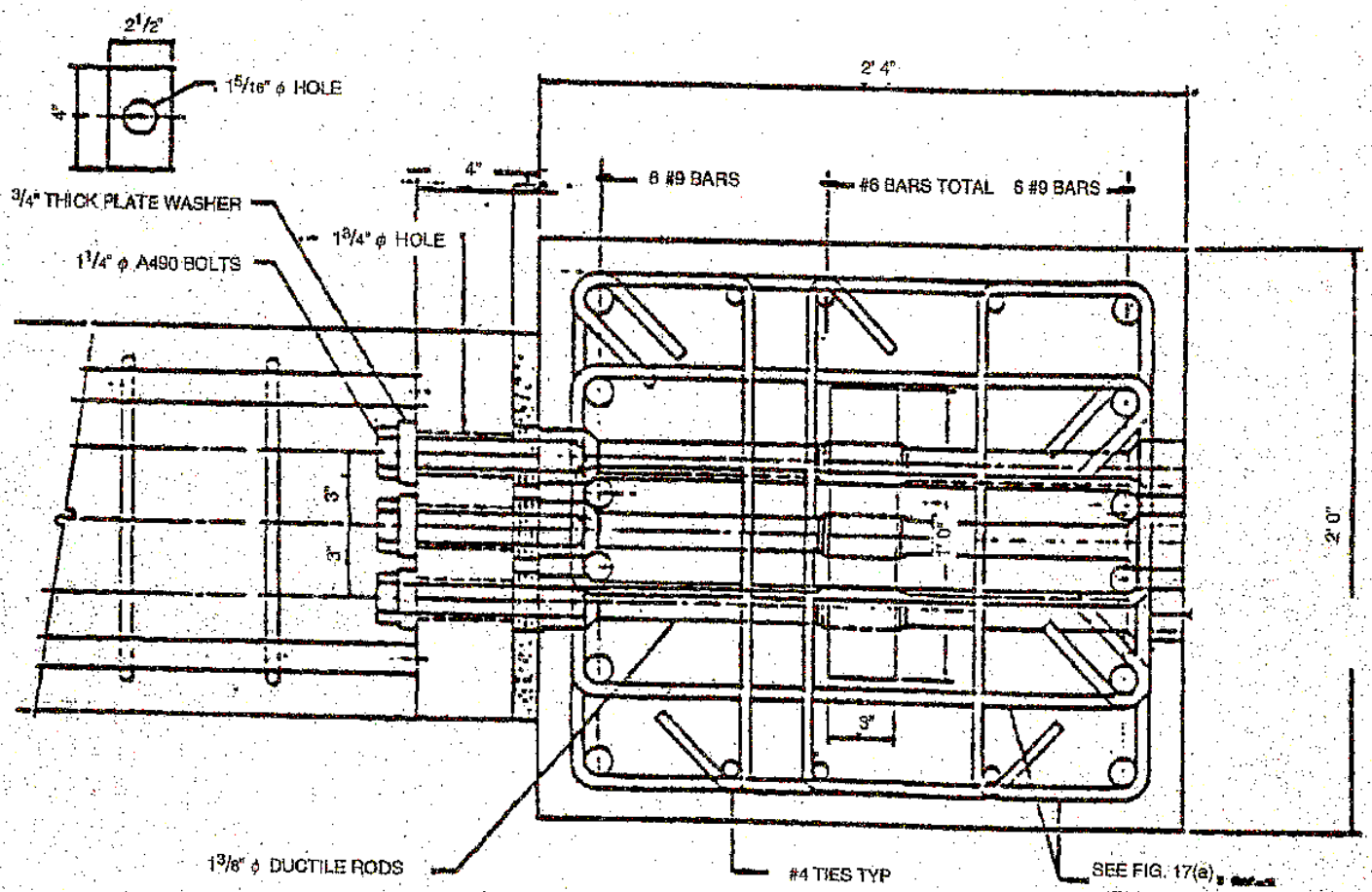

Figure 87: DDC \#2 plan view of the column at the ductile rod elevation in the joint (Englekirk 1995) 


\section{Appendix I.}

Table 15: Super hybrid day of testing properties (Chang, Hutchinson, and Englekirk 2007)

\begin{tabular}{|c|c|c|}
\hline \multicolumn{3}{|c|}{ Super Hybrid DOT Properties Table } \\
\hline & & $\begin{array}{c}\text { Super Hybrid } \\
(\text { Pankow \#2) }\end{array}$ \\
\hline \multirow{3}{*}{$\begin{array}{l}\text { Expected strength } \\
\text { values }\end{array}$} & $\mathrm{f}^{\prime} \mathrm{c}_{(\mathrm{COLUMN})}(\mathrm{ksi})$ & 10 \\
\hline & $\mathrm{f}^{\prime} \mathrm{c}_{(\mathrm{BEAM})}(\mathrm{ksi})$ & 5 \\
\hline & $\mathrm{f}^{\prime} \mathrm{c}_{(\mathrm{SLAB})}(\mathrm{ksi})$ & 3 \\
\hline \multirow{3}{*}{$\begin{array}{l}\text { Actual (DOT) } \\
\text { strength values }\end{array}$} & $\mathrm{f}^{\prime} \mathrm{c}_{(\mathrm{COLUMN})}(\mathrm{ksi})$ & 10.25 \\
\hline & $\mathrm{f}^{\prime} \mathrm{c}_{(\mathrm{BEAM})}(\mathrm{ksi})$ & 7.7 \\
\hline & $\mathrm{f}^{\prime} \mathrm{c}_{(\mathrm{SLAB})}(\mathrm{ksi})$ & 3.39 \\
\hline
\end{tabular}

Table 16: Super hybrid material test data (Chang, Hutchinson, and Englekirk 2007)

\begin{tabular}{|c|c|c|c|c|c|c|}
\hline Description & $\varepsilon_{\mathrm{y}}(\mathrm{in} / \mathrm{in})$ & $\mathrm{f}_{\mathrm{y}}(\mathrm{in} / \mathrm{in})$ & $\varepsilon_{\mathrm{p}}(\mathrm{in} / \mathrm{in})$ & $\mathrm{f}_{\mathrm{p}}(\mathrm{ksi})$ & $\varepsilon_{\text {ult }}(\mathrm{in} / \mathrm{in})$ & $\mathrm{f}_{\text {ult }}(\mathrm{ksi})$ \\
\hline DDC & 0.0040 & 60 & 0.124 & 91 & 0.195 & 82 \\
\hline Dywidags & 0.0054 & 144 & 0.074 & 169 & 0.11 & 165 \\
\hline \#4 rebar & 0.0041 & 64 & 0.11 & 92 & 0.20 & 88 \\
\hline \#5 rebar & 0.0046 & 77 & 0.079 & 98 & 0.14 & 94 \\
\hline \#6 rebar & 0.0044 & 67 & 0.10 & 111 & 0.16 & 105 \\
\hline \#11 rebar & - & 69.5 & - & - & - & - \\
\hline
\end{tabular}




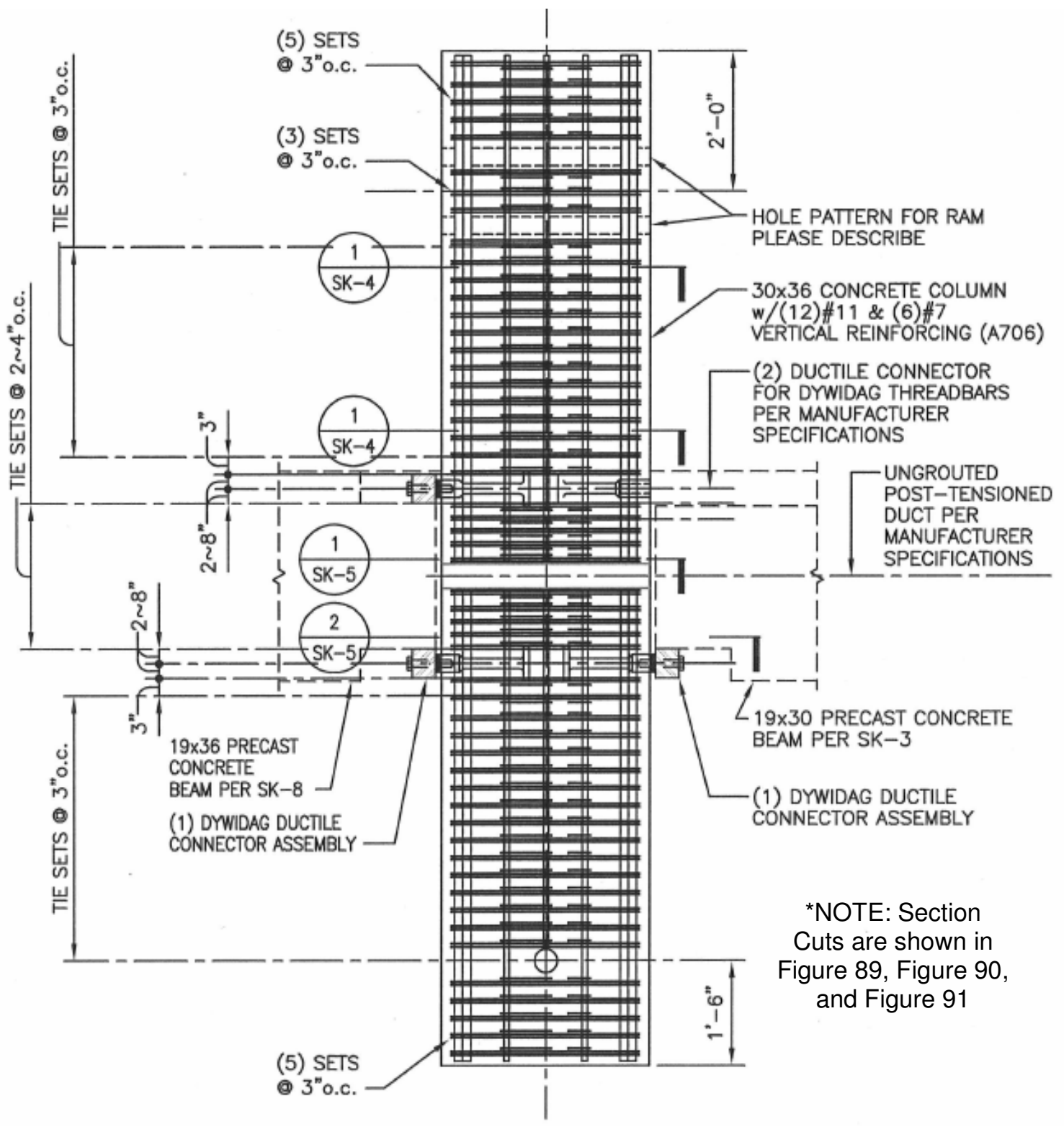

Figure 88: Super hybrid column elevation (Chang, Hutchinson, and Englekirk 2007) 


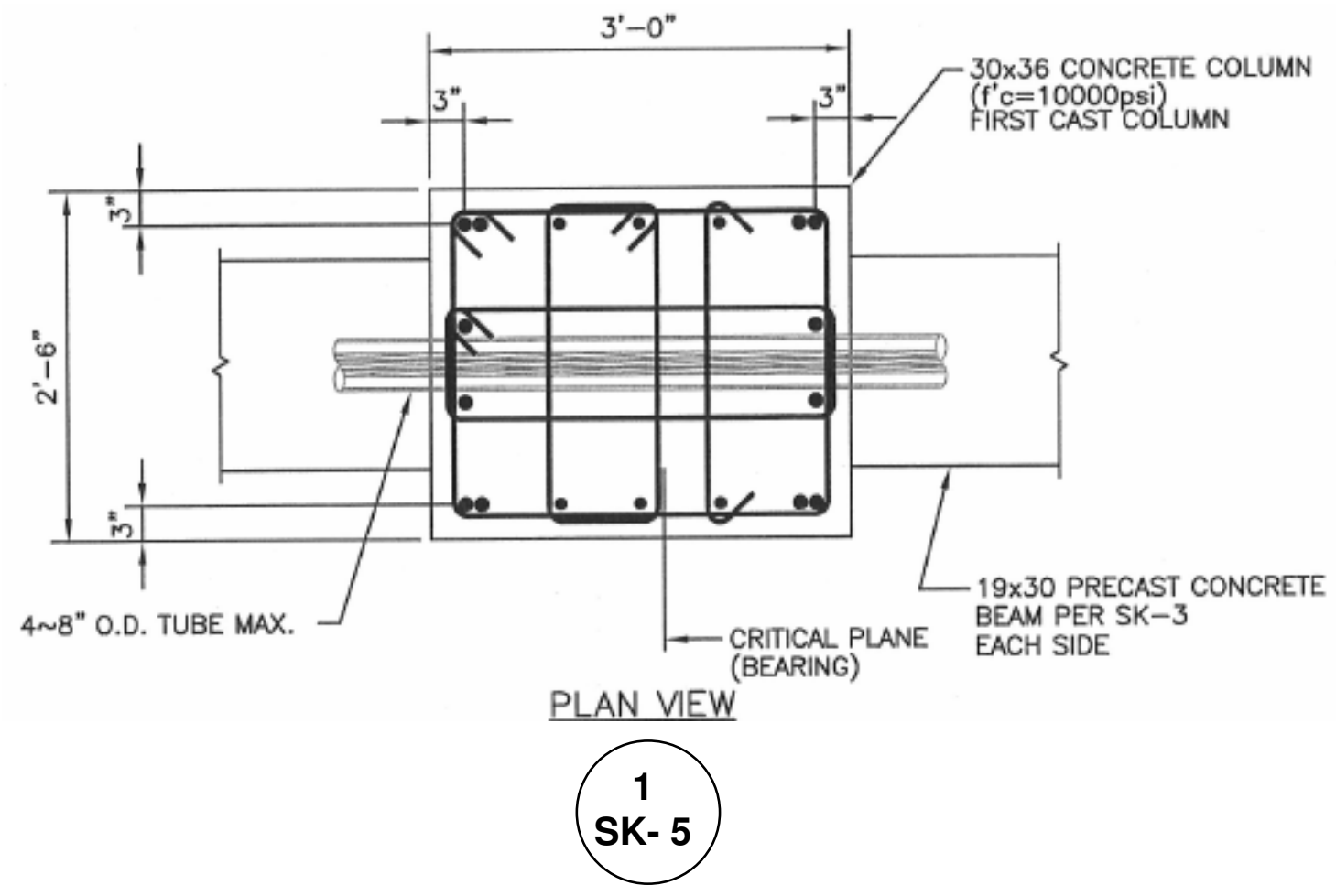

Figure 89: Super hybrid section cut 1/SK-5 through the column (Chang, Hutchinson, and Englekirk 2007)

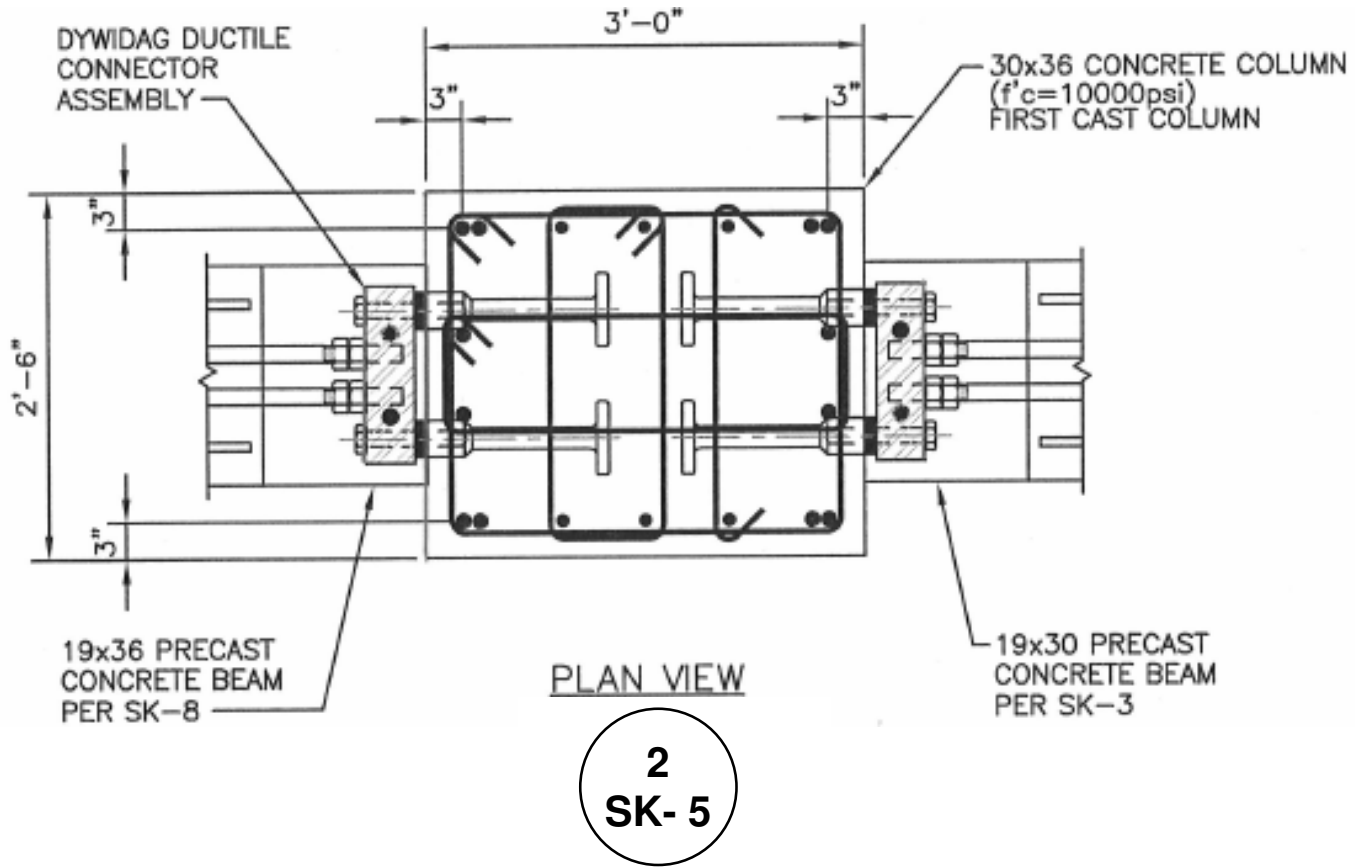

Figure 90: Super hybrid section cut 2/SK-5 through the column (Chang, Hutchinson, and Englekirk 2007) 


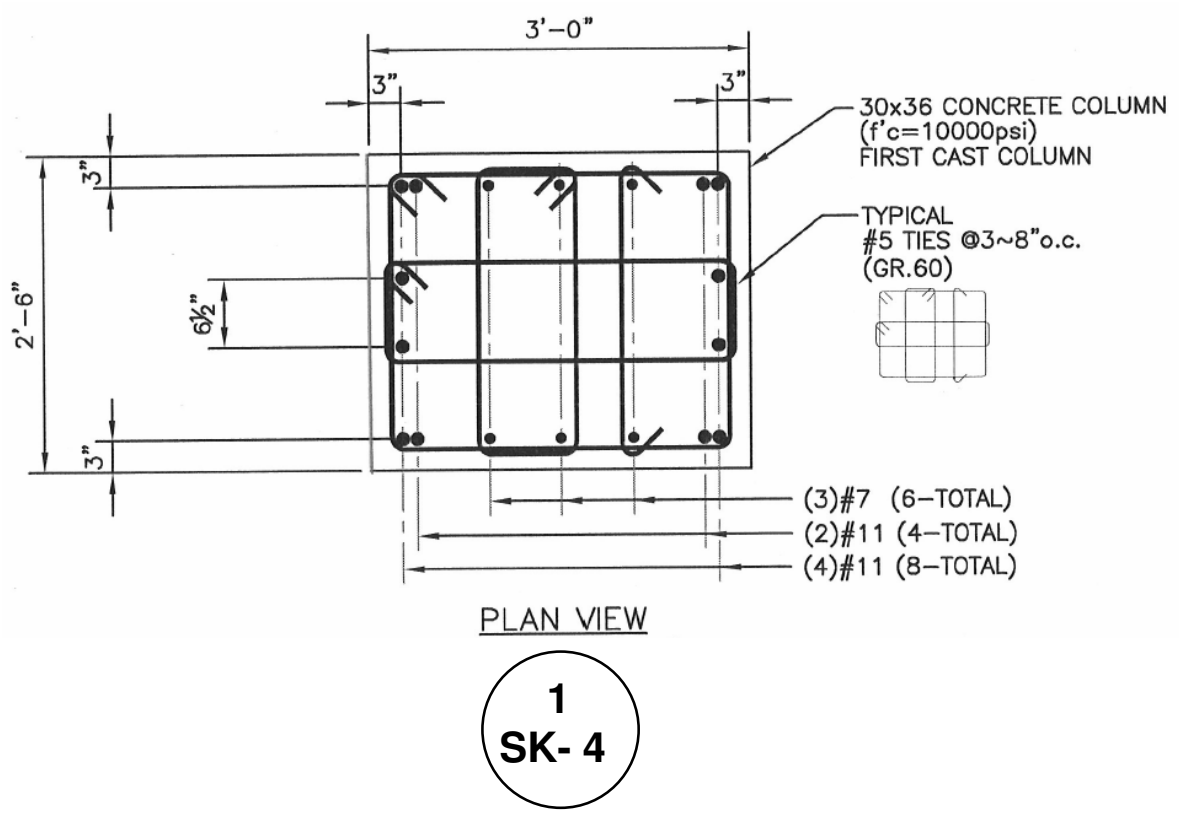

Figure 91: Super hybrid section cut 1/SK-4 through the column (Chang, Hutchinson, and Englekirk 2007)

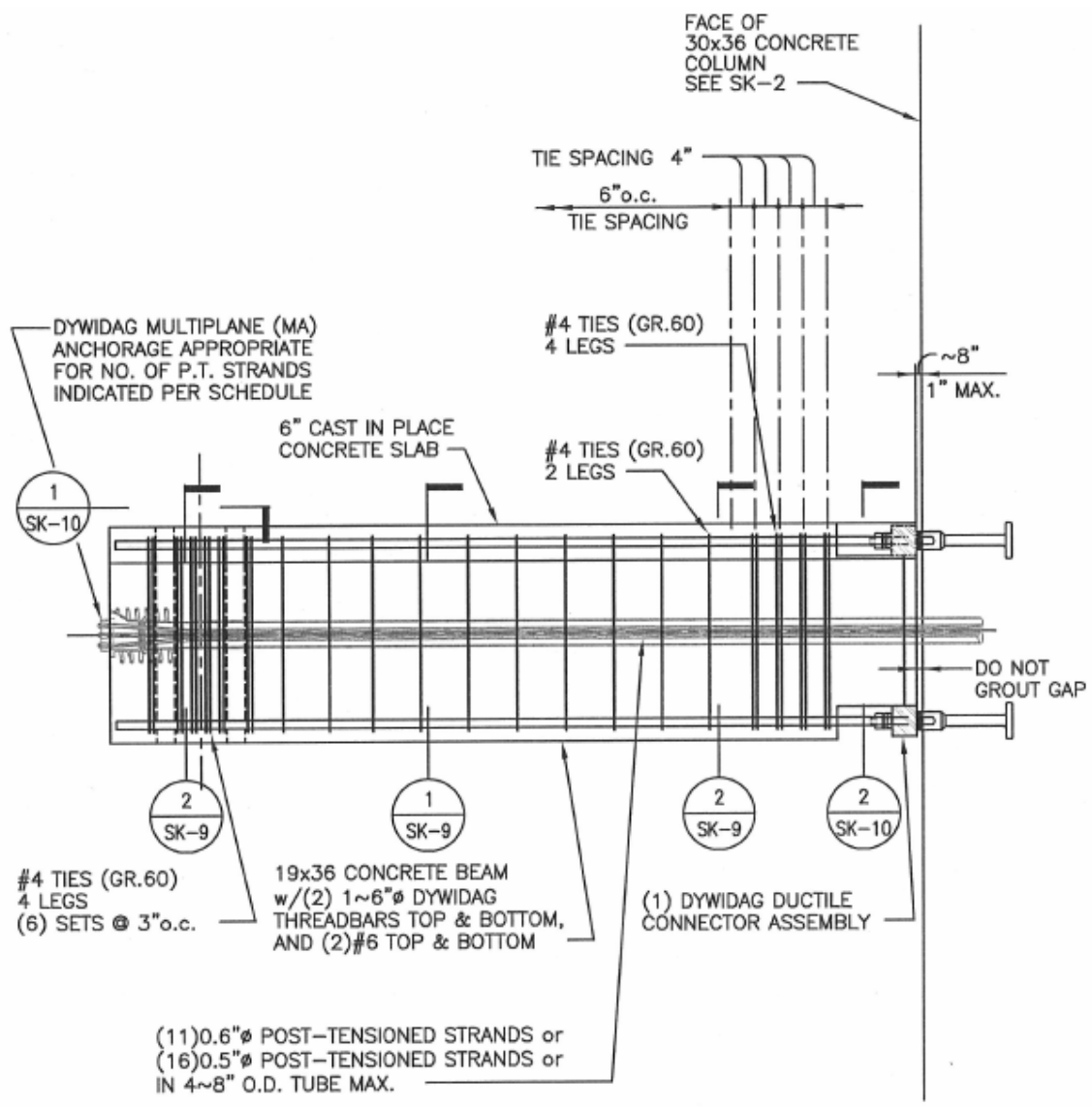

Figure 92: Super hybrid south beam elevation (Chang, Hutchinson, and Englekirk 2007) 


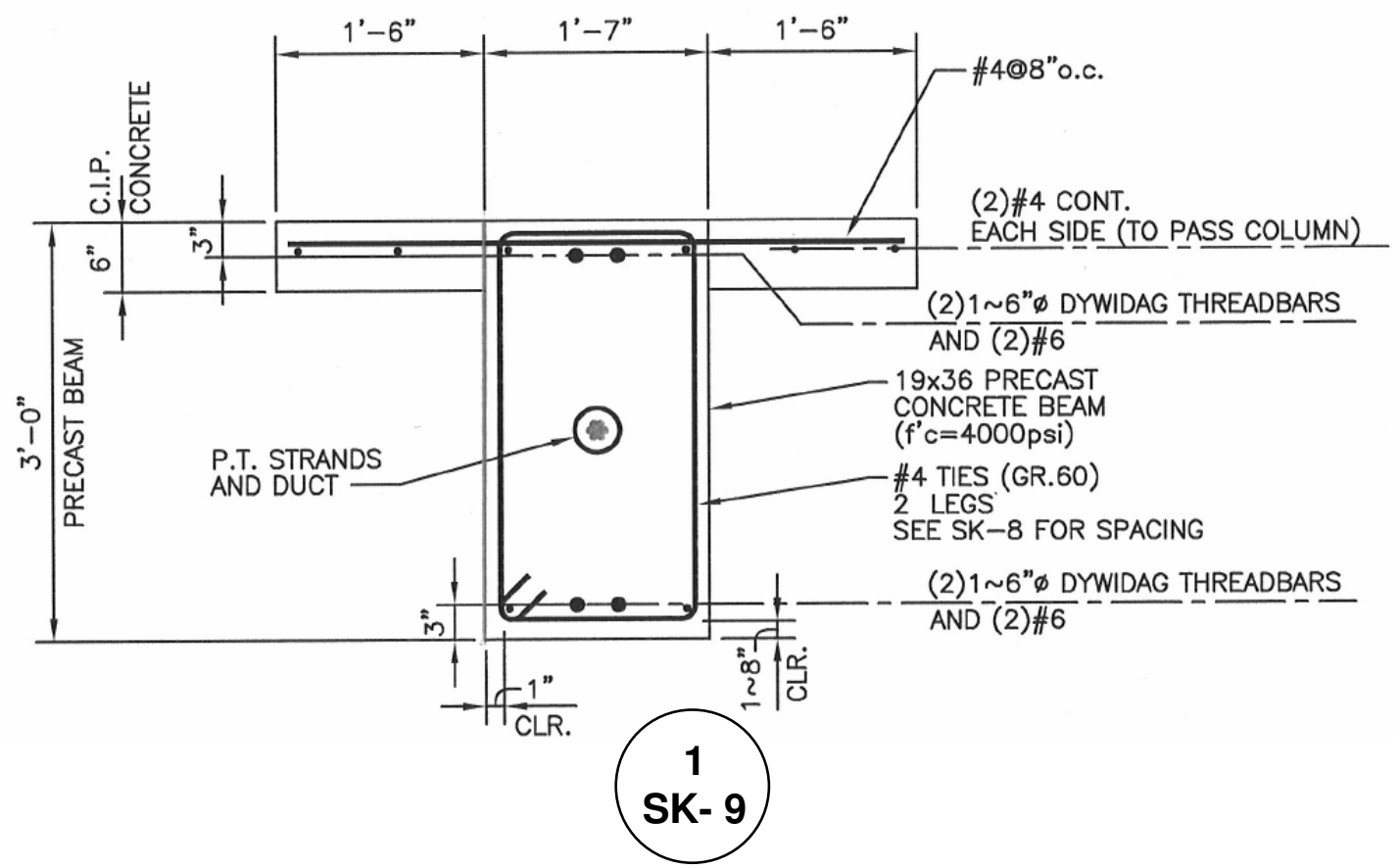

Figure 93: Super hybrid section cut 1/SK-9 through the south beam (Chang, Hutchinson, and Englekirk 2007)

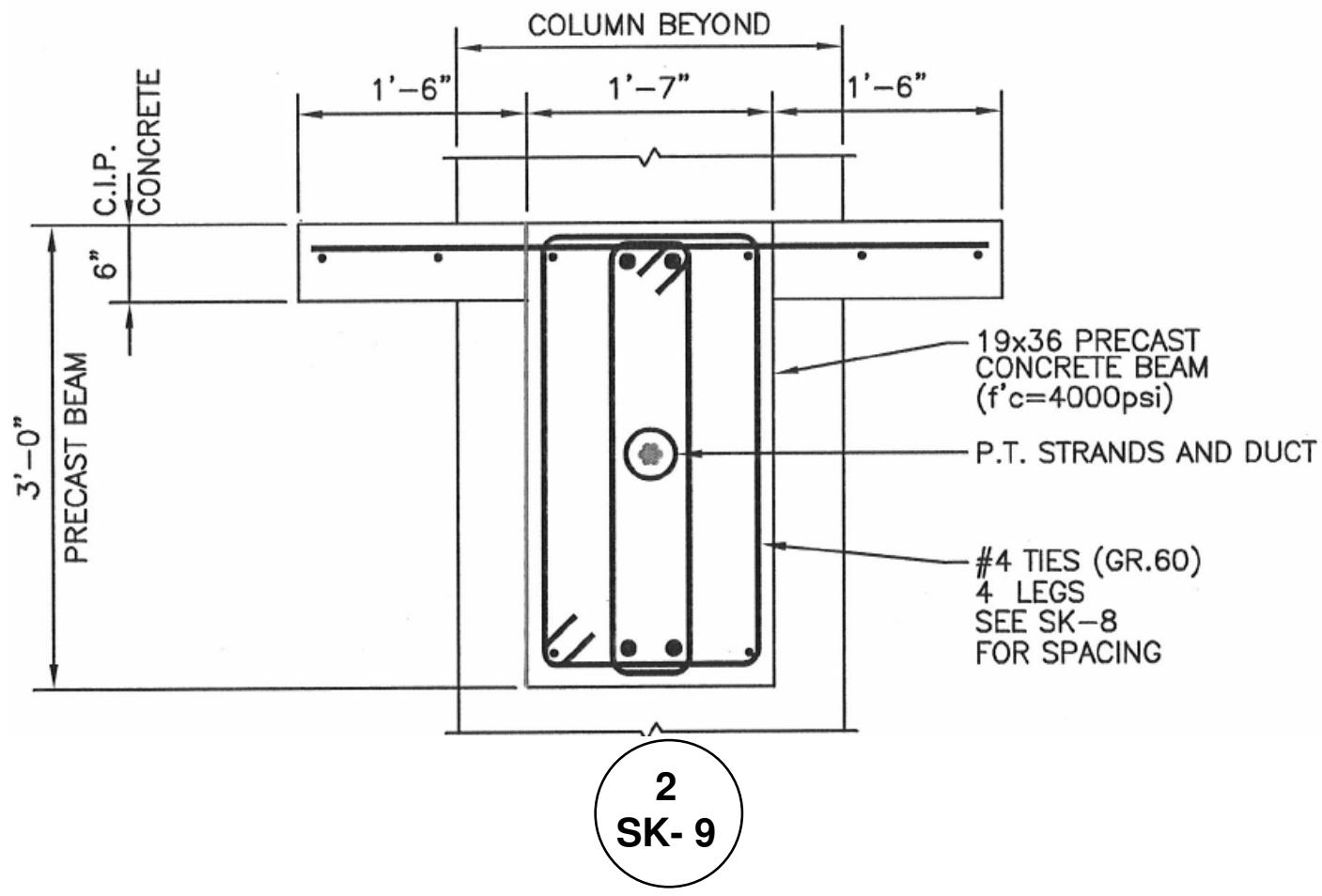

Figure 94: Super hybrid section cut 2/SK-9 through the south beam (Chang, Hutchinson, and Englekirk 2007) 


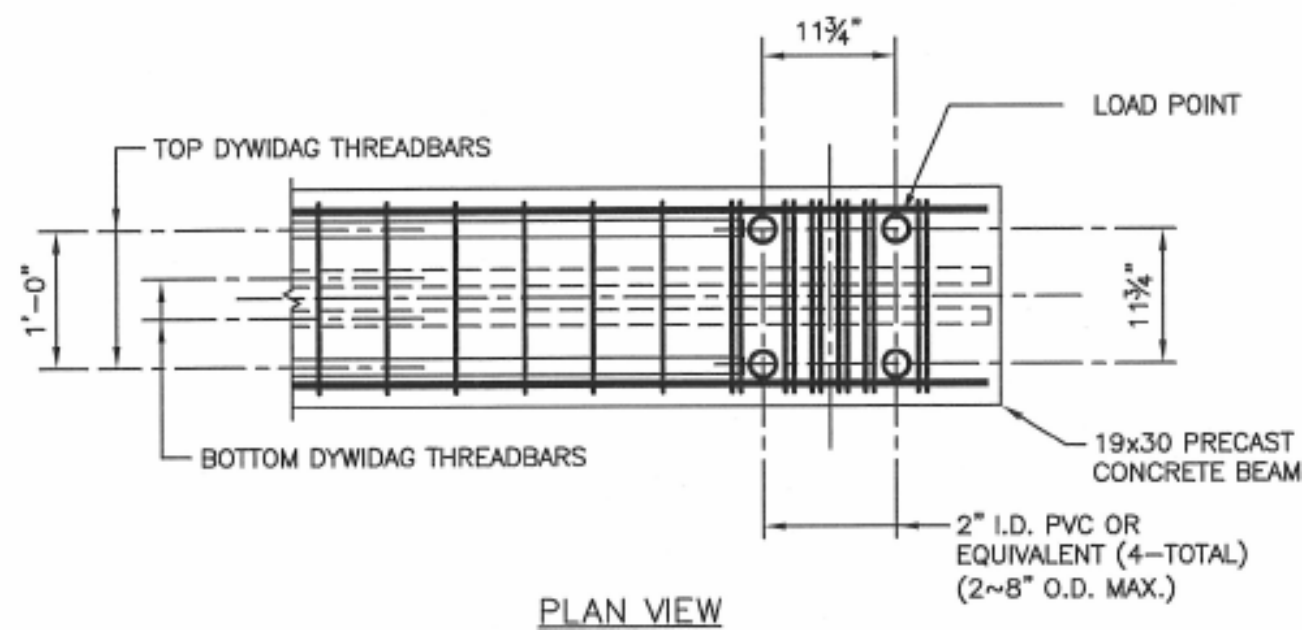

Figure 95: Super hybrid plan of the north beam at the pinned end connection (Chang, Hutchinson, and Englekirk 2007)

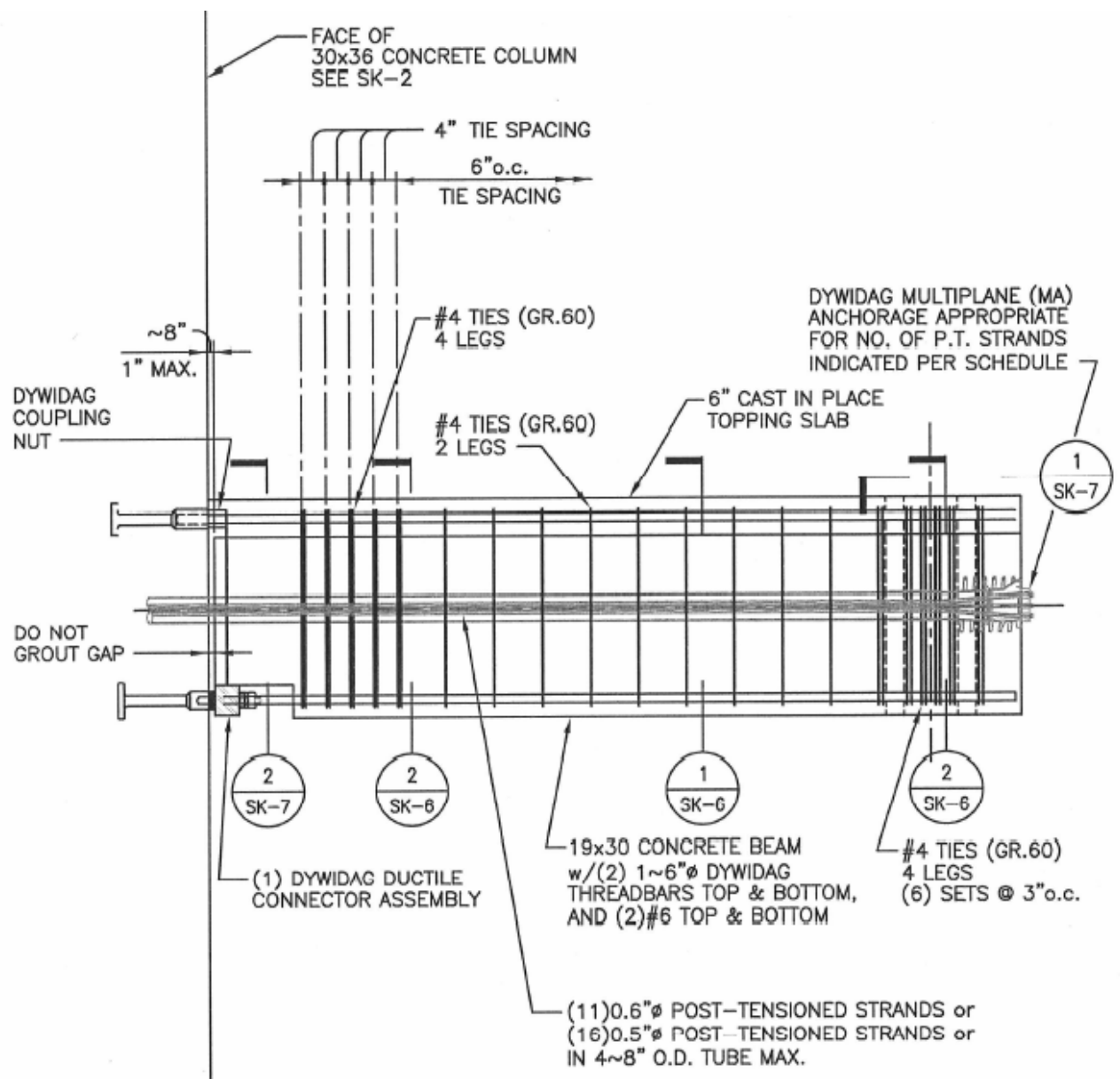

Figure 96: Super hybrid north beam elevation (Chang, Hutchinson, and Englekirk 2007) 


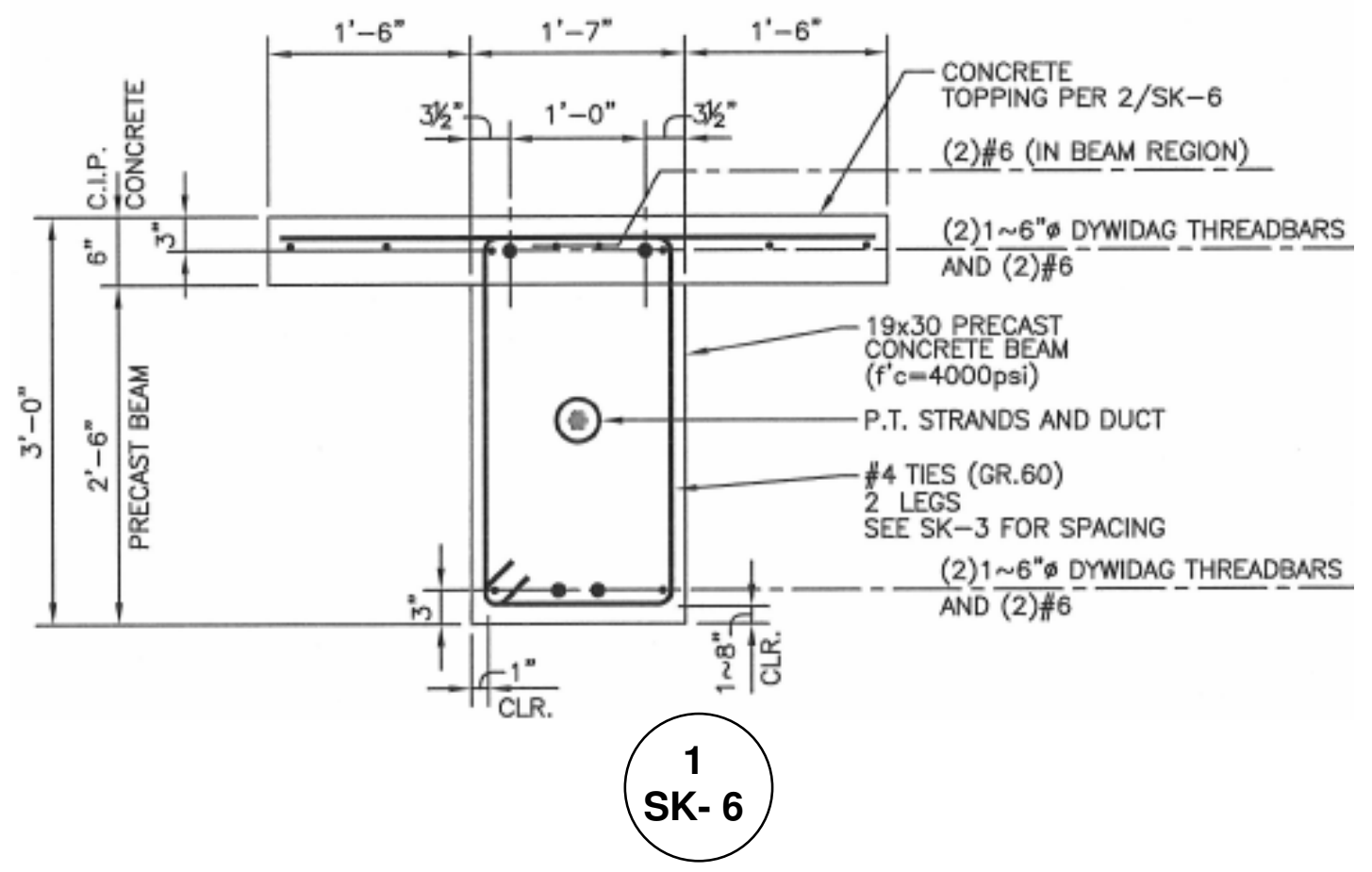

Figure 97: Super hybrid section cut 1/SK-6 through the north beam (Chang, Hutchinson, and Englekirk 2007)

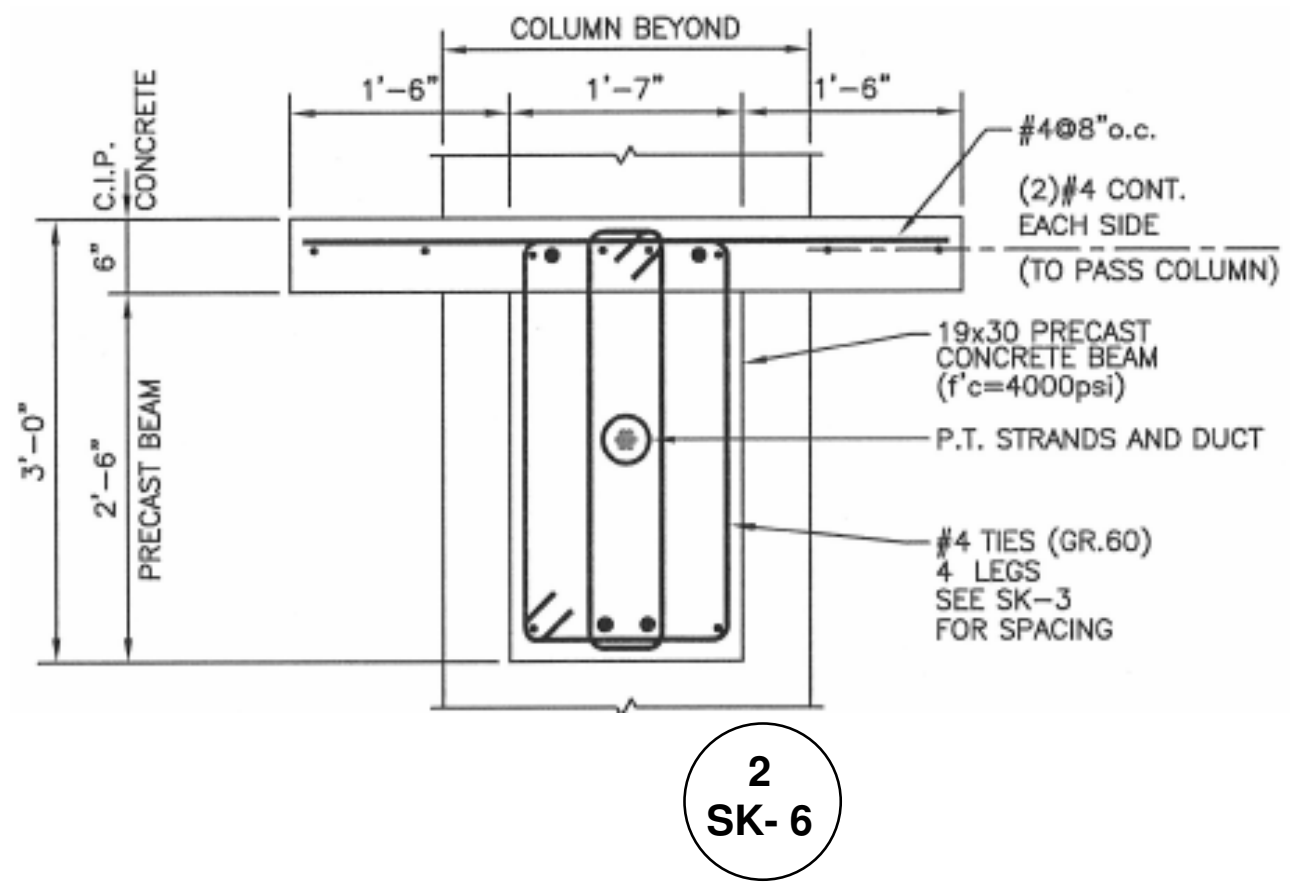

Figure 98: Super hybrid section cut 2/SK-6 through the north beam (Chang, Hutchinson, and Englekirk 2007) 


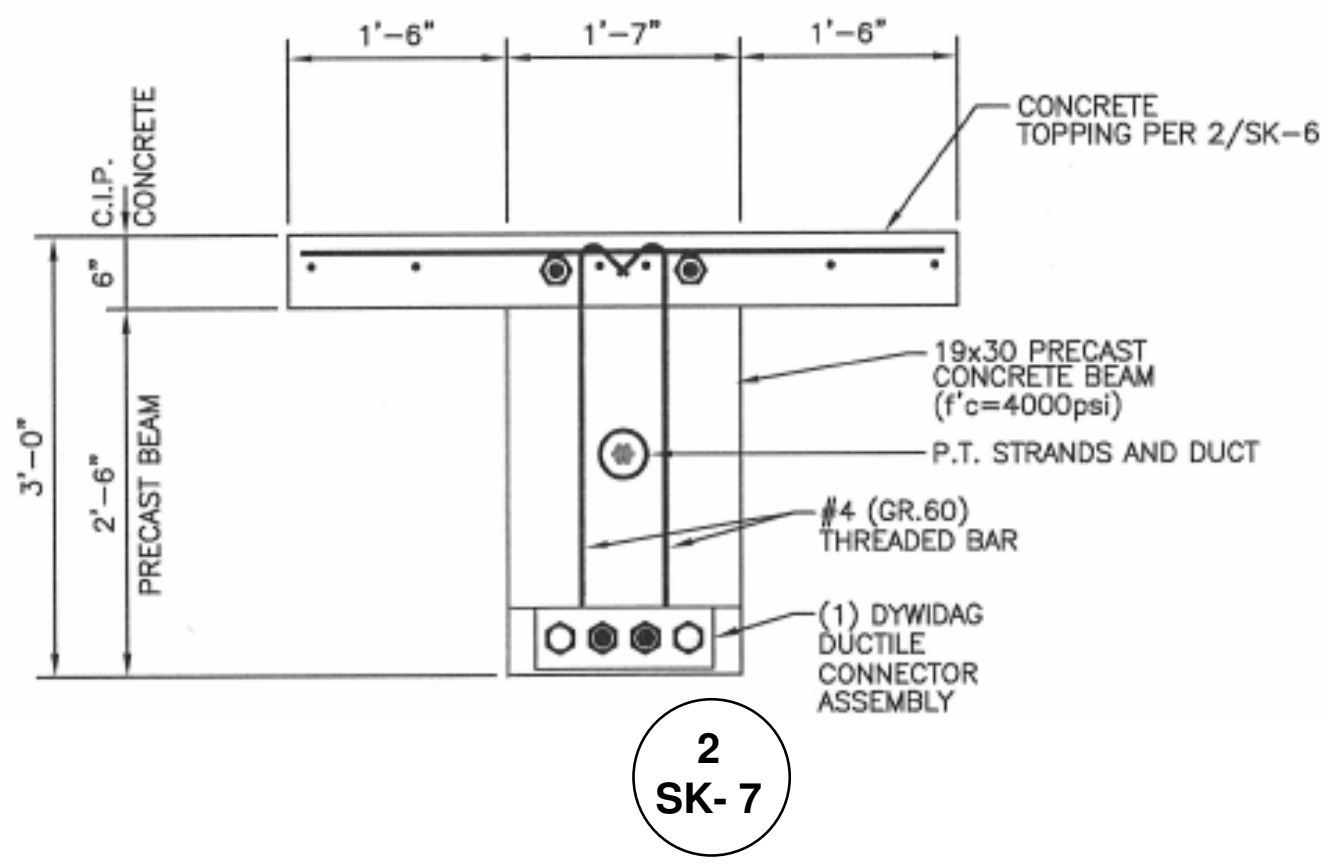

Figure 99: Super hybrid section cut 2/SK-7 through the north beam (Chang, Hutchinson, and Englekirk 2007)

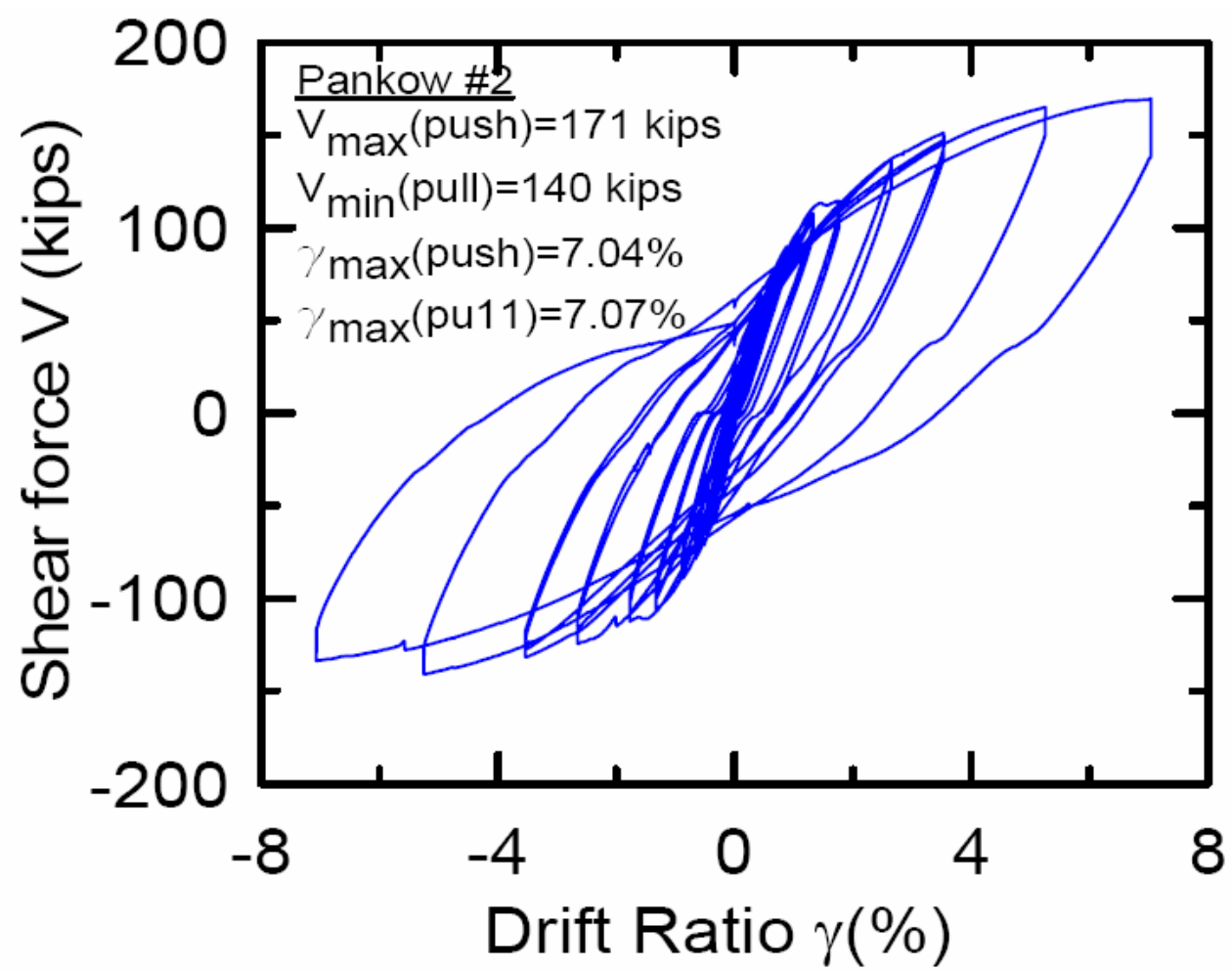

Figure 100: Super hybrid force-displacement hysteretic data (Chang, Hutchinson, and Englekirk 2007) 

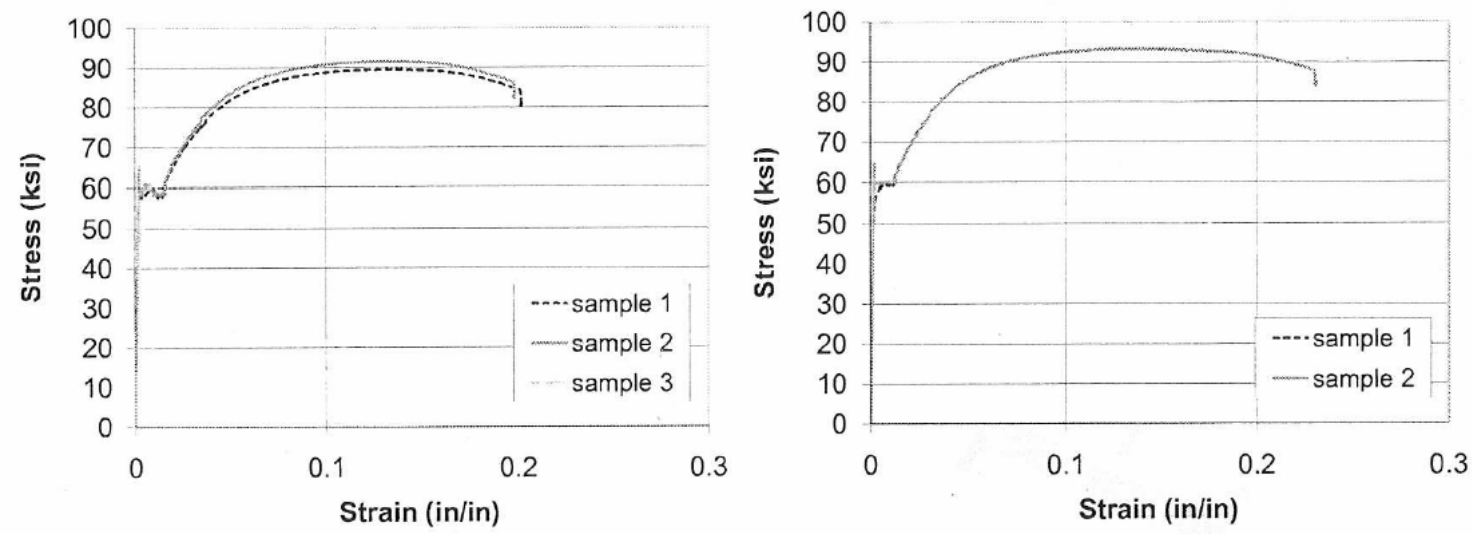

(a) Stress-strain plot for DDC rods threaded into Dywidag

(b) Stress-strain plot for DDC rods threaded into steel coupler block

Dywidag bars Pankow 2
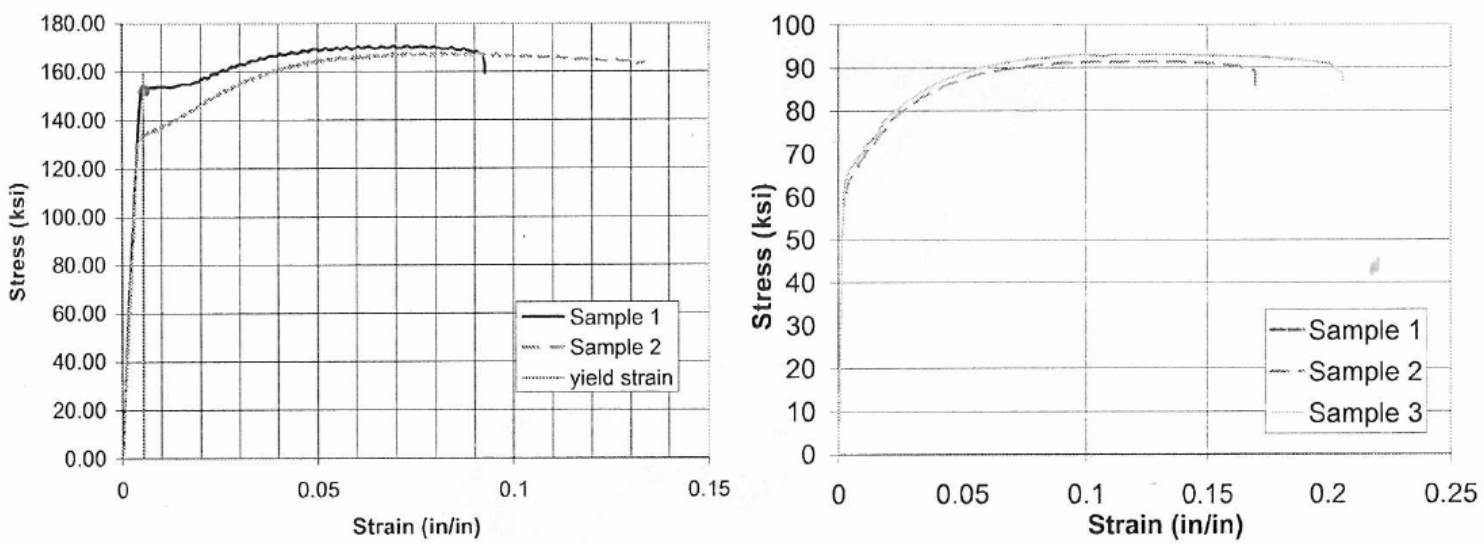

(c) Dywidag material tests

(d) Stress-strain plot for \#4 rebar
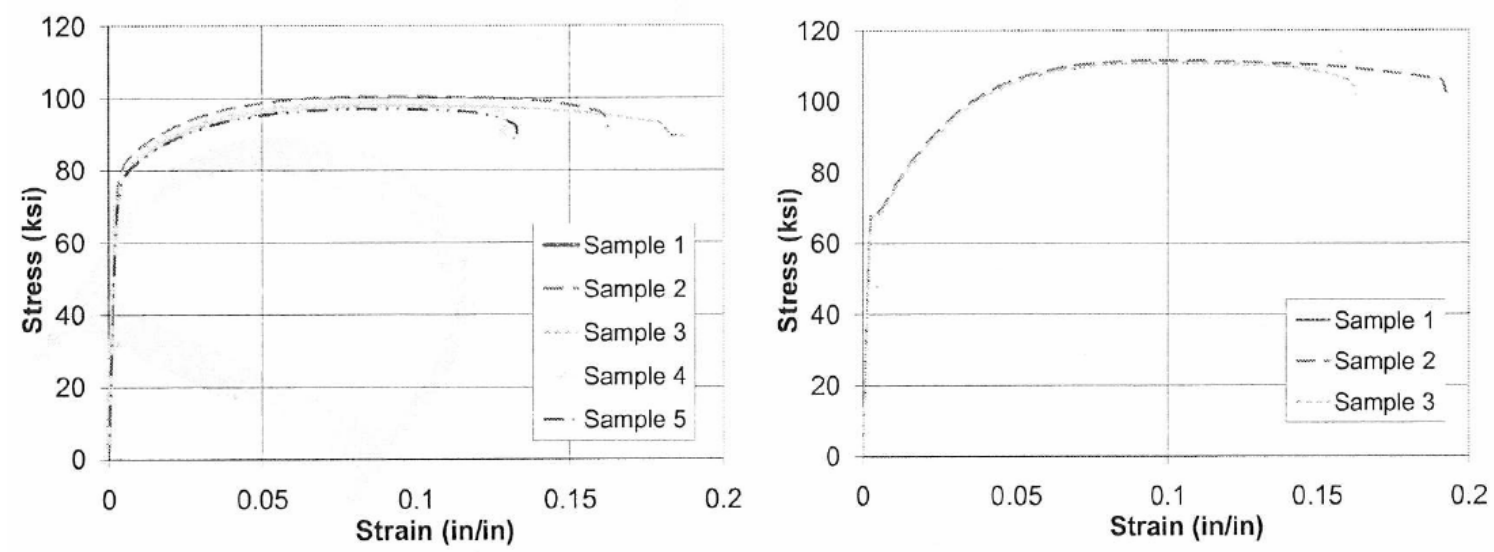

(e) Stress-strain plot for \#5 rebar

(f) Stress-strain plot for \#6 rebar

Figure 101: Super hybrid material tests (Chang, Hutchinson, and Englekirk 2007) 